PNL-10074

AD-902

HAZARDOUS WASTE DISLODGING AND CONVEYANCE:

THE CONFINED SLUICING METHOD
D. A. Summers ${ }^{a}$
R. D. Fossey
M. D. Mann ${ }^{\mathrm{a}}$
J. G. BTaine
M. W. Rinker, PNL Project Manager

September 1994

Prepared by the University of Missouri-Rolla for the U.S. Department of Energy under Contract DE-AC06-76RLO 1830

This work is funded by the Office of Technology Development, within the Department of Energy's Office of Environmental Management, under the Underground Storage Tank-Integrated Demonstration Program

Pacific Northwest Laboratory Richland, Washington 99352

"University of Missouri-Rolla High Pressure Waterjet Laboratory Rolla, Missouri 


\section{DISCLAIMER}

This report was prepared as an account of work sponsored by an agency of the United States Government. Neither the United States Government nor any agency thereof, nor any of their employees, make any warranty, express or implied, or assumes any legal liability or responsibility for the accuracy, completeness, or usefulness of any information, apparatus, product, or process disclosed, or represents that its use would not infringe privately owned rights. Reference herein to any specific commercial product, process, or service by trade name, trademark, manufacturer, or otherwise does not necessarily constitute or imply its endorsement, recommendation, or favoring by the United States Government or any agency thereof. The views and opinions of authors expressed herein do not necessarily state or reflect those of the United States Government or any agency thereof. 


\section{DISCLAIMER}

Portions of this document may be illegible in electronic image products. Images are produced from the best available original document. 


\section{Preface}

The work performed by the University of Missouri, under Professor David Summers, was funded through a subcontract with Sandia National Laboratory. This work was directed by the Waste Dislodging and Conveyance system, through the DOE EM 50 Office of Technology Development, Underground Storage Tank Integrated Demonstration. The Pacific Northwest Laboratory is publishing this document as a contractor report because the Waste Dislodging and Conveyance is managed at PNL. 


\section{DISCLAIMER}

Reference to specific products or items in this report imply no endorsement of those or any products by the University of Missouri-Rolla. 


\title{
HAZARDOUS WASTE DISLODGING AND CONVEYANCE THE CONFINED SLUICING METHOD
}

\author{
A Final Report \\ Submitted to: \\ Sandia National Laboratories \\ P. O. Box 5800 \\ Albuquerque, NM 87185 \\ by: \\ David A. Summers \\ Robert D. Fossey \\ Michael D.Mann \\ James G. Blaine \\ University of Missouri-Rolla \\ High Pressure Waterjet Laboratory \\ Rolla, MO. 65401
}

\begin{abstract}
Final Report
Contract Title: Development of a Shrouded Waterjet Extractor

TTP Number: AL-232003

B \& R Code: EW401040

April 14, 1994

Revised: July, 1994
\end{abstract}


, 


\section{EXECUTIVE SUMMARY}

This report describes an investigation of a means for dislodging and conveying waste currently stored in underground storage tanks. A series of experiments have been carried out to evaluate the potential of a medium pressure, medium flow rate cutting system as a means of dislodging the waste. It has been found that waterjets at a pressure of 10,000 psi can effectively cut the material which has been chosen to simulate the hardened saltcake within the storage tanks. Based on a parameterization test it has thus been calculated that an inlet flow volume of approximately 30 gallons per minute will be sufficient to excavate 30 gallons per minute of waste from a tank.

In order to transport the resulting slurry from the tank, a modified jet pump has been developed and has demonstrated its capability of conveying fluid and waste particles, up to one inch in diameter, to á height of more than 60 feet.

Experiments were conducted to examine different configurations to achieve the production levels required for waste removal and to clean the walls of residual material. It was found more effective to clean the walls using an inclined angle of impact rather than a perpendicular angle of impact in order to provide a safeguard against driving the water through any cracks in the containment. It was demonstrated that excavation can take place with almost total immediate extraction of the water and debris from the cutting process. The results have qualitatively shown the potential of a medium pressure waterjet system for achieving the required results for underground storage tank waste retrieval. 



\section{TABLE OF CONTENTS}

Page

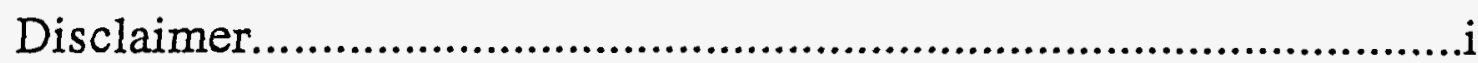

Executive Summary ...................................................................

Chapter 1. Jet Pump Test Evaluation...................................................

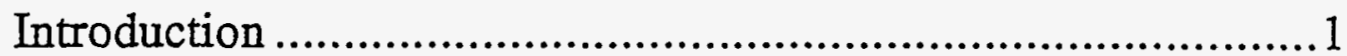

Jet Pump Principles...........................................................

Test Procedures .......................................................................

The Test Apparatus ......................................................................

Quality Assurance ..................................................................

Evaluating the Commercial Pump..............................................

Testing the HPWL Jet Pump........................................................ 12

Conclusions .............................................................................. 21

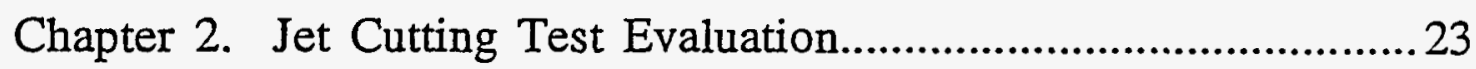

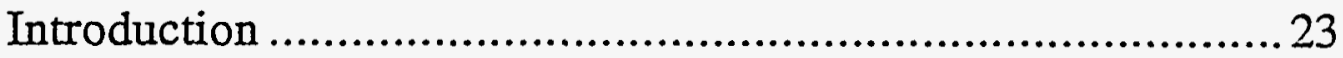

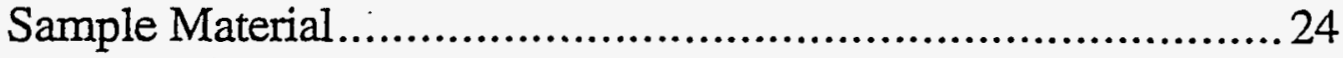

Method of Test ....................................................................25

Experimental Results.......................................................... 27

Data Analysis.................................................................... 28

Projections from the Data...................................................... 35

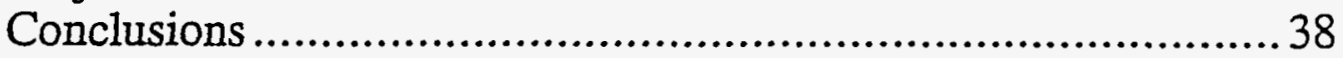

Chapter 3. Integrated Testing ........................................................... 40

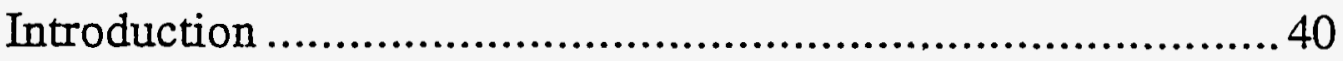

Integrated Design...............................................................40

First Test Observations....................................................... 43

Large Tank Test Facility........................................................4 44

Shroud Design ...................................................................... 47

Cutting Performance Tests.................................................5

Cutting Tests with a Varied Test Surface ...................................58

Cutting Tests with a Varied Simulant Surface.............................64

Cutting Evaluations with Various Nozzle Design

Configurations.....................................................................68

a) Linear Cutting Tests ...............................................69

b) Rotary Cutting Tests................................................... 73 
c) Fan Jet Cutting Tests.

.74

Chapter 4. Investigations of the Effects of Waterjets on

Damaged Walls.

Introduction ............................................................... 76

Distorted Metal Tests................................................... 76

Horizontal Testing...................................................... 80

Inclined Jet Testing .................................................... 85

Recommendations and Conclusions .................................. 87

Chapter 5. Development of a Flexible Mount for the Cutting Head.....88

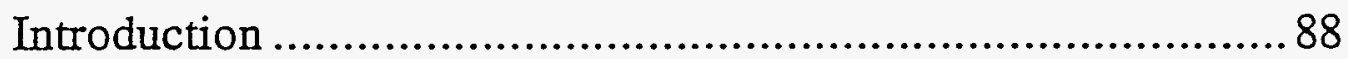

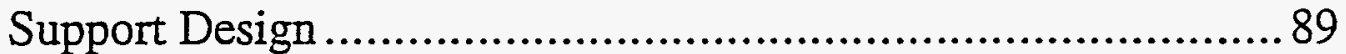

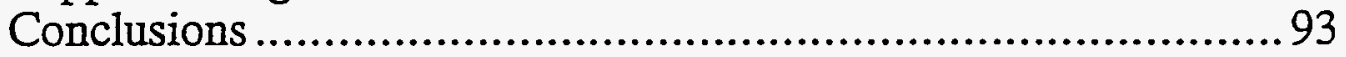

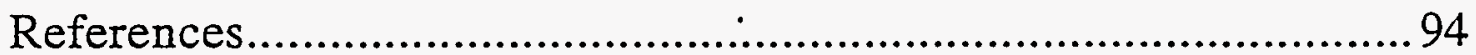

Appendix 1. MSDS Material on Fertilizer......................................95

Appendix 2. Data from the Initial Tests on The Softer Fertilizer...... 100

Appendix 3. SOP for the Testing Program .............................. 103 


\section{Chapter 1. JET PUMP TEST EVALUATION}

\section{Introduction}

This chapter describes an initial stage in the development of a Shrouded Waterjet Excavator for the removal of material from waste storage tanks. A major step in that process is the conveyance of the excavated material from the tank to the ground surface above the tank, a step that requires the material be elevated to a height of as much as 60 feet Concurrently the target performance for the extractor is that the excavated material be conveyed to the ground surface at the rate of at least $30 \mathrm{gpm}$ of waste.

One candidate for the conveyance system is a high-pressure water-powered jet pump. Water jet pumps have been developed to operate at pressures of up to 10,000 psi and provide a relatively small, simple and convenient addition to the system being assembled to excavate the material from the tanks. However, although water jet pumps can be obtained commercially, the exact specifications for a pumping system capable of meeting system requirements has not been defined. Further, the effect of changes to the pump operational variables on its performance needs to be defined, so that some estimate of the size of the device required may be made.

Potential advantages to the use of the jet pump go beyond the small overall size of the unit. The unique requirements of the tank waste excavation problem call for a system which is extremely reliable in operation. A jet pump contains no moving parts which significantly improves its overall life and operational reliability. Further, the location of the operating jets around the perimeter of the flow channel inlet will ensure that the excavated material is carried out through the conveyance line, rather than sticking to the delivery section of the feed tube.

The work undertaken has been carried out in two parts. The study began by evaluating the performance which could be obtained from an existing jet pump obtained from a commercial supplier. On the basis of the data from that initial study, a second pump was constructed in the High Pressure Waterjet Laboratory (HPWL) of the Rock Mechanics and Explosives Research Center (RMERC). The design of this second unit was deliberately chosen to allow for changes in the internal configuration of the pump during the testing process. 


\section{Jet Pump Principles}

A jet pump has a number of potential advantages for use with the remote excavation system foreseen for use in removing material from the underground storage tanks. To understand where these benefits arise, it is important to understand the underlying basis on which such a pump operates.

The jet pump consists of a number (which can be as low as one) of high velocity jets of fluid which are directed into a passageway which has a reducing diameter. The jets are normally either directed axially along the passage, or from the surrounding degrees, inclined inward toward the downstream axis of the passage. As the jet(s) flow into and through this passage they create a low pressure region in the larger areas of the passage and provide a drag force to move the fluid in the narrower sections of the chamber. This drag force translates into a momentum transfer between the original high velocity fluid and the chamber fluid (Ref. Karassik, I.J., Krutzsch, W.C., Fraser, W.H., and Messina, J.P. Chapter 4, Pump Handbook, Second Edition, McGraw Hill, 1985). In an optimum configuration, the final fluid travels out of the original mixing chamber through a diffuser, which gradually changes the velocity of the fluid into a driving pressure with as little energy loss as possible. The narrowest part of the passage is generally referred to as the throat of the pump.

It can be seen that this type of pump has no moving parts likely to need replacement during the time that it must operate, providing that the nozzles can be maintained in a correct geometry. In addition, the unit has a small footprint and can be made small and light enough to fit within the geometric requirements for the system which must be fielded. Finally, the pump will be providing a pressure to drive the fluid and debris out of the tank, for the bottom. Thus, it is pushing the debris out of the tank rather than trying to suck the column all the way from the bottom of the tank to the outer surface. This means that it is possible to continuously pump fluid and debris from the tank even where the delivery pipe is full of fluid. 


\section{Test Procedures}

It should be borne in mind that the depth of this investigation was limited by the time constraints under which it was carried out, and the limited objectives of establishing the parameter range in which the required pump output would be achieved. Within this report, the testing procedures used to determine the performance of both jet pumps will be described. An initial pump characterization was achieved using a jet pump purchased from Aquadyne of Houston, TX. Preliminary evaluation of the data from operation of that pump was used in developing the second pump which was constructed in the HPWL, and this was then characterized using the same testing procedures. The flexibility built into the design of this second unit was then exploited to modify the design until the pump was operating within the target range of output, which for this initial evaluation was set at $40 \mathrm{gpm}$ of water at 60 feet of head. This test series did not look at the inclusion of the solid component of the slurry. That will form the subject of a subsequent investigation.

There are many variables which affect the performance of a jet pump, and only some of these could be studied. It was determined that only the jet pressure, orifice size and flow channel sizes would be studied at this time, since this would indicate the direction of design change required to achieve the set objective. In order to evaluate pump performance, the evaluation was based on the quantity of water pumped, under a given pressure head. In order to conserve space, this measurement was based on a gated restriction in the outlet line, rather than, as had been the case earlier in the program, physically pumping the water up through a vertical feed line to determine the output power. This procedure, although not exactly equivalent to the required condition, allowed a more controlled test environment and facilitated a more accurate assessment of the pressure head against which the pump was operating than would have been the case with the open vertical pipe. (Approximately one-half psi is equivalent to one foot of vertical lift for water, so 30 psi would be equivalent to a 60 foot lift.)

The detailed test procedure was written in the form of a Standard Operating Procedure (SOP), provided in the Appendix 3 to this report. 


\section{The Test Apparatus}

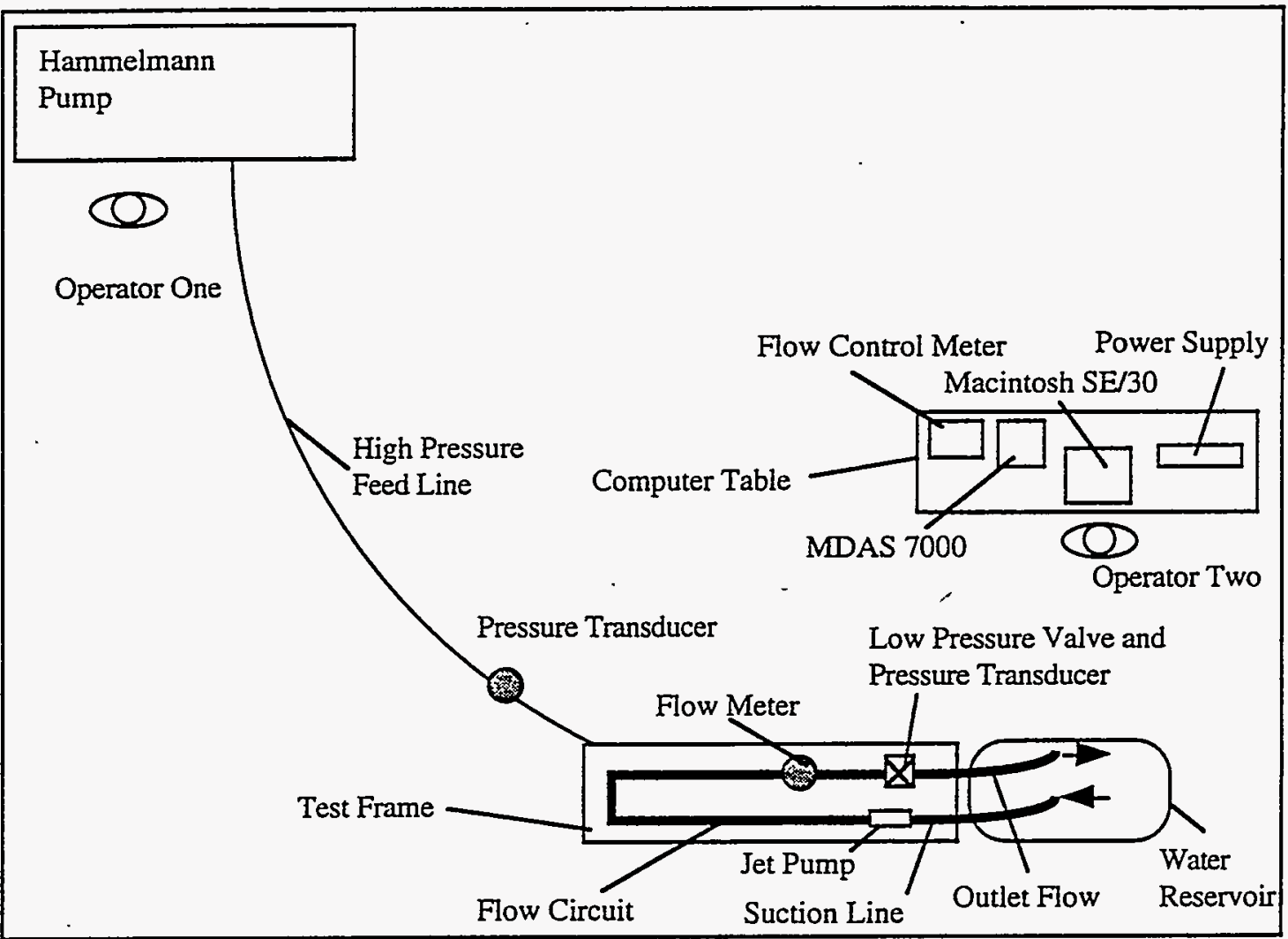

Figure 1.1 Schematic of the Equipment Layout.

The test stand was assembled (Figure 1.1 and Figure 1.2) from 2-inch steel angle in the form of an open rectangular table, to which the components of the test circuit could be attached. The circuit itself was made up from lengths of PVC pipe, ranging from 0.5 to 2.0 inches in diameter, which was first built into the circuit and then attached to the test stand.

The jet pump under test was fitted with the nozzles of the correct size and connected into the circuit. The instrumentation in the circuit was attached through control cards to the monitoring computer, mounted on an adjacent table. The Hammelmann pump provided the high pressure water to run the jet pump. In operation, the jet pump drew water through the suction line from the water storage tank. The flow passed through the pump and was then fed into a pipe circuit some 12 feet long, which carried the flow the length of the stand and brought it back to a pressure control valve installed 6 feet from the elbows. By gating the flow through this valve it was possible to simulate vertical head pressure. 


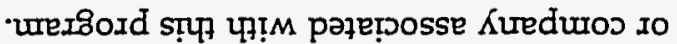

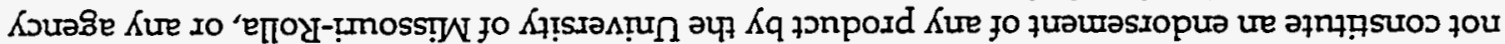

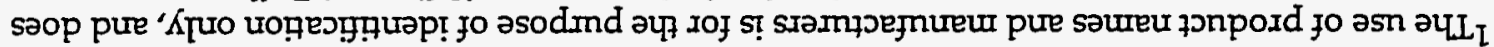

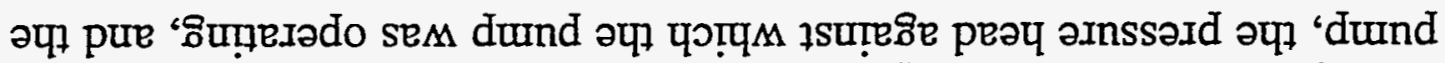

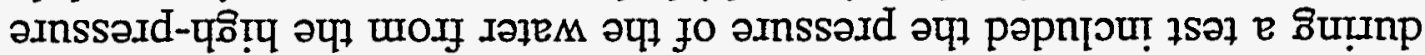

( $\varepsilon \cdot I$ วлnoิI

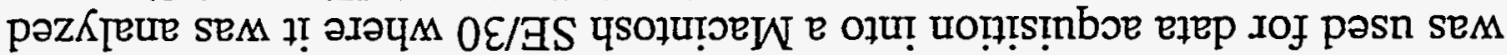

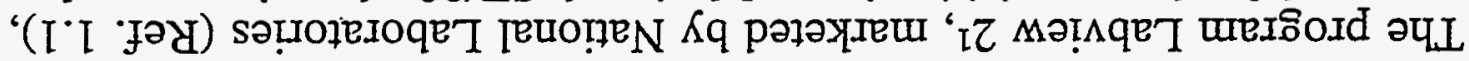

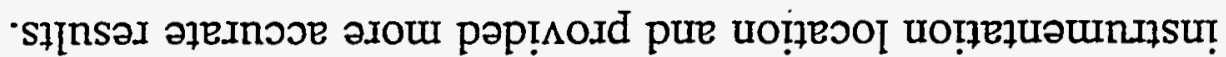

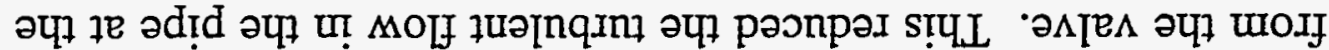

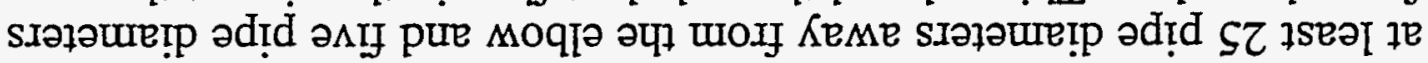

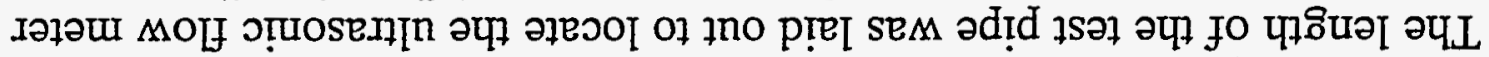

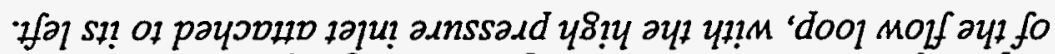

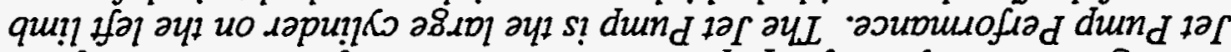

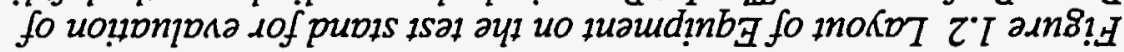

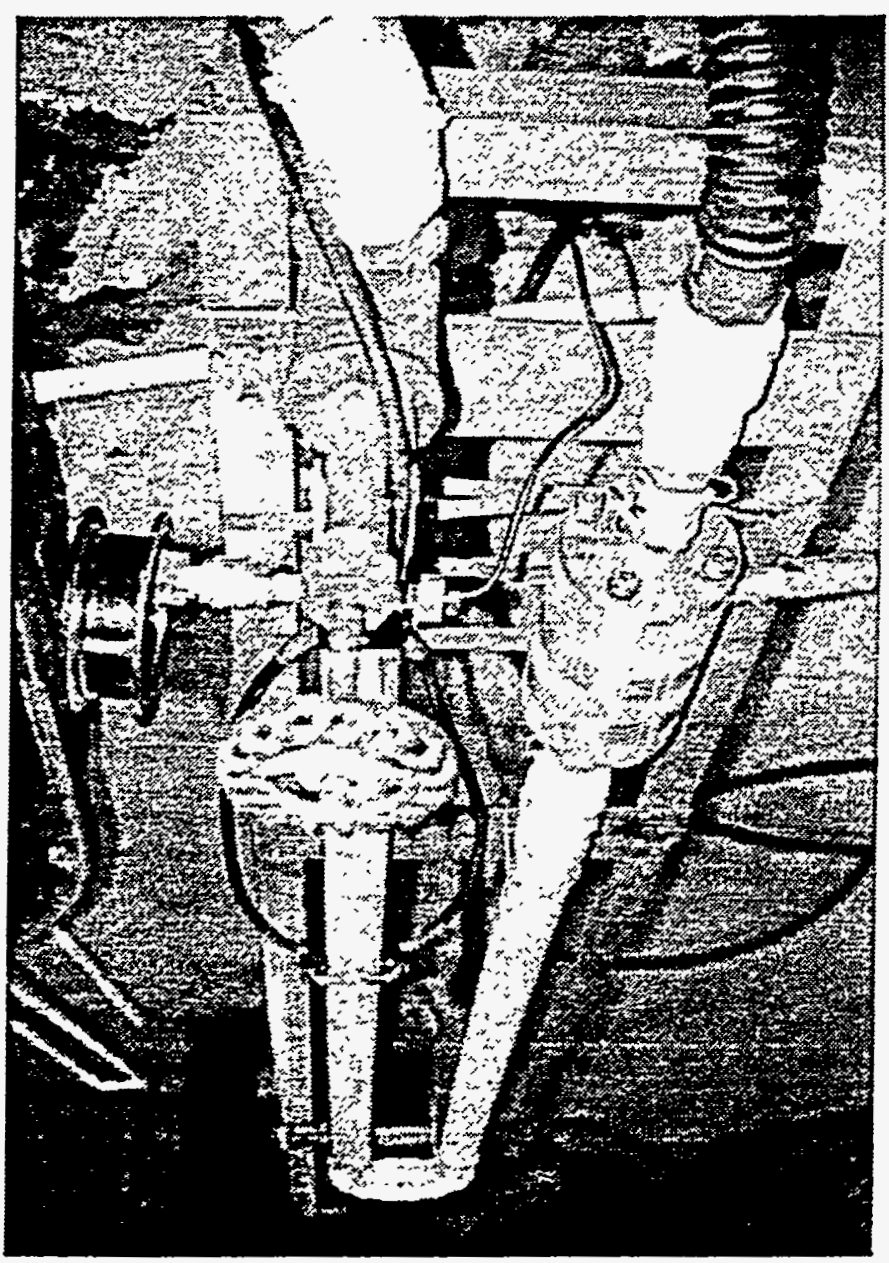


flow rate. The data was acquired using electronic sensors, sampled by the MDAS 7000 system (Ref. 1.2), available from Kaye Instruments, and transferred to the computer for display and recording.

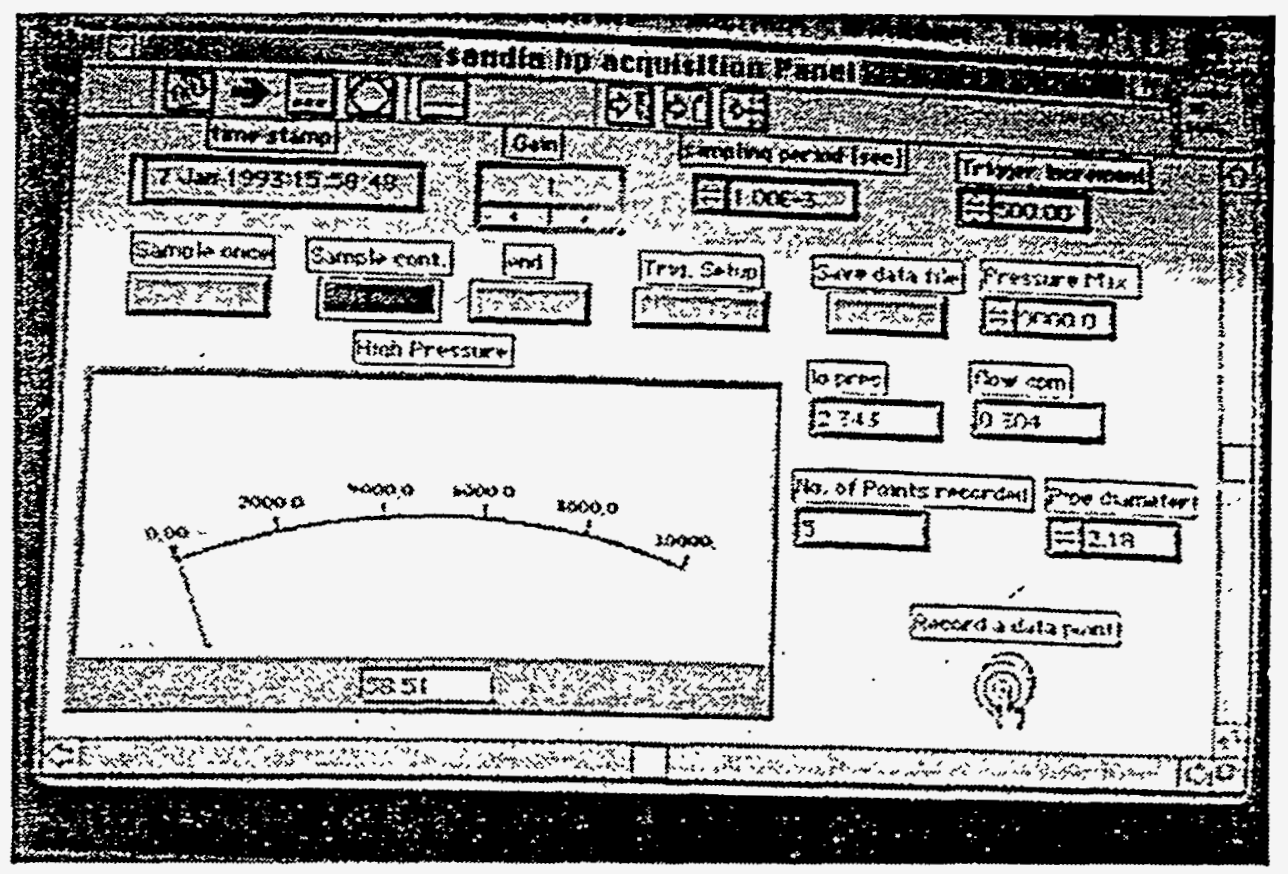

Figure 1.3 Configuration of the Computer Screen during Data Acquisition, using the Labview Program.

Once the equipment reached a steady state operation, the pressure of water from the Hammelmann pump was increased in steps and stabilized after each increment to record the flow conditions. The normal pressure range for operation of the Hammelmann pump during a test ranged from 3000 psi to 9000 psi with data recorded typically at 500 psi step increments. A more detailed explanation of the test procedure is given in the test SOP which is presented in the Appendix 3.

\section{Quality Assurance}

At regular intervals throughout the program, the flow meter calibration was qualitatively checked by measuring the quantity of water pumped into a tank within a measured time interval. An approximate flow rate could then be calculated, and this always was within 10 percent of the flow meter reading. Given the relatively short duration of the test period and the large quantity of fluid flowing, this was considered satisfactory agreement.

The sensors were also regularly checked and the calibration validated electronically. The ultrasonic pressure transducers for the flow meter 
were moved from the elbow to the output valve in ten steps in an attempt to check the variation in flow rate readings as a function of distance from the disturbance caused by the bend within the pipe circuit. The manufacturer had suggested the flow transducers be placed at least twenty-five pipe diameters beyond the elbow turning the flow. Similarly it was recommended that the sensor should be located five pipe diameters or more above any downstream obstruction. The data obtained from this sensor position study supported the company's suggestion on transducer placement (Figure 1.4). The data plotted was for the velocity of flow down the pipe. It can be seen that as the instrument moves away from the bend, the velocity stabilizes, and then it increases again as the instrument approaches the valve, with its constriction on the flow.

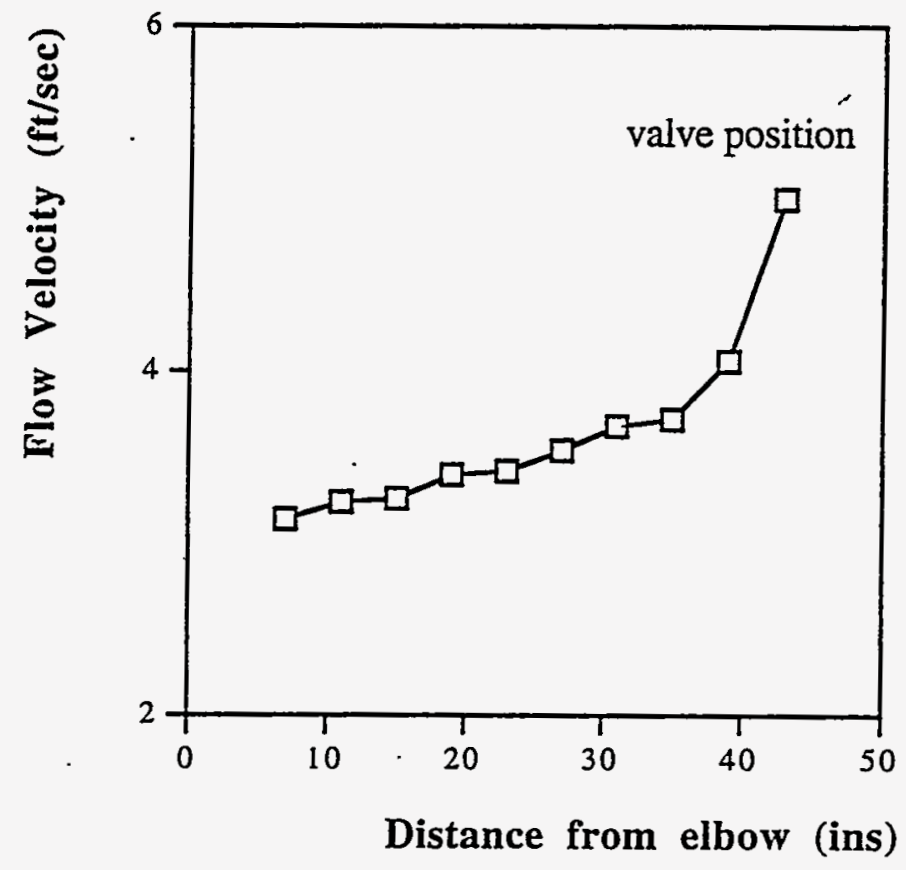

Figure 1.4 Flow Rate indicated as a function of Instrument Distance from the Circuit Turn.

\section{Evaluating the Commercial Pump}

The initial pump was purchased from Aquadyne, based on its ability to lift not only fluids but also loose debris. In an earlier, less-well-defined test this pump had shown that it could pump fluid to vertical heights of over 30 feet. The pump was, therefore, used to derive a set of performance characteristics that would serve as a base line in evaluating the results from the HPWL pump. The Aquadyne pump was operated over a range of driving pressures to 10,000 psi, with three different nozzle diameters, 
$0.032,0.038$, and 0.042 inches, to control fluid flow. The pump could only be tested across a limited range of outlet pressures because of its configuration. Three nozzles were set within the pump, at equal intervals around the pump throat and directed into a throat to provide motive power for the fluid being pumped (Figure 1.5).

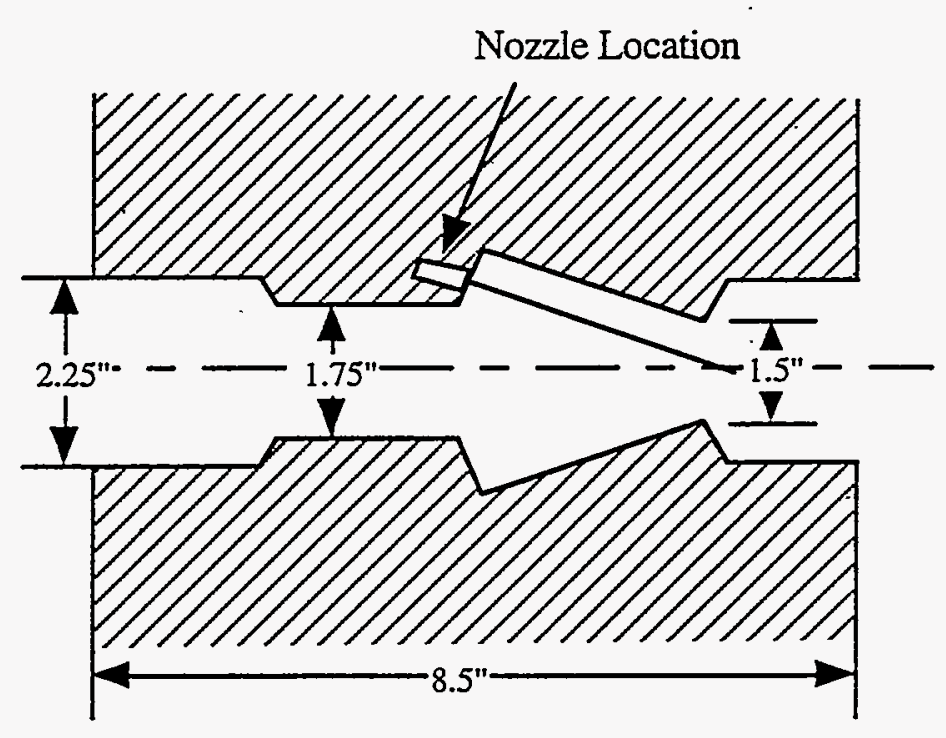

Figure 1.5 Section showing the Configuration of the Aquadyne Jet Pump:

In general, the outlet flow decreased as the pressure head was increased (Figure 1.6 and Figure 1.7). It should be noted that when a larger diameter nozzle was used, this greater driving flow raised both the head pressure against which the pump could operate and the flow rate which it could produce against that head. The other important observation from this first test was that as the output pressure increased, the flow curve shifted downward. Thus, more driving pressure was required to give the same flow rate at a higher head.

For comparative purposes, only selected values from the data obtained have been presented. However, the trends which are evident in this data are consistent with the data which is not included. The pump used for this test could only produce $10 \mathrm{gpm}$ of flow, and this, therefore, restricted the upper range of pressure at which the pump could be operated. 


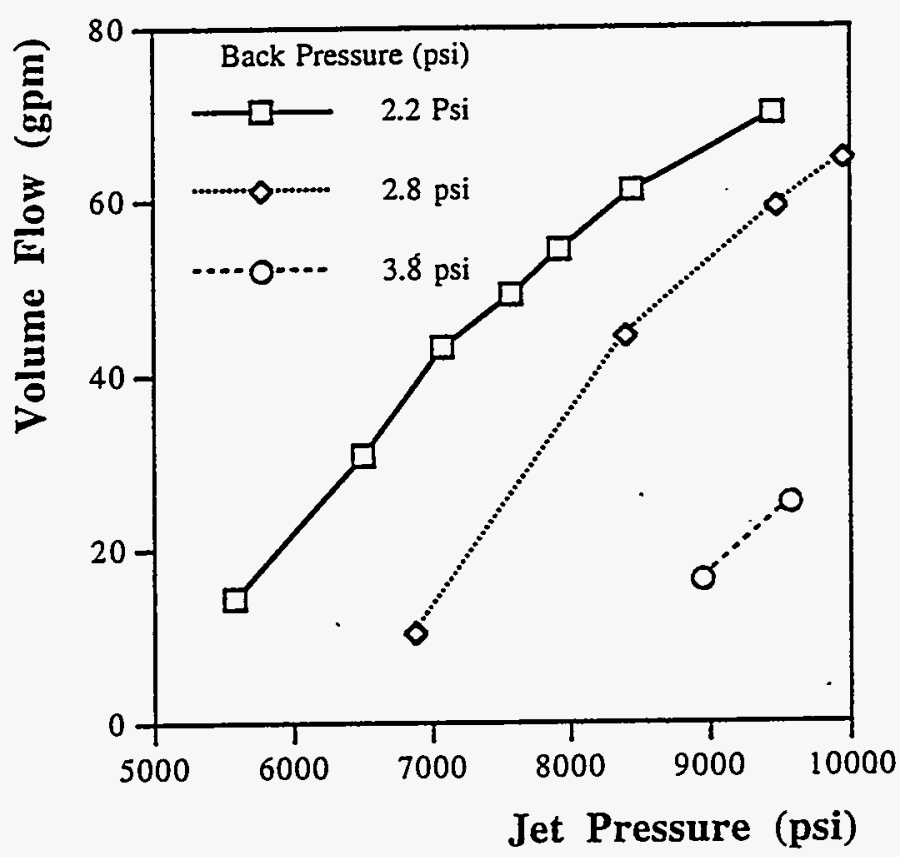

Figure 1.6 Delivered Volume as a function of Driving Pressure, with a 0.032 inch diameter set of 3 jet orifices, using the Aquadyne pump.

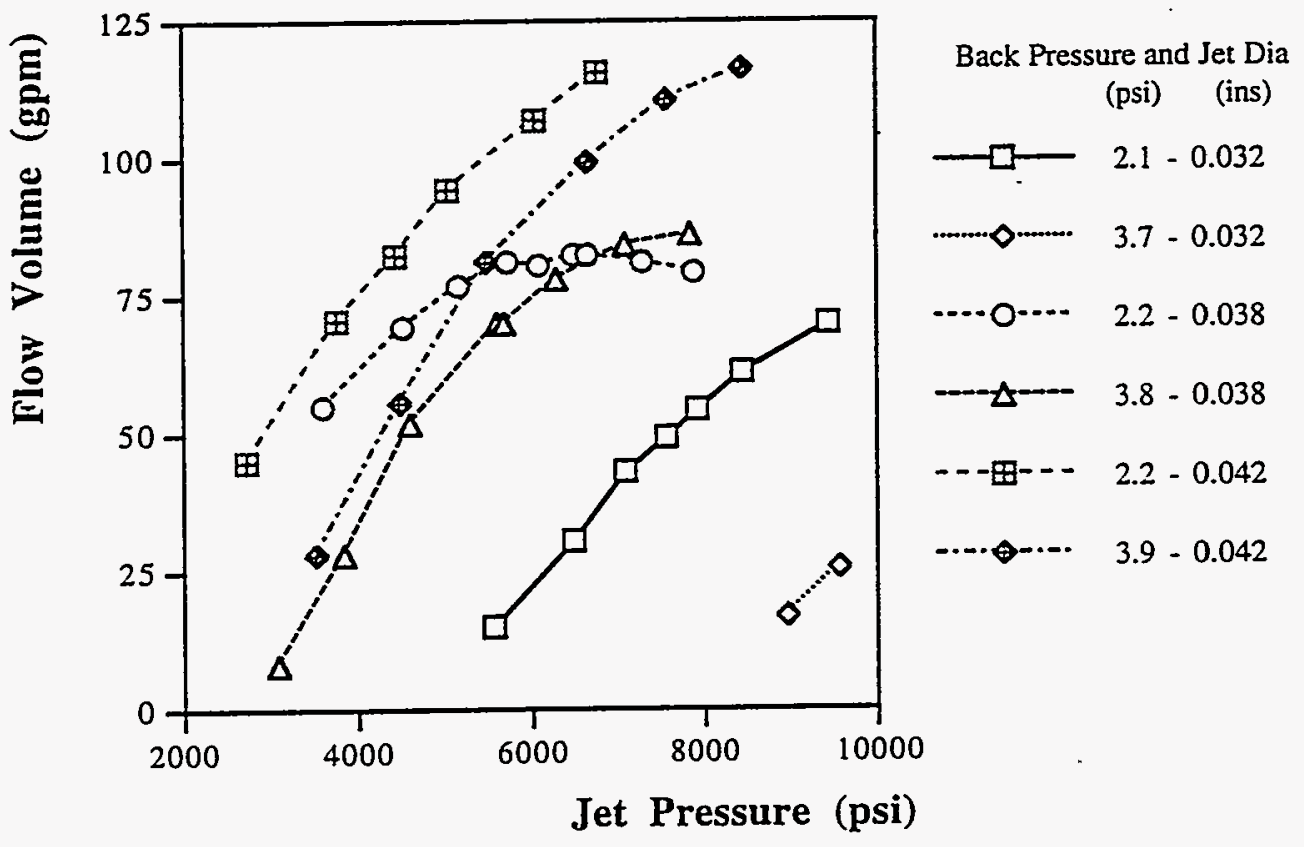

Figure 1.7 Delivered Volume as a Function of Driving Pressure, for three Orifice Sizes and 2 Back Pressures, using the Aquadyne Pump. 
The above plots of the raw data allowed some interpretation of the performance parameters of the pump. Performance was clearly quite negatively influenced by the back pressure against which the pump had to operate, and jet delivery was enhanced by increasing both nozzle diameter and jet pressure.

Since both these jet parameters increased the power supplied to the pump, neither result was, in itself, surprising. However, as a means of more accurately determining how these factors influenced overall pump performance, the horsepower injected into the pump was calculated and compared with that of the total output flow (including injected fluid). The resulting value was derived as a relative efficiency of the pump performance (Figure 1.8). For comparative purposes the same two sets of data have been used for this secondary analysis. The term relative efficiency has been used since the calculation did not consider the actual flow rate through the driving nozzles, but rather calculated a theoretical flow rate assuming a Vena Contracta value of 1.0.

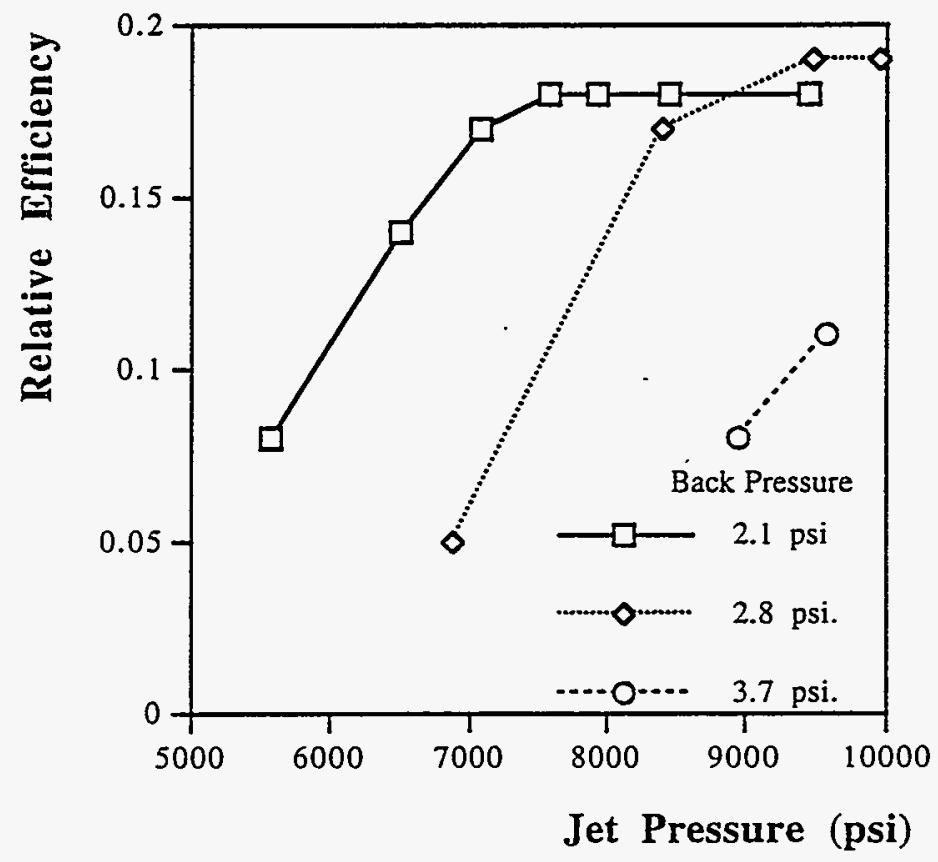

Figure 1.8 Relative Efficiency of Energy Transmission for the 0.032 nozzle assemblies as a function of pressure and downstream head.

It would appear that the pump works more efficiently at higher pressures, and that the higher the downstream pressure then the higher the jet driving pressure required for the pump to work effectively. 
When the change in nozzle diameters was factored into the analysis by again comparing the performance obtained at two different back pressures for the three nozzle sizes tested, the results obtained are not as clear cut (Figure 1.9). This is partially because the data from the two larger nozzles are virtually coincident, in contrast with the clearly distinct results from the tests carried out with the smallest nozzle size.

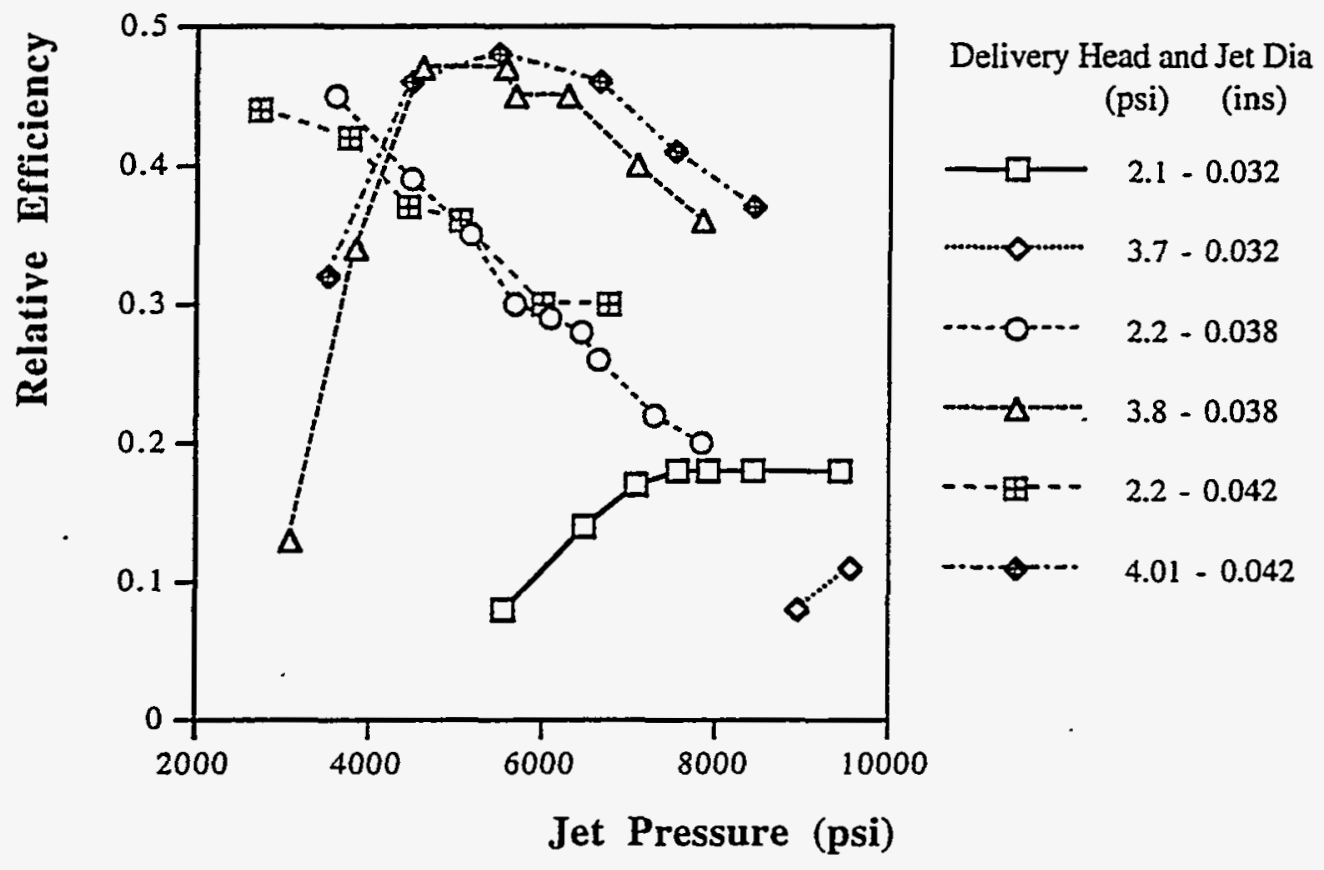

Figure 1.9 Relative Efficiencies of the Aquadyne Jet Pump with Different Nozzle Diameters, Driving Pressure and Back Pressures.

At the smallest nozzle diameter the jet pump was more efficient at the higher jet pressures but against a lower pressure head. No clear optimum pressure value could be defined. When larger jet nozzles were used, however, this is not the case and it appears that there is a clear optimum jet pressure for the device. For both nozzles this appears to be in the 4,500 to 5,500 psi pressure range, with the pump apparently working more efficiently against a higher pressure head. At a lower pressure head, the pump works more efficiently at a lower driving pressure.

For the Aquadyne pump, the maximum output pressure which could be obtained throughout the suite of tests was against a head of 16 psi, equivalent to just over 30 feet which was confirmed by a test in which the pump delivered fluid into a vertical hose section. To meet the required performance parameters for the proposed field application, the pump should pump efficiently against at least twice this delivery pressure. The overall design of the pump appeared, at least initially, to be satisfactory, 
however, and accordingly a second pump was designed and constructed in the HPWL. The design of this pump included additional flexibility in manufacture to allow a greater range of performance parameters to be investigated.

\section{Testing the HPWL Jet Pump}

The first task for this phase of the project was to design a jet pump which would allow a sufficient flexibility in operation so a greater range of parameters could be tested. As a result the new pump (Figure 1.10) had significant internally differences from the original pump contour. It was designed so that the original intake and exhaust ports were 0.5 inches in diameter, but allowed the size to be reamed during the program to a diameter of 2 inches. In addition, the pump nozzle ring was bored so that it was capable of using either 2,3 , or 4 nozzles to form a 30 degree converging cone of high-pressure driving fluid around the input port.

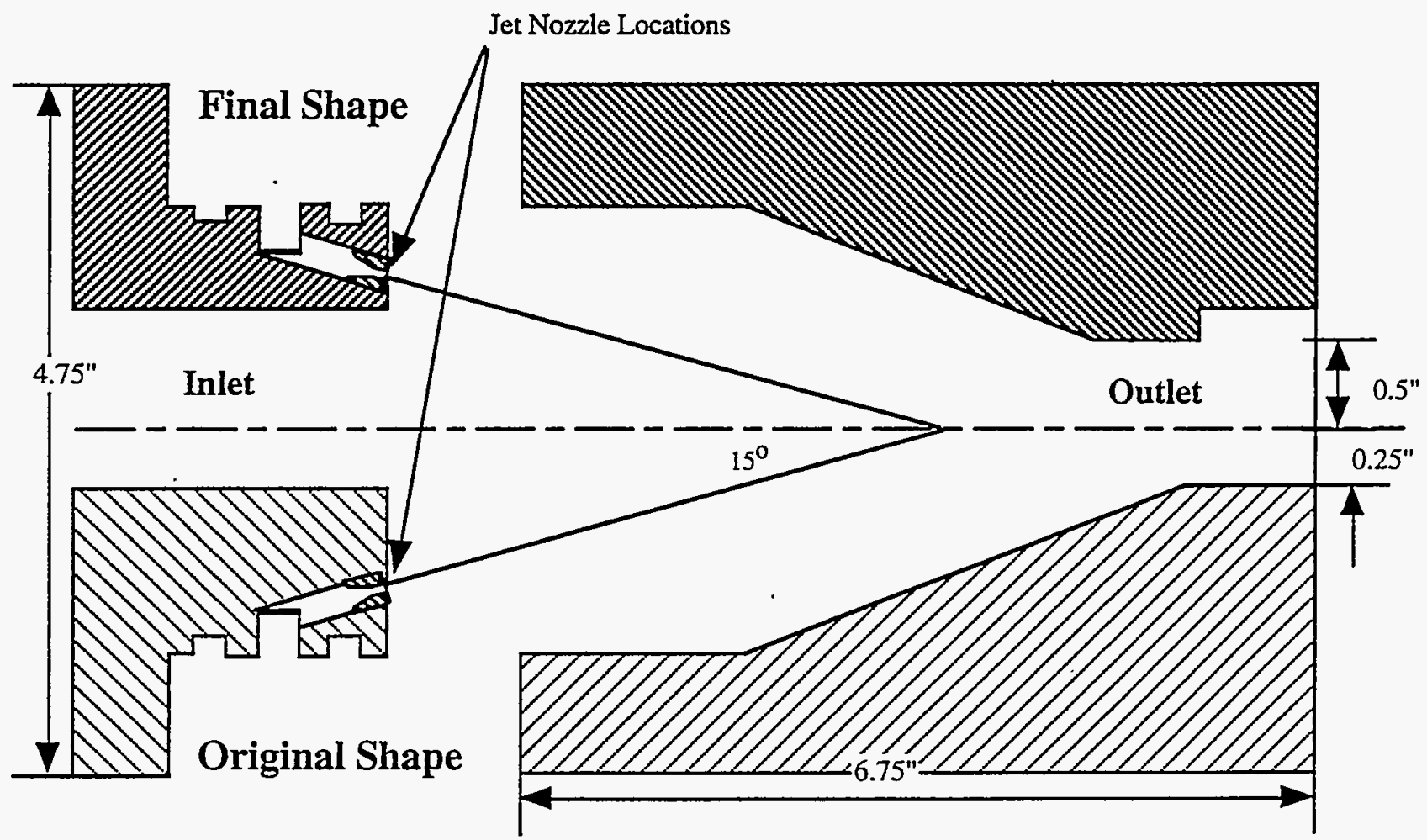

Figure 1.10 Designs of the HPWL Jet Pump.

To properly evaluate the new pump, the test stand had to be modified to cope with the smaller outlet pipe range (from 2.0 to 0.5 inches), with a similar change in the inlet line. In the latter case the lead-in to the jet pump was changed to a $1 / 2$-inch pipe which connected to a 1 -inch elbow 
section. This assembly then connected to the output valve and the return tank.

To get a better idea of the new pump's capabilities, several tests were performed. As in the testing of the original pump, the test series was designed to evaluate the pump performance over a range of different jet nozzles, jet driving pressures and output pressures. The nozzles used were $0.032,0.038$, and 0.042 inch in diameter. The delivered head pressure varied from 10 to $28 \mathrm{psi}$. This initial range was used to give an indication of jet parameter effects on the effectiveness of this new pump design.

As with the initial pump, the first test series was carried out with the smallest set of nozzles (Figures $1.11 \& 1.12$ ). With the smaller flow passage, the back pressure against which the pump had to deliver the fluid was increased in 5 psi increments until a level of 25 psi was achieved. The resulting fluid delivery shows a smooth increase in pumped fluid with driving pressure (Figure 1.11). This indicated that there were no large turbulence problems or choking in the system. Obviously fluid delivery still declined with increase in head, yet these results with the new pump gave an indication that the design goal could be reached. It was interesting to note that the relative efficiency values for the new pump were significantly higher than those of the initial unit (Figure 1.12).

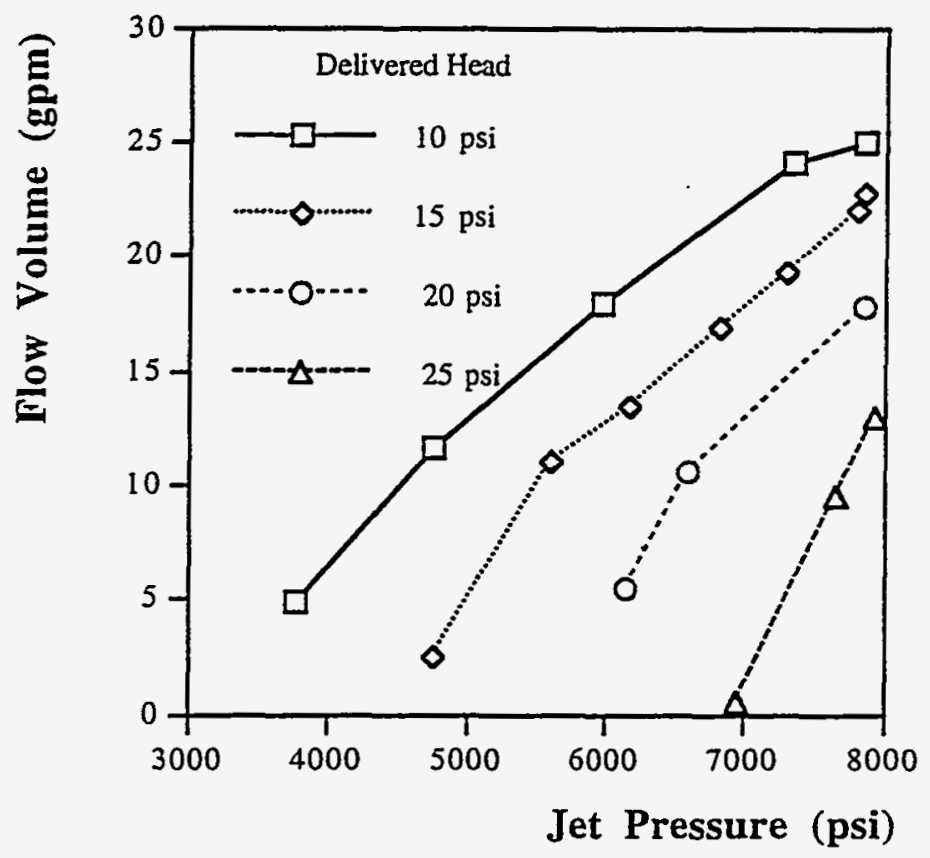

Figure 1.11 Delivered Volume as a function of Driving Pressure, with a 0.032 inch set of 3 jet orifices, using the HPWL pump. 


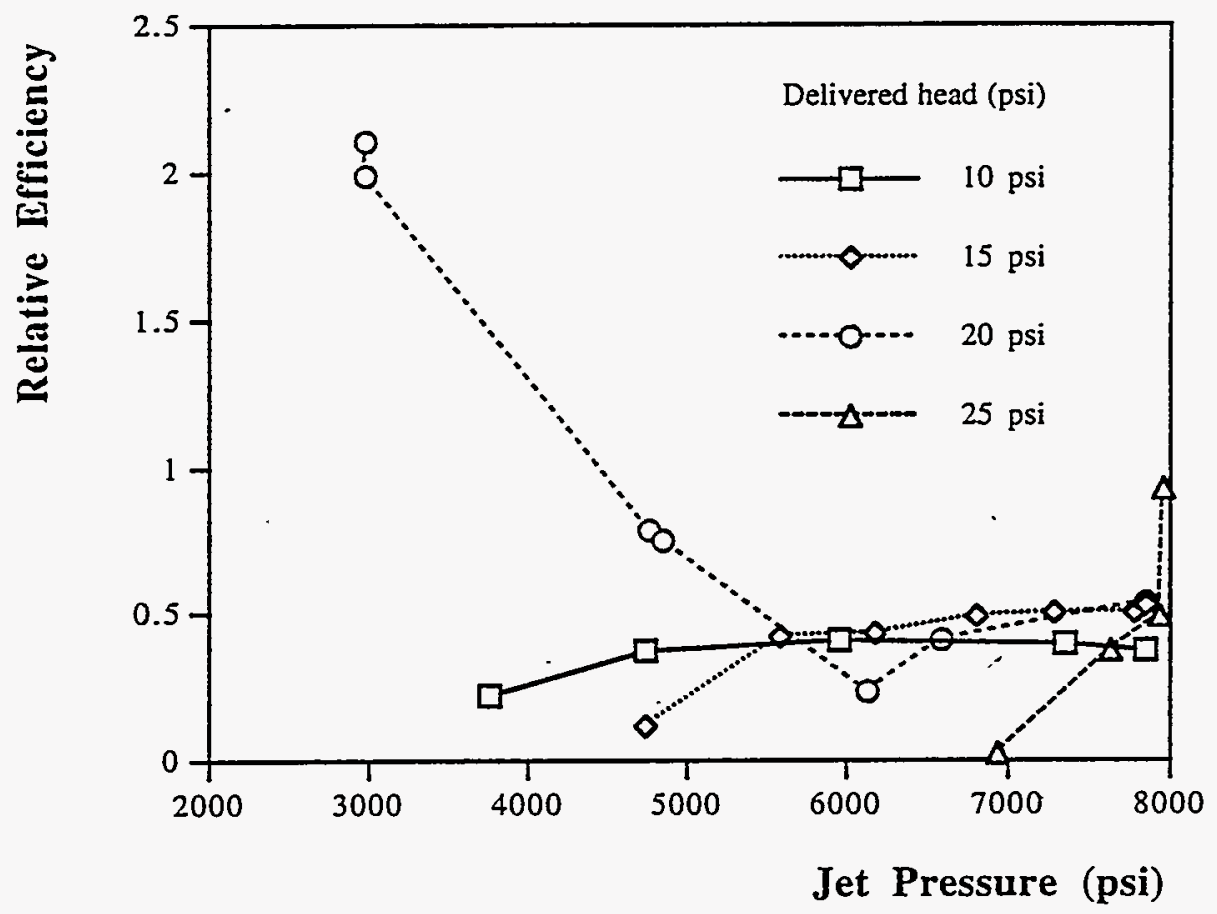

Figure 1.12 Relative Efficiency of Energy Transmission for the 0.032 nozzle assemblies as a function of pressure and downstream head, with the HPWL pump.

A review of the data using 0.032-inch diameter nozzles in the HPWL pump showed that this nozzle size would not provide enough power to achieve the design goals. Accordingly, 0.038-inch diameter nozzles were installed and the pump was retested (Figure 1.13) over the same range of delivery head.

For the first time the pump seemed to be choked. The flow was almost constant, at about $25 \mathrm{gpm}$, above 5,000 psi input pressure. This had been about the maximum flow rate which had been tested with the 0.032 -inch diameter jets. This was an interesting phenomena which is believed to be caused by the small diameter of the original intake and exhaust pipes attached to the pump. To test this theory the output pipe was bushed up to 1 inch immediately out of the pump. This change provided a $6 \mathrm{gpm}$ increase in flow (Figure 1.14). 


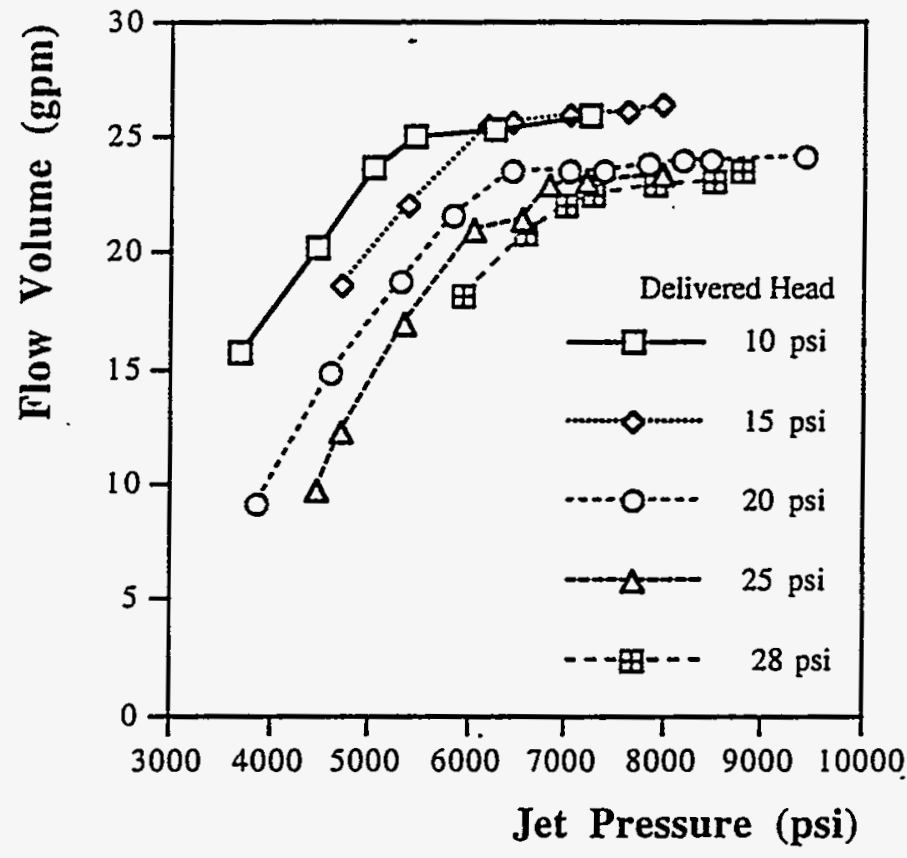

Figure 1.13. Flow as a function of Driving Pressure and Delivery Head for the 0.038 inch diameter nozzles in the HPWL pump.

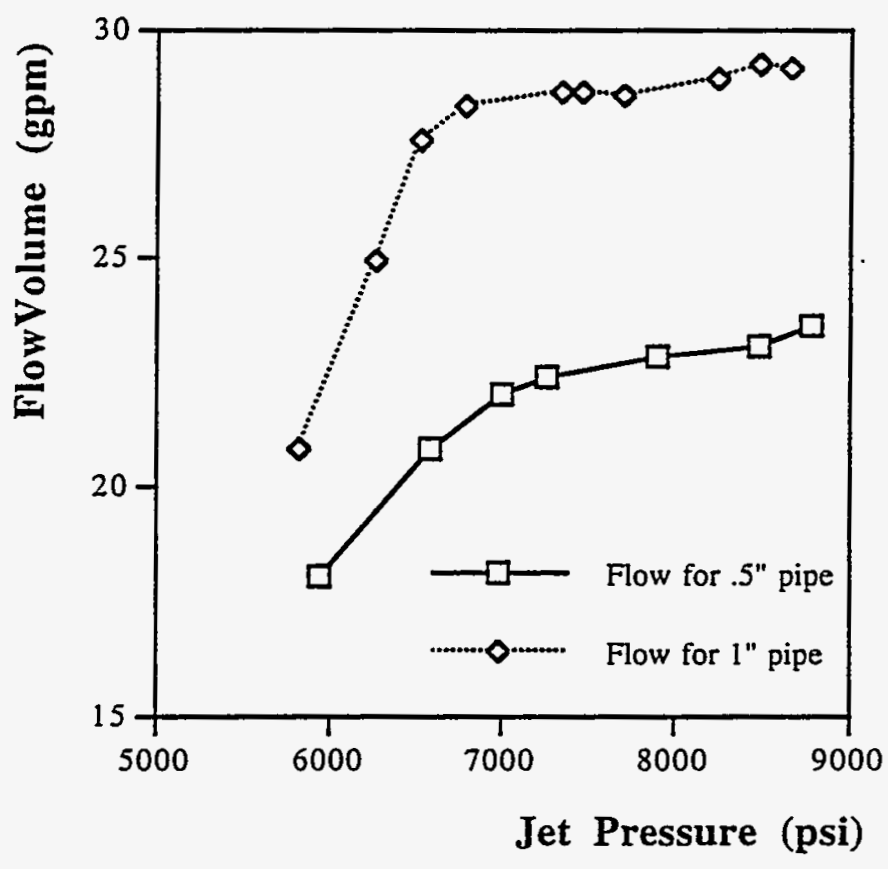

Figure 1.14 Flow as a function of Driving Pressure and Delivery Head for the 0.038 inch diameter nozzles in the HPWL pump, with enlarged outlet channel. 
There was still some restriction on achievable flow, but there was also an increase in pumping efficiency (Figure 1.15). The gain was clear, up to the point where the system "choked" (Figure 1.16), indicating that an additional modification was required for the circuit.

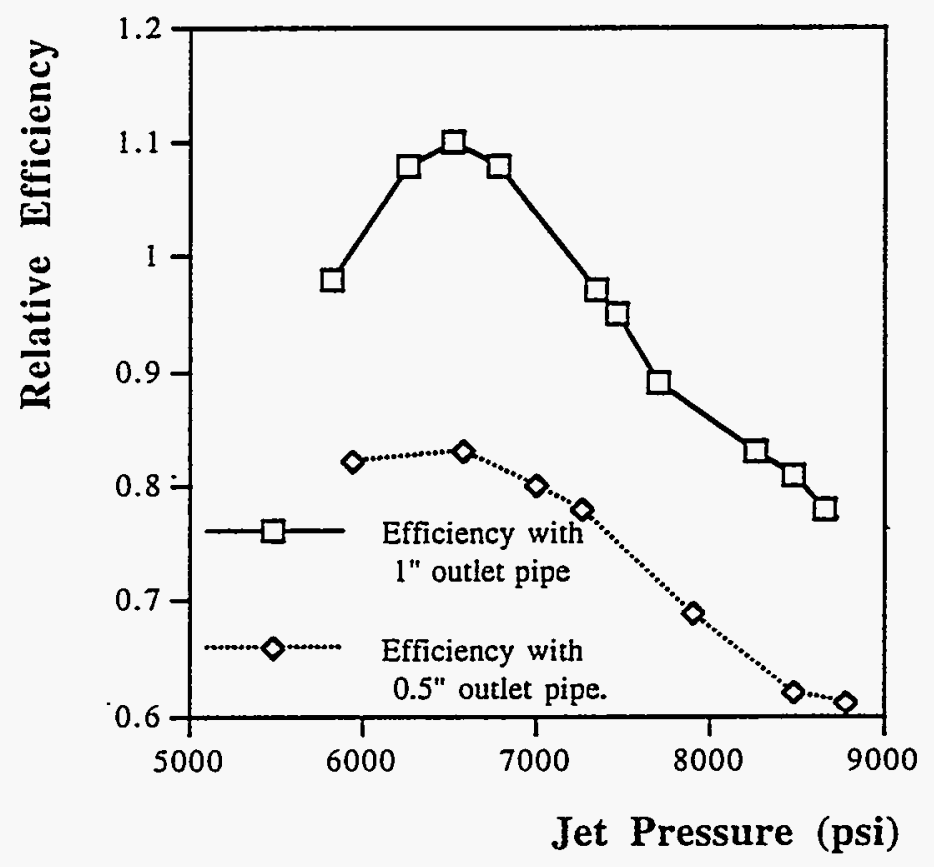

Figure 1.15 Change in Pumping Efficiency with an increase in outlet diameter.

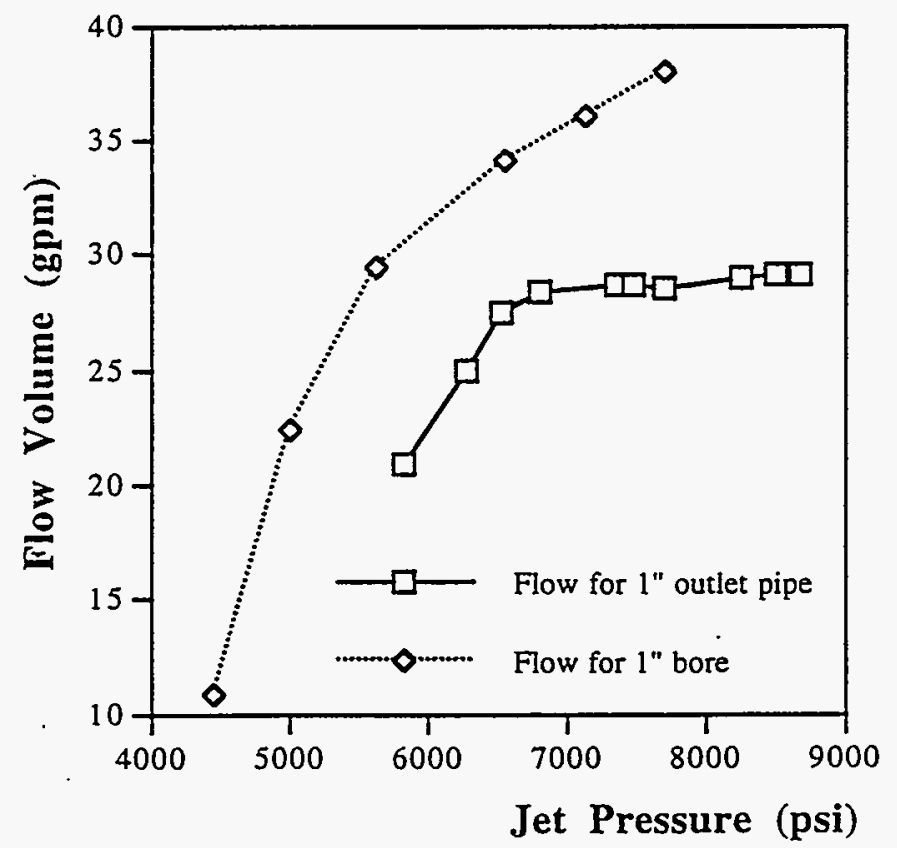

Figure 1.16 Gain in Flow Achieved by opening the HPWL Pump Inlet. 
The benefit achieved to this point had been a limited gain of roughly $30 \%$ in flow for a doubling of the pipe radius. This suggested that there was another restriction to a further increase in the flow. It was decided to increase the intake diameter of the pump to 1-inch and to thread the mounting of the intake line so that a 1-inch feed pipe could be attached. The internal pump throat diameter was, however, kept at 0.5 -inch (see Figure 1.10). This modified pump increased the flow by an additional 8 gpm. Obviously this modification eliminated the "choking effect" for the 0.038-inch diameter nozzles (Figure 1.16).

The output flow had now been increased to $38 \mathrm{gpm}$ at a head of $28 \mathrm{psi}$ which is equivalent to lifting the water column to 56 feet. At the same time it is of interest to note that the pump was operating more efficiently at a lower driving pressure than was the case when it was choked (Figure 1.17). Choking occurred at a pressure of around 6,500 psi with a 0.5 -inch pipe.

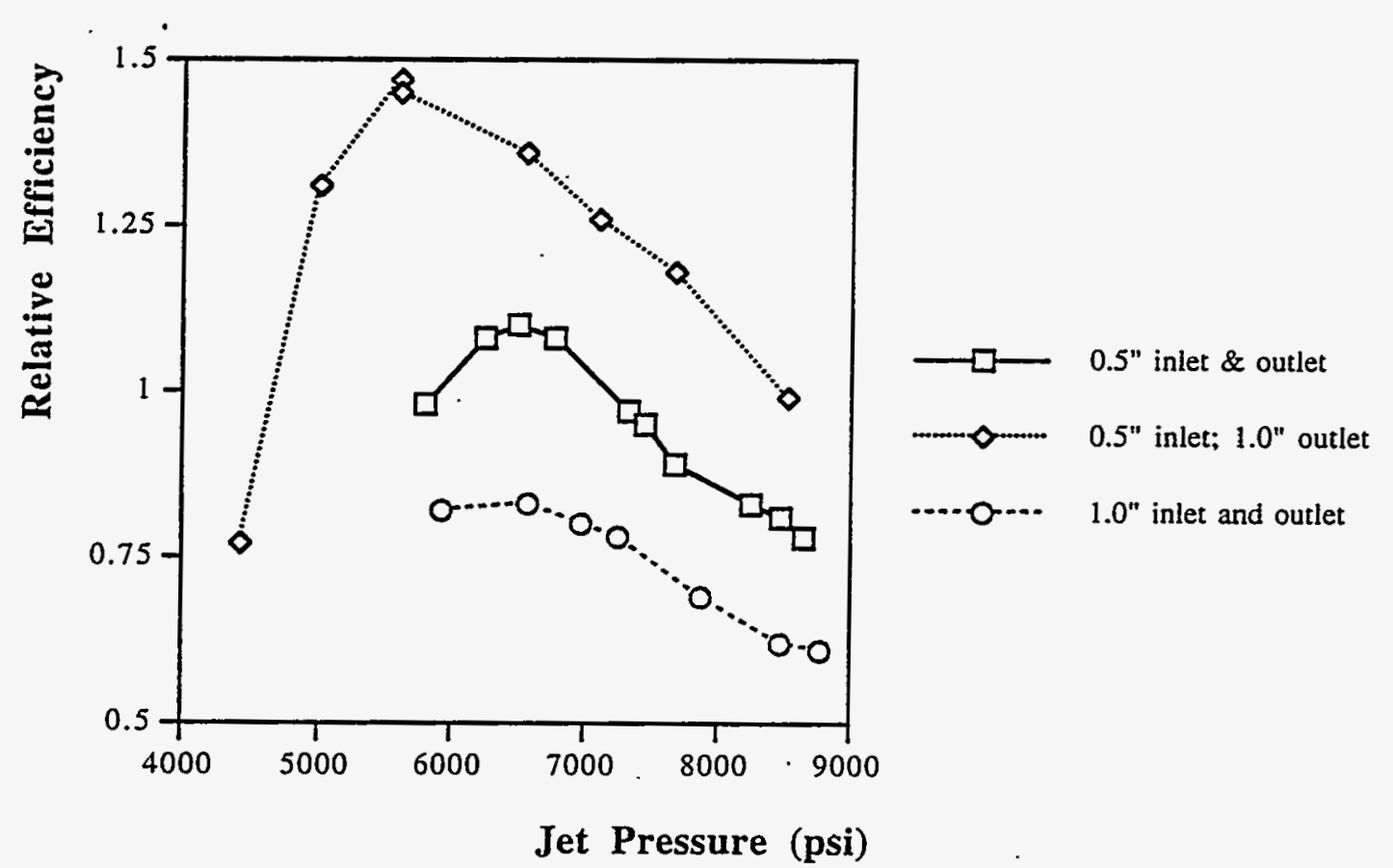

Figure 1.17 Relative Efficiency of Fluid Delivery with increase in the inlet bore for the HPWL pump.

There was not quite enough flow to achieve the design specifications. The jet pump nozzles were increased in diameter, matching the largest series tried (0.042-inch) with the Aquadyne pump. Given that the pump could now produce larger volume flows against the higher head, testing was continued at this level. Since the data from the 0.038 series had indicated the problems with flow choking occurred with narrower feed and outlet bores, these tests were carried out with a 1 inch inlet and both a 1-inch and a 2-inch outlet pipe. 
The 0.042 -inch diameter nozzles were sufficient to provide the vertical lift (60 feet) and volume of flow (40 gpm) required in the initial specifications for the Confined Sluicing Waterjet End Effector. In the initial configuration, the pump showed a choking effect (Figure 1.18), although it produced 39 gpm at 28 psi head which met the design specifications. When the outlet pipe was increased from 1-inch to 2-inches in diameter, flow increased to $62 \mathrm{gpm}$ at 28 psi pressure (Figure 1.19).

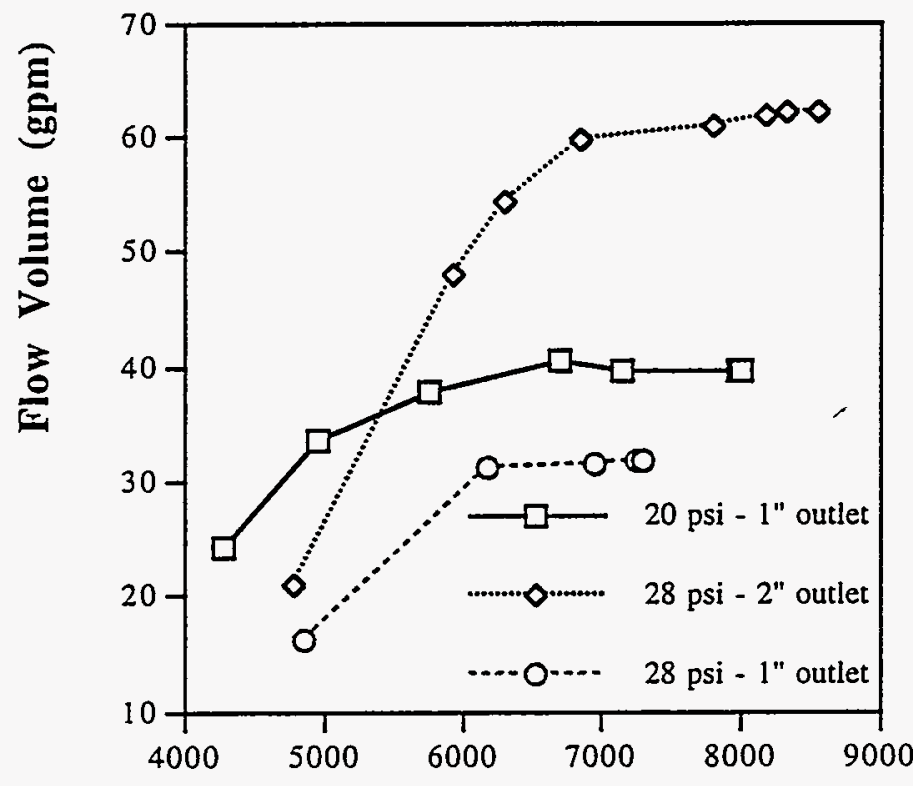

Jet Pressure (psi)

Figure 1.18 Flow Rates as a Function of Drive Pressure for the 0.042 inch drive nozzles.

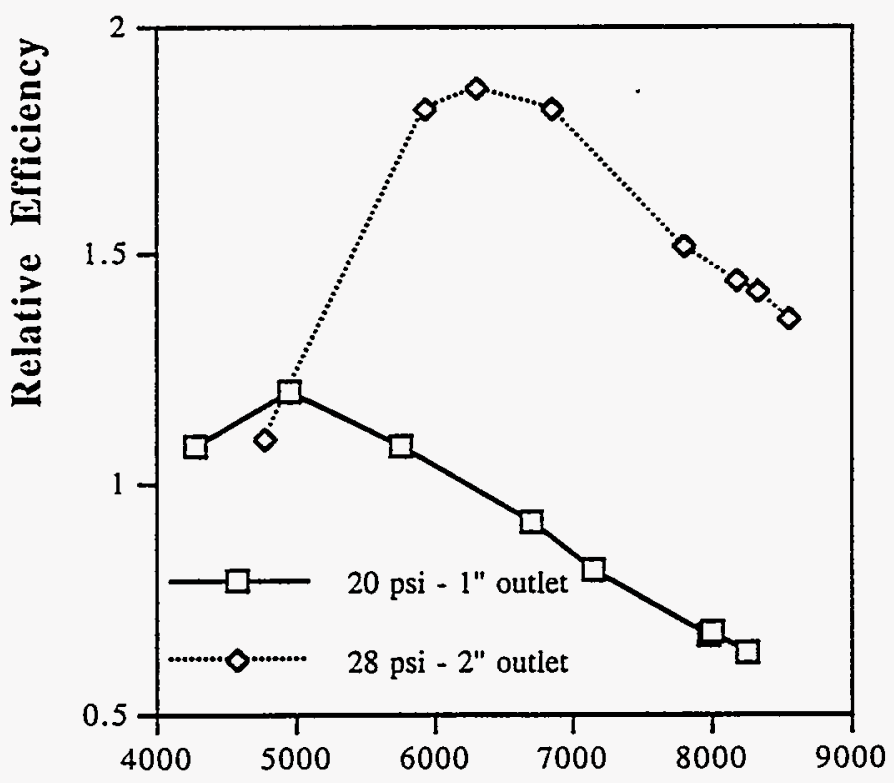

Jet Pressure (psi)

Figure 1.19 Relative Efficiencies of the HPWL pump fitted with 0.042 inch diameter nozzles. 
These changes produced a significant improvement in the operational efficiency of the pump, with the increase in nozzle diameter and outlet line against the higher delivery pressures.

As a final part of this initial study the jet pressure was maintained at around 7,000 psi while the back pressure against the pump was varied. Unfortunately, due to the nature of the test, it was not possible to accurately read the flow values over the full range of the run. Thus, there is some question about the values at pressures below 40 psi back pressure. Nevertheless, the curves in Figure 1.20 indicate that the jet pump can be run at significantly higher performance specifications that originally required ( $40 \mathrm{psi}$ which is equivalent to a lift of 80 feet).

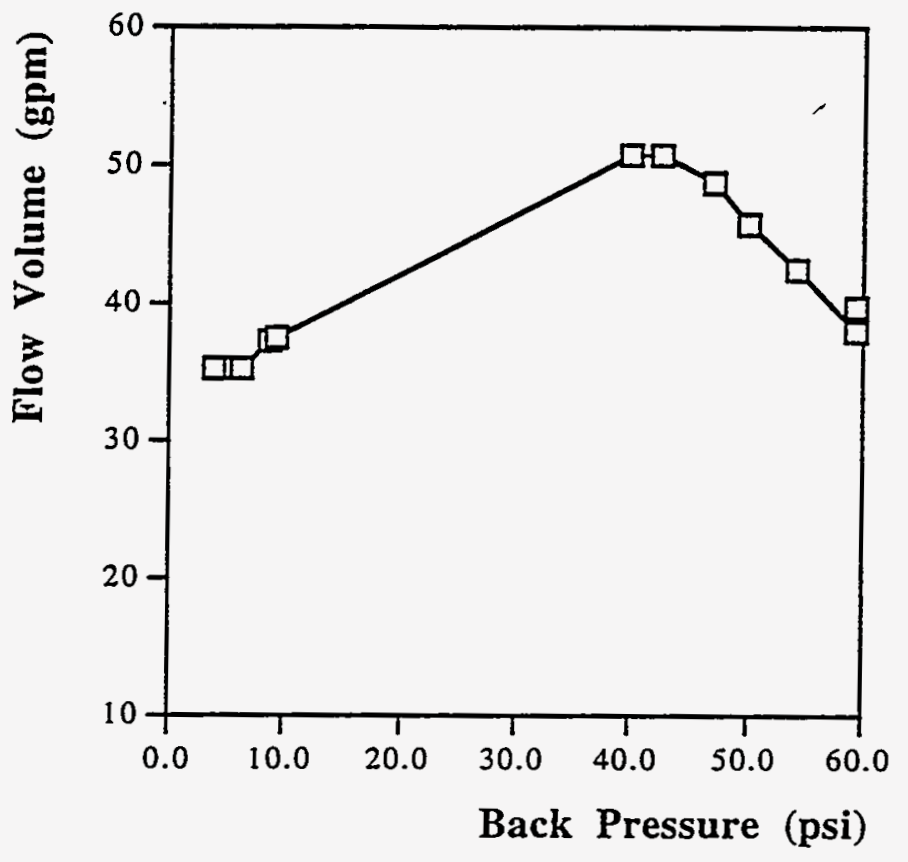

Figure 1.20 Effect of Change in Back Pressure on Jet Pump Delivery.

In a similar manner, when the relative efficiency of delivery is calculated, higher values are obtained than those indicated in the earlier phases of the work. The data (Figure 1.21) again indicates a problem in the monitoring instrumentation at lower test pressures, yet it also reveals the potential benefit from properly tuning the pump, since output levels continue to increase where the proper jet pressure and nozzle diameters are used in the construction.

In order to summarize the results of the test program to date, a plot was constructed of representative curves from the three nozzle series tested 
with the new pump assembly (Figure 1.22). The data plotted were chosen to reflect the problem, addressed above, of pump choking when the system supply lines are of inadequate size. Since the data were collected for the smaller nozzles at lower delivery pressures, the plot shown is for a head of 20 psi. This is purely because this value had the greatest amount of data available.

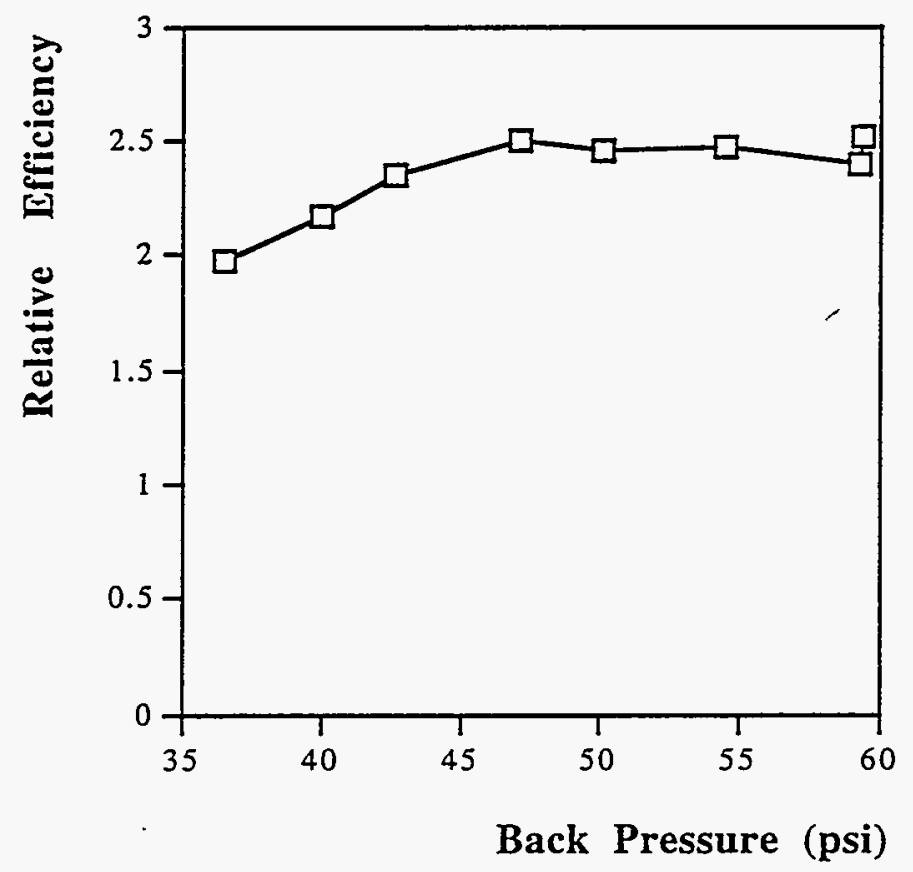

Figure 1.21 Change in Pump Efficiency with Back Pressure, at a Jet Driving Pressure of 7,000 psi through 0.042 inch diameter jets. 


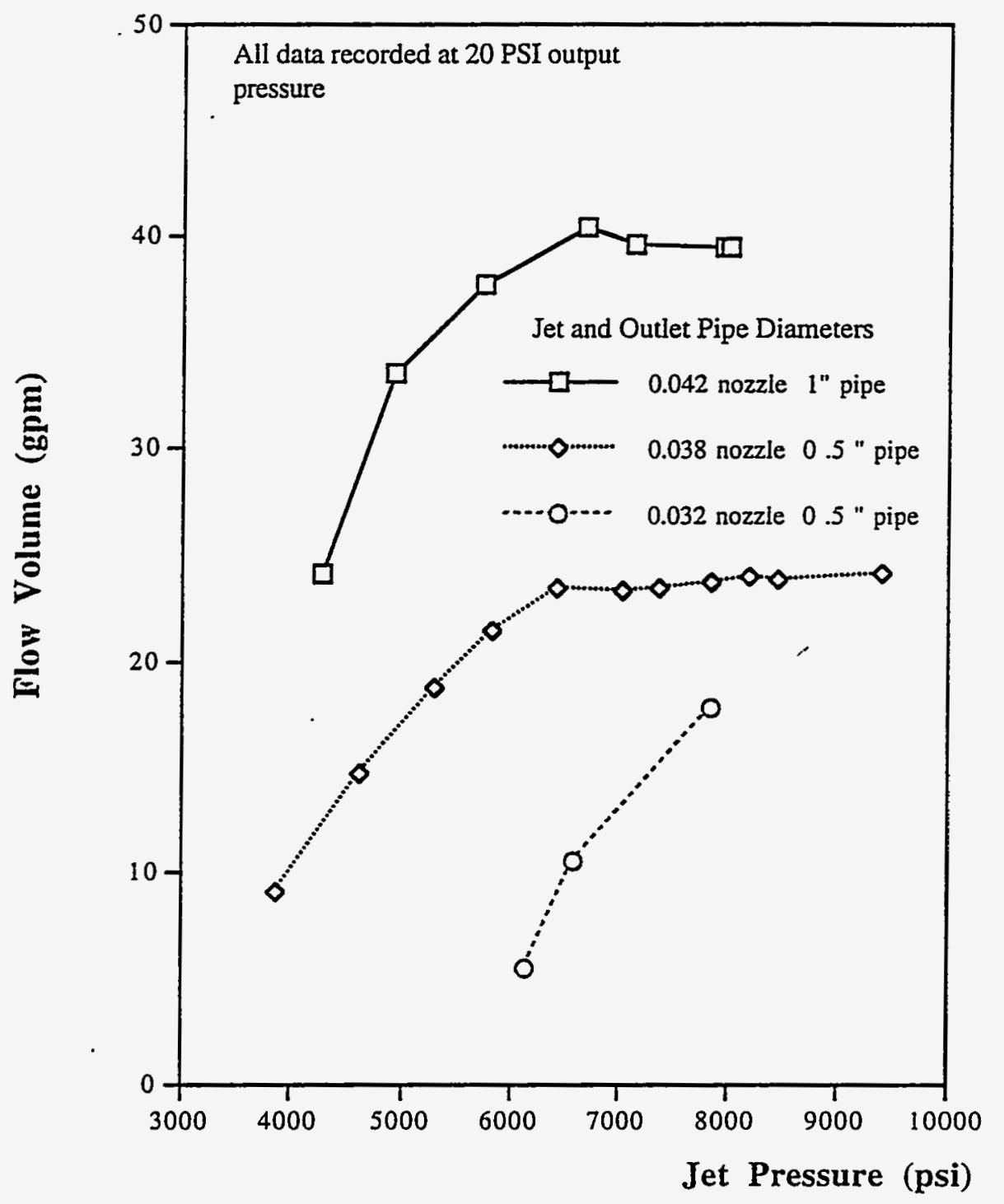

Figure 1.22 Representative Flows with varying Jet pump nozzle diameters, as a function of driving pressure.

\section{Conclusions}

The objective of this initial study of jet pump behavior was to establish the conditions which would be required to pump 40 gpm through a delivery line against a head of roughly $30 \mathrm{psi}$. Because of time and other constraints only a relatively simple set of test procedures were carried out to drive the design in the direction required. Nevertheless, as is shown in the above figures, volume flow rates in excess of $50 \mathrm{gpm}$ against a head of more than 40 psi could be achieved. 
A more detailed study of the results of the experimentation remains to be made. Indications are that with the smaller nozzle diameters, an insufficient amount of energy is reaching the throat of the pump. By changing the pump configuration to deliver a greater proportion of the jet energy to the throat area, it should, therefore, be possible to enhance the pump performance and reduce the quantity of water required for the pumping port of the system design.

Concurrently, the ability of the pump to deliver the required flow rate with a delivery pipe diameter between 1- and 2-inches suggests that the support requirements for such a transport line can be minimized, relative to those required for an air conveyance system, in the design of the supporting arm within the tank.

It is recommended that the problem, and these results, be reviewed at a later stage, when the size of the particles to be pumped has been better defined. Within that constraint it will also be necessary to improve the design of the pump through additional iteration in order to achieve the ability to carry the maximum amount of solid material within the transport train from the waste storage tank. 


\section{Chapter 2. JET CUTTING TEST EVALUATION}

\section{Introduction}

The removal of waste from the Underground Storage Tanks at the Hanford site requires, among other tools, a means of breaking out and conveying the waste from the tanks. As one approach to solving this problem, the High Pressure Waterjet Laboratory (HPWL) of the Rock Mechanics and Explosives Research Center (RMERC) of the University of Missouri-Rolla (UMR) is developing a means for confined sluicing of the material, using high-pressure waterjets delivered to the tank as a method both for cutting and for providing the power to pump the material from the tank.

In the confined sluicing concept, a series of high-pressure waterjets are used to cut into, and break out, the material in the tank. The cutting head operates within a surrounding shroud, with the shroud connected to the intake line feeding a jet pump (Figure 2.1). As the waterjets cut and dislodge material, the excavated material is immediately aspirated into the pump intake and pumped out of the tank. In this manner there is no net flow of water into the tank and, thus, the risk of leakage of material from the tank is minimized.

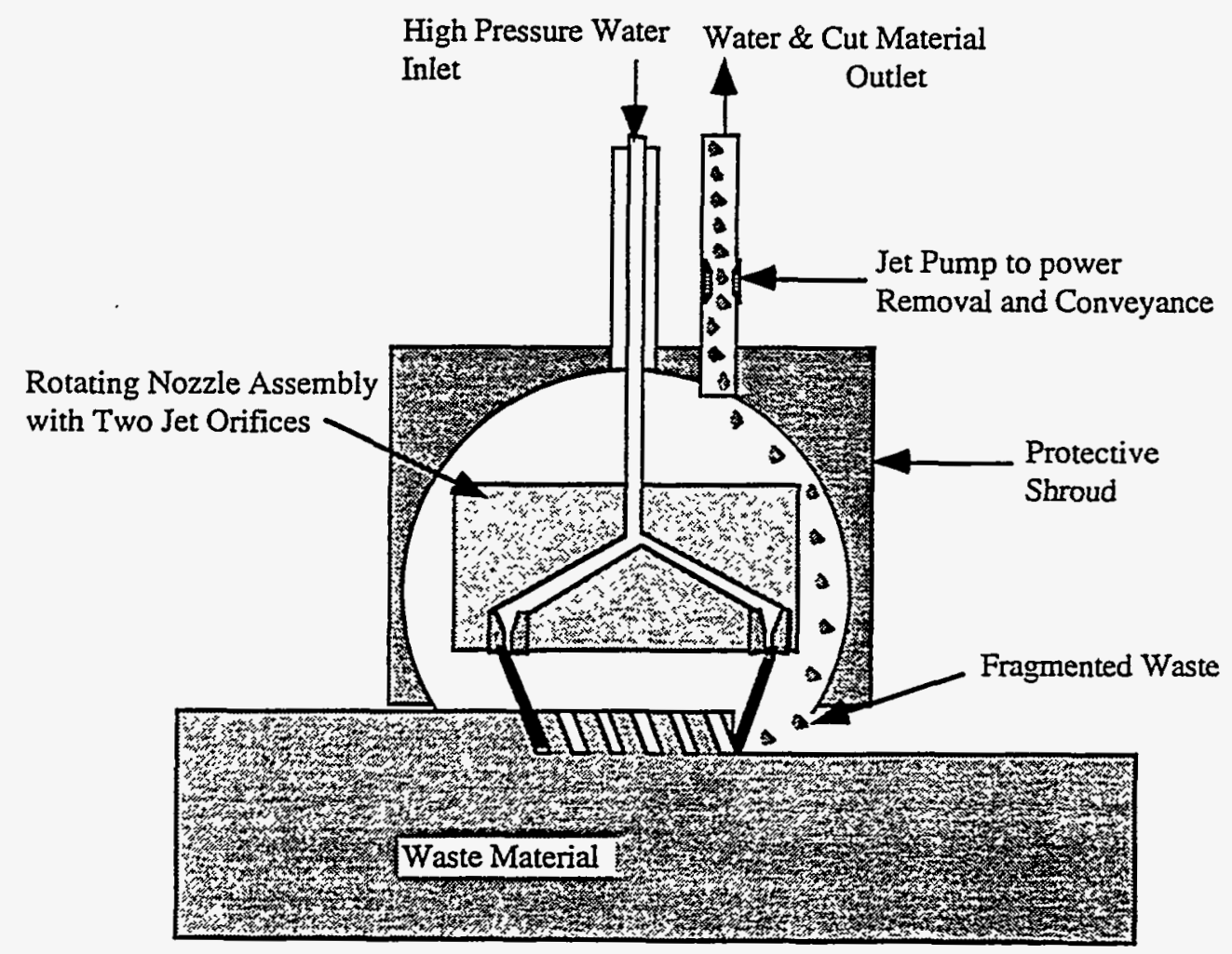

Figure 2.1 Initial concept for the removal of Waste from an Underground Storage Tank (UST) using a Confined Sluicing Method. 
This report deals with a preliminary evaluation of the ability of highpressure waterjets to cut a simulated waste material, a potassiummagnesium fertilizer, prepared to a specification supplied to the HPWL by the Pacific Northwest Laboratory (PNL). In a separate report (Ref. 2.1) the parameters controlling the operation of the jet pump have been reported; and its ability to lift water 60 feet, the distance from the bottom of the tanks to the ground surface, was demonstrated.

The experiments were directed at demonstrating that waterjets can cut the , simulant, and identifying the range of jet operating conditions which might be required to remove up to $30 \mathrm{gpm}$ of actual waste material from the tank. Using test data for this preliminary concept, it is possible to identify some of the operational characteristics of an end effector, and features of the interface between such a tool and the Long Reach Arm on which it will be operated.

\section{Sample Material}

The ability of high-pressure waterjets to cut through and mobilize a wide range of materials suggests that the most important initial test material should be the one which is most resistant and most likely to be encountered during tank cleaning operations. (This approach at present does not address the problems of cutting in-tank hardware but does consider the need to clean tank walls.) The material identified is the hard salt cake within the tanks, and the simulant proposed for modeling its behavior is a $\mathrm{K}-\mathrm{Mg}$ fertilizer (MSDS given in Appendix 1).

An initial test series was carried out on $\mathrm{K}-\mathrm{Mg}$ fertilizer that contained an oil additive. Following completion of these tests a standard sample preparation was specified by Dr. Elmore, requiring, inter alia, that the specimens demonstrate a uniaxial compressive strength of 3,000 psi. When such tests, using ASTM test specification D-2938-71a, were carried out on the initial material, the strength was found to be only $1200-1500$ psi. This was considered inadequate and was judged to be due to the oil additive. For the purpose of completeness, a summary of the results obtained with this initial material are presented as Appendix 2 to this report.

Fresh $\mathrm{K}-\mathrm{Mg}$ fertilizer was obtained, sold under the trade name "Dynamate", which did not contain any oil additive. Before preparing test specimens, samples were taken for compressive strength testing. Because the fertilizer dissolves it could not be cored wet, and when a diamond coring tool was used with air cooling, the material melted under the bit. To provide a simple, inexpensive, method for test sample preparation, it 
was decided to cast specimens in prepared lengths of plastic tubing. After the material had solidified and matured for a specified period, in accordance with the PNL specification, the tubing was removed and the sample was tested for uniaxial compressive strength. Values obtained exceeded 3,000 psi (3,200 and 3.250 psi, respectively) for the specimens tested, and the simulant was judged to be acceptable.

In the earlier testing, the test material had been cast into 2-foot diameter tanks. This used a considerable amount of material and did not allow sample testing at the traverse speeds which will be used by the actual cutting tool. A new method for testing was therefore developed.

\section{Method of Test}

Two-inch diameter samples were prepared, as for the compressive strength testing, and tested in a specially prepared device (Figure 2.2). This tool, known as PETE (for Parameter Evaluation Test Equipment), rotates the sample cylinder at $120 \mathrm{rpm}$. While at this speed a waterjet is traversed across the face of the cylinder cutting a groove in the surface. In the initial proposed method (SOP attached as Appendix 3) an intermediate plate was located between the nozzle and the target, with three holes in the plate. As the jet traversed, the holes were sized to give a jet exposure to the target for a single rotation of the sample at three 0.25 -inch radial increments. When this was tried, however, the reflection from the sides of the jet cutting into the sample was found to confound existing circles. The procedure was therefore modified, and a single slot replaced the perforated plate (Figure 2.3).

With this plate in place, the jet would cut a single spiral into the surface. To ensure no interference between adjacent cuts, the gearing on the lance advance drive was changed to give a feed of 0.15 -inch between adjacent passes (Figure 2.4). In this way, with more than three nozzle diameters between the two cuts, there would be no overlap of the jet cuts.

To measure the depth of cut, the sample face was scribed with two perpendicular pencil lines to identify the center of the sample. A digital caliper was then used to identify points at which the cut centerline was at the 0.25-, 0.5- and 0.75-inch radii, and the slot depth was measured at each point.

The experimental program was originally designed with three pressures and three nozzle diameters; but based upon the early test results, this was expanded until a series of 5 pressures, three traverse speeds and three 
nozzle sizes had been evaluated. Following this evaluation, a fourth nozzle diameter was included (0.052-inch) with a set of six jet pressures. Given that the averaged pressure value was approximately equivalent to that of the three earlier data series, the average value of this fourth data set was included in the data plots.

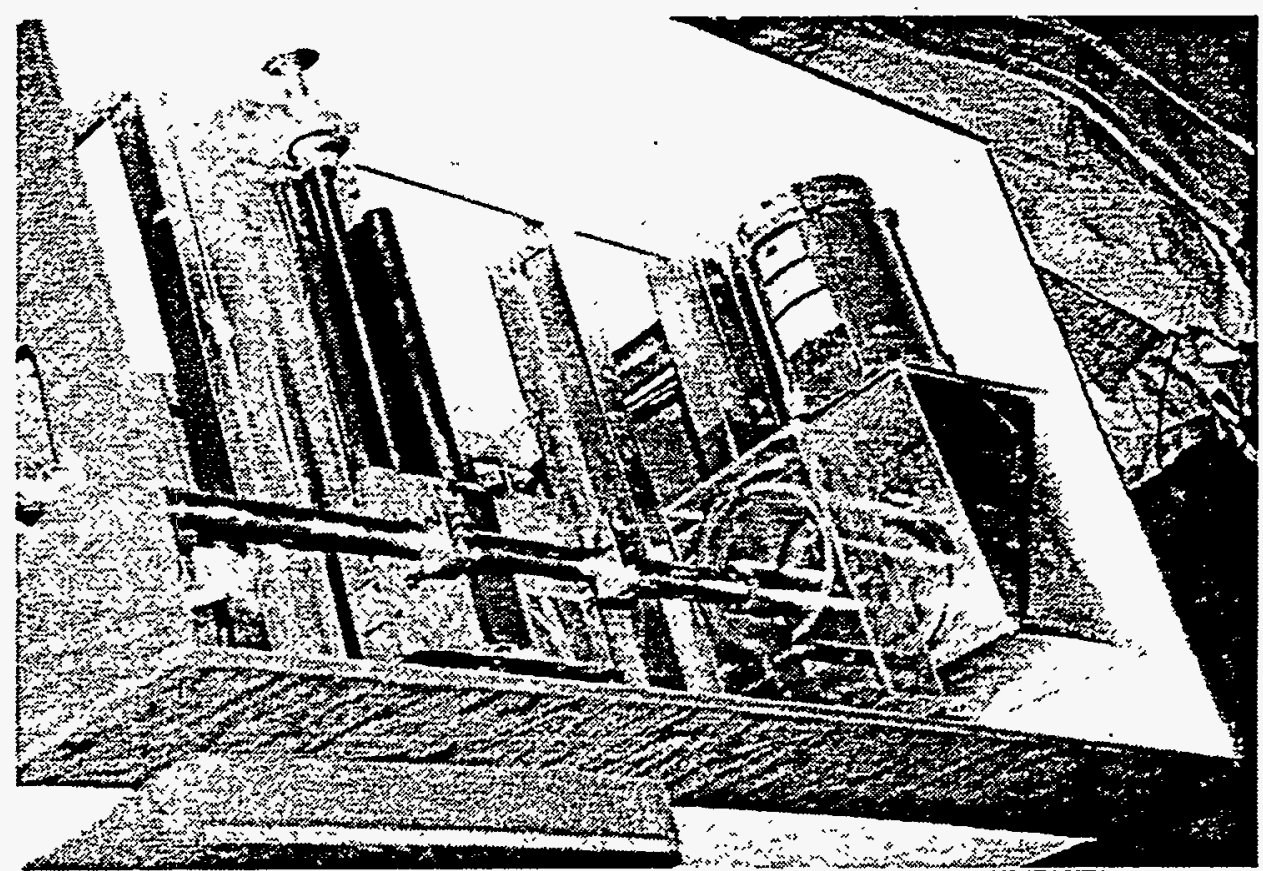

Figure 2.2 Parameter Evaluation Test Equipment (PETE).

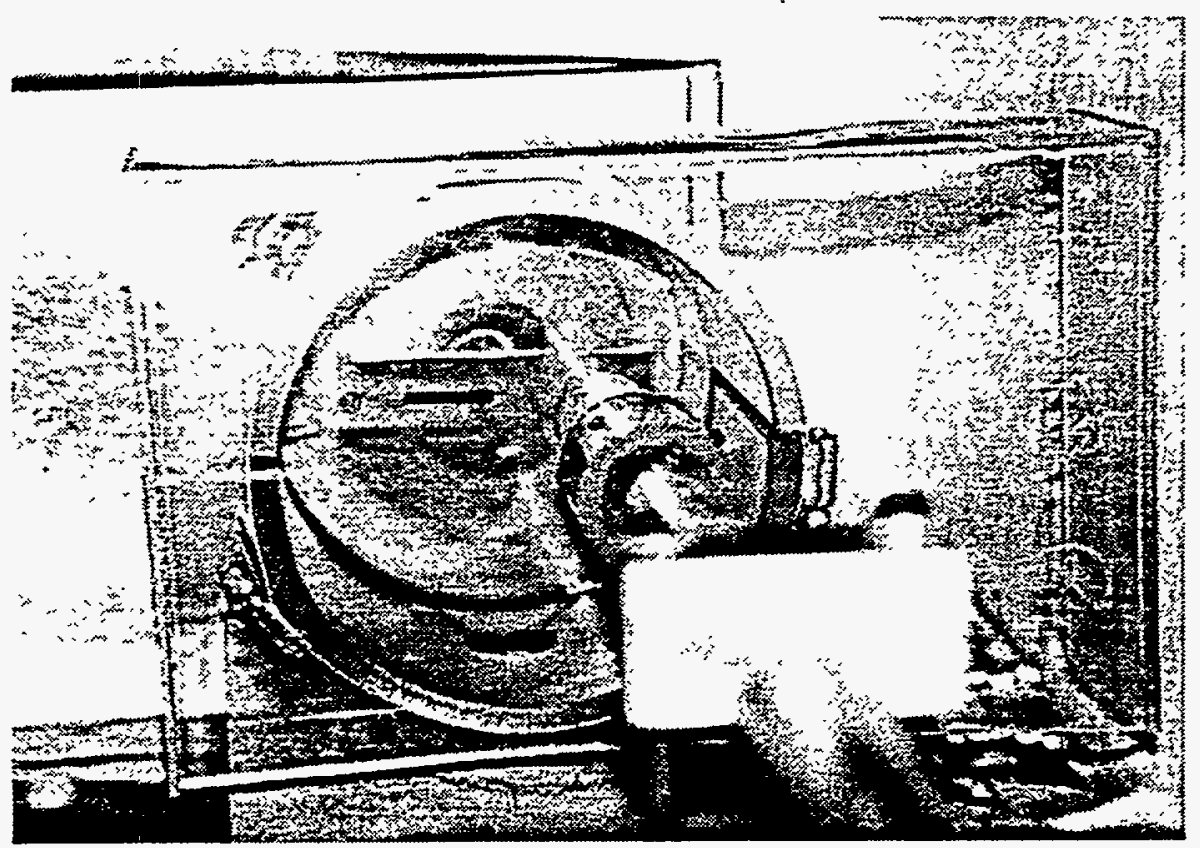

Figure 2.3 PETE with a slotted plate between the nozzle and the sample. 

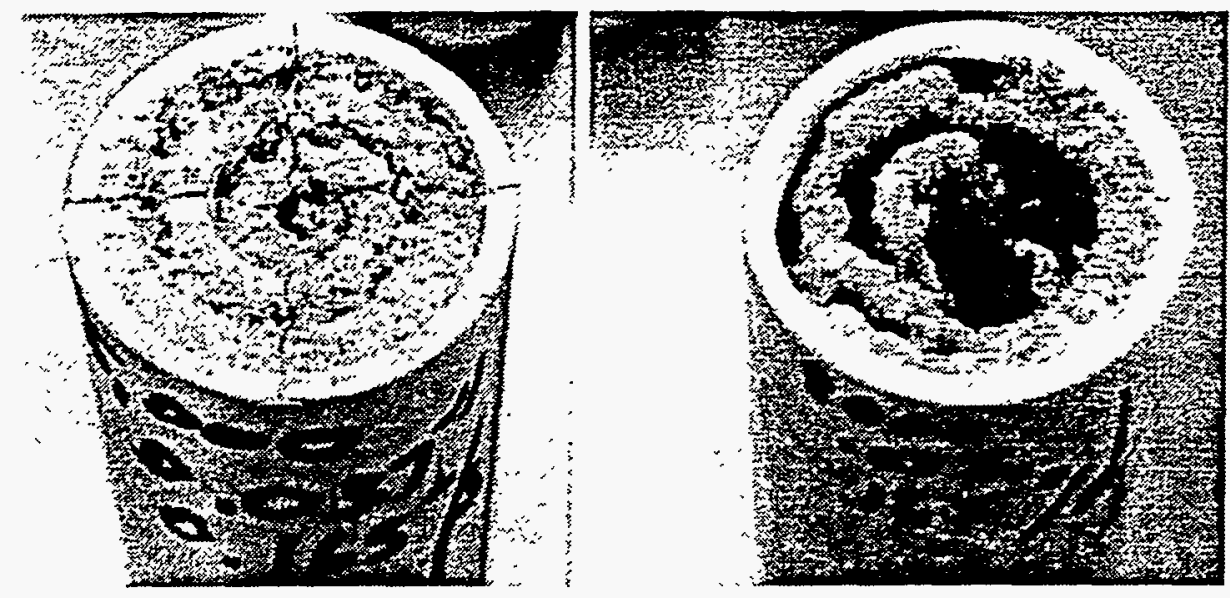

Figure 2.4 Cut Configuration on the Face of a Sample, showing the pencil marks used for Center Location.

\section{Experimental Results}

The extracted data is presented as a measured depth of cut, with the tables separated by nozzle diameter, and with the rows identified by the jet pressure in psi at which the tests were run.

Averaged values for the data are presented at the end of each row and column. Rather than give the reading as defined by the radius at which it was measured, the value has been converted into the linear traverse speed at which the jet moved over the surface, in in/sec. This was felt to be a more useful representation of the data and is used in the subsequent data analysis.

Table 1. Depth of Cut for a given Nozzle Diameter and as a Function of Jet Pressure and Nozzle Traverse Speed.

Nozzle Diameter 0.028 inches

Let Pressure

11,000

10,000

9,000

7,000

$\underline{5,000}$

Ave $\underline{3.14}$

0.52

0.43

0.447

0.16

$\underline{0.1}$

0.33

Nozzle Diameter 0.037 inches

Let Pressure

11,000

10,000

9,000

7,000

$\underline{5,000}$

Ave

\begin{tabular}{c} 
speed \\
$\mathbf{6 . 2 8}$ \\
\hline 0.4 \\
0.39 \\
0.385 \\
0.13 \\
$\underline{0.1}$ \\
0.28
\end{tabular}

speed

$\frac{6.28}{0.79}$

0.79

0.78

0.75

0.17

$\underline{0.25}$

0.55 (in/sec)

\begin{tabular}{c}
9.42 \\
0.35 \\
0.21 \\
0.347 \\
0.15 \\
0.084 \\
\hline 0.23
\end{tabular}

A ve

0.42

0.34

0.39

0.15

0.09

0.28

(in/sec)
Ave

0.71

0.75

0.63

0.17

0.25 


\begin{tabular}{|c|c|c|c|c|c|}
\hline \multicolumn{2}{|c|}{ Nozzle Diameter 0.042 inches } & \multirow{2}{*}{$\begin{array}{l}\text { speed } \\
\underline{6.28}\end{array}$} & \multirow[t]{2}{*}{$(\mathrm{in} / \mathrm{sec})$} & \\
\hline Jet Pressure & $\underline{3.14}$ & & & 2.42 & Ave \\
\hline 11,000 & 1.46 & 1.00 & & 0.88 & 1.11 \\
\hline 10,000 & 0.79 & 0.59 & & 0.52 & 0.63 \\
\hline 9,000 & 0.85 & 0.60 & & 0.35 & 0.60 \\
\hline 7,000 & 0.42 & 0.30 & & 0.18 & 0.30 \\
\hline$\underline{5,000}$ & $\underline{0.26}$ & $\underline{0.24}$ & & $\underline{0.14}$ & $\underline{0.21}$ \\
\hline Ave & 0.76 & $\overline{0.55}$ & & $\overline{0.41}$ & $\overline{0.57}$ \\
\hline Nozzle Diameter & 0.052 inches & speed & (in/sec) & & \\
\hline Jet Pressure & $\underline{3.14}$ & $\underline{6.28}$ & & 9.42 & Ave \\
\hline 11,000 & $\overline{1.65}$ & $\overline{0.91}$ & & $\overrightarrow{0.91}$ & 1.16 \\
\hline 10,000 & 1.18 & 0.65 & & 0.58 & 0.80 \\
\hline 8,000 & 1.17 & 0.94 & & $* 0.85 *$ & 0.99 \\
\hline 7,000 & 0.94 & 0.62 & & 0.55 & 0.70 \\
\hline 6,000 & 0.53 & 0.42 & & 0.43 & 0.46 \\
\hline 5,000 & 0.46 & 0.33 & & 0.33 & $\underline{0.37}$ \\
\hline Ave & 0.99 & 0.65 & & $\overline{0.61}$ & 0.75 \\
\hline
\end{tabular}

\section{Data Analysis}

Because the data had been collected through a factorial experiment, it was relatively easy to extract the information on the effect of change in the major parameters on the depth of cut achieved.

The data has been summarized to extract both first order and second order effects (Ref. 2.3); however, the limited number of data points make the validity of the second order effects somewhat questionable and they are provided, in graphical form, purely as an indicator of trends, rather than as the basis for the subsequent analysis.

In order to establish the first order effects, i.e. the primary relationship between the major variables and the cutting ability of the jets on the simulant, three curves have been plotted (Figures 2.5, 2.6 and 2.7). In a full factorial experiment the experimental program is designed so that each level of each variable is run, in combination with each level of each other variable, one time. Thus, in the table of results shown above, each combination of variables appears once. The inter-relationship between each primary variable and the depth of cut can then be obtained by averaging all the readings taken for each level of that variable since the only change, between the entire sets of data, lie in the change in that one variable (Ref. 2.2). The averaged data has, therefore, been plotted using the program Cricket Graph (Ref. 2.3), which has the power to compute a best fit to the curve and to plot this line relative to the underlying data. 


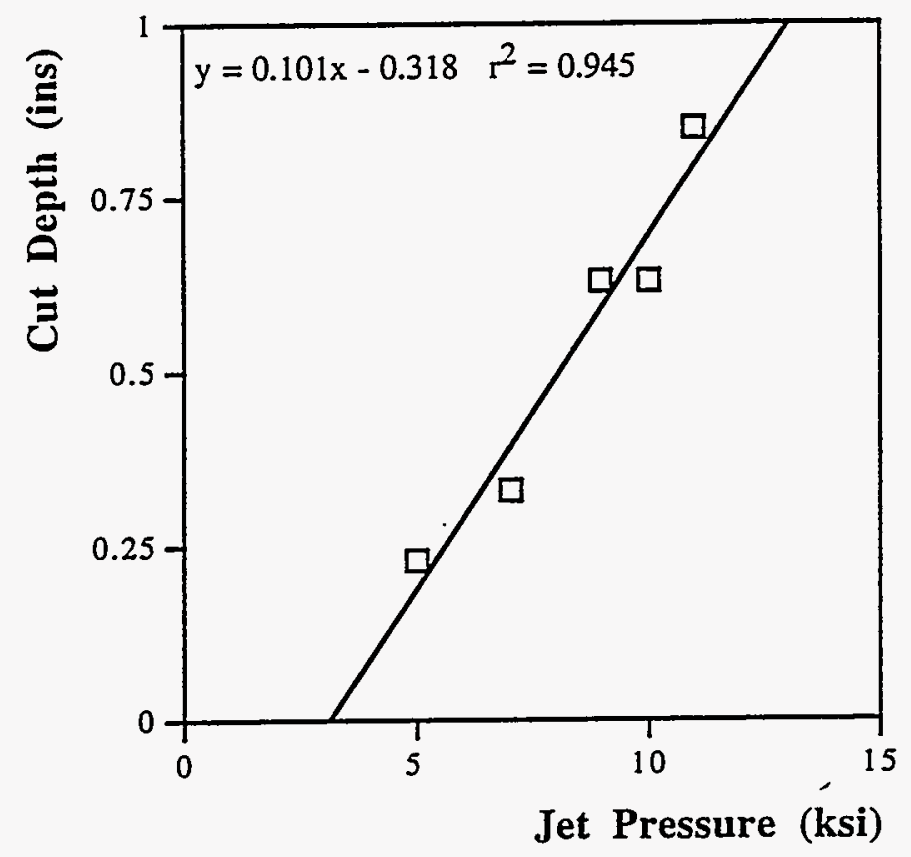

Figure 2.5 Depth of Cut as a Function of the Jet Cutting Pressure.

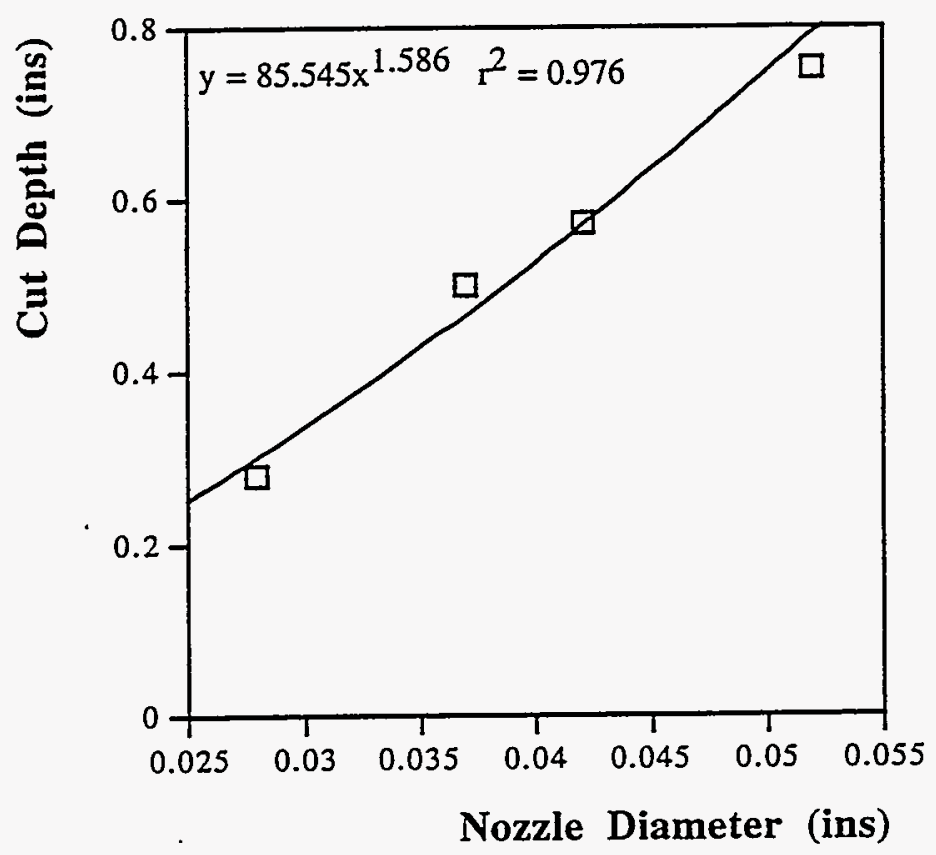

Figure 2.6 Depth of Cut as a Function of the Nozzle Diameter. 


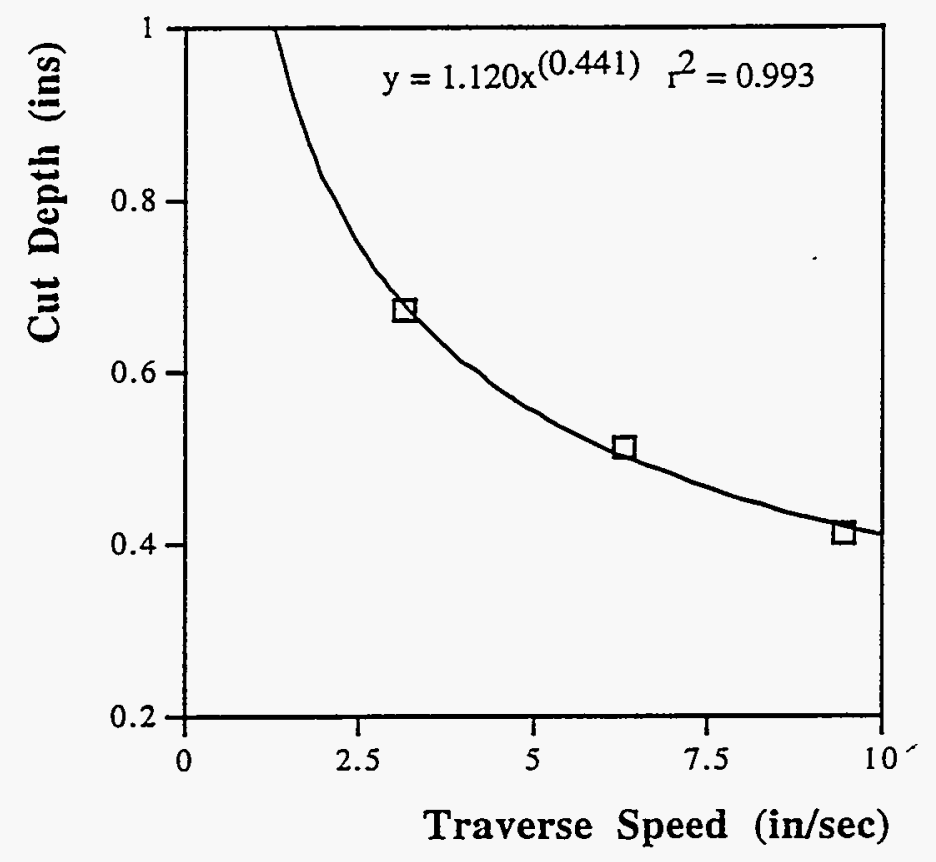

Figure 2.7 Depth of Cut as a Function of Traverse Speed.

One of the advantages of using a factorial design is that one can then go on to plot second order interactions (e.g. the effect of change in jet pressure on the relationship between the depth of cut and the speed of traverse) by only averaging across one section of the data set. However, in this case, that reduces the number of samples being averaged, which with the potential scatter possible in the data, does not give complete confidence in a prediction based on the relationships shown. The second order plots have been included as a way of indicating the trends in the data developed in the program (Figures 2.8, 2.9, 2.10, 2.11, 2.12, and 2.13). 


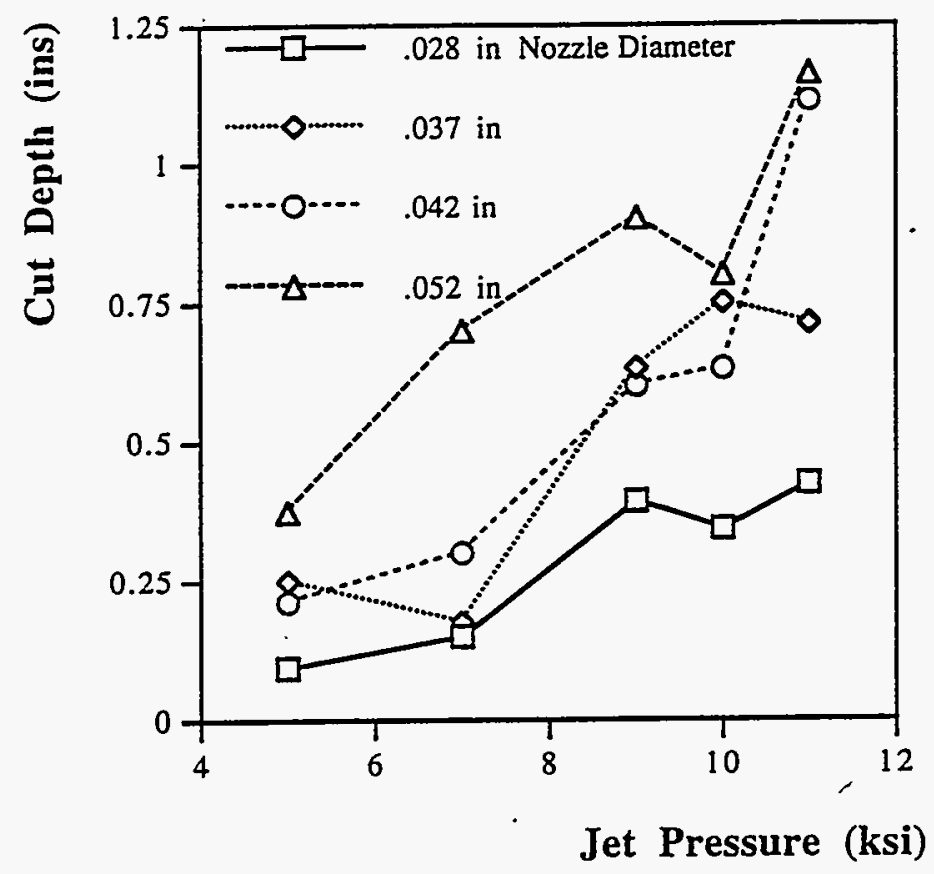

Figure 2.8 Depth of Cut as a Function of Jet Pressure, with Changing Nozzle Diameter.

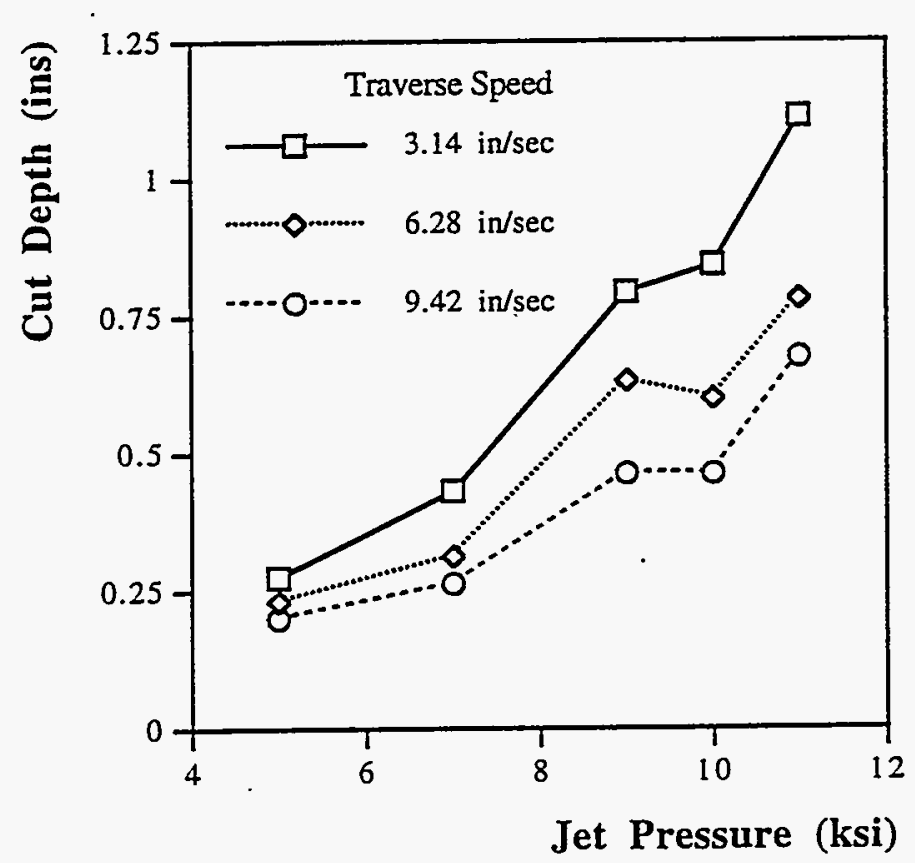

Figure 2.9 Depth of Cut as a Function of Jet Pressure, with Changing Traverse Speed. 


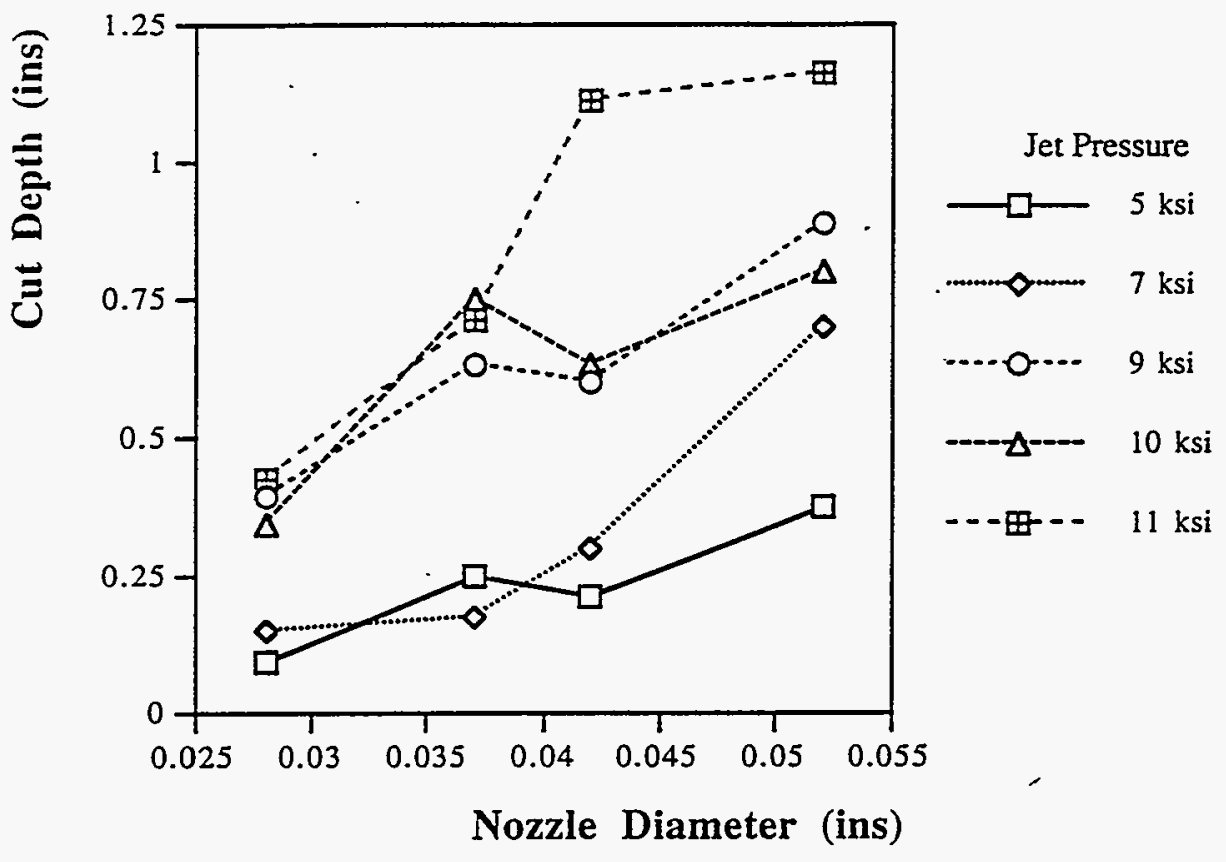

Figure 2.10 Depth of Cut as a Function of Nozzle Diameter, with Changing Jet Pressure.

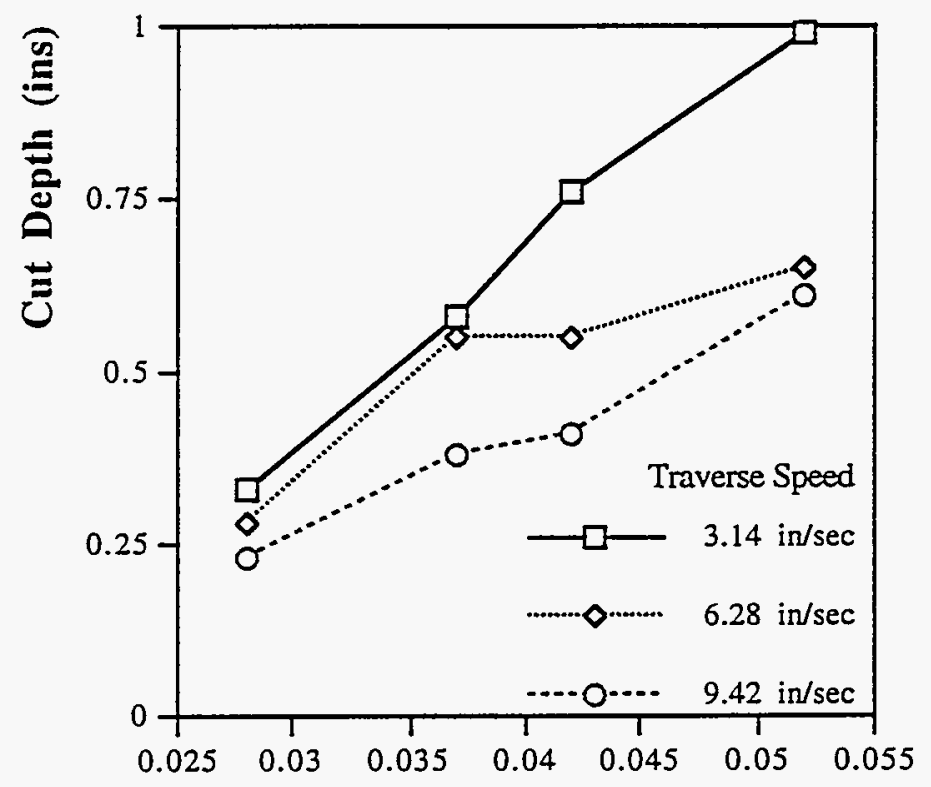

Nozzle Diameter (ins)

Figure 2.11 Depth of Cut as a Function of Nozzle Diameter, with Changing Traverse Speed: 


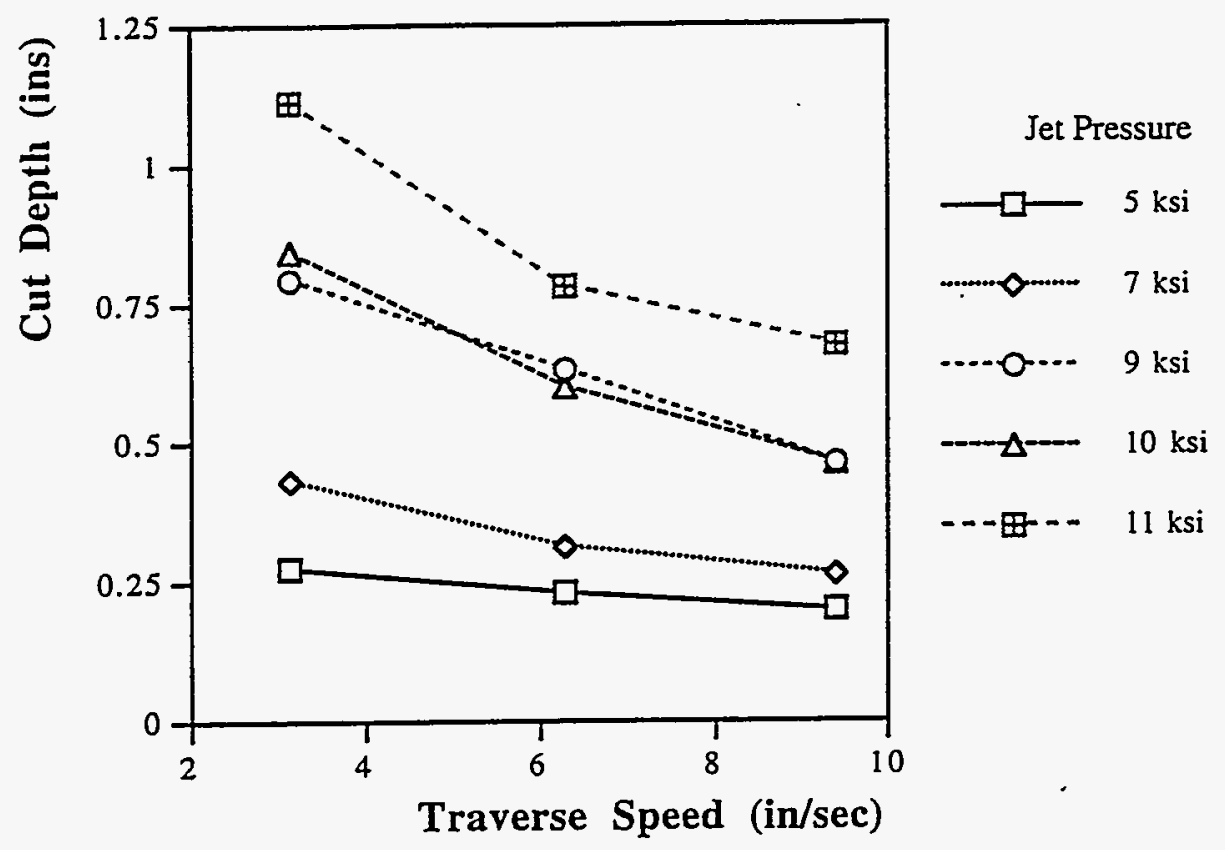

Figure 2.12 Depth of Cut as a Function of Traverse Speed, with Changing Jet Pressure.

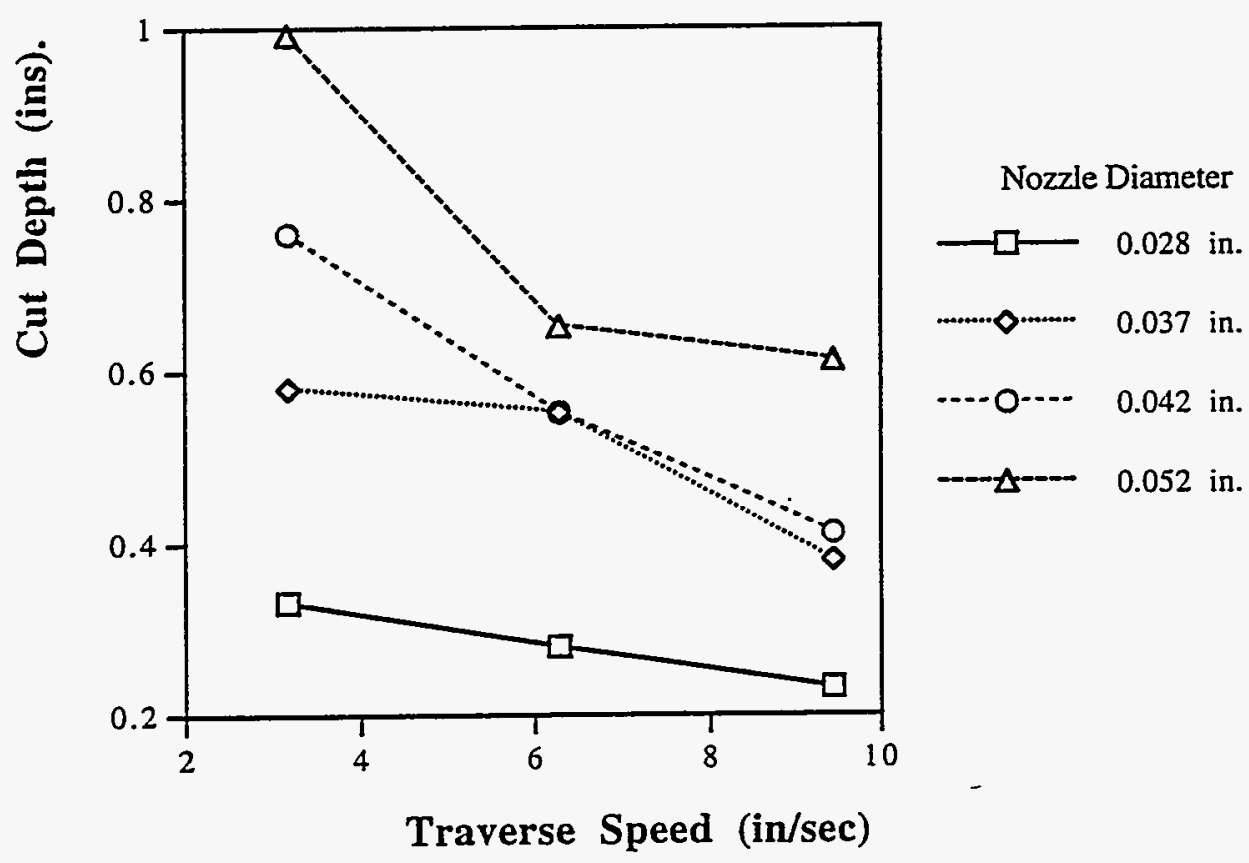

Figure 2.13 Depth of Cut as a Function of Traverse Speed, with Changing Nozzle Diameter 
The above curves were evaluated in terms of the expected performance relationships established over a wide range of test materials both at Rolla and at other laboratories and research establishments (Ref. 2.4).

The curves generally fell within the forms of relationship expected. A generic, first order and simple relationship of the form:

$$
\text { Depth of Cut }=\frac{(\text { Pressure })^{1.0} \cdot(\text { Nozzle Dia })^{1.5}}{(\text { Traverse Speed })^{0.33}}
$$

has previously been defined (Ref. 2.4). This relationship did not quite fit the data obtained from these experiments. However, the cuts made at the lowest jet pressure were, under some test conditions, at around the threshold of cutting for the material; in this range, the above relationship does not hold. (In the following projection from the data, therefore, only results from pressures of 8,000 psi and above were used.) Because the data was otherwise sufficiently close to this form, this relationship was used in the subsequent data projection.

One additional step was taken in the analysis of the data. In order to. determine optimal efficiencies obtained for cutting within the range of parameters tested, a crude form of relative removal efficiency was calculated. The calculation was based on a quantification of the volume of material removed from the surface for a given condition, divided by a measure of the relative quantity of energy required to remove it.

The volume of material removed was calculated as:

Volume $\left(\mathrm{in}^{3} / \mathrm{sec}\right)=$ traverse speed $\mathrm{x}$ depth of cut $\mathrm{x} 3 \mathrm{x}$ nozzle dia.

The value of three nozzle diameters was used to represent the projected width of cut, as a likely typical value.

At the same time the energy contained in the jet is a function of the jet pressure and the fluid volume. The volume flow rate is a function of the square root of the jet pressure and the square of the nozzle diameter.

Relative Energy Used $=$ Constant $(\text { Pressure })^{1.5} \cdot(\text { Nozzle Dia })^{2.0}$ 
Thus, by dividing the volume calculated for each condition by the relative energy value (foregoing the use of the constant), a measure of the relative excavation efficiency for each condition could be obtained.

\section{Table 2. Relative Measures of the Volume of Material Removed Per Unit of Jet Energy}

\begin{tabular}{cc}
$\begin{array}{c}\text { Nozzle Diameter } \\
\text { Jet Pressure }\end{array}$ & $\underline{0.028}$ inch \\
\hline 11,000 & $\underline{3.14}$ \\
10,000 & 4.80 \\
9,000 & 4.57 \\
7,000 & 5.57 \\
$\underline{5,000}$ & 2.91 \\
Ave & $\underline{3.01}$ \\
\hline .17
\end{tabular}

Nozzle Diameter 0.037 inches

\begin{tabular}{cc} 
Jet Pressure & $\frac{3.14}{\mathbf{5 . 5 8}}$ \\
11,000 & 7.65 \\
10,000 & 6.51 \\
9,000 & 2.47 \\
7,000 & $\underline{6.13}$ \\
5,000 & $\mathbf{5 . 6 7}$ \\
\hline Ave &
\end{tabular}

\begin{tabular}{ccc} 
speed & (in/sec) & \\
$\frac{6.28}{7.38}$ & $\frac{9.42}{9.68}$ & Ave \\
8.30 & 6.70 & 7.29 \\
9.69 & 12.97 & 6.53 \\
4.72 & 8.17 & 9.38 \\
$\frac{6.02}{7.20}$ & $\underline{7.68}$ & 5.27 \\
9.02 & $\underline{5.54}$ \\
\hline .80
\end{tabular}

Nozzle Diameter 0.042 inches

Let Pressure

11,000

10,000

9,000

7,000

$\underline{5,000}$

Ave

Nozzle Diameter 0.052 inches

\begin{tabular}{cc} 
Jet Pressure & $\underline{3.14}$ \\
\hline 11,000 & 8.19 \\
10,000 & 6.77 \\
8,000 & 9.37 \\
7,000 & 9.19 \\
6,000 & 6.47 \\
5,000 & $\underline{7.45}$ \\
\hline Ave & 7.91
\end{tabular}

$\frac{3.14}{8.98}$

5.57

7.06

5.09

$\underline{5.22}$

6.38

3.14

8.19

9.37

9.19

6.47

7.91 speed (in/sec)

6.28

11.03

12.48

$-14.14$

4.67

11.57

10.78

speed (in/sec)

6.28

12.30

8.43

9.97

7.27

9.63

9.52

speed (in/sec)

6.28

9.04

7.45

15.05

12.13

10.35

10.69

10.79

(in/sec)
9.42

10.99

12.80

12.45

6.60

15.44

11.66

Ave

9.20

10.98

11.03

4.58

11.04

9.37

9.42

16.23

11.06

8.72

6.54

8.43

10.20

Ave

12.50

8.36

8.58

6.30

7.76

8.70

$\frac{9.42}{13.56}$
9.97
$* 20.42 *$
16.14
15.90
16.04
15.34

Ave

10.26

8.06

14.94

12.49

10.91

11.40

11.34

\section{Projections from the Data}

The current requirements for the excavation and retrieval tool are that it must produce some $30 \mathrm{gpm}$ of waste material from the tank and must, concurrently, extract all the fluid used to generate that volume of material. 
In order to estimate what would be required for such an excavation tool, in terms of power, water flow rate, and reaction forces generated on the Long Reach Manipulator a numerical model was created, based on the experimental results obtained to date. This model has been generated on a computer spread sheet using the EXCEL computer Program. A copy of the spreadsheet is available from the authors.

\title{
Table 3. A Result derived from the Experimental Program
}

\author{
If an

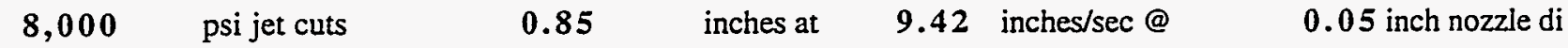 \\ What performance can be expected from a

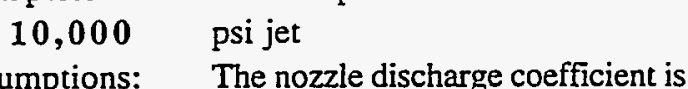 \\ $\begin{array}{cl}\text { Assumptions: The nozzle discharge coefficient is } \\ 4 & \text { nozzles, set on a ring, diameter }\end{array}$ \\ cutting at 188 inches/sec @ \\ 0.85 and there are \\ 20 inches, rotating at \\ 0.06 inch nozzle di \\ $3 \mathrm{rev} / \mathrm{sec}$. \\ If a$$
8,000 \text { psi jet cuts }
$$ \\ 0.85 \\ inches at \\ 9.42 inches/sec @ \\ 0.052 inch dia \\ then a \\ 1.06 \\ inches at \\ 9.42 inches/sec@ \\ 0.052 inch dia \\ From which a \\ 10,000 psi jet cuts \\ 1.32 \\ inches at \\ 9.42 inches/sec @ \\ 0.06 inch dia \\ From which a \\ 10,000 psi jet cuts \\ inches at \\ 188 inches/sec @ \\ 0.06 inch dia \\ If we assume that the head can break off ribs of width equal to their depth i.e. \\ 0.49 inches \\ then the volume removal equals the cut width \\ multiplied by twice the depth of cut*

$\begin{array}{cl}20 & \text { in } \\ 0.98 & \text { ins } \\ 352.77 & \text { ins } \\ 913.61 & \mathrm{cu} \text { ins } \\ 30 & \mathrm{gpm}\end{array}$ \\ multiplied by the advance rate \\ $30 \mathrm{gpm}$ \\ With the given coefficient of discharge, nozzle and jet conditions \\ Water Flow rate required will be \\ 9.36 gpm per nozzle \\ $37.45 \mathrm{gpm}$ total \\ Hydraulic Horsepower required \\ 54.62 HHP per nozzle \\ 218.5 HHP total \\ Maximum Reaction Force will be \\ $48.68 \mathrm{lb}$ per nozzle \\ 194.7 lb. total. \\ * each nozzle makes two cuts along the path \\ as it goes around the circle. \\ The program layout is, to a large degree, self-explanatory. It can be \\ broken down into several parts. Note that with the exception of the 188 \\ inch/sec traverse velocity (which can be either input as a value or, if left as \\ is, will be calculated by the program), all the bold numbers are values \\ which are input by the operator. The remainder are then calculated. \\ 1) On the second line, the program operator is asked to input the jet \\ pressure, depth of cut, traverse rate and nozzle diameter data from the \\ experimental program. (The data shown in Table 3 is the asterisked data \\ from Tables 1 and 2).
}


2) On the fourth line information is to be given as to the pressure and nozzle diameter at which the cutting head will be run. Note that the cutting speed may either be input at this point, or left to be calculated from subsequent input information. The latter course is recommended.

3) On the following line the program has a default value for the discharge coefficient of a typical nozzle. Should a more accurate measurement be available, it should be input at this point.

4) The operator should then input a representative data value for the number of nozzles, their rotational diameter and the speed of rotation of the cutting head.

5) The program goes through a series of steps, based on the above equation for depth, to determine the depth of cut achievable with the jet parameters input for the Confined Sluicing Head (COSH).

6) The program will predict a depth of cut to be achieved with the parameters input for the COSH design. This is then used to calculate a traverse speed with which COSH will move over the surface of the material, and to calculate the volume rate of removal of the material.

Note:

- The model assumes that the jets will cut, and break off, pieces of material which can be spaced, at a maximum, at the depth of cut.

- The model calculates an advance rate based on the width between adjacent cuts and the input speed of rotation of the nozzles.

- The model calculates the volume of material removed based on the depth of cut, the number of nozzles, the advance rate and the width of the cut (the path diameter).

- The volume excavated is calculated in terms of gallons of material/minute.

- The amount of water required to generate this volume is calculated, together with the horsepower. The maximum reaction force against the interface plate, assuming the nozzles are directed perpendicular to the plate, is also calculated (they will actually be inclined at some angle to the plates reducing the level of this force). 
The model allows iterations, by changing the input parameters, to reach the required objective. One such possible option is shown in the demonstration example of the model given above.

\section{Conclusions}

A series of cutting tests on a simulant have verified that the material can be effectively cut at jet pressures of 5,000 to 10,000 psi - within the scope of available commercial equipment.

A factorial experiment, varying the jet pressure, nozzle diameter and traverse speed was carried out to determine their effect on cutting depth. As a result a predicted requirement for a Shrouded Sluicing End Effector was established, projected to be capable of removing $30 \mathrm{gpm}$ of waste from an Underground Storage Tank. This production rate was set as an initial target for material removal from the tank. The values derived relate to the jet power required to break the material free from the solid, and do not include the additional power required to pump the resulting sludge from the tank. That information has been derived in an earlier report.

The required conditions are:

- 4 rotating nozzles (one orifice per nozzle).

- Rotation diameter (i.e., shroud diameter) 20-inches.

- Rotation Speed 3 revolutions/second.

- Jet Pressure 10,000 psi.

- Nozzle Diameter 0.06-inches.

- Total Water for Jets 37.45 gpm.

- Hydraulic Horsepower for the jets 218.5 HP.

- Maximum Reaction Force on the Interface Plate 194.7 pounds.

Note that these conditions are projected from existing data. They make some assumptions about the validity of the parametric equations which go beyond the range (particularly for the speed relationship) over which the relationships were established.

Further, the relationships will require a high degree of efficiency in the transmission of the cutting energy from the pumps to the target surface. Before complete confidence can be placed in this prediction, it is recommended that a more detailed study be made of design optimization and equipment performance at these operating conditions. 
In particular, there are a number of different conditions and designs which can be used to provide the required waste removal rate. It is suggested that, a study of forces generated on the head, and path consideration be studied.

Concurrently, it would be advisable to compare existing cutting heads and, potentially, to study enhancements in their performance to ensure that an adequate performance, at the levels required above, can be met before the equipment specification is hardened. 


\section{Chapter 3. INTEGRATED TESTING}

\section{Introduction}

In the first part of this program, a series of tests had shown it was possible to cut the simulated hard saltcake, which would be left as a "heel" in the storage tanks, with waterjet pressures of under 10,000 psi. Concurrently, tests with a jet pump had also shown that, at pressures of roughly 7,000 psi, a jet pump design could be used with sufficient power that it could carry the three likely components of a waste stream out of the storage tank at the required volume removal rates. Based on the preliminary analysis of cutting, this waste stream would consist of $30 \mathrm{gpm}$ of waste material, 40 $\mathrm{gpm}$ of high pressure water to excavate the material, and $10 \mathrm{gpm}$ of pump water to convey the resulting slurry up out of the tank along a delivery pipe against a 60 foot head. The program requirement for the next phase of the program was to develop an initial integrated design and to demonstrate its effectiveness in a series of parametric tests.

\section{Integrated Design}

The first tests carried out were relatively crude in scope, and primarily directed at providing a visual understanding of the processes involved so that the individual aspects of the problem could be observed and identified. Based on that observation it would then be possible to consider design approaches to resolve the potential problems. It should be borne in mind, as the description of this process evolves, that at the time of completion of this report, the program is still ongoing and not all the problems identified have yet been fully resolved.

Although the waste removal process is usually described as being a twocomponent process (dislodging and conveyance), there are, in fact, three aspects to the removal; and the importance of the third element, that of waste mobilization, became apparent as part of the initial visual evaluation. It is a problem which must be addressed in more detail than will be covered in this initial evaluation. Simplistically it relates to the need, once the fragments of the waste have been dislodged, to move them into the port of the conveyance system. Since this is a suction device, at least over its lowest section, the problem may be simplified if the mobilization presents the debris in a mobile form, within the influence zone where the conveyance suction is strong enough to lift and capture the particles and water. 
The process can be illustrated by the process carried out during the first review tests, and the problems noted from the results obtained (Figure 3.1). In the first combined test, the lower half of a 55-gallon steel drum was used as a test containment vessel and filled with the simulated saltcake. Three different configurations were developed, in the first of which the simulated saltcake was poured as a flat layer over all the tank, and in the second and third cases the tank was laid on its side while the saltcake simulant was poured into the lower half. In the third case (Figure 3.2) a broken steel tape was placed into the simulant before it hardened, to represent a possible additional complication in the actual tank cleanout. For this first evaluation Missouri clay found within 2 feet of the ground surface in the Rolla vicinity was used to fill the remainder of the tank after it had been returned to the vertical. The tank was mounted on a turntable which would allow it to rotate under the cutting nozzle assembly, but only for a portion of a pass.

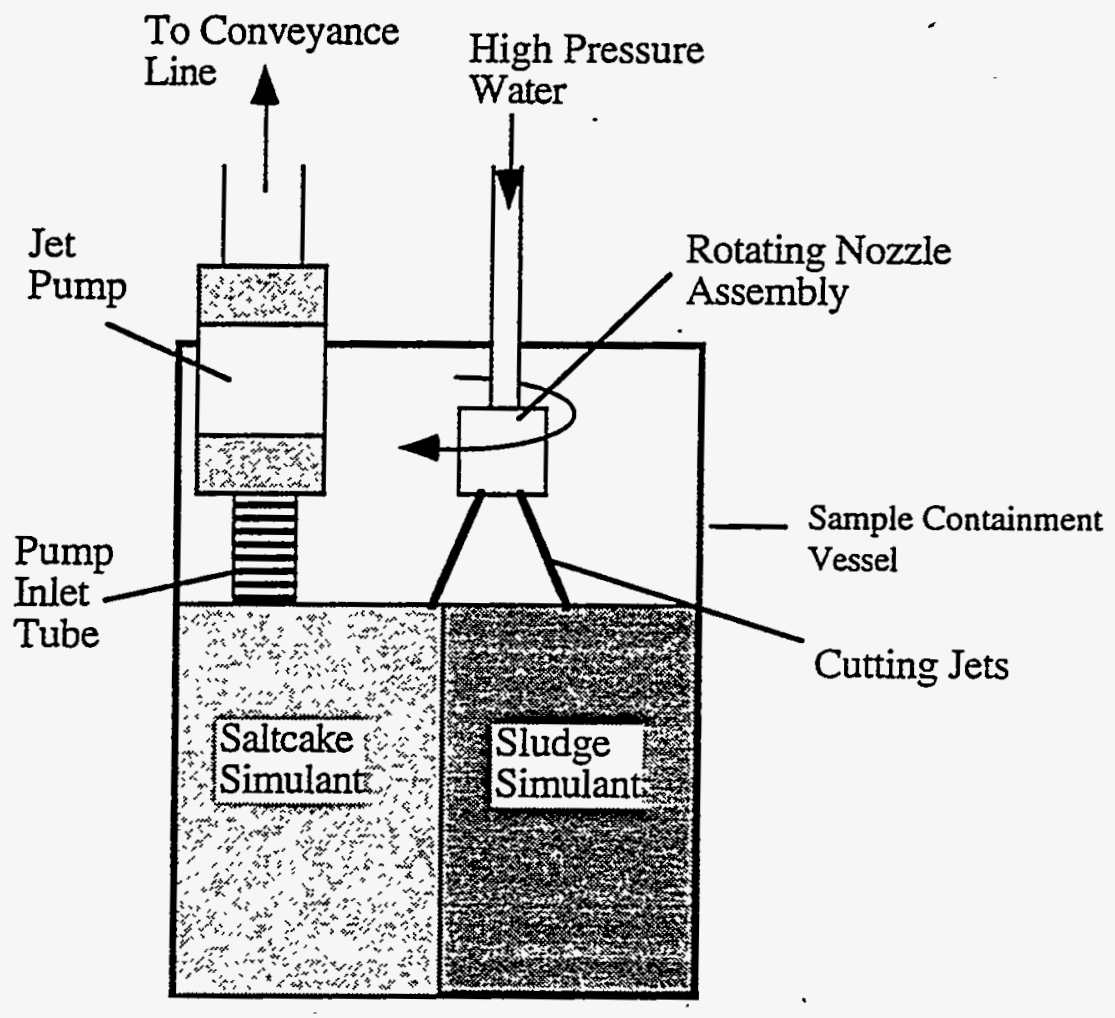

Figure 3.1 Early Test Configuration.

The initial nozzle body used was one which had been constructed to allow a variety of nozzle combinations to be tested and, for the first test, it was run with two forward pointing jets which were inclined out to cut a path wider than the nozzle body. Concurrently with this design, the nozzle assembly was rotated by an external motor, rather than have the nozzles selfrotating, as had been conceived for the final design. 


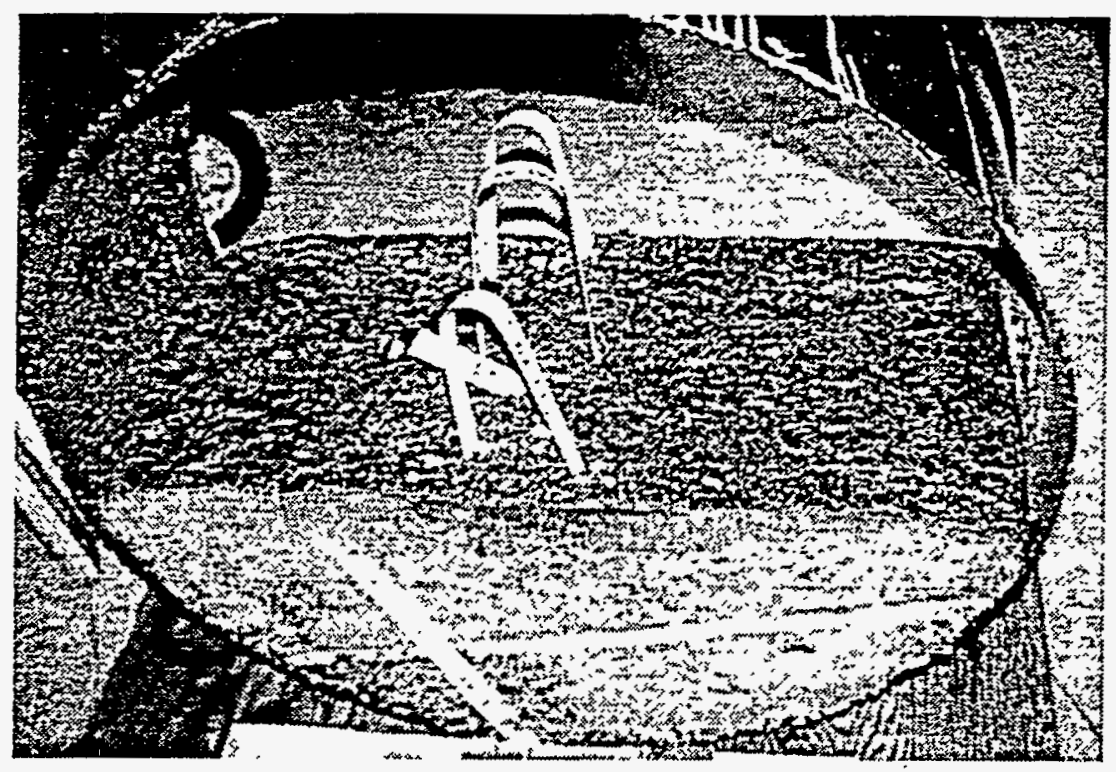

Figure 3.2 Configuration of Tape in Simulant for cutting Test 3.

The intake hose for the jet pump was not attached to the cutting head for this test, but was separately directed into the tank. Thus, observations could be separately made of the cutting and entrainment actions. The test was run with a cutting jet pressure of approximately 7,000 psi and with an equivalent pressure being used for the jet pump. (The Aquadyne pump was used in this series of tests.)

The result obtained was purely qualitative, and indicated that while the cutting jets cut a path into the simulant, to a depth on the order of one inch, there was a significant amount of "splash back" from the cutting zone which made observation of the test difficult. As the test progressed, however, a thin layer of water was established on the surface of the simulant and this tended to cushion the rebound of the water, and to capture the particles being removed by the cutting jets. The resulting slurry was entrained into the pipe of the jet pump; and after a short initial period there appeared to be a "fluid balance" established in which as the water level approached the inlet to the jet pump, the pump would remove the fluid and thus there was no net gain in water level within the tank.

For the second test, the demonstration nozzle was replaced with a selfrotating nozzle assembly which was available at the RMERC. This initial design was chosen because it was available and was again intended to allow an observation of the cutting ability of the jets, and the potential for interaction between the cutting and removal portions of the design. 
Since the head was driven at a slower rotational speed in the first test, it was anticipated that the depth of cut would be somewhat reduced in this second test. However, because of the nature of the trial, no attempt was made to measure the speed of rotation of the nozzle assembly during the test. After running the nozzle over the sample surface, it was noted that the cutting jets had removed the clay "sludge simulant" down several inches as the jets had been able to cut and mobilize this material into a thinner fluid which was easily sucked into the jet pump intake. In contrast, however, the jets had cut only a relatively shallow depth into the hard simulant.

A similar result was obtained with the third test, and the jet did only superficial damage to the tape. Although the tape was broken at one point at the contact with the simulant, this was not felt to be conclusive.

\section{First Test Observations}

A number of superficial observations were made as a result of these tests. The first was that the depth of cut achieved with the self-rotating nozzle assembly was significantly below the anticipated depth of cut. This was of sufficient concern that a small study was made of the system losses between the pump and the nozzles, and of the discharge conditions at the pump. The pressure gages were also all recalibrated. As a result of this it was determined that the pressure loss across the rotary swivel which allowed the nozzle rotation was over $1,500 \mathrm{psi}$. Given the proximity of the jet pressure to the threshold pressure at which the simulant was effectively cut, this explained a large part of the anomaly. It was not until later in the test series, however, when the change in saltcake hardness with age and the presence of excess quantities of water was determined that a full explanation for this change in behavior could be established.

The second observation was that the self-rotating nozzle assembly provided sufficient fluid to both cut and mobilize the sludge simulant at a much greater volume removal rate than with the saltcake. Although the pressure of the jets were not as high as had been desired, nevertheless, it was concluded that a set of jets rotating at high speed should have no problem in dislodging and mobilizing the sludge and that the jet pump would similarly have no problem in removing it.

Third, the jet pump (even in a lower power version) was able to satisfactorily retrieve all the fluid being used in the cutting process and to remove both it and the loosened sludge as fast as it was generated, once the 
level of the fluid brought it into the range of influence of the jet pump intake.

These results indicated that the technique had significant promise; however, a different test set up would be required to allow a better study of the problem. Accordingly a new design for a test apparatus was developed (Figure 3.3). In order to save on the amount of time required to construct the equipment, available and commercially inexpensive components were used wherever possible in the design of this device, which was used for the next suite of tests.

\section{Large Tank Test Facility}

The small confines of the 55-gallon drum meant that this was not sufficiently large to allow any accurate studies of cutting jet behavior. While a much more sophisticated arrangement had originally been conceived, a relatively simple arrangement was, instead, developed to overcome this problem.

The preliminary calculations on head design had suggested that a cutting head of around 20 inches in diameter would be sufficient to achieve the retrieval rates required. For this reason it was felt that a 6 foot diameter tank would be sufficient to allow modeling of the head behavior without the constraints of scale a smaller version would have, and without the costs of a larger tank.

In order to simplify the controls, it was decided to rotate the tank, rather than develop a more complex robotic assembly (Figure 3.4). In this way a simple linear traversing device would give the required motion to the cutting arm. The jet cutting head would then be mounted on the arm and be able to traverse to give the radial position required for a cutting test. A rotary drive could be mounted on the lance arm. A feed mechanism to move the nozzle forward into the cut could also be mounted on the lance arm (Figure 3.5). The arm positioning, the speed of rotation of the tank, and the speed of rotation of the lance nozzles could all be controlled through the program Labview. A modified series of control cards had been purchased to allow the program to control these experimental variables. 


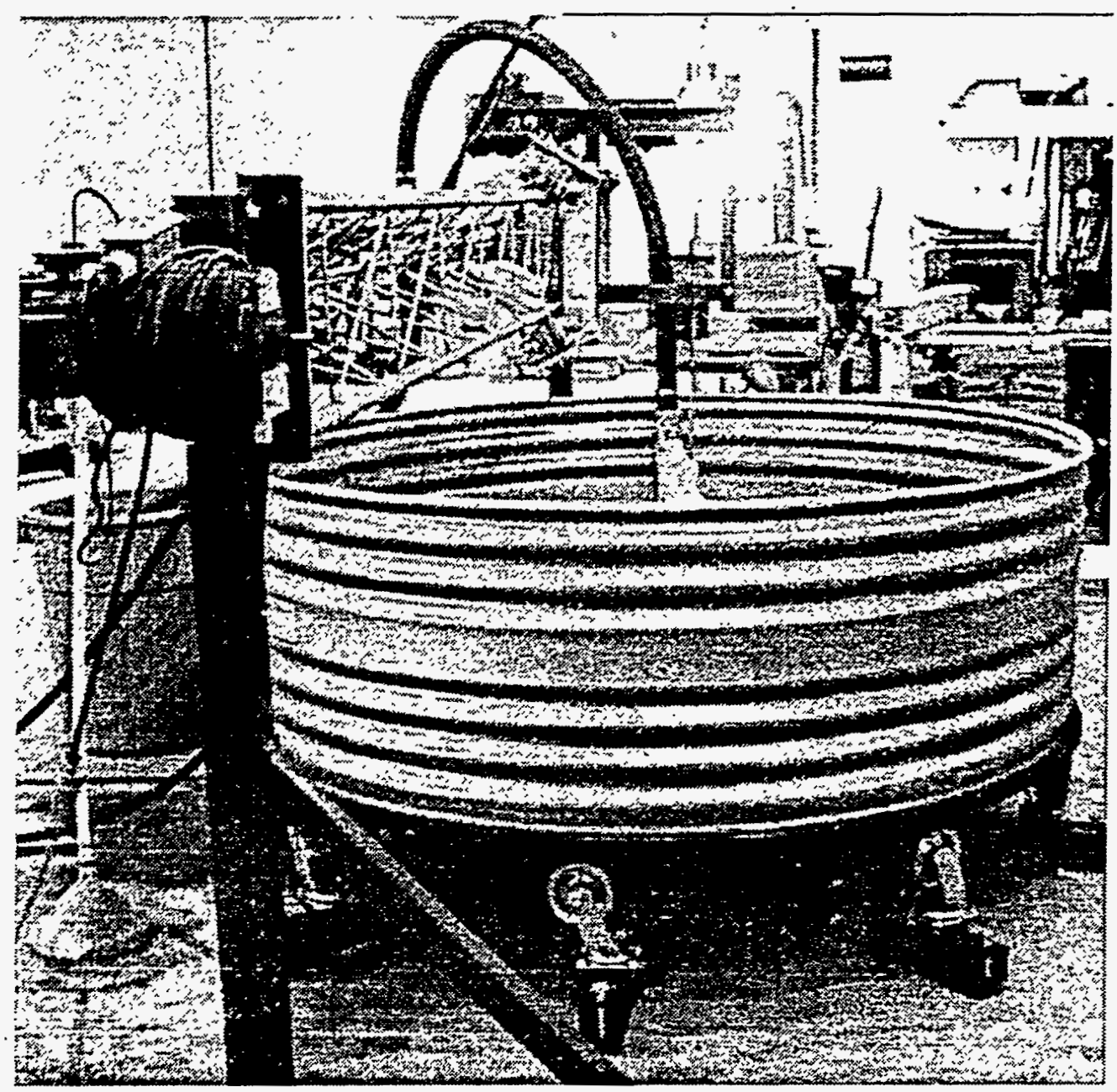

Figure 3.3 Overall View of the Tank, Rotational Drive and Lance Support Arm. 


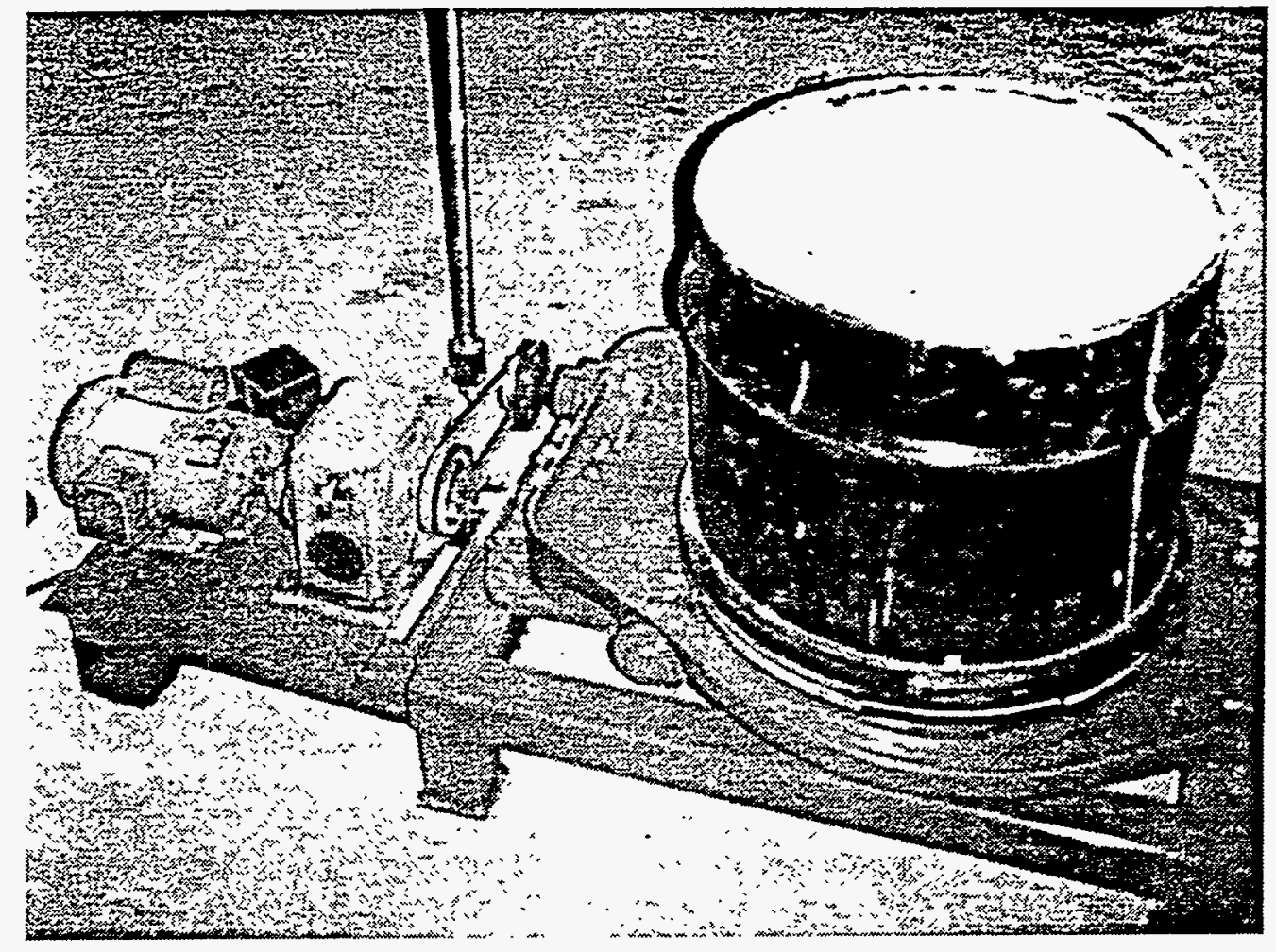

Figure 3.4 Tank Rotation Assembly. (Note - to show the drive assembly a smaller tank has been placed on the platform.)

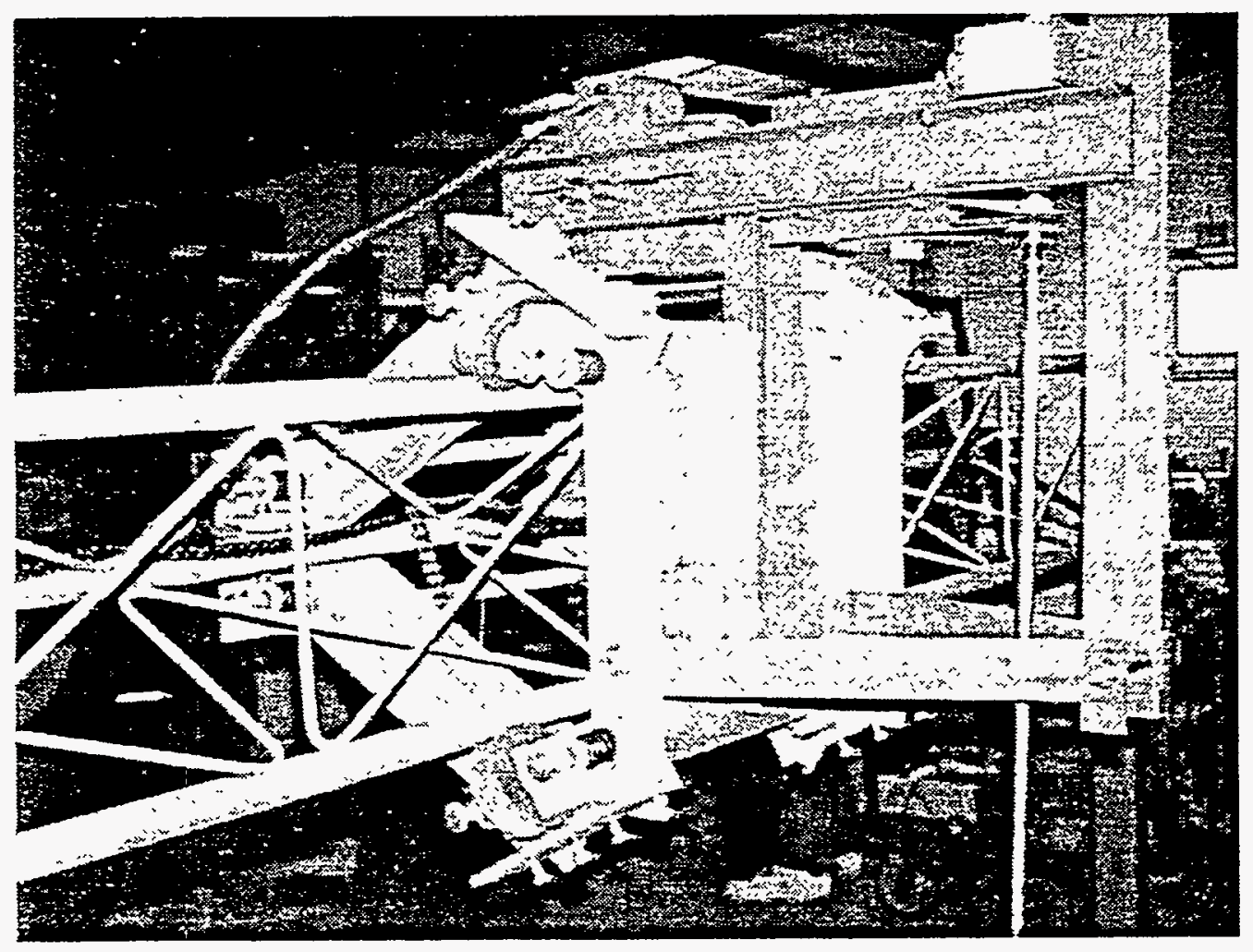

Figure 3.5 Lance Motion Driver. 
It had been decided, based on the evaluation of the system losses with the first self-rotating nozzle and the desire for a better control of nozzle rotation speed, that the nozzle assemblies would be mechanically driven at this stage in the experimentation, rather than having the nozzles self rotate. This gave a higher degree of control to the experiments, but it did add an additional component into the head assembly. For simplicity at this stage the drive was electric. An air-driven motor could be used for the final assembly when designed for actual tank operations.

A problem complicating the use of a rotating tank was that the drive motors available had a limit to the amount of power they could transmit to the tank rotary platform. This constraint reduced the amount of material which could be poured into the tank at one time to 6 inches. This was felt to be sufficient for these series of tests, which were to look at potential cutting combinations, rather than developing a more comprehensive set of longer term cutting tests (although some of those were also tried).

At the time that the next series of tests were carried out, the intention was to initially carry out the same set of cutting tests as had been carried out earlier, namely to study the cutting ability of the jets under a varied set of conditions and to establish how well the overall concept would work. To this end the first modification to the assembly was to develop a containing shroud to capture the cuttings and spent water.

\section{Shroud Design}

Although the following development took place over a number of months and required a large number of iterations in design, for brevity and the purposes of simply outlining the thought processes involved, the entire development is summarized at this time.

The first shroud (Figure 3.6, 3.7, and 3.8) was constructed from a fiberglass mold and built to attach to the cutting nozzle assembly as the main support member. The feed to the jet pump was then led from the top of the assembly as a hose connection to the pump itself, which was mounted on the frame of the Arm Support Assembly. 


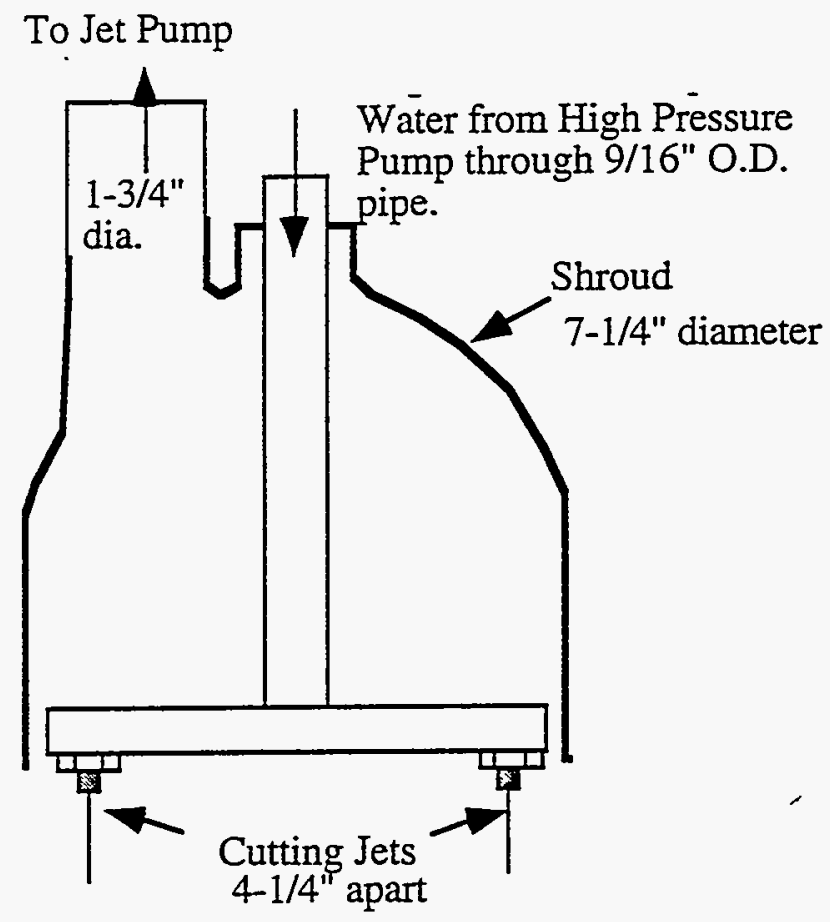

Figure 3.6 Schematic Section through the first fiberglass Shroud.

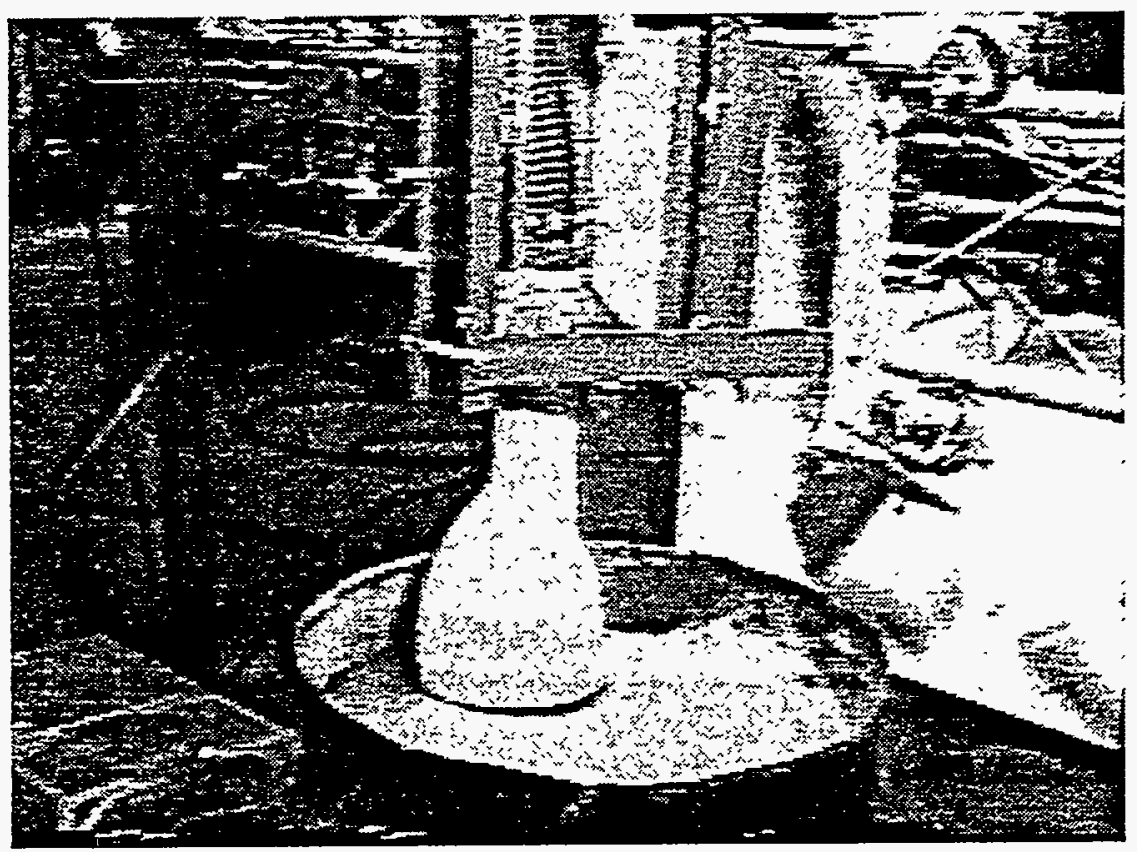

Figure 3.7 First Shroud in Use. 


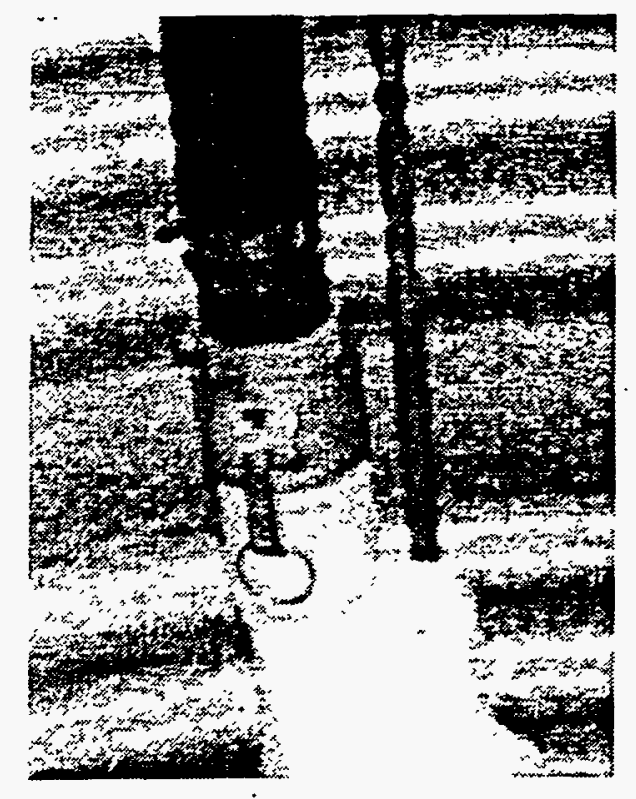

Figure 3.8 Location of the connections to the Shroud.

When the unit was first demonstrated, the internal nozzles for the cutting head were inclined inward to the axis of the shroud. The shroud was then positioned so that the edge rode just above the surface of the simulant. A positive lock on the shroud position was found necessary since, in a later test, the shroud was allowed to rest on the surface. When that occurred and the surface was smooth, the suction developed by the jet pump was sufficient so that the shroud locked down onto the surface of the simulant. The force generated was sufficient to stall the rotation motor for the tank, and this was not an effective result.

When this design was initially tested the water confinement was satisfactory, and initial cutting tests retained almost all the water within the bounds of the shroud. There are a number of problems perceived, however, with using the jet cutting nozzles with an inclination only toward the center of the shroud. The most obvious of these was immediately clear when the head moved along the wall of the tank. With an inward inclined set of nozzles, it was not possible to cut the last one or two inches of material along the wall contact (Figure 3.9). In order to reach that material the jets would need to cut to at least the perimeter of the shroud, and possibly a little beyond it (Figure 3.10). 


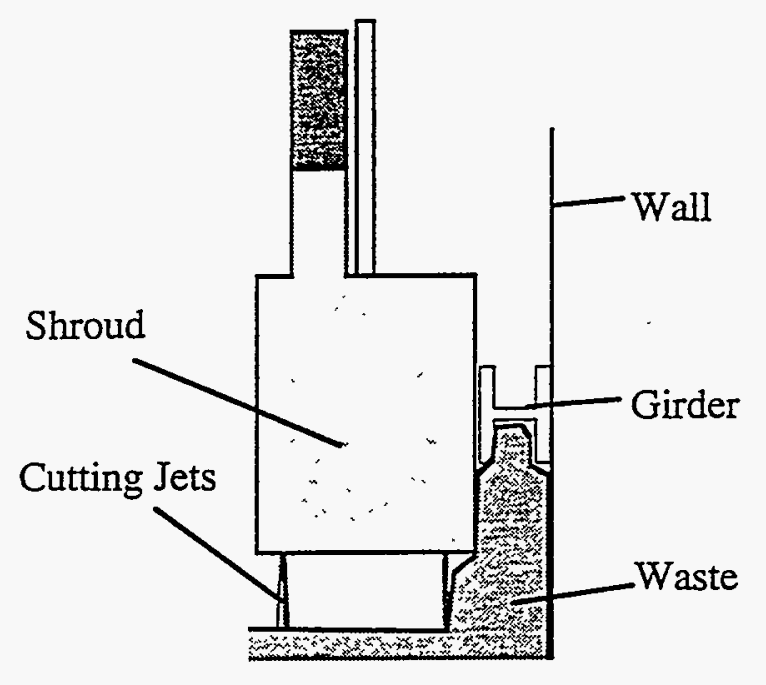

Figure 3.9 Configuration of Initial Jets showing their inability to clean near a wall or obstruction.

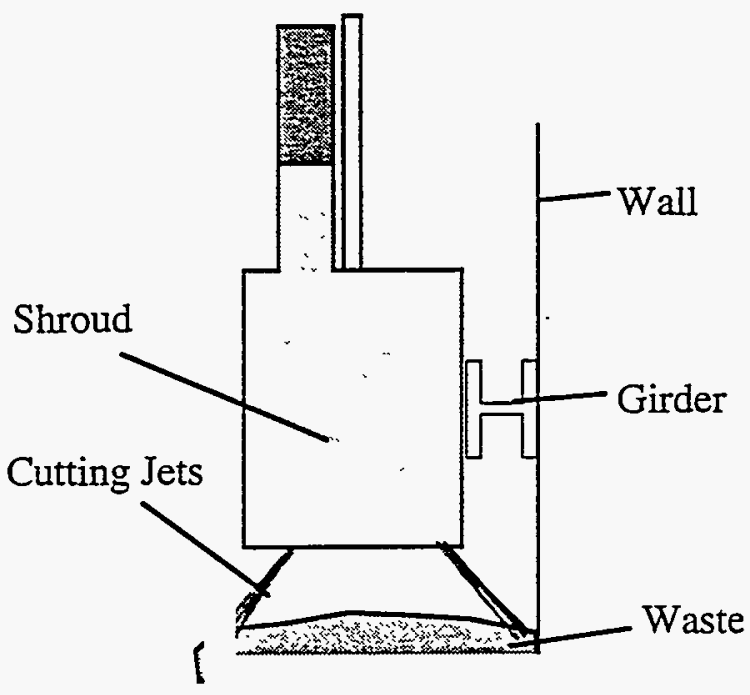

Figure 3.10 Inclined jets showing how these can reach beyond the shroud boundary to clean the wall or an obstruction.

When the jets were initially inclined outward at an angle of 15 degrees, it was found that the initial shroud design would not capture all the debris and spray rebounding at the shroud edge. Bringing the shroud close to the surface allowed most of the water and fragments to be captured, but some problems were identified where the jets cut deeper into the simulant and a considerable gap developed between the shroud edge and the surface. A flexible barrier was required to fill this gap. and to create an adjustable edge which would ride over the surface, even when quite rough, and which would be stiff enough to retain the spent water and cuttings. 
Two solutions were developed; and while neither was completely satisfactory, they did provide a considerable improvement in water retention, with some combination being likely required as a final solution.

Where the surface is relatively smooth, a large flat plate was coated with a rough fibrous material (artificial turf) and set around the jet nozzle assembly and pump inlet. By holding the tolerance between this plate and the surface to a close distance, the pump was able to capture all the water and material from the cut (Figure 3.11). While this limited the air flow into the sides of the cut, the device also allowed all the water and debris to be collected where the jets cut to a depth of over 2 inches into the simulant (the projected maximum cut on any one pass).

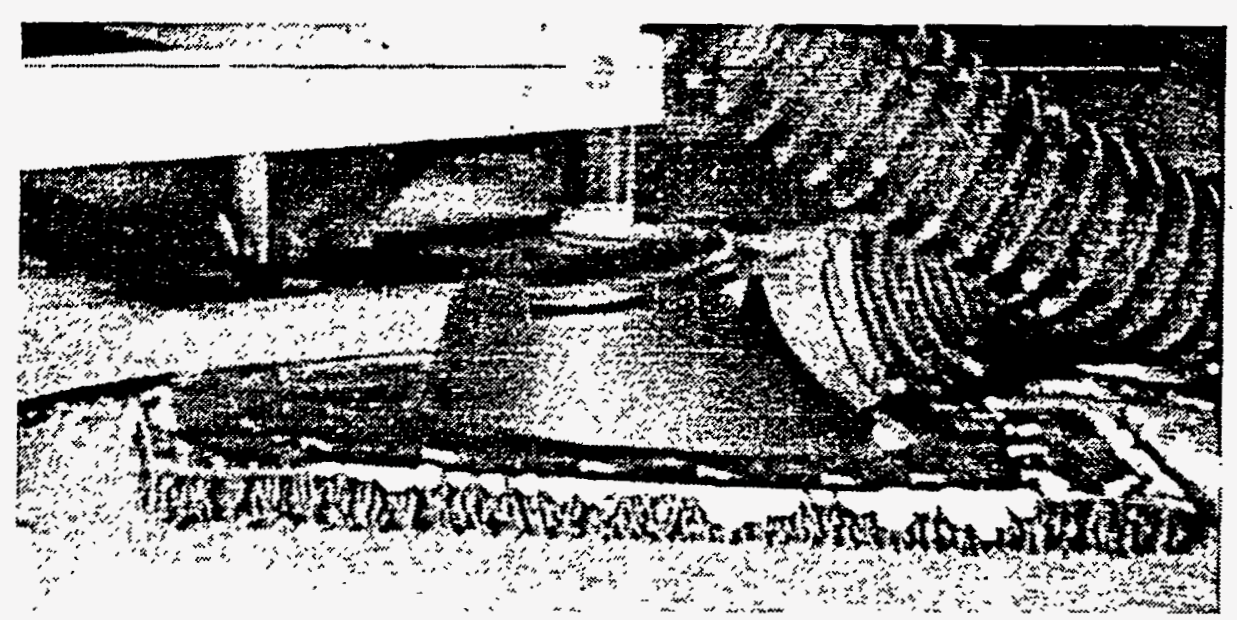

Figure 3.11 Flat Shroud Design in Action showing lack of water flow.

As a precautionary comment it should be noted that angled jets rebounding onto this flat plate could lift it off the surface and break the close tolerance required for best aspiration of debris. The design did not cope well, however, where the surface was very rough with surface variations of more than 3 inches. (It should be noted, in passing, that during several of the tests in the program the jets cut into the simulant to depths of more than 12 inches). Although the head could be quite effective where the conveyance intake was ahead of the cutting head (Figure 3.12), a more effective extraction of debris was found where the suction inlet trailed the cutting action. 


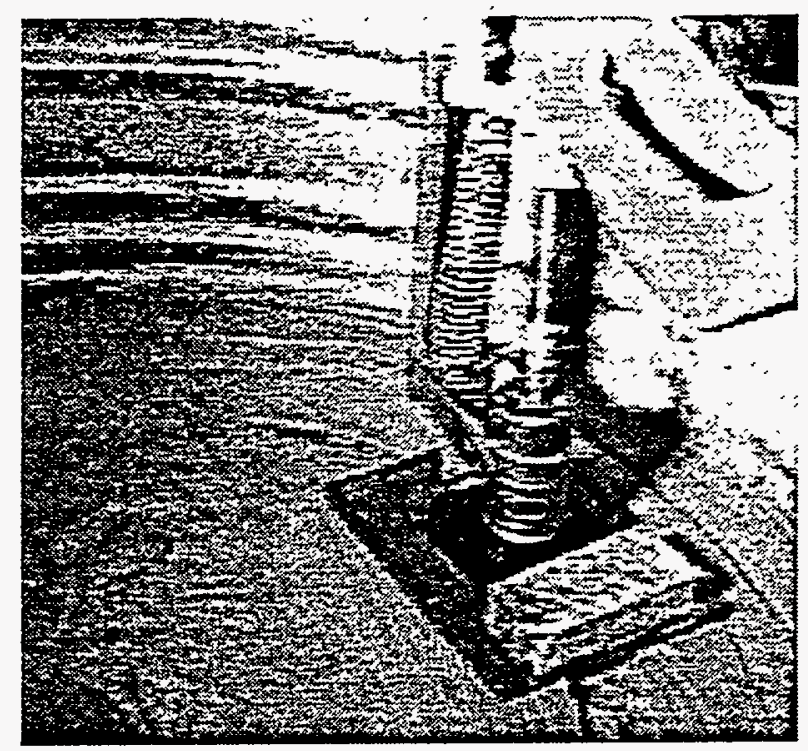

Figure 3.12 Flat Shroud with leading suction.

In the alternate solution, a set of stiff bristles was set around the edge of the shroud to both act as an air and water/debris barrier. In the first evaluation of this design a series of short bristles was used (Figure 3.7). The test showed that a longer set of bristles would be required and when a stiff set of fibers was used, this proved quite effective (Figure 3.13).

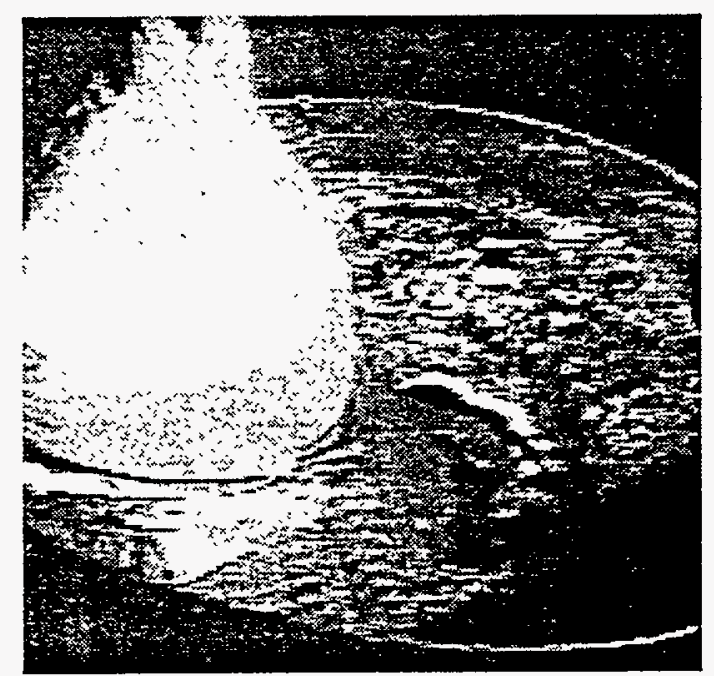

Figure 3.13 Shroud edge with Effective Bristles on the rim of the Shroud.

This was quite effective in retaining the debris, even where the jets cut to the edge of the shroud. An improved version was then developed with different lengths of bristles around the shroud edge. While these worked well in rougher surfaces a significant problem with this concept arose in 
removing sludge simulant. The test was not completely definitive, since the trial removed a significant layer of the sludge (around 3 inches) on a pass. However the simulated sludge began to build up ahead of the brushes and could not flow through them into the path of the cutting jet (Figure 3.14).

The head therefore began to plow the material up, and this placed a high load on the arm drive mechanism, sufficient that the head was manually maneuvered during part of the test. Nevertheless the jets did liquefy the clay and all the material in the tank could be easily removed by the head. An additional problem in cutting the clay was that there was no sense of where the bottom of the cut was and it proved quite easy for the head to advance below the level of the lip of the uncut material.

Alternative tests tried shaping a leading edge to carry the shroud over the clay (for example Figure 3.15); however, none of the designs tested were very successful and since the positioning of the shroud would be an integral part of the robotic arm control, this line of investigation was not actively pursued.

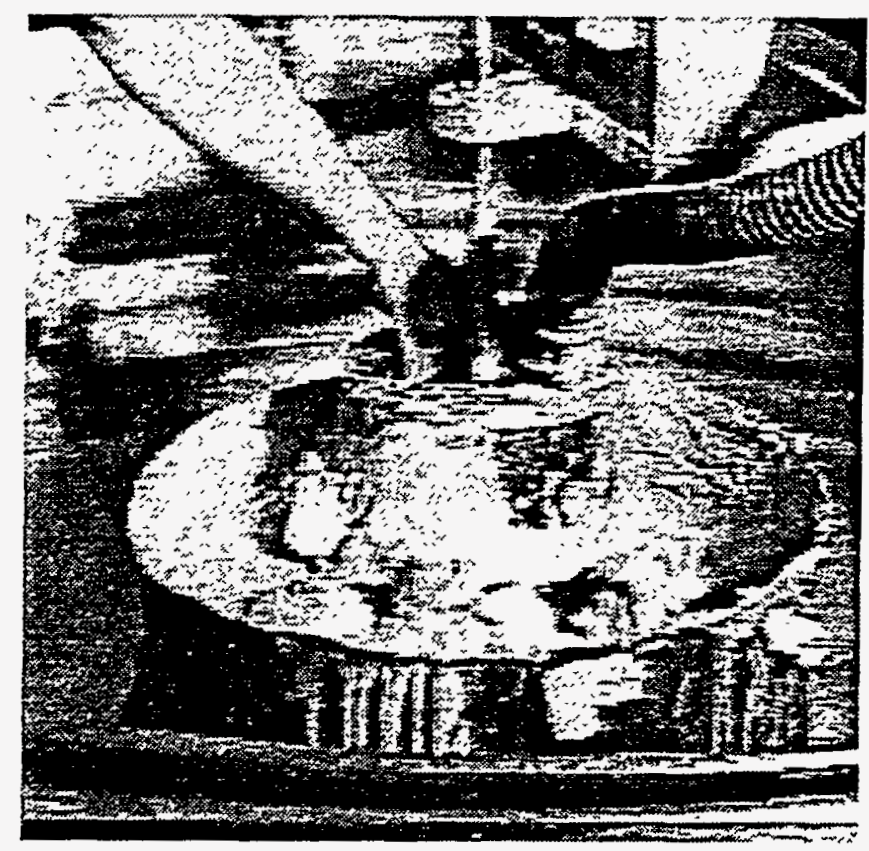

Figure 3.14 Shroud Cutting in Clay simulant. 


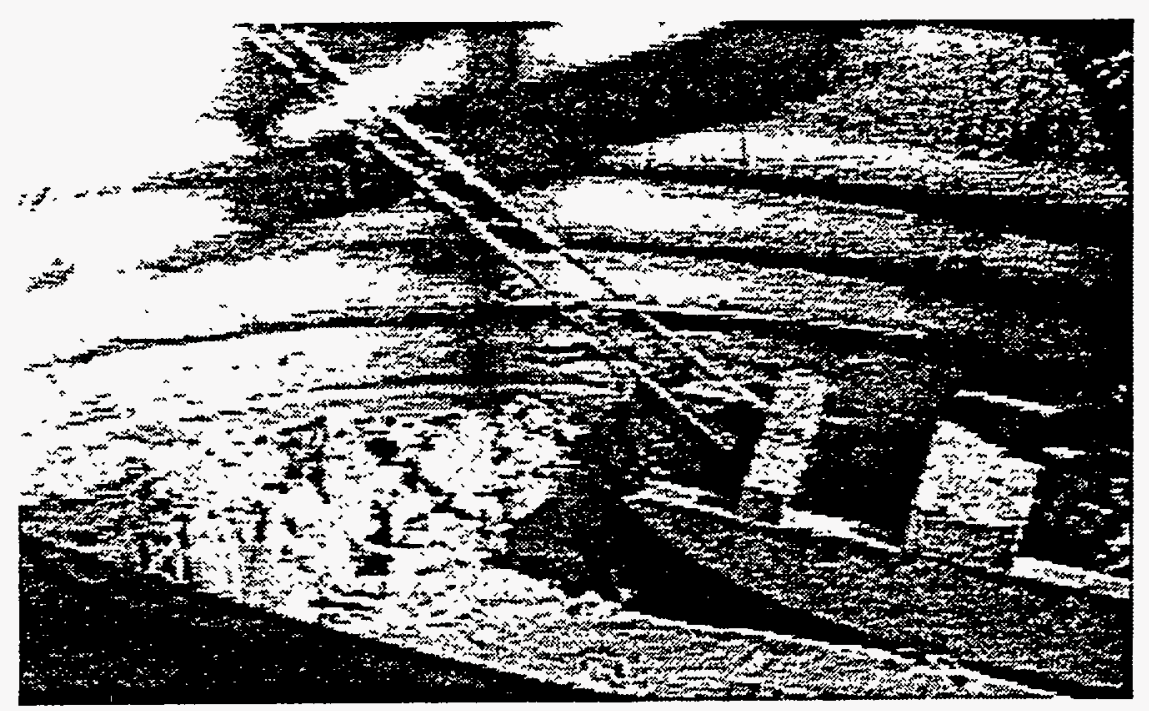

Figure 3.15 "Boat" shape to part of a shroud design.

When very long bristles were used on the shroud (Figure 3.16), these dragged across the surface when the head was close to the simulant and could interfere with the cutting action of the jets. They could not be selectively shortened since the head was required to be flexible in the direction in which it moved, and the head to surface distance could not be accurately predicted. The evaluation of the shroud edging material is thus not yet conclusively decided.

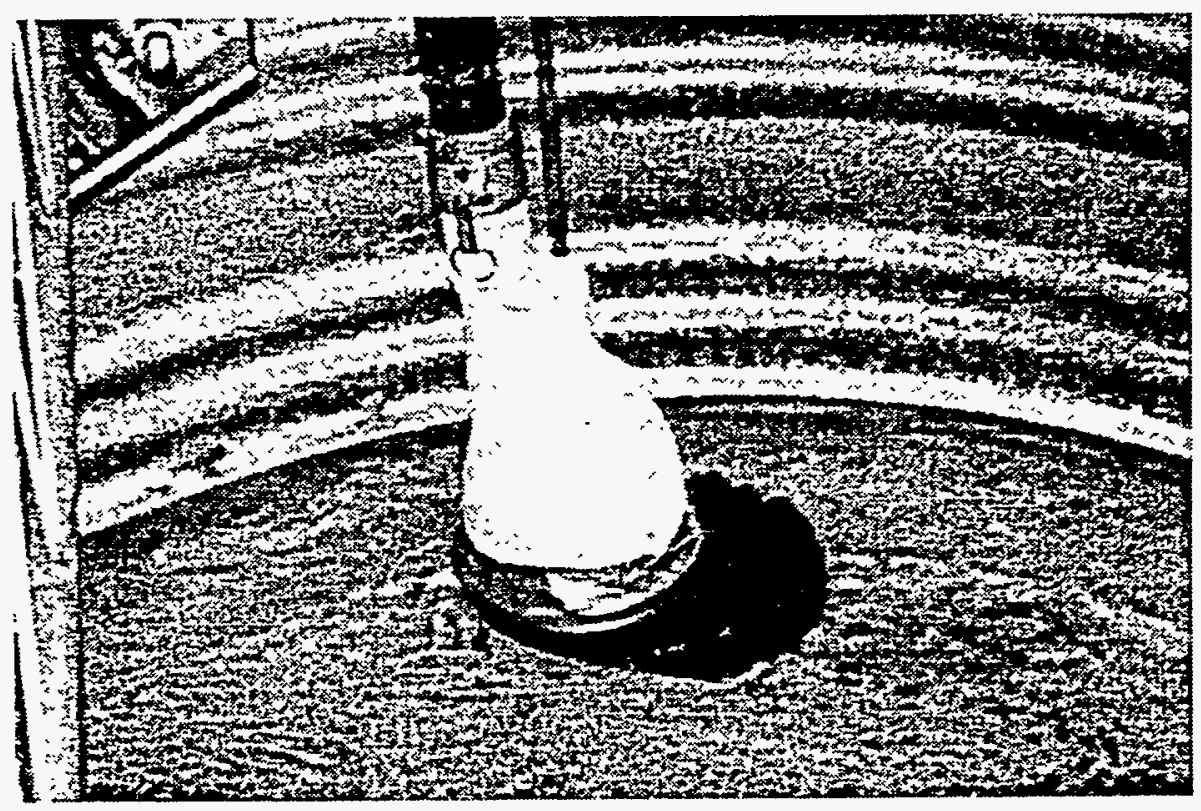

Figure 3.16 Long-bristled shroud edging. 
It did prove possible, with the flat design, to cut slots up to two inches deep and capture all the material removed (whether sludge or saltcake simulant). It also proved possible in limited testing to cut holes more than 4 inches deep (to the bottom of the simulant) with the bristle head and retain almost all the fluid and cuttings within the zone of action of the shroud; however, with the deeper cutting there was a significant water presence on the surface of the cut before the water reached a level where the jet pump could be most effective.

It is therefore concluded that a significant effort still must be made before the problem of complete water retention within the shroud environment is completely solved. At present it is proposed to overcome the problem of water loss outside the shroud during a cutting pass by the design of the mining strategy. If the head follows a "race track" or "surface Mine" contouring cut (Figure 3.17) which moves progressively outward then the center of the cut can be designed to be deeper than the perimeter. Thus, each time the head starts a new and deeper cut, from the center, it will revisit that center and draw off any excess water present.

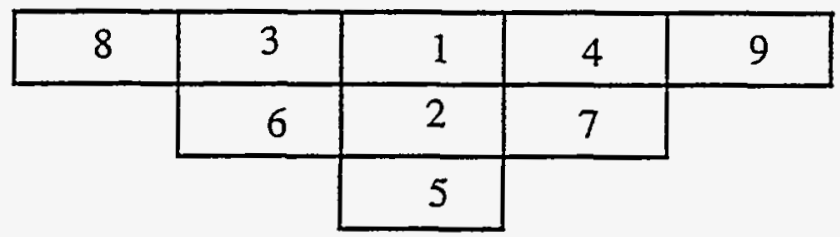

Figure 3.17 Cutting Sequence Proposed.

\section{Cutting Performance Tests}

The Cutting tests in the tank were begun to examine the effect of differing jet parameters on the effective removal rate of the various simulants being evaluated. For the purposes of comprehension, those of equivalent type have been grouped together, even though the tests may not have occurred in strict chronological order.

The tests were carried out to examine the effects of nozzle diameter, nozzle angle, and the speeds of the system on removal rate. The factors considered in a test are illustrated with the results of two such tests, at a jet angle of 30 degrees, carried out early in the program: 


\begin{tabular}{ccccccccc} 
Date & Test No. & \multicolumn{8}{c}{ Cutting Tests in simulant } \\
& & \# of Jets Diameter Pressure Lance & Tank & Head dia. Path Radius \\
$6 / 25 / 93$ & 1 & 2 & 0.056 & 6000 & 84 & 0.4 & 9 & (in) \\
& 2 & 2 & 0.056 & 6000 & 84 & 0.33 & 9 & 28
\end{tabular}

$\begin{array}{cccccc}\begin{array}{c}\text { Traverse } \\ \text { Speed } \\ \text { in/min }\end{array} & \text { Depth of Cut } & \text { Removal Rate } & \text { Inc. Distance } & \text { Water use } & \text { HHP } \\ & & \text { gpm } & \text { in } & \begin{array}{c}\text { nominal } \\ \text { (gpm) }\end{array} & \\ 70.36 & 0.75 & 2.06 & 0.21 & 14.86 & 52.03 \\ 58.05 & 0.75 & 1.70 & 0.17 & 14.86 & 52.03\end{array}$

The results from this particular test were quite disappointing; however, it was found that there was some significant system loss in the design of the flow channels to this nozzle and when this was corrected the performance improved. (It should be pointed out, however, that a significant problem arose with simulant strength and reproducible quality throughout the following series of tests, which was not finally concluded because of the lack of reproducibility; this will be discussed below).

The initial test series examined the variation in nozzle angle (at levels of 30, 45 and 90 degrees), tank rotation speed, and lance rotation speed. The major variables under test were the incremental distance between adjacent passes (varied between .5 and 1.75 inches) and the ability of the jet to remove the defined ribs between the cuts. Where the jet could remove the remaining rib, it was anticipated that the required effective removal rates could be achieved.

In order to achieve the variation in angle with the greatest ease, a special nozzle mount was developed (Figures 3.18 and 3.19) and this made it simpler to adjust both nozzle angle and spacing to maintain the cut width. 


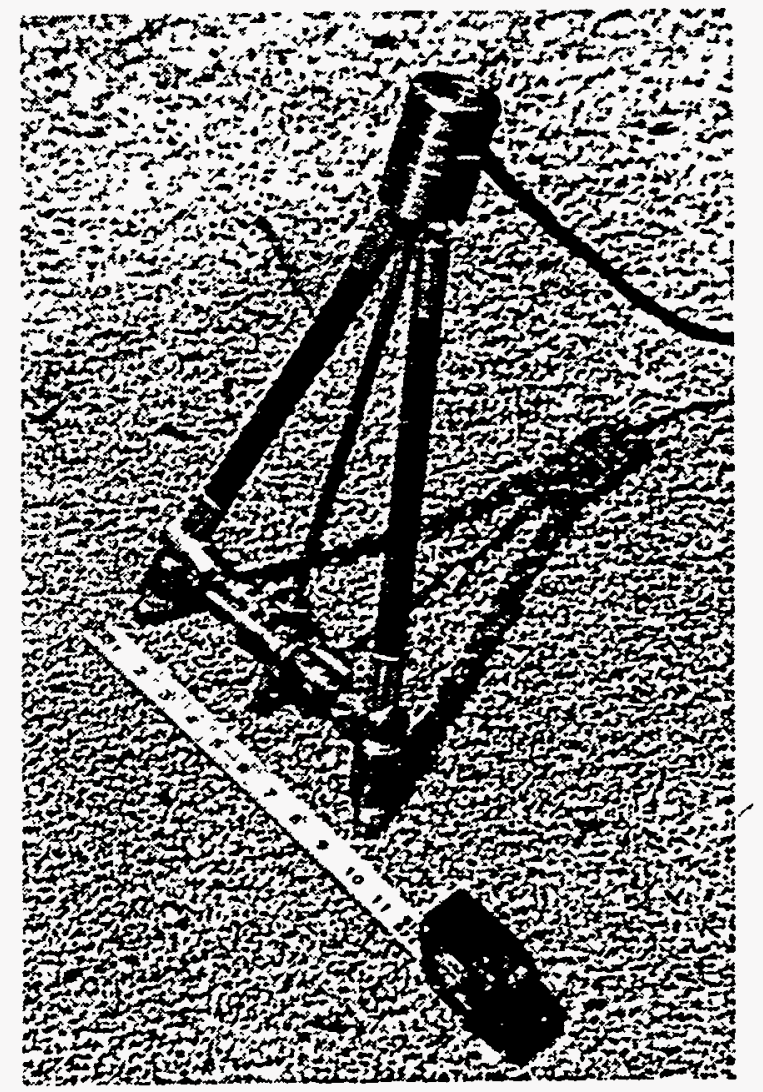

Figure 3.18 Adjustable Nozzle Angle Assembly.

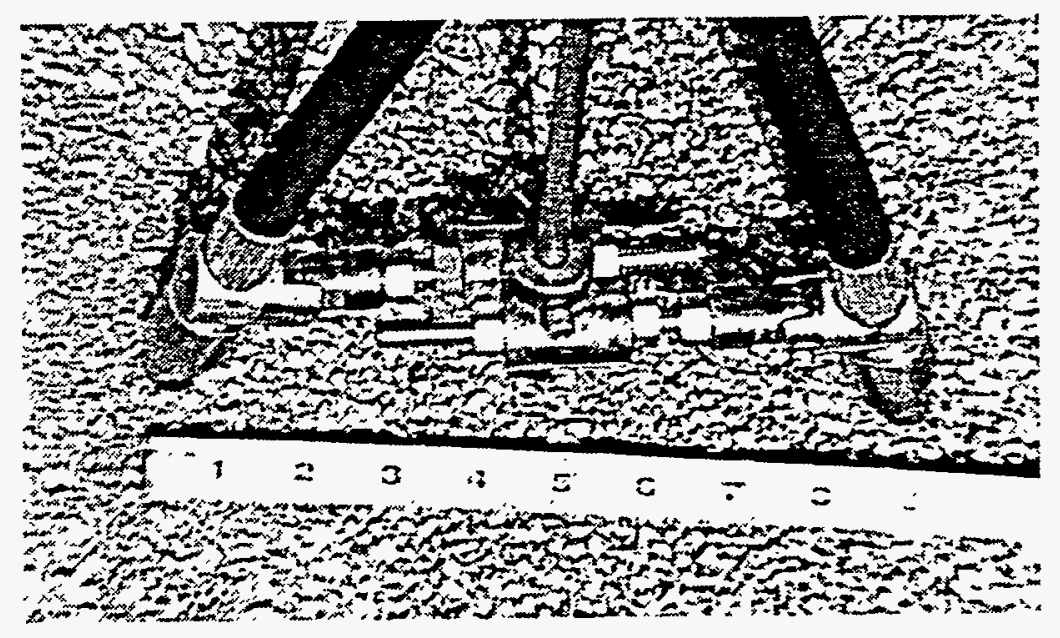

Figure 3.19 Detail Showing Angle Adjustment Mechanism.

In order to simplify the test arrangement the tank was set to rotate at a given speed, and during a single pass the lance rotation was adjusted to give three different values. By measuring the depth of cut in the center of each segment of the test run, it was then possible to generate the projected volume rate of material removal. 
The test results (Appendix B) were not satisfactory and did not give any greater production rate than $6 \mathrm{gpm}$ of simulant. The problems which were identified in only achieving this lower value were considered to be as a result of five factors:

- The arm support mechanism was not rigid enough and the paths of the jets on successive passes were not exact enough to cut the grooves to remove the pieces outlined on the earlier passes.

- Only the initial surface measurements were taken rather than making a series of deeper passes which would reach a steadier state of cutting and would remove some of the material left on the first set of passes.

- The ridges in many of the tests were too thick for the jets to break with this set of configurations.

- The jet pressure at the nozzles was still not as high as that registered at the pump.

- There was still a question as to the reproducibility of the simulant strength. It was found that there was a significant change in strength in the presence of excess water and that this change in strength varied with time. Thus, in order to have a consistent sample strength, the block cuts were all made as rapidly as possible in sequence so as to minimize this problem. A two-hour wait between tests was found to be too long.

While some of these points were to be controlled by the robotic arm (and in subsequent discussion were found to be as great a problem under that control) it was decided that an alternate approach should be investigated. This involved the use of inclined jets cutting in pairs. However, before that test series was carried out, another aspect of the program was addressed.

\section{Cutting Tests with a Varied Test Surface}

From a practical point of view, the anticipated cutting strategy for the head is that it will traverse over the surface in a series of horizontal sweeps, cutting the surface down to a defined plane. This recognizes that the surface is not originally flat, but is felt to give a better control over the excavation process than trying to follow the original surface contour (Figure 3.20). 


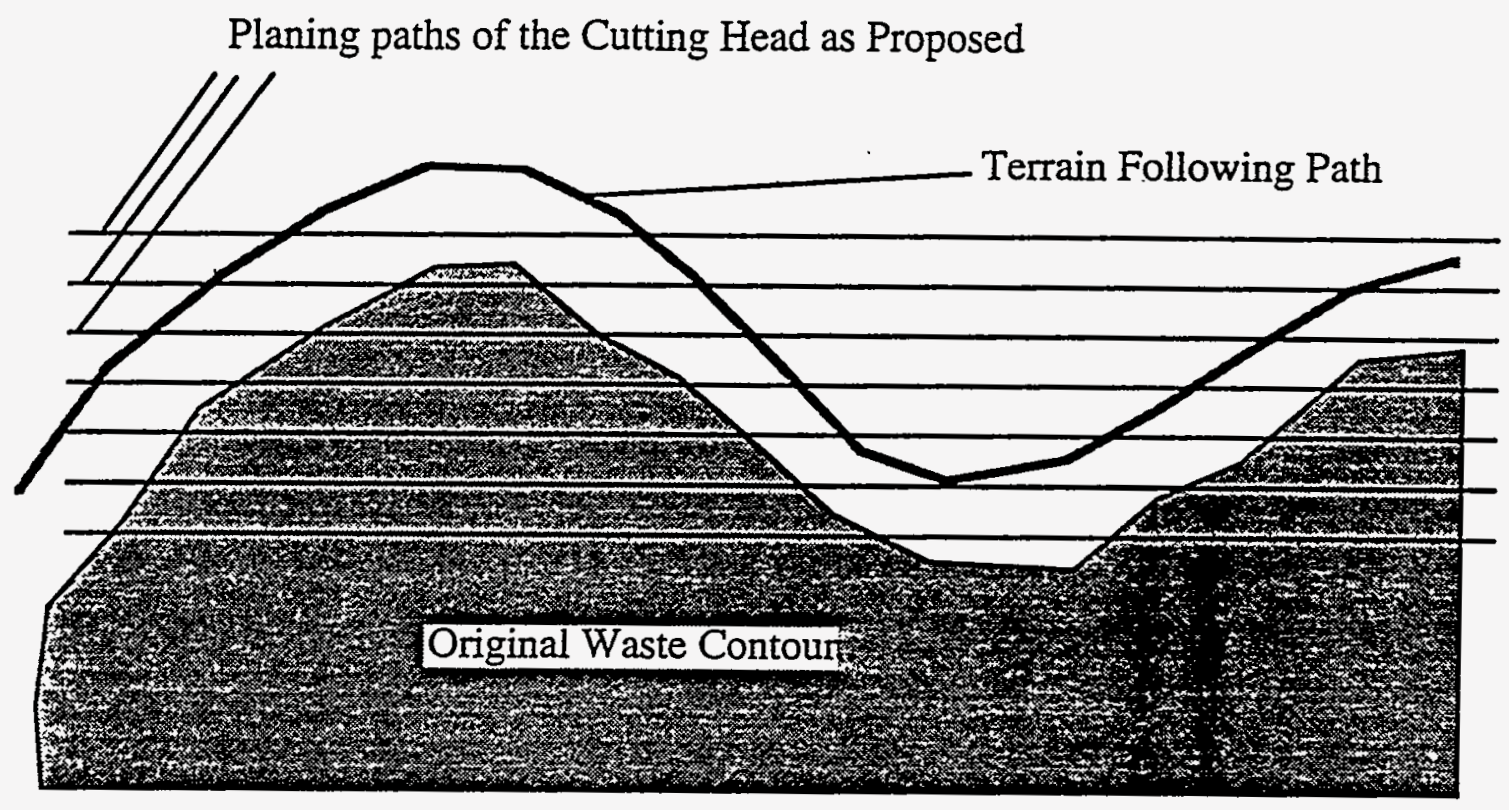

Figure 3.20 Methods of coping with a varying surface topography.

The result of this is to drive toward a final controlled surface contour.

This raised two questions, one of which was whether the jets would cut far into the simulant (and ultimately the waste) and if the jets could successfully cut under a depth of water, and the second was what condition the surface would be cut to and how would the jets and the shroud deal with this surface.

The questions were addressed separately, because of the limited power available to drive the larger tank. To establish the ability of the jets to cut and excavate over distance, a pour was made into a 55-gallon drum and a head rotated over the surface of the central section of the material. The simulant was just under two feet thick and this test was combined with a test on shroud configuration to ensure that the material would all be aspirated out of the cut as the depth of cut increased.

The first cut made with this configuration used two jets to cut a channel into the surface of the simulant, some two inches wide and over four inches deep (Figure 3.21). The cut was made from a flat surface, and created a channel into which all the spent water and debris flowed with most of it being carried, by the remaining jet energy, out underneath the edge of the shroud. Given that the test was being carried out in a drum, however, this fluid was rapidly caught and aspirated out from the tank as the fluid flowed back over the surface towards the head. 


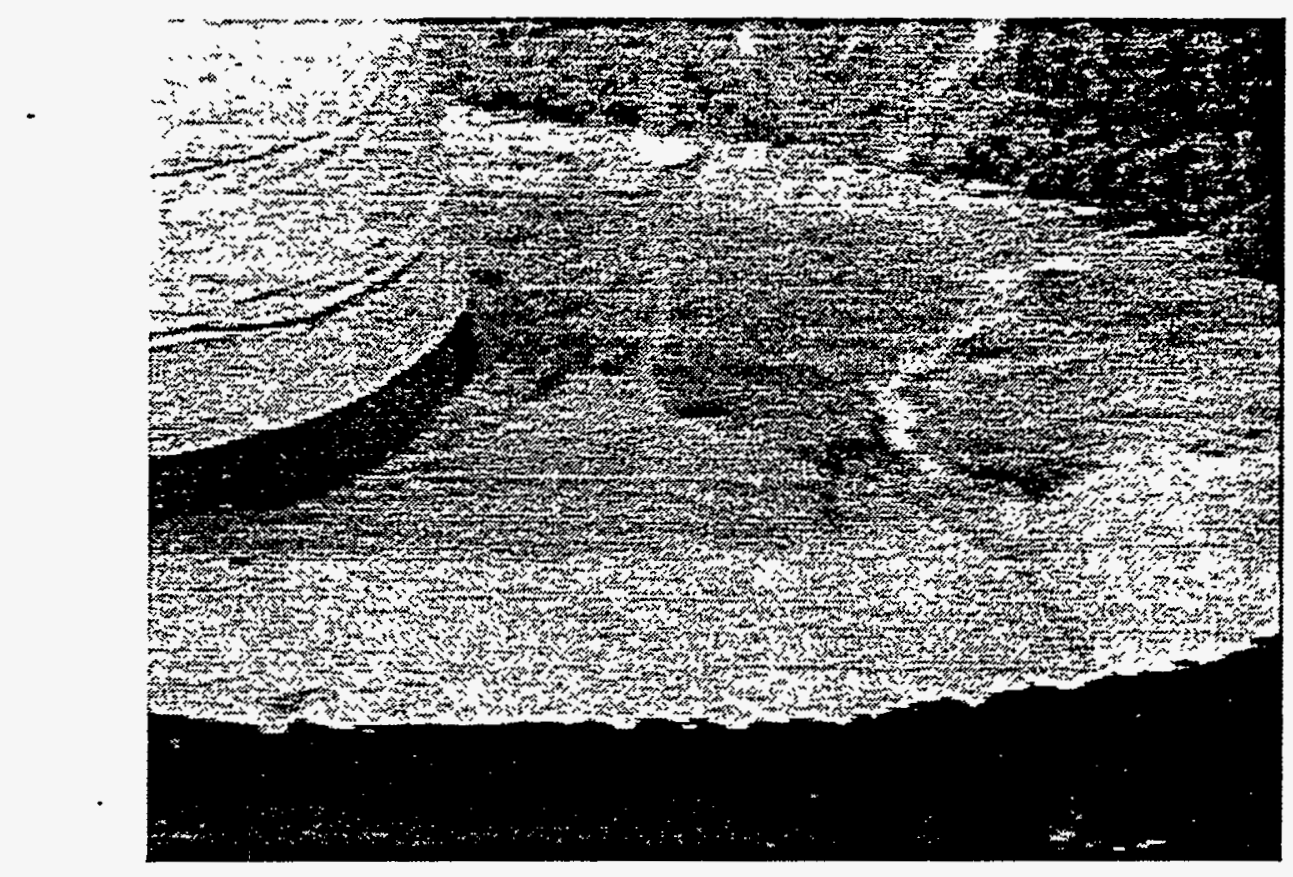

Figure 3.21 Cutting a deep slot into the simulant, with fluid escape.

(The slot is two inches wide and roughly four inches deep - it is partially hidden by the fluid escaping from under the shroud on the upper left of the picture.)

This test indicated that cutting a slower, deeper pass over the surface would not, with the standoff distance attempted, give effective debris removal. The flexible bristle depth was only some half an inch in this test. It was also noted that with the deeper cuts, the slots generally filled with water.

A series of tests in this configuration did, however, provide further information on the ability of the jet to cut into the simulant and the type of surface that might be generated. First, however, the nozzles were moved further apart to give a shallower cut (Figure 3.22).

During the next test the head was traversed radially over the surface, as the tank turned so as to cover the entire exposed surface that could be reached. The test was carried out with a relatively slow traverse over the sample (the tank rotated every $2 \mathrm{~min} 10 \mathrm{sec}$ ) and with a total test time of 5 minutes. During that time the central section of the simulant was cut down to the bottom of the tank (a distance of 14 inches, Figure 3.23) although the surface was not evenly cut. 


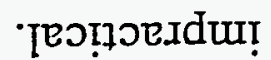

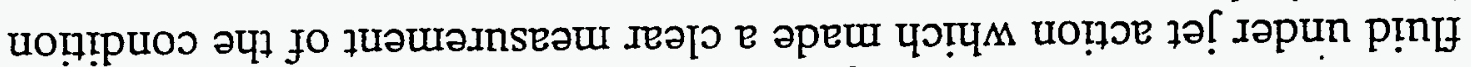

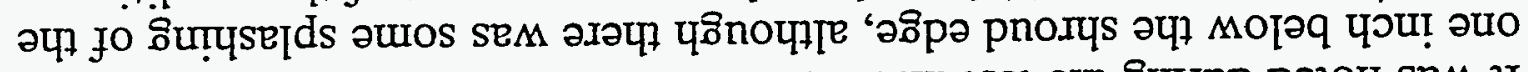

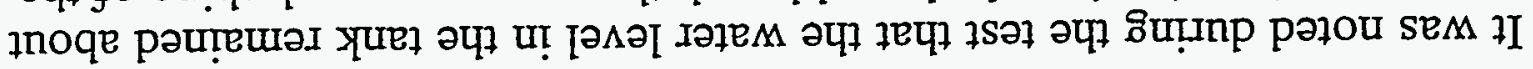

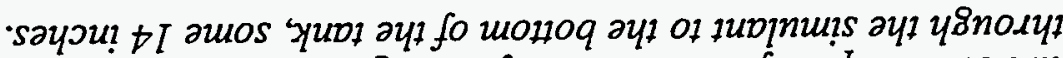

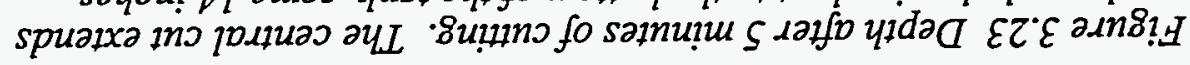

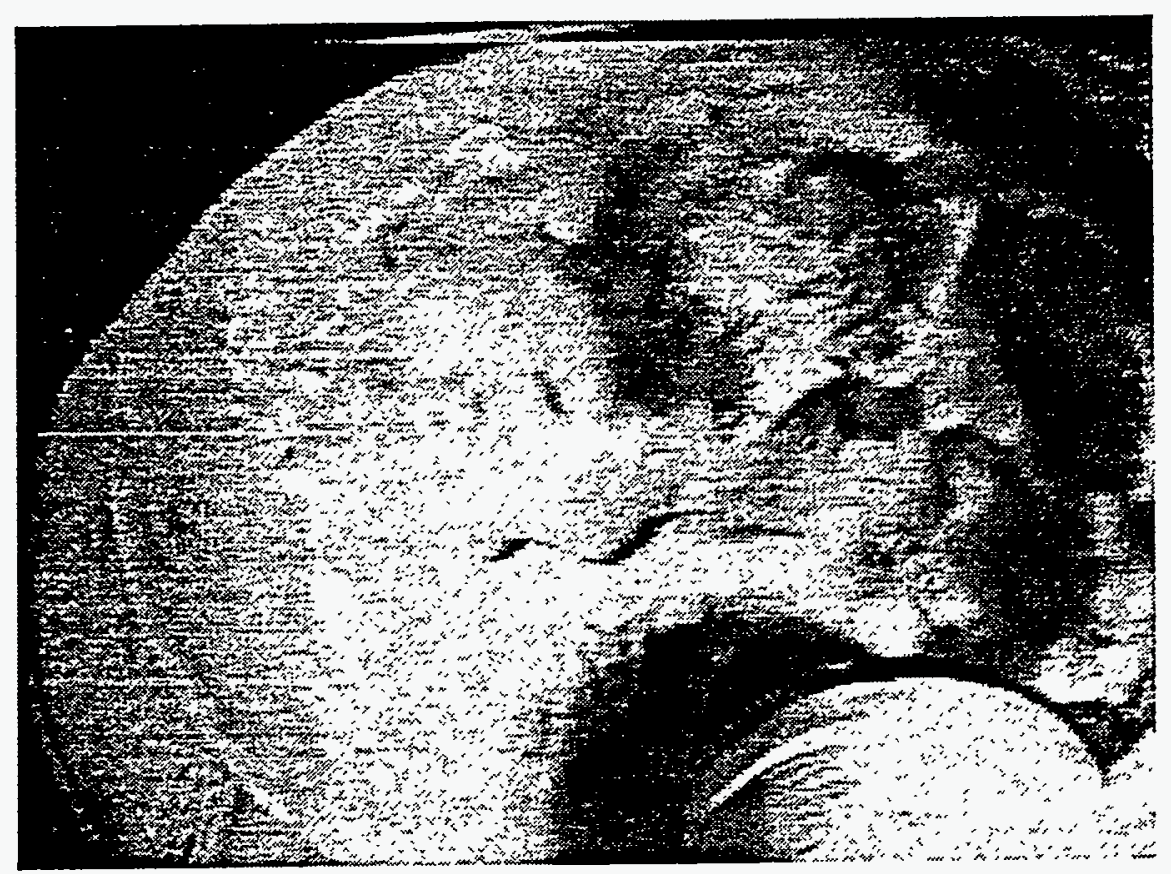

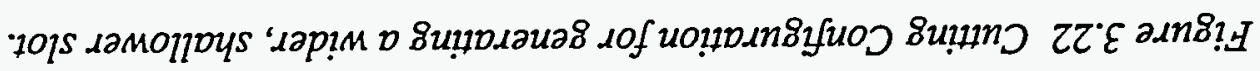

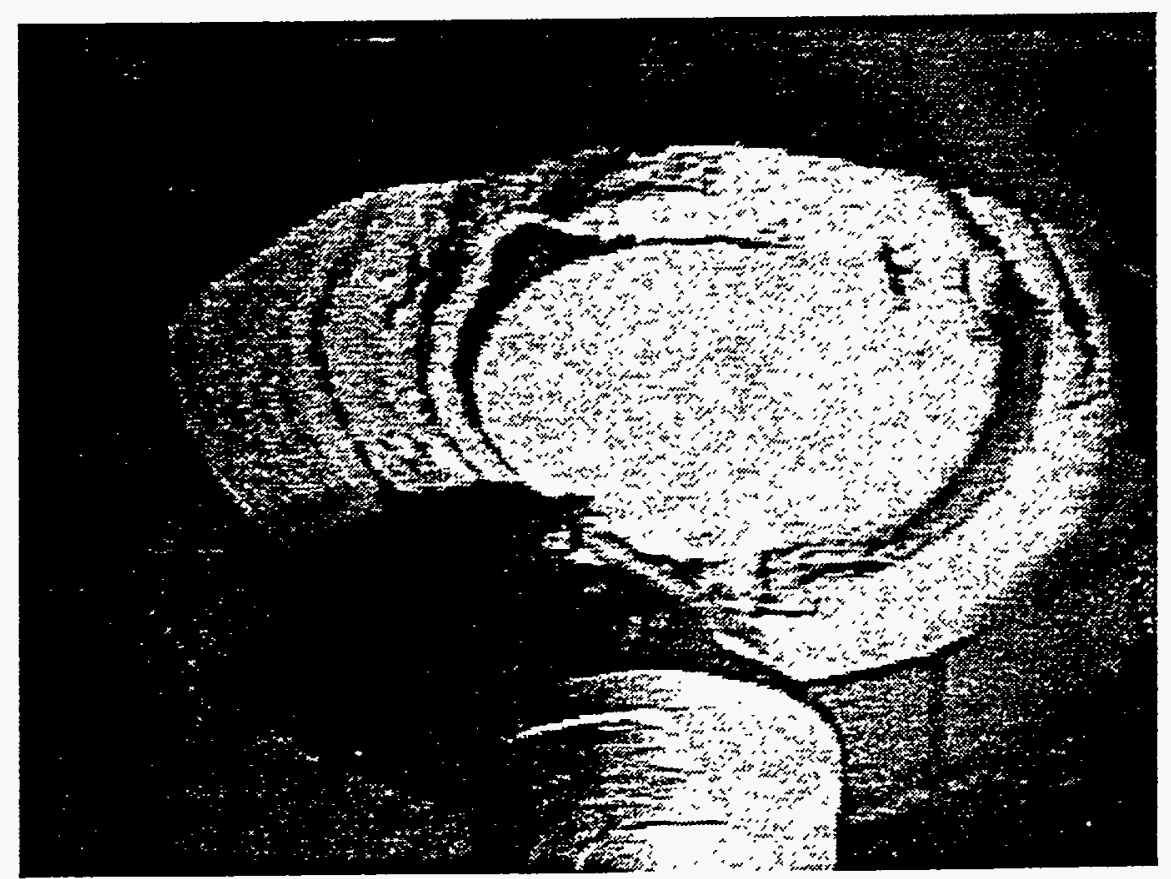


The testing to this point had centered around large standoff distances between different points on the surface. Under these conditions it was felt that the head would not be totally effective, regardless of shape, in immediately aspirating all the material into the conveyance line. Tests were carried out with steps in the surface of the simulant; and it was clear that with a gap of four inches (between a central excavated section and the perimeter), the suction was not effective in aspirating all the material.

However, this problem was recognized in the development of a planned sequence of excavating cuts which would allow, relatively rapidly, the head to recapture the material lost on earlier passes. The question remained as to whether the shroud would retain most of the water during a cutting operation over surfaces which had been cut down by the action of the cutting head. To demonstrate this a series of passes were made over the surface of a layer of simulant in the tank, with the cuts continuing until the material had been planed down to the underlying metal (Figure 3.24). The shroud design for this was slightly modified, with a trailing "brush" to retain as much of the spend debris as possible within the zone of influence of the conveyance inlet (Figure 3.25).

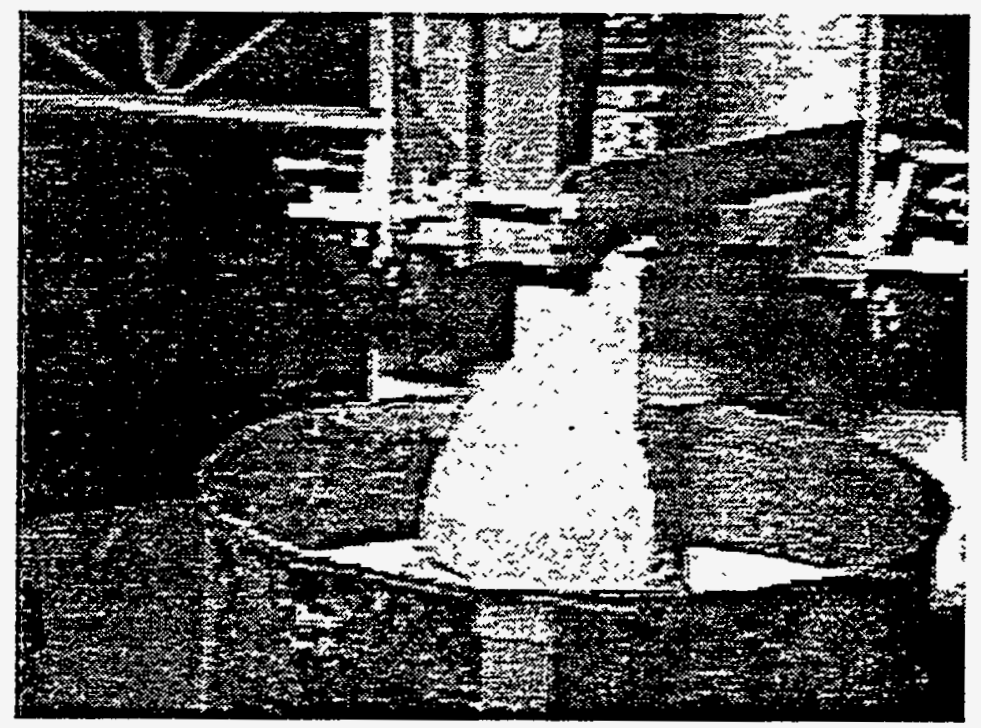

Figure 3.24 Test run in which the jets cut to the bottom of the 55-gallon drum (notice there is no spillage of water.) 


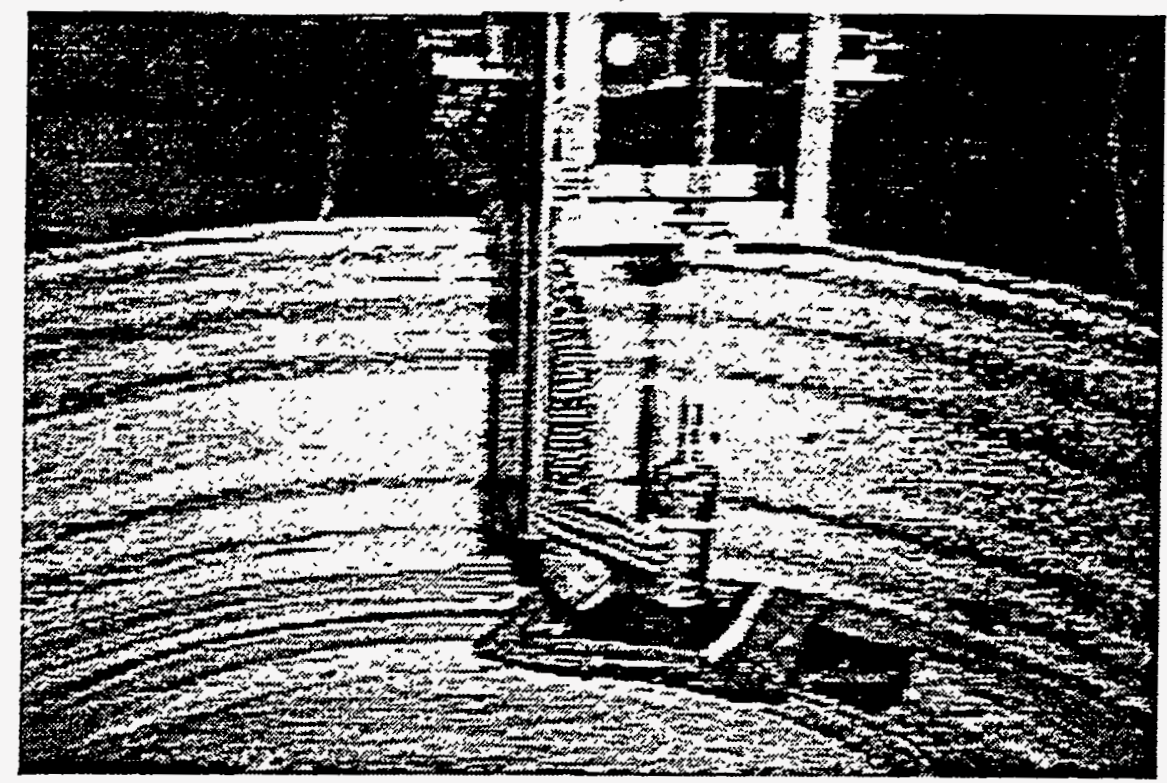

Figure 3.25 Shroud for Continuous run test.

With the completion of this test (Figure 3.26), it was clear that the preliminary concept of removing the debris from the cutting zone was, in fact, a practical one. At this stage it was, therefore, concluded that more emphasis should be placed on evaluating the ability of the jet to cope with different surfaces, and on reviewing the jet configuration to give greater productivity. This effort was, therefore, discontinued at this time.

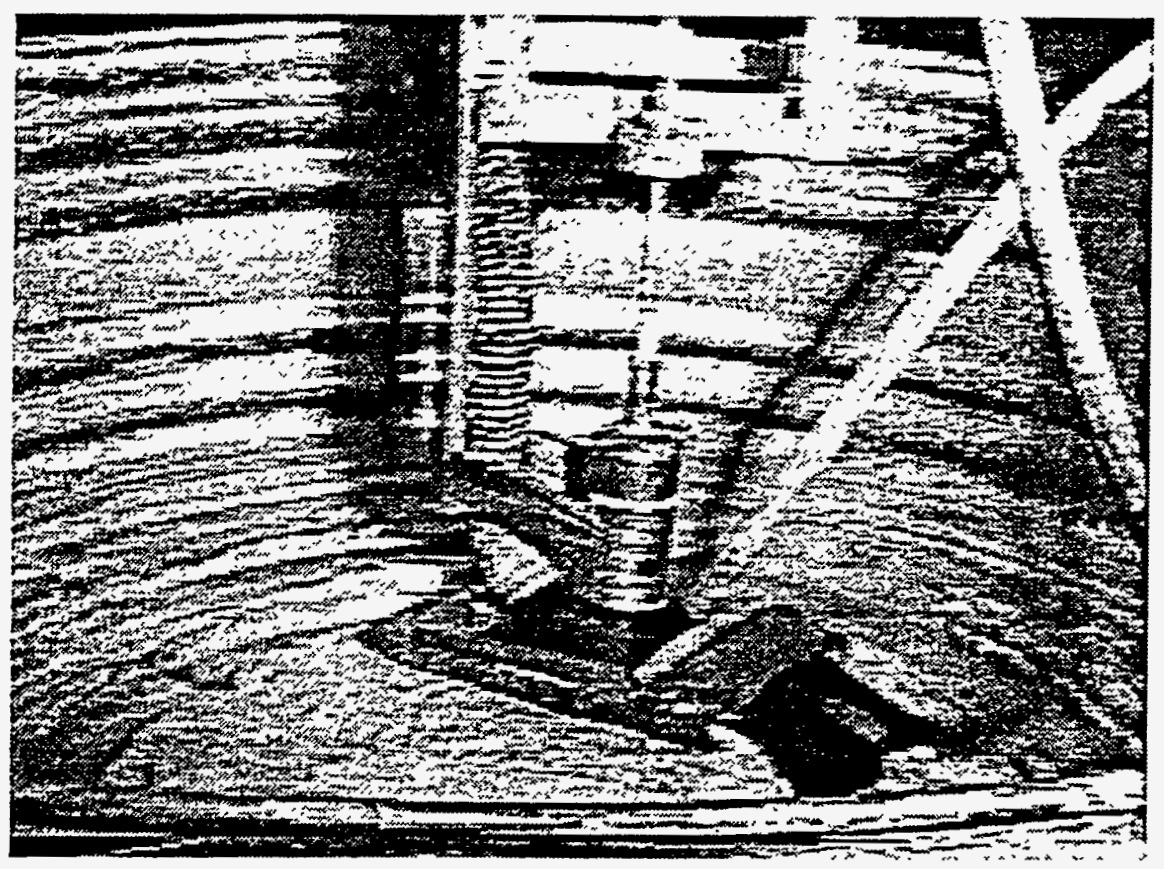

Figure 3.26 Surface Configuration during a "long run" test. 


\section{Cutting Tests With a Varied Simulant Surface}

During the course of this program two different materials were modeled. These were the saltcake simulant, which has been the major target for the experiments described above, and a sludge simulant. For sludge, a thin clay (from Missouri) was used as well as a kaolin clay:water combination manufactured to specifications from PNL.

In total four sets of tests were run with the sludge simulant. The first of these was described earlier, in which a thinner clay (from Missouri) was used to model the sludge. In that test a 55-gallon drum was half filled with the saltcake simulant and half with sludge simulant (Figure 3.1). The division was a vertical one and the head was then traversed horizontally over the total surface. With the weaker clay it proved relatively easy to take the clay particles into suspension and to pump them out of the tank. In comparison, the saltcake was much more resistant. For that reason much of the development work was subsequently carried out using the saltcake as the test material.

Reported results from other investigations suggested, however, that the removal of a kaolin simulant for the sludge was not as easy to accomplish as with the thin Missouri clay. Additional material was obtained and a short series of tests carried out to establish the practical conditions for removing the kaolin clay.

The test program was carried out in three parts. In the first a 55-gallon drum was partially filled with the simulant and a simple shrouded head rotated over the surface of the simulant. The shroud was relatively heavy and was initially allowed to rest on the bristle points defining the shroud edge. This was not effective since the jets rapidly undercut the edge of the shroud, causing it to sink into the clay and thus creating a ledge which the shroud would encounter as it moved around the tank (Figure 3.14).

The positioning control was therefore made more positive, and the head only lowered by manual operation after a pass had been made. In this second run it was obvious that the jets were cutting to a significant depth into the sludge and creating a suspension which the jet pump was easily able to remove. Successive passes over the surface of the simulant were made with several inches of advance between them, and the barrel cleaned of clay.

In order to try to overcome the problem with the clay being pushed up into the path of the cutting head, a "boat" shape was designed for the front of 
the shroud and tested (Figure 3.15). The test was not very successful because of the large coefficient of friction between the shroud and the clay and the relatively large bearing surface over which it was applied.

A continued evaluation of this problem led to the conclusion that the cutting of clearance for the shroud would need to be addressed within the mining strategy development, and the location and protection of the shroud would need to be considered in the motion of the cutting arm, as it was developed.

At this point the test program was changed to examine how the cutting head would cope with a cutting surface which contained two simulants. In the first part of this test a central portion of the saltcake simulant in the large test tank was removed and the central cavity thus revealed was filled with the sludge simulant.

Because of the weight restriction on the amount of material in the tank, only a six-inch thick layer of clay was used in this test. The cutting head was configured as it had been when it successfully removed the saltcake. The next pass was made over the sludge simulant (Figure 3.27).

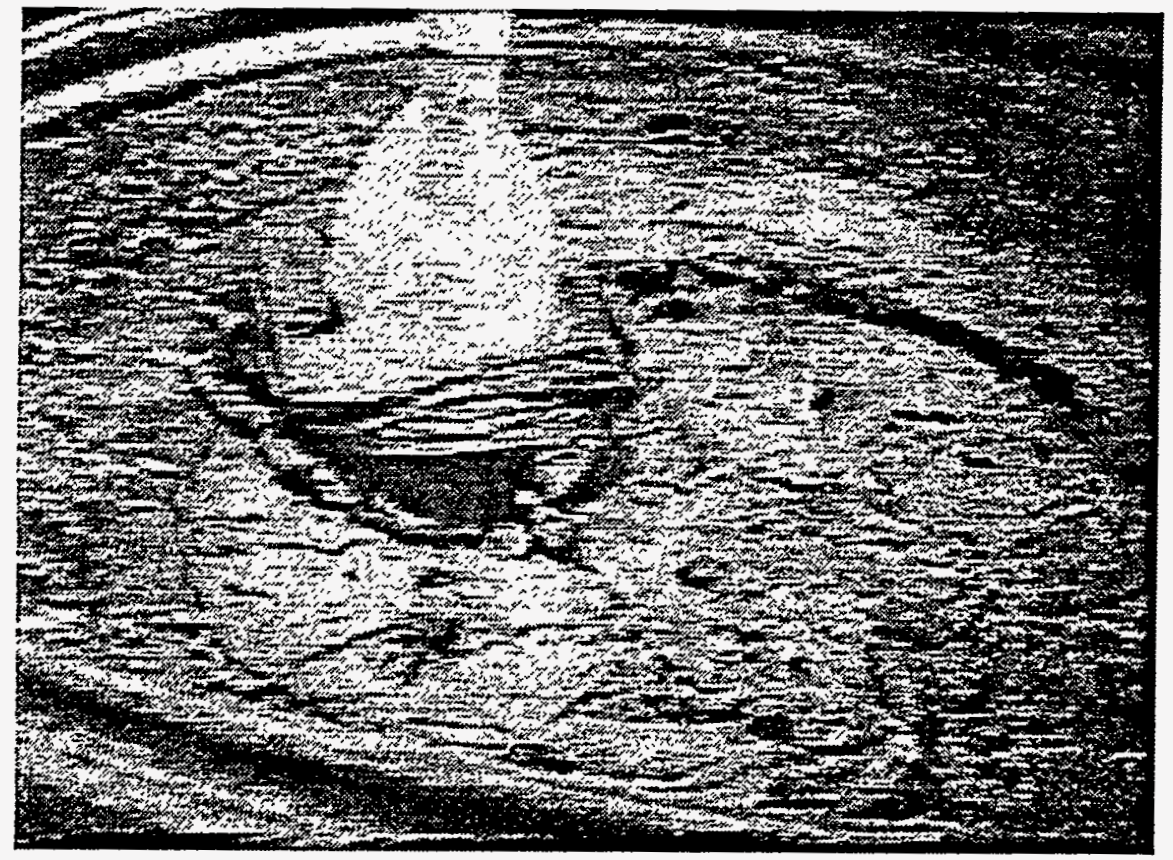

Figure 3.27 Cutting clay simulant within the central section of saltcake.

The test was not a success. The waterjets rapidly cut through the entire thickness of the clay, down to the underlying metal and flowed along that surface, debonding plates of clay without mixing the water with them 
(Figure 3.28). This was not effective for two reasons. First, the clay particles produced were too large to be aspirated into the suction line and the conveyance.

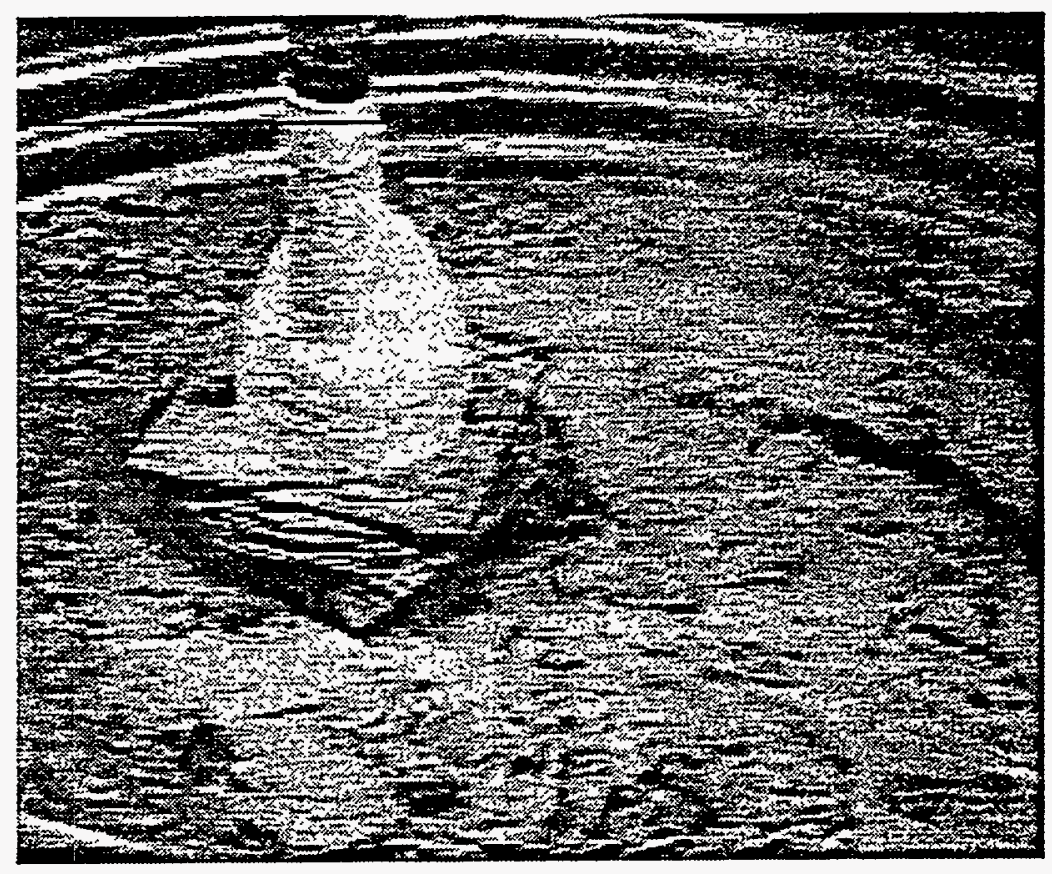

Figure 3.28 Unsuccessful clay cutting.

Second, the water which would mobilize the clay was being distributed over the entire base of the cavity in which the clay was located, so that none of it was available to help move the clay into the conveyance line (Figure 3.29).

Analysis of this result suggested that the waterjet contained too much energy for the task required. Simplistically, this could be defined as cutting and fluidizing the material directly under the shroud so that it could be aspirated into the conveyance line. To achieve this the depth of cut had to be restricted to perhaps two inches and the water contained in the area of influence of the shroud.

An evaluation of the way in which the jets cut and the head was configured led to a conclusion which fitted in with similar conclusions being drawn from the cutting of the saltcake. (These will be addressed in the following section.) Of particular relevance to the cutting of the sludge, it was decided that the head would be more effective if the nozzles were rotated at a much higher speed than that considered to date. The would be beneficial from two aspects. First, it would limit the distance that the head moved forward between adjacent passes of the jets over the surface, putting a 
higher density of water into the cutting zone and more reliably ensuring that all the material removed could be mobilized. Second, it would produce a shallower cut into the material so that the water and debris would be more closely restricted to lie within the range of the conveyance suction.

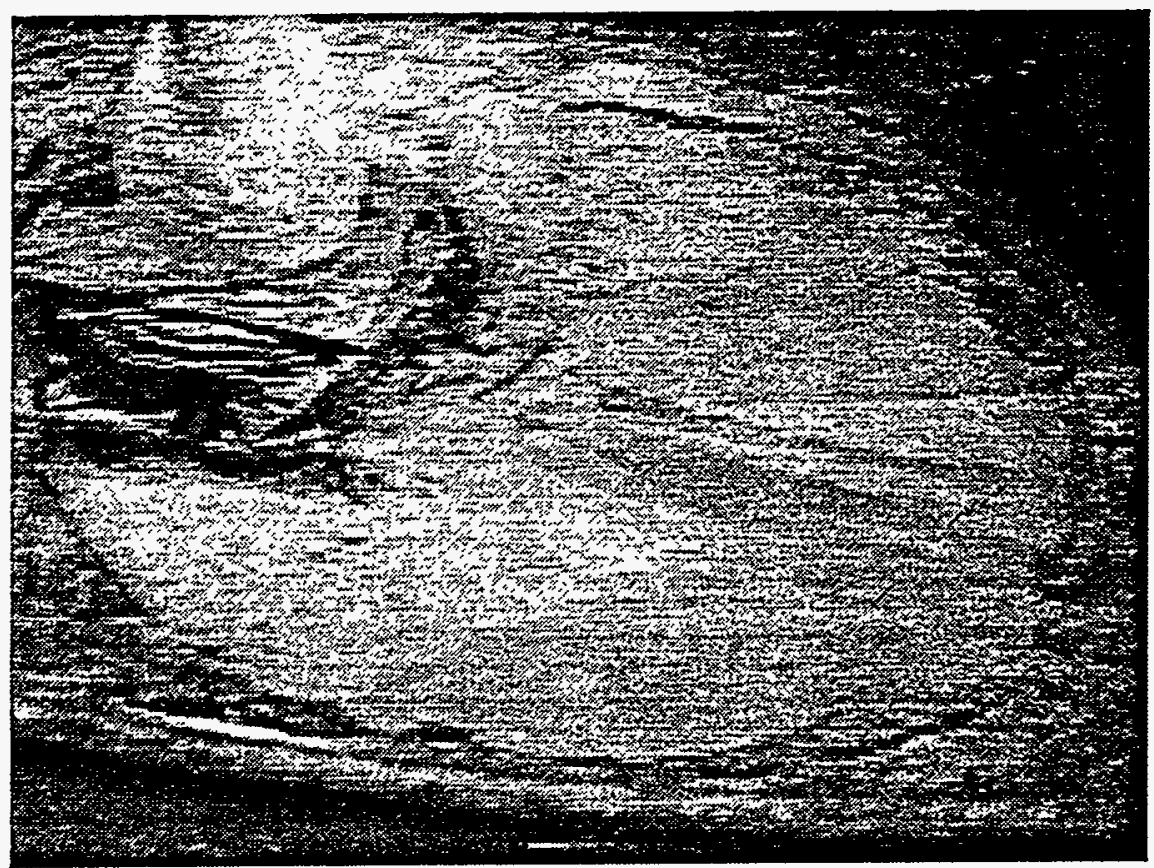

Figure 3.29 Distributed Water around the "clay" inclusion.

This modification was made and successfully demonstrated as being effective. As one illustration of this, during the demonstration videotape provided as part of the reporting of this research a cut was made over a channel cut into saltcake simulant and filled with the kaolin mixture. The jets (which had previously been used to cut the channel) effectively removed the kaolin on a single pass (Figure 3.30).

The cutting head had thus successfully demonstrated that it could remove both sludge and saltcake simulant from a surface and aspirate them into the conveyance. This therefore successfully concluded this portion of the investigation. 


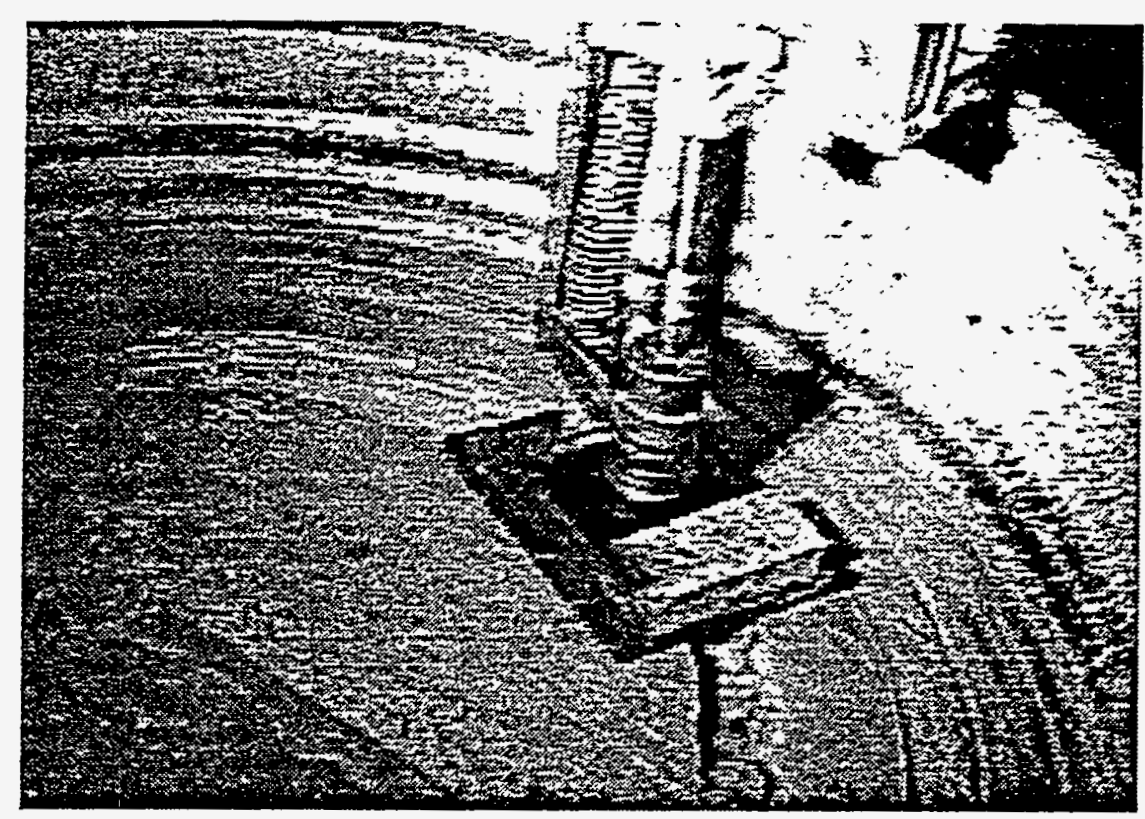

Figure 3.30 Removing sludge simulant from a channel.

\section{Cutting Evaluations with Various Nozzle Design Configurations}

Productivity with the cutting head design originally conceived appeared, from the test program carried out to date, to be very sensitive to the movement of the head. Given that this movement was, in turn, controlled by a robotic arm which had a defined reproducibility and accuracy which were greater than the tolerance required for the head, another approach to the head operation was required.

From a specific energy point of view, most effective jetting operation occurs when the jets cut a slot which defines and then removes an adjacent rib of material. However, for the jet to be effective in this mode, the rib dimension must fall within a relatively narrow bound on thickness. Having the head speed change as the unit advanced would move the rib thicknesses to exceed that limitation if the jets were located on opposing sides of the main shroud assembly. Alternative nozzle arrangements were therefore investigated.

The head movement could not be guaranteed to meet the feed conditions to define, between two jet passes, the required rib width. Thus, in order to achieve the required separation, a design was developed in which two jets would cut adjacent paths into the surface at the same time, but from opposing directions, in order to cut out the required particle sizes (Figure 3.31). 
pəisn!pe aq pInoo

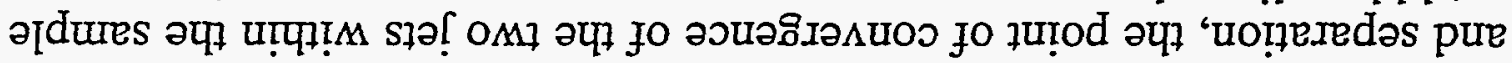

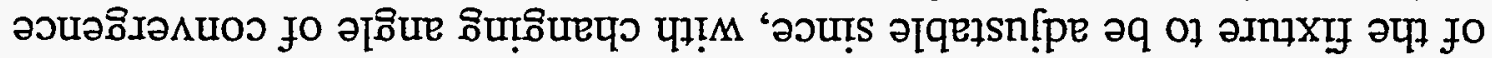

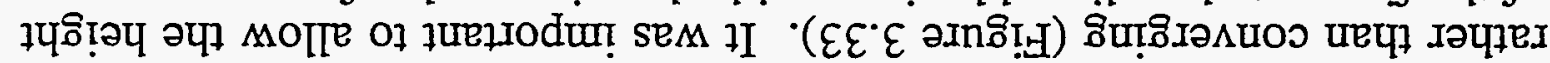

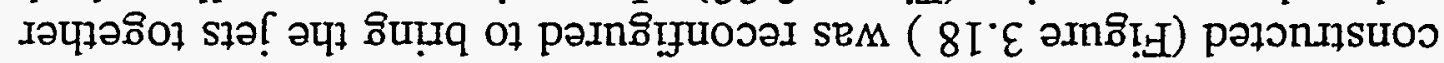

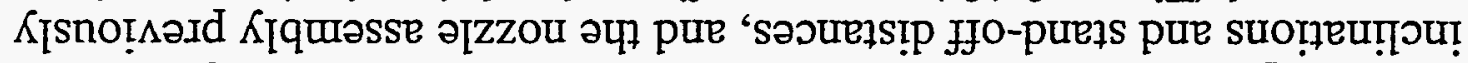

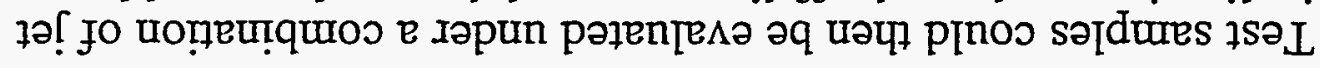

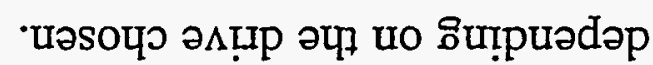

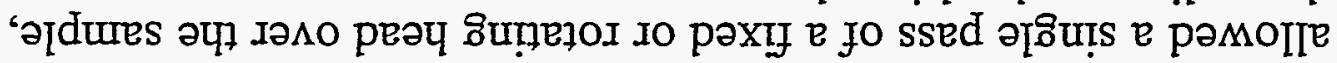

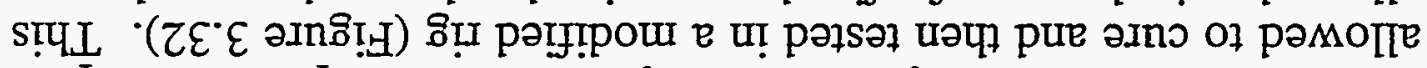

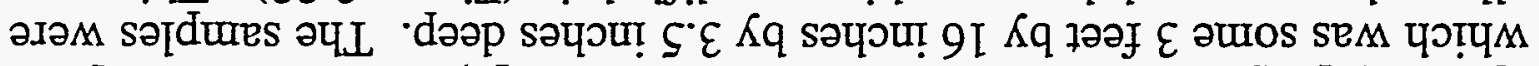

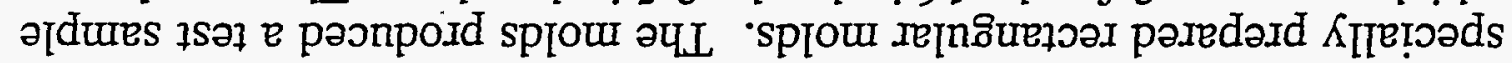

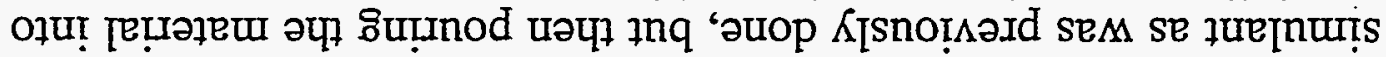

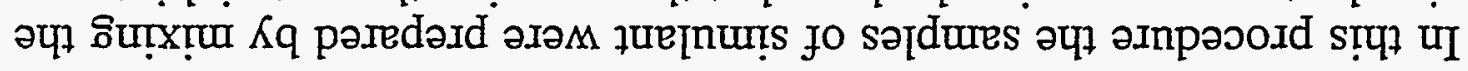

- Inposold Iə[dur!s $e$ olu!

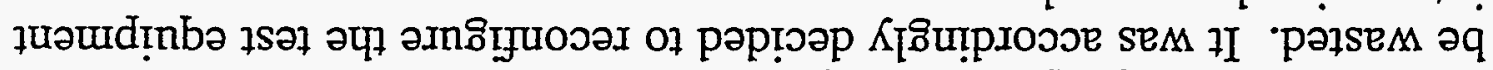

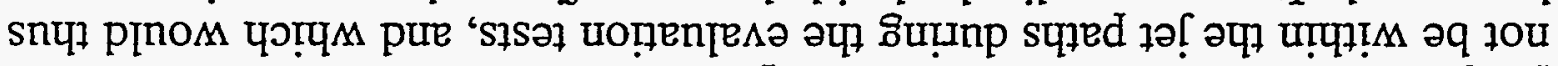

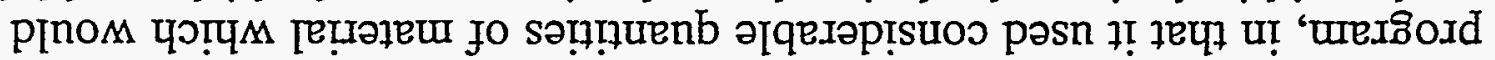

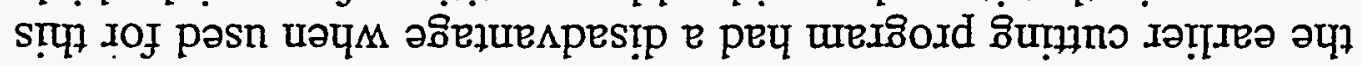

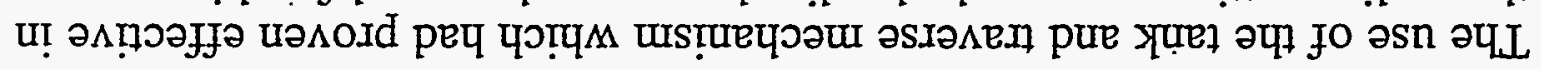

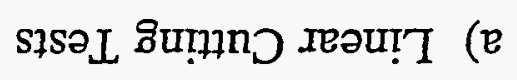

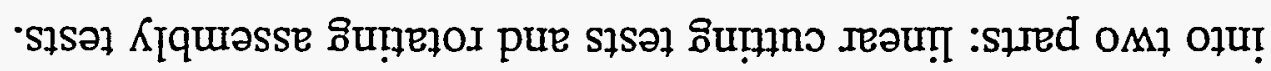

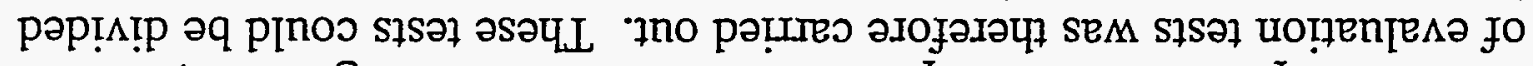

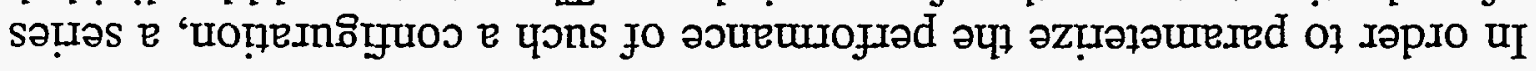

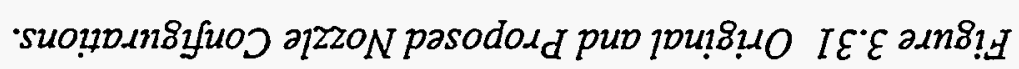

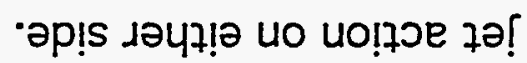
snoəuez|nu!s Kq pəzeəu!|әp

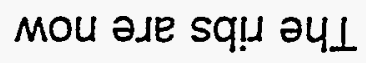

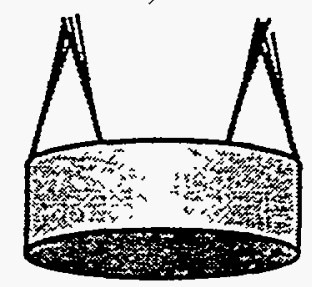

-ə|npom әцा to sap!s

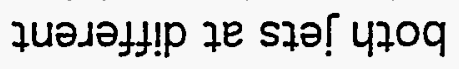
modf sassed 47!M sq! әu!|7no s7a! ןeu!b!10

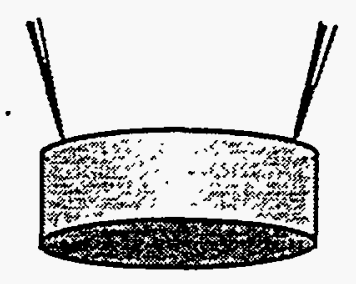




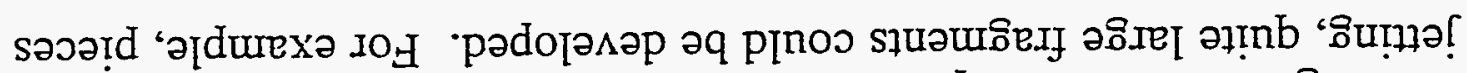

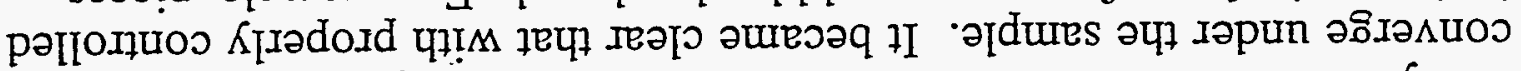

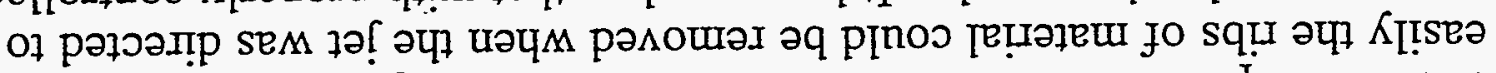

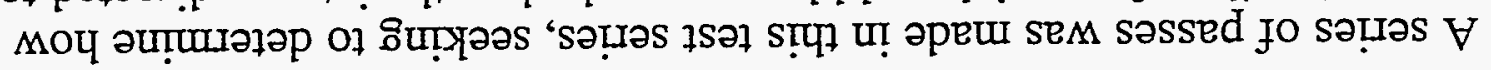

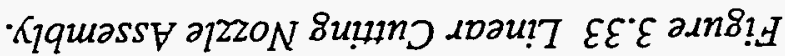

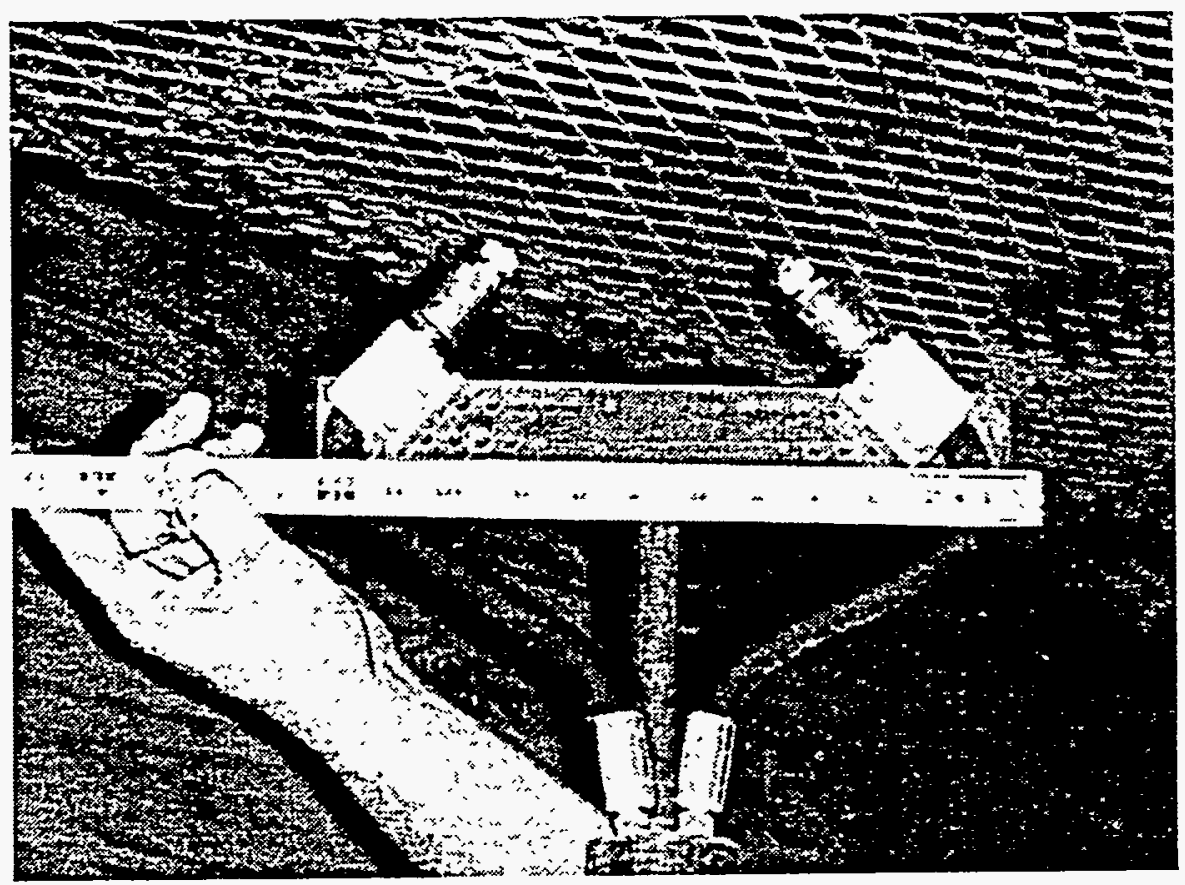

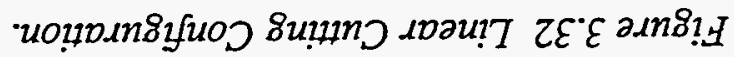

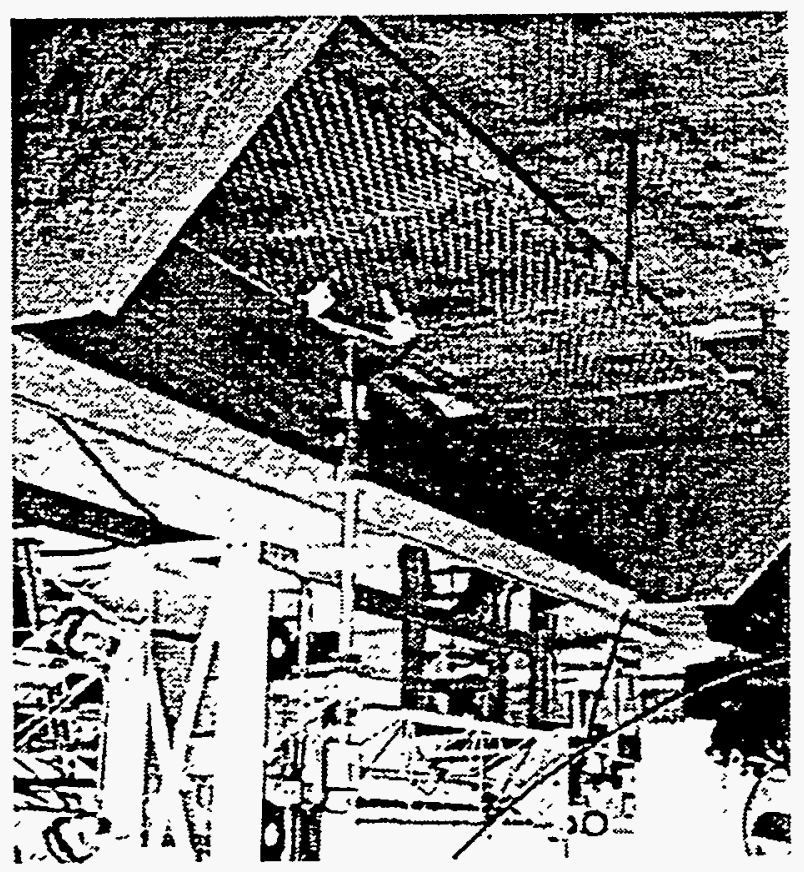


over 3.5 inches wide at their surface exposure were removed with the jet converging 1.25 inches below the surface (Figure 3.34). However, relatively small changes in standoff distance for the jet or changes in angle which created a supporting rib between the cuts (Figure 3.35) meant that almost no material was removed. (See also the left cut in Figure 3.34.)

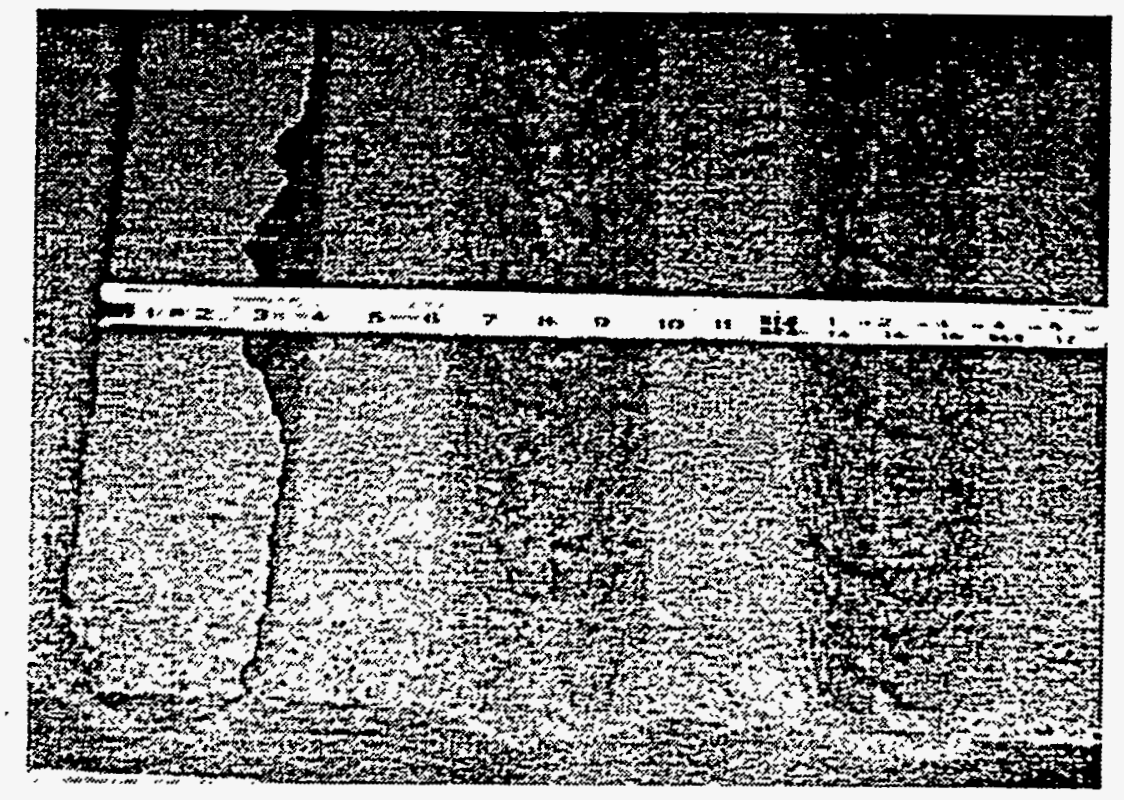

Figure 3.34 Sample after test with central section left and removed.

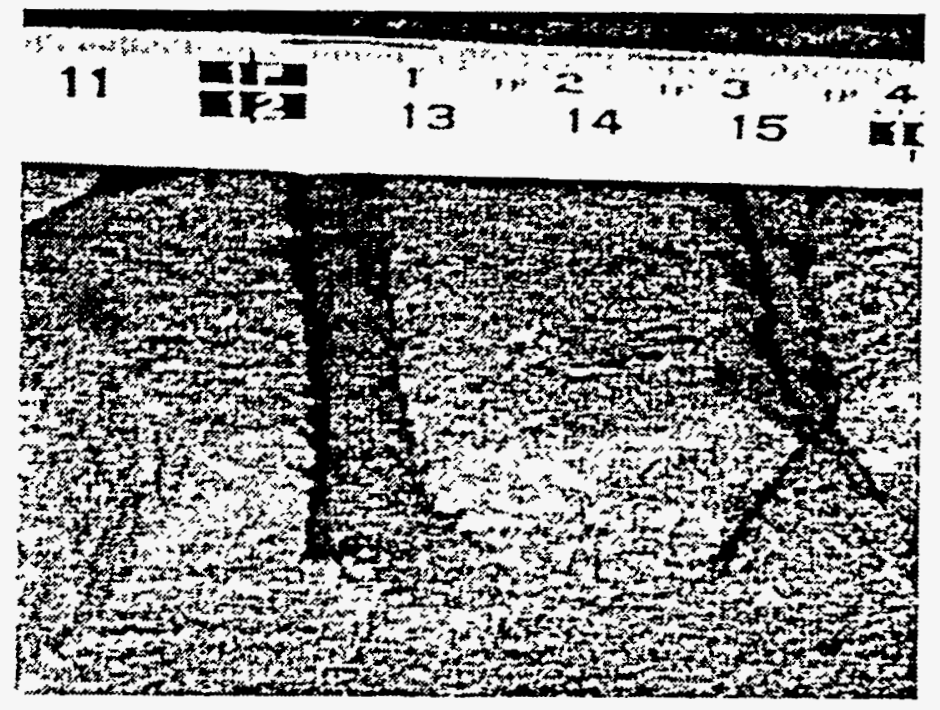

Figure 3.35 Sample showing rib retention.

These tests showed that it would be possible to remove fragments of the waste in pieces significantly larger than either conveyance system could comfortably handle, and thereby indicated that jet cutting of the waste was 
practical using coincident jets. Running the tests to determine the depth and spacing at which rib removal occurred was still expensive in time and material with this procedure; and a modification was made in which, when the test was carried out, one end of the sample was elevated two inches relative to the other. Thus the convergence point would become deeper and deeper into the sample and this would lead to a residual rib and failure of total excavation. It provided, in one test, the depth that this would occur for a given jet angle and spacing (Figure 3.36).

With the information which was obtained from this test series, however, it was possible to make some predictions on performance of a rotating converging jet assembly, and tests were accordingly designed to evaluate how such a system might operate. The test rig could be left the same, only adding a method for rotating the lance. The spacing of the jets could be adjusted, so that varying patterns. of width and, as a function of angle and speed, also of varying depth could be cut into the surface of the simulant.

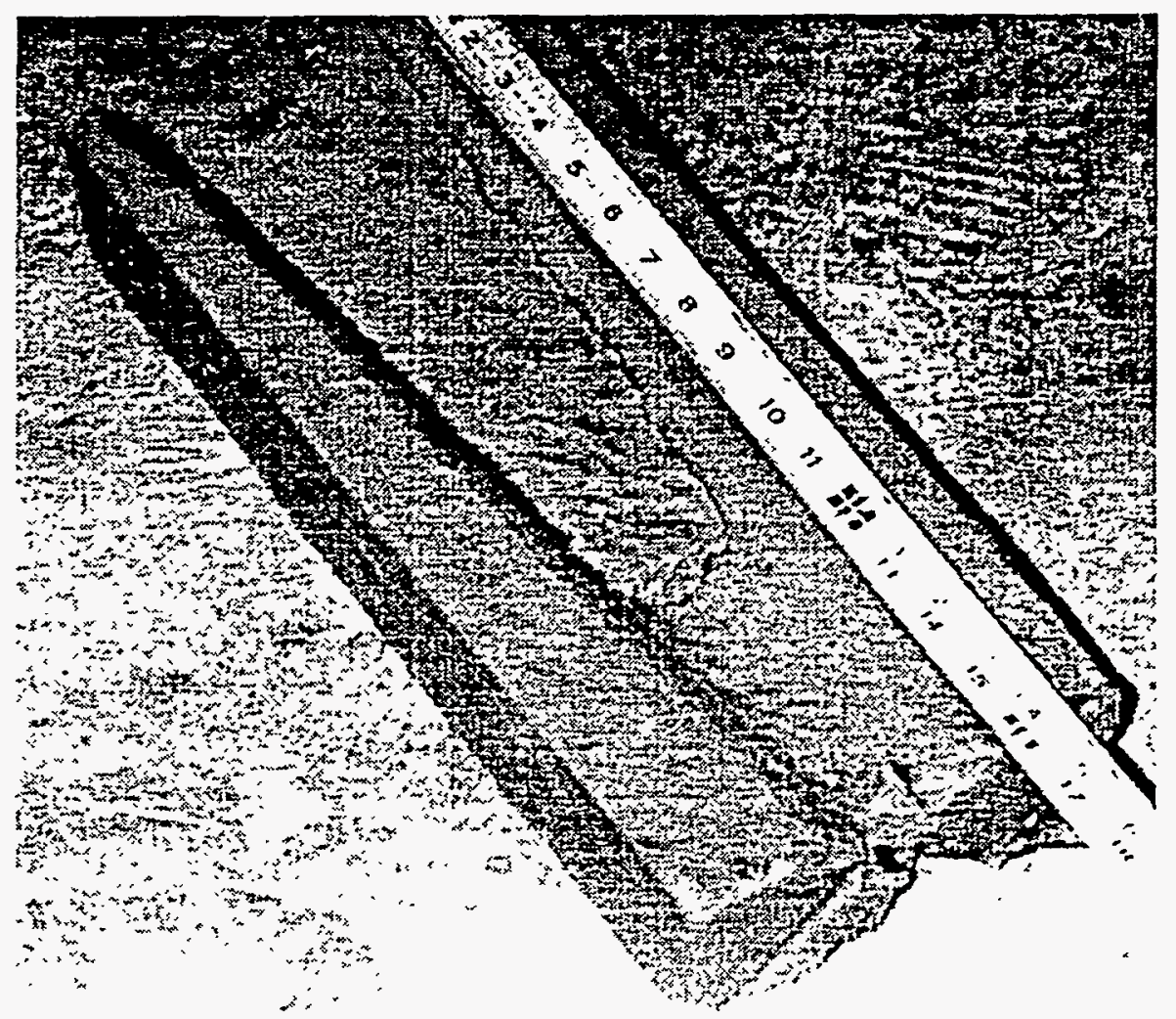

Figure 3.36 Result from a linear cut on a tilted sample, showing section removal. 
b) Rotary Cutting Tests

The pump available for testing with the rotating pair of jets was of limited capacity so that only two jets could be driven at one time. This was unfortunate since it limited the range of tests which could be carried out. For example, in most of the configurations planned the nozzle assembly was intended to cut on the edge of the module as it rotated (Figure 3.31). For a balanced assembly this would require two sets of jets; and when the tests were carried out using only a single pair of jets, the out-of-balance forces on the traveling rig made it very difficult to maintain the steady motion of the head over the surface required for most efficient rib removal.

Even so a sequence of tests were made showing that the material could be removed, both with large sweeping patterns (Figure 3.37 ) and with narrow patterns (Figure 3.38).

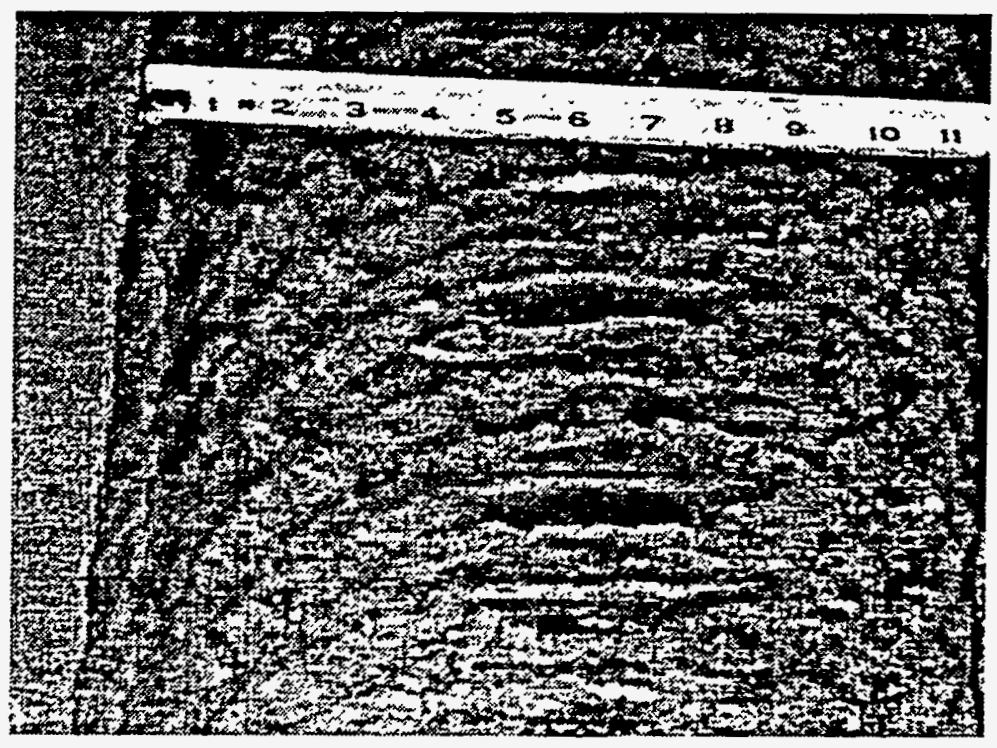

Figure 3.37 Wide pattern cut with the converging nozzle assembly.

The data obtained from this test series was instructive from a number of different points of view. The converging jets, when able to remove the intervening ribs (such as in the left cut of Figure 3.38) cut effectively and promised to give the volume removal rates anticipated (for this test, around $15 \mathrm{gpm}$ ). However, when the dimensions of the cut were changed to seek to attain this level, production could not be achieved where the rib thicknesses left within the cut exceeded 0.5 inches in thickness (for example, the center and right cuts in Figure 3.38). These ribs were 
removed in second and third passes over the surface where greater productivity levels could be obtained; however, the out-of-balance loading that this placed on the drive system made it almost impractical to achieve the steady feed required to maintain the necessary rib thickness to leave the surface relatively smooth for subsequent cuts.

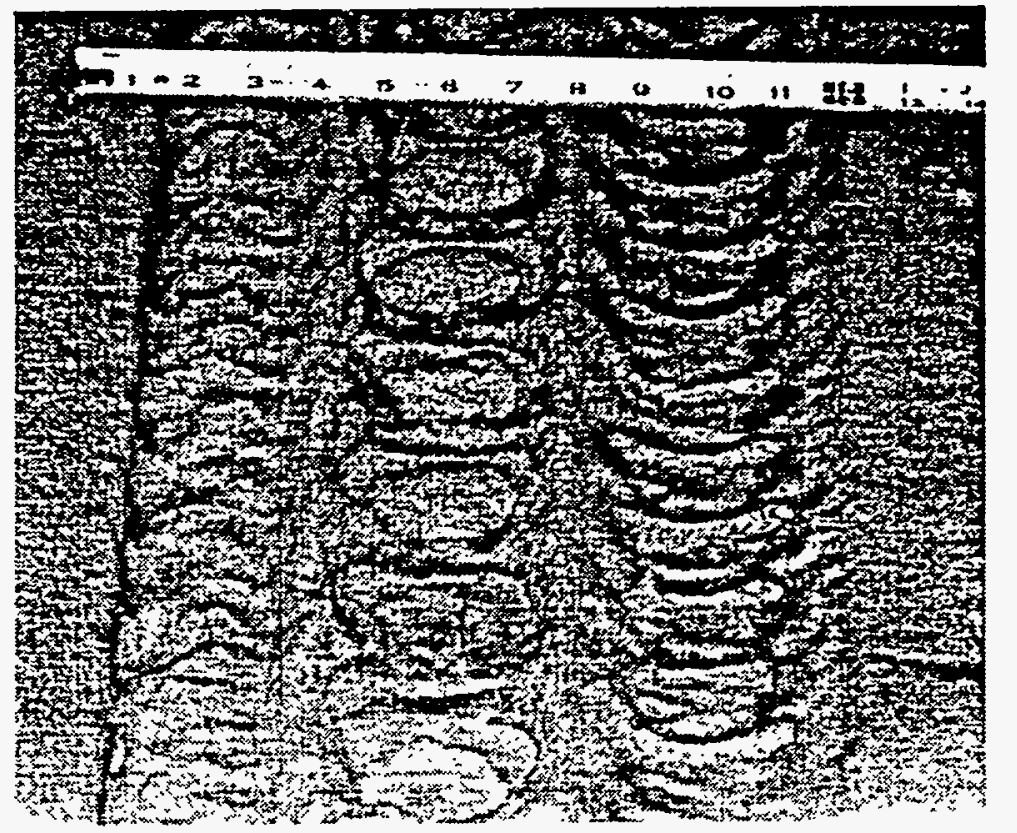

Figure 3.38 Three cuts made with varying feed creating different rib thicknesses.

This combination of circumstances suggested that the converging jet pair system, which was being evaluated, was too sensitive to standoff distance and to smooth motion of the feed arm for fully effective use in this program. Thus, design considerations were given to alternate methods. One which had been suggested was the use of fan jets, rather than rotating jets, to provide a wider cut without the problem of rib removal.

\section{c) Fan Jet Cutting Tests}

Although not a specific task for this research program, a factorial experiment was set up to investigate the use of fan jets for removing simulant, as a function of standoff distance from the nozzle and as a function of varying jet pressure, diameter and traverse velocity.

This data will, comprehensively, be published elsewhere, but it did indicate that fan jets would remove the simulant. In these tests cuts were made over blocks of material set at varying standoff distances from the nozzle and, from these tests, one could prognosticate the cutting ability of the nozzle in the configurations being considered. 
Given that the over-riding conclusion was that the jets produced were too sensitive to stand-off distance (Figure 3.40), the full set of data is not presented here, but may be accessed through the thesis of $\mathrm{Dr}$. Xu, who carried out the work.

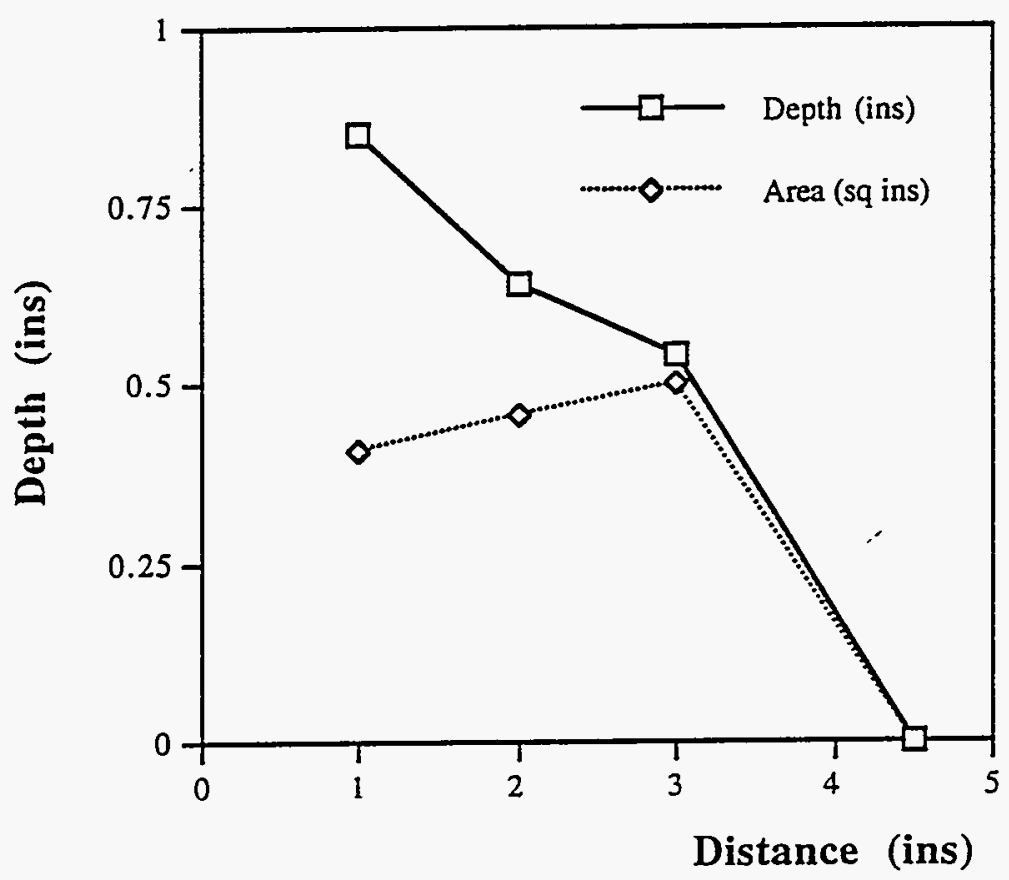

Figure 3.40 The Effect of Standoff Distance on the Performance of Fan Jets in Cutting Simulant. 


\section{Chapter 4. INVESTIGATIONS OF THE EFFECTS OF WATERJETS ON DAMAGED WALLS}

\section{Introduction}

A major concern with the use of high-pressure waterjets for the dislodging and conveyance of material from the underground storage tanks relates to the possibility of leakage through the tank walls. It is known that the wall condition is no longer as sound as it was at the time the facility was constructed. The condition of the wall was therefore considered to be either that of a thin wall, a distorted and damaged wall, or a cracked wall. This in turn, posed a series of questions on exactly how the waterjet cleaning system would be able to cope with these conditions.

In order to demonstrate the effect of waterjets in the 10,000 psi pressure range, three test series were developed. The first looked at removing saltcake simulant from a deformed metal surface. The second looked at the impact of a waterjet through saltcake on to a horizontal tank surface where the waterjets impacted perpendicular to the wall. Simulated open and covered cracks were built into these samples. The third test series examined the events when an inclined waterjet was traversed over an inclined sample, again with simulant covering metal used to simulate a cracked wall surface. Artificial cracks were driven through the simulant as part of the evaluation of the third test condition.

\section{Distorted Metal Tests}

The major question to be answered in this phase of the program was whether the waterjet would cut into the deformed metal or leak through into the surrounding strata. Another issue is whether the waterjets can effectively clear corroded surfaces. To evaluate the likelihood of this, the bottom end of a 55-gallon drum was severely and violently deformed. This end section was then sealed into a wooden frame which was mounted on top of the holding tank where the cutting tests would take place (Figure 4.1).

The sample was not placed on top of the tank until the upper metal surface had undergone significant corrosion. The tank section was then filled with a layer of simulant which was allowed to dry for the normal period. A small cutting module was then mounted over the test sample (Figure 4.2) and rotated over the surface. The intention in the test was to observe if any water leaked through the test sample, since this would be captured in the underlying tank. 


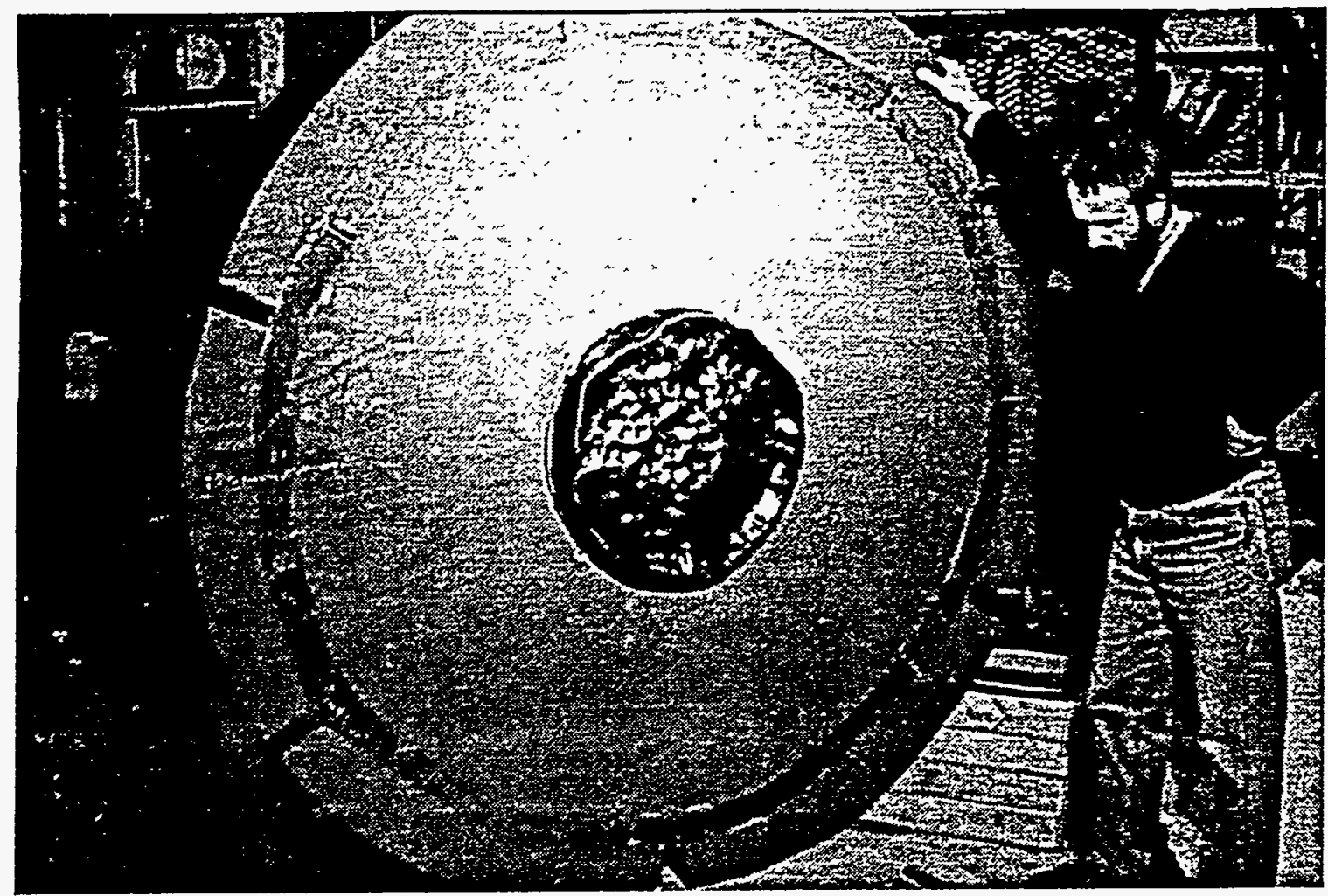

Figure 4.1 Under view of the deformed metal surface.

During the tests the lance made a single rotation around the tank and this was effective in removing the simulant from the tank since there was a relatively poor bond at the saltcake:wall interface.

In none of the tests did any water leak through the simulated tank wall into the underlying tank. Under normal testing conditions, the surface layer of simulant was removed and some of the underlying rust corrosion (Figure 4.3). In one case, the nozzle was not rotated during the test. At this lower lateral traverse speed, the jet cut twin paths across the metal. While this was sufficient to remove the simulant (Figure 4.4), the jets also were able to cut down through the corrosion on the metal surface and leave a white metal finish.

The ability of the waterjet at 10,000 psi to clean the metal down to a white metal finish indicates that it will be possible to clean virtually all the surface metal corrosion from the walls of the tank. This may significantly improve the final cleaning level achieved in the removal of undesirable products from the tank during the cleaning process. Given that the major result sought in this test series was to determine whether or not waterjets would damage and leak through distorted metal, the results indicate that they will not (Figure 4.5). 


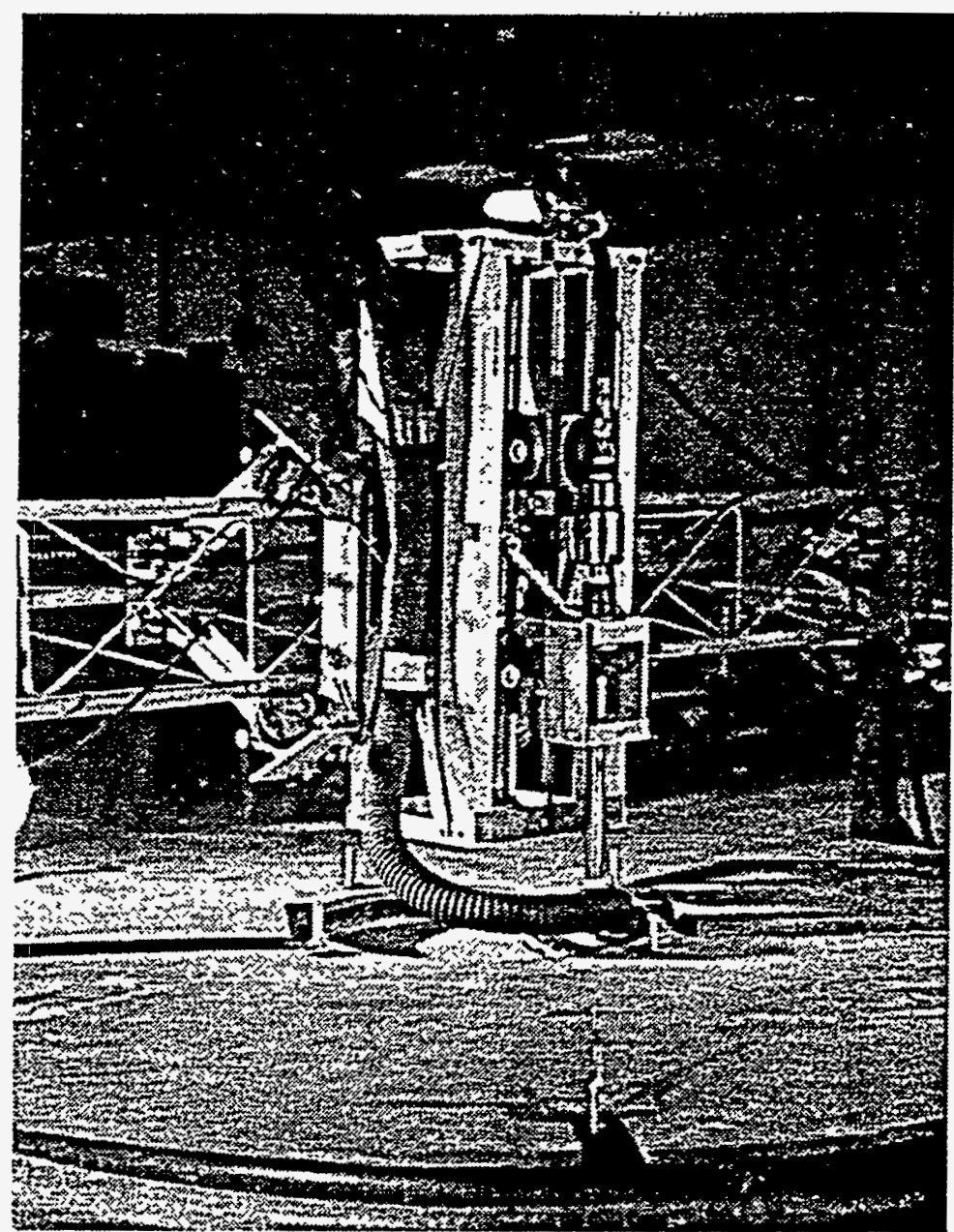

Figure 4.2 Experimental test set up showing the cutting head in place.

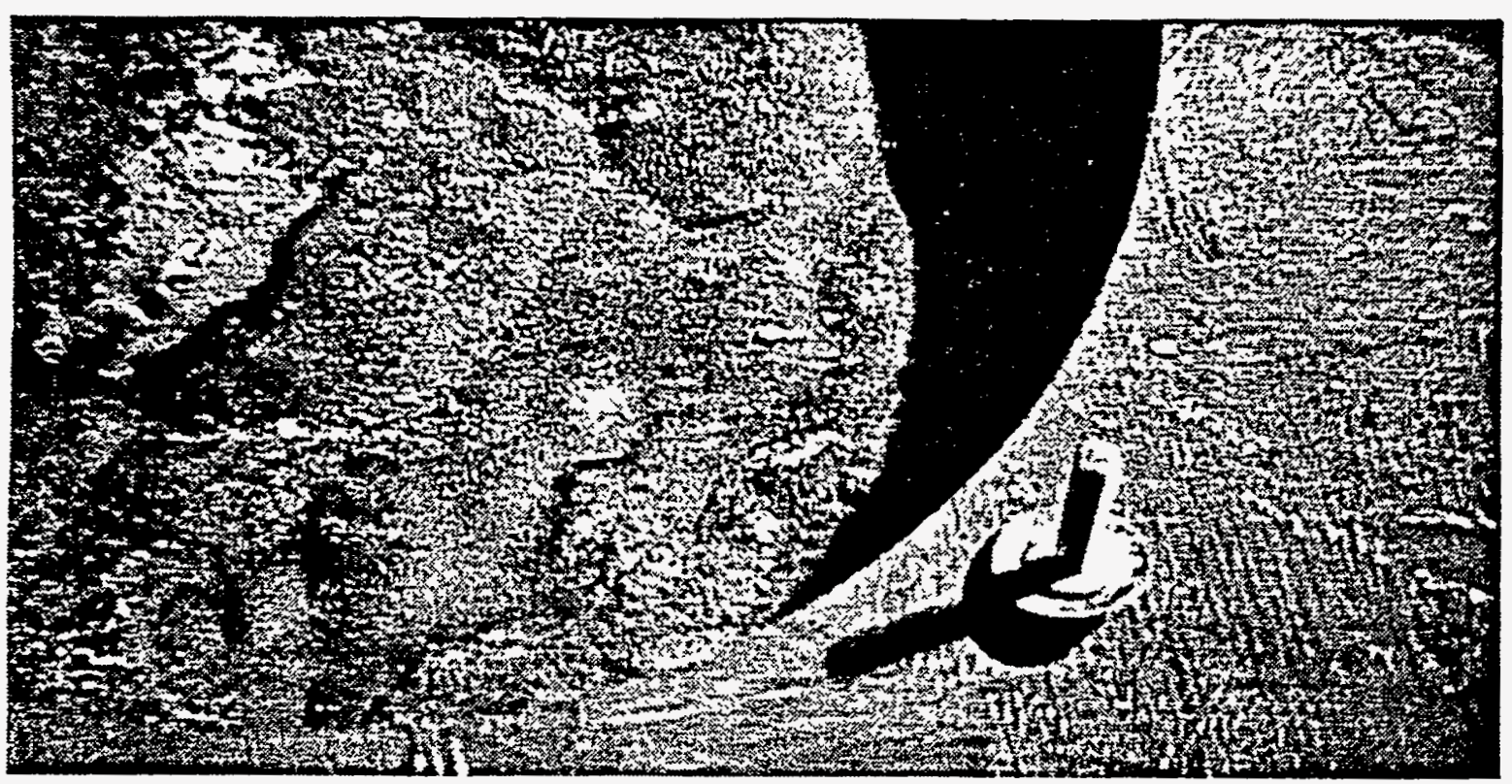

Figure 4.3 - Metal surface after simulant removal. 


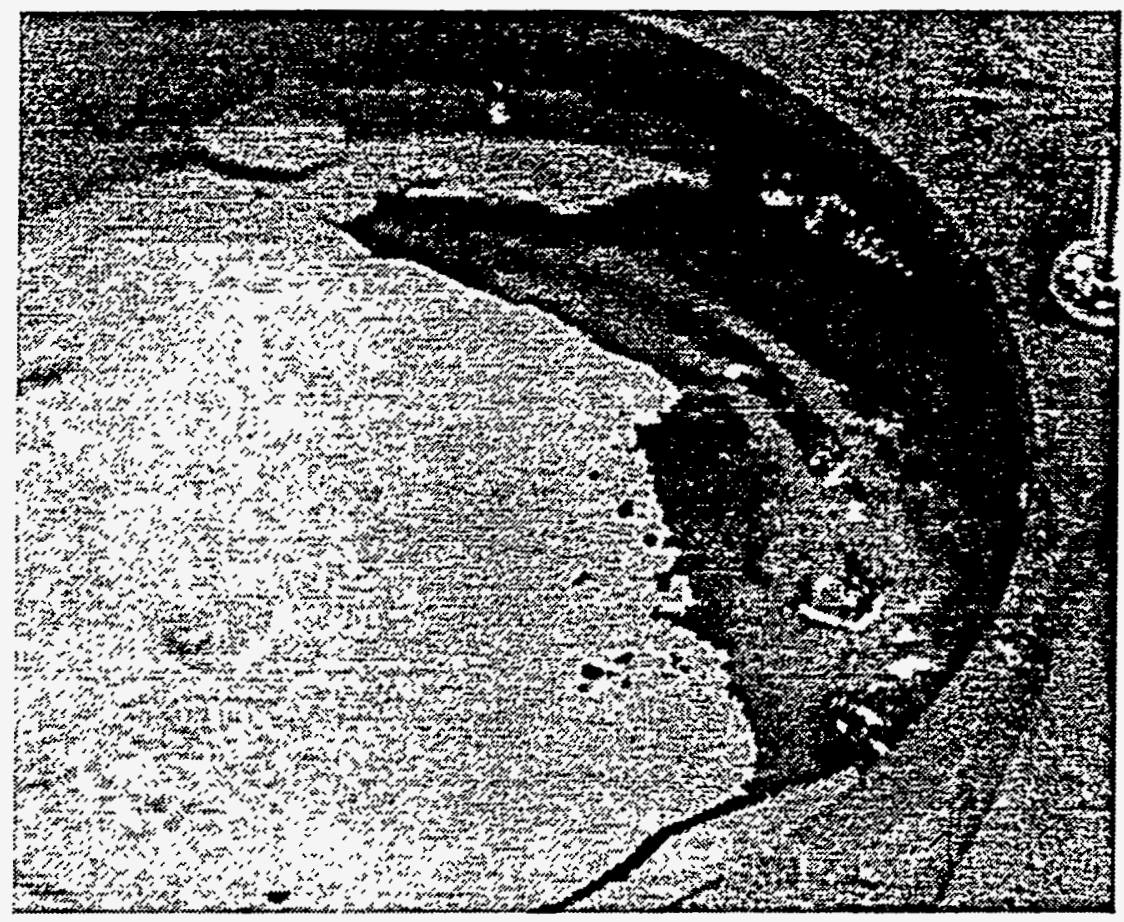

Figure 4.4 Sample without jet rotation.

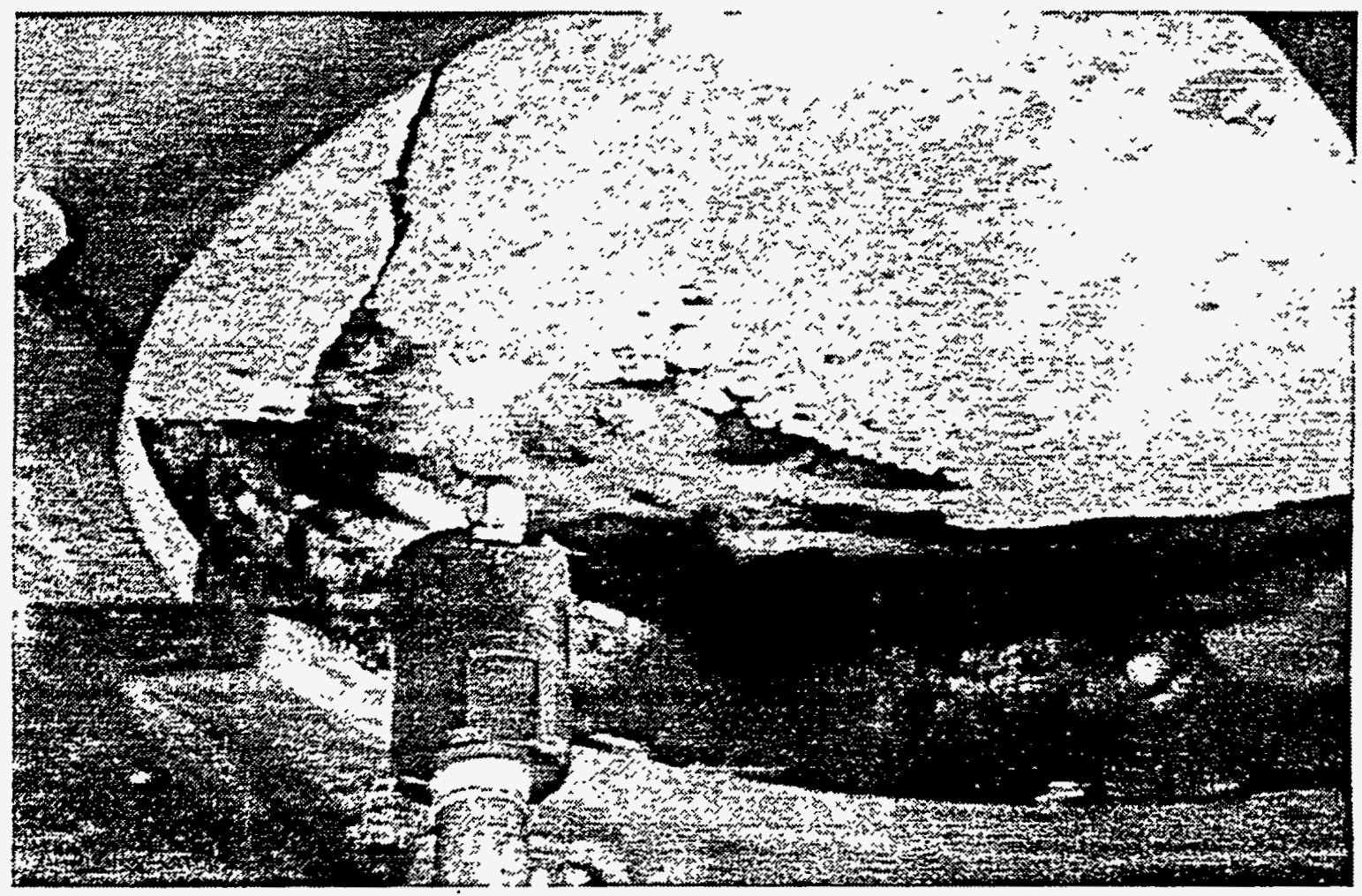

Figure 4.5 Detail of sample surface showing white metal cleaning. 


\section{Horizontal Testing}

The above tests indicated that the waterjets would not penetrate through metal at the impact pressures proposed. The next question to be addressed was whether the jets would significantly penetrate metal containing cracks. In order to assess this, special samples were made up. The sample test blocks began by casting polystyrene foam into a layer of the simulated saltcake (Figure 4.6). After this had been leveled in place, twin metal plates were set side by side on top of the sample surface with a narrow gap between the plates to simulate the presence of a crack. The sample was then filled to the top of the frame with additional simulant which was tamped in place and allowed to dry. Three initial samples were made in this configuration.

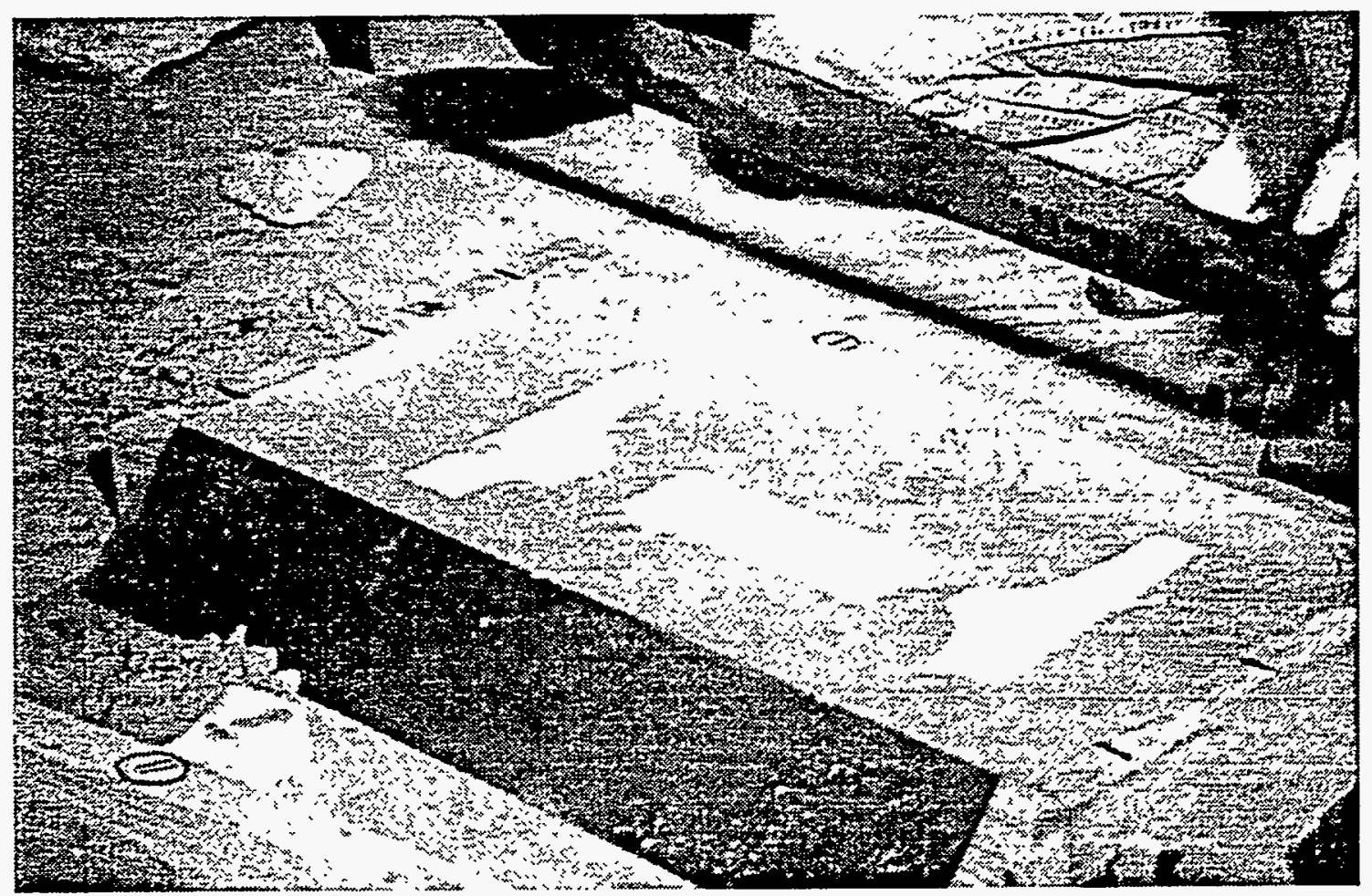

Figure 4.6 Polystyrene supports in the test samples.

Prior to the test the polystyrene foam was removed from beneath the metal plates and the samples were placed on the metal support frame which had previously been used in the last series of tests. A new cutting head and shroud were constructed for this test series with the inlet to the jet pump mounted behind the cutting head section. The jets were concentrated in a relatively narrow path in order to intensify the cutting action and exacerbate any problems which the waterjet impact might cause. (Figure 4.7). 


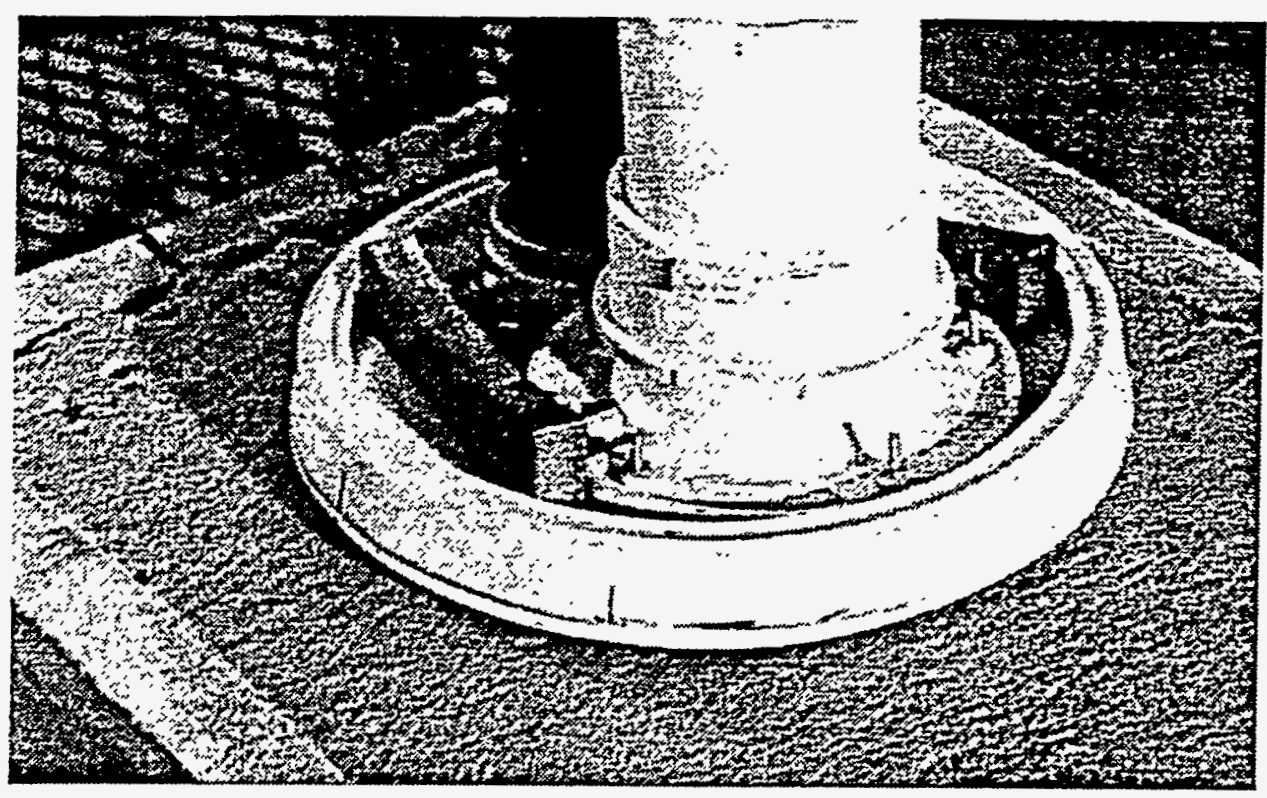

Figure 4.7 Detail showing the cutting head used in this series.

The cutting head was traversed over the sample surface, cutting down through the simulant to the underlying metal. From the start of this test program, small amounts of water were observed issuing from the edges of the sample frame box (Figure 4.8).

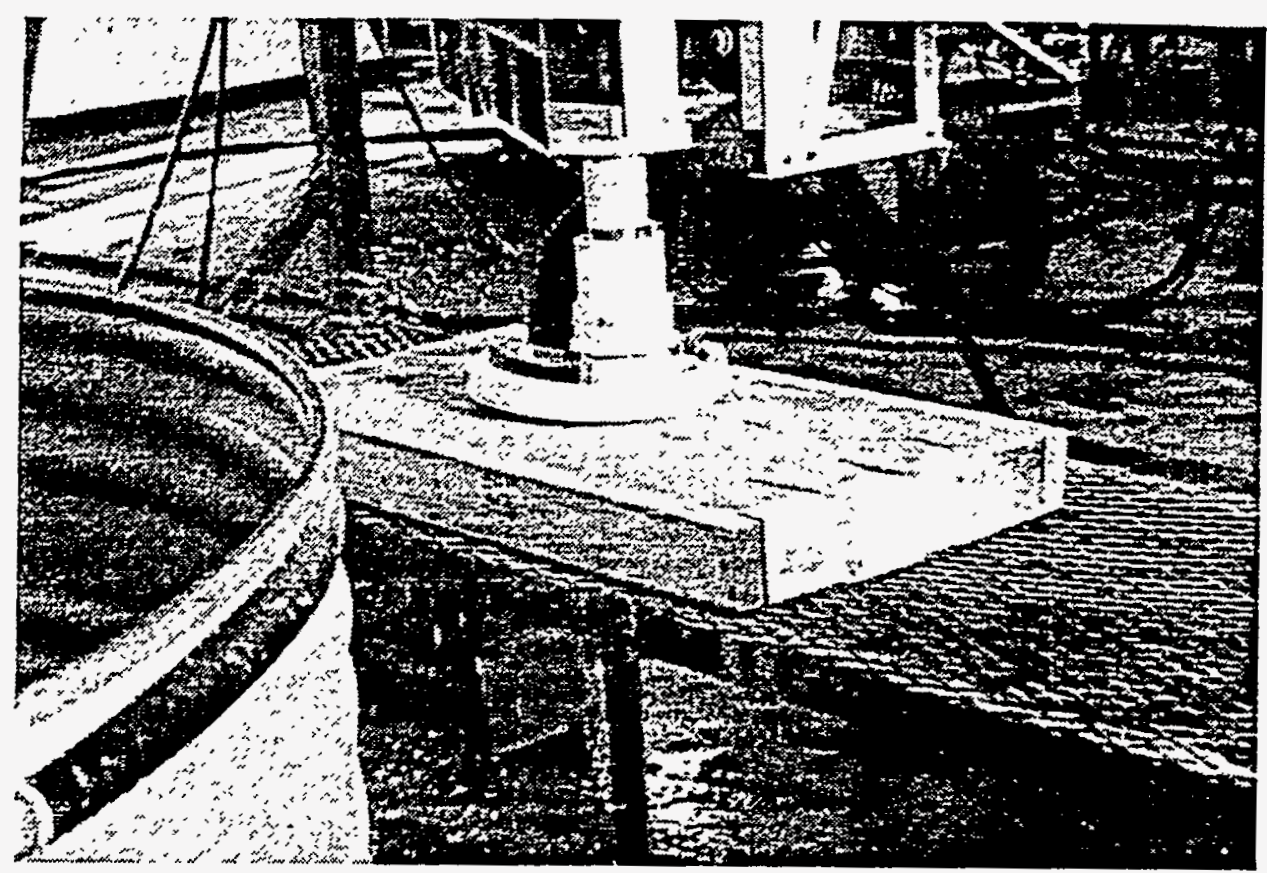

Figure 4.8 Water escaping at the edge of the frame.

Cuts were initially made approximately 2 inches from the crack in the metal, yet observation from underneath the tank indicated that there was 
already some small amount of leakage. The second pass was made across the joint intersection, and there was considerable water flow through the sample. At the same time, a significant amount of water rebounded behind the cutting module from the rebound of the jet on the underlying metal plate (Figure 4.9).

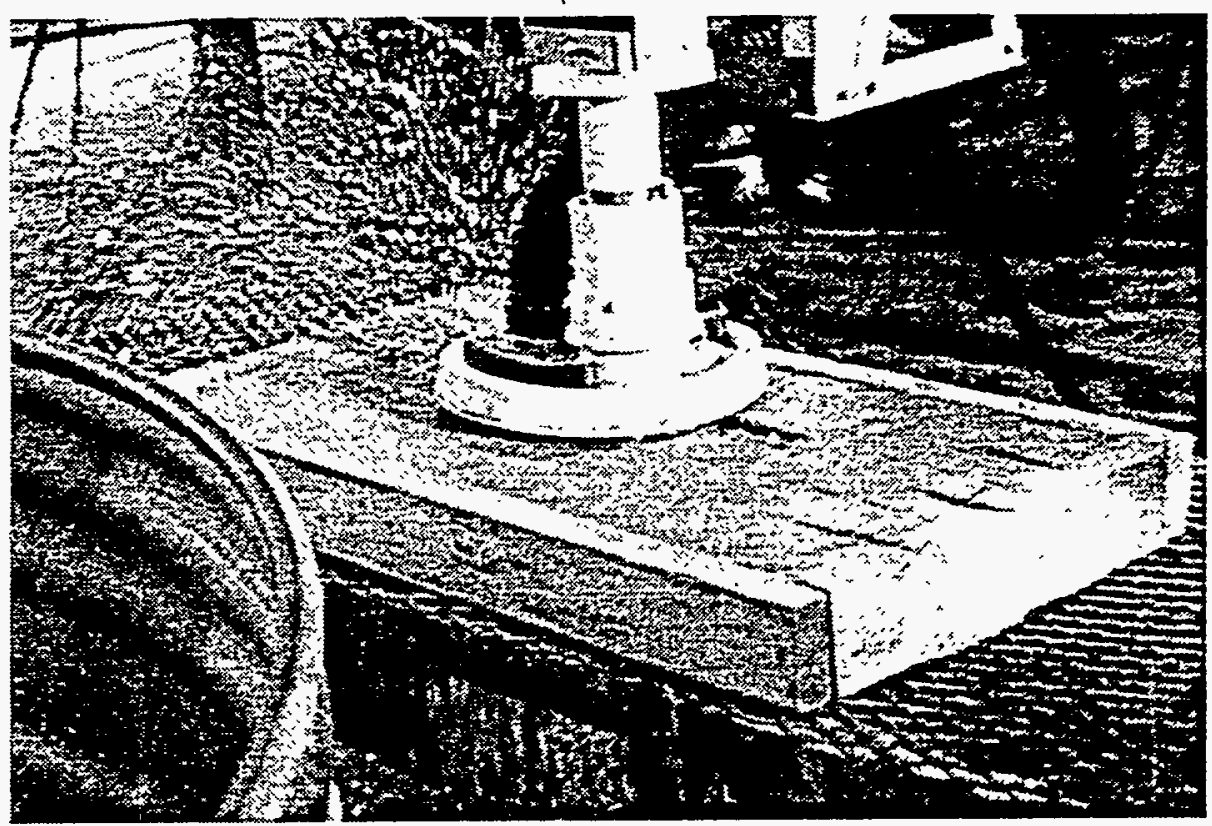

Figure 4.9 Sample showing water flowing underneath the sample, as well as the rebounding water from the metal plates.

Continued observation through a series of tests and with various attempts to confine the jet spray to the cutting zone led to the conclusion that as soon as the jets hit the metal which lay perpendicular to the jet path, the water would flow laterally along that surface either to the crack or to the sample boundary. While this was effective in cleaning the metal surface (Figure 4.10), it also suggested that directing the waterjet perpendicular to the metal surface to be cleaned would also increase the amount of leakage through any adjacent cracks. 


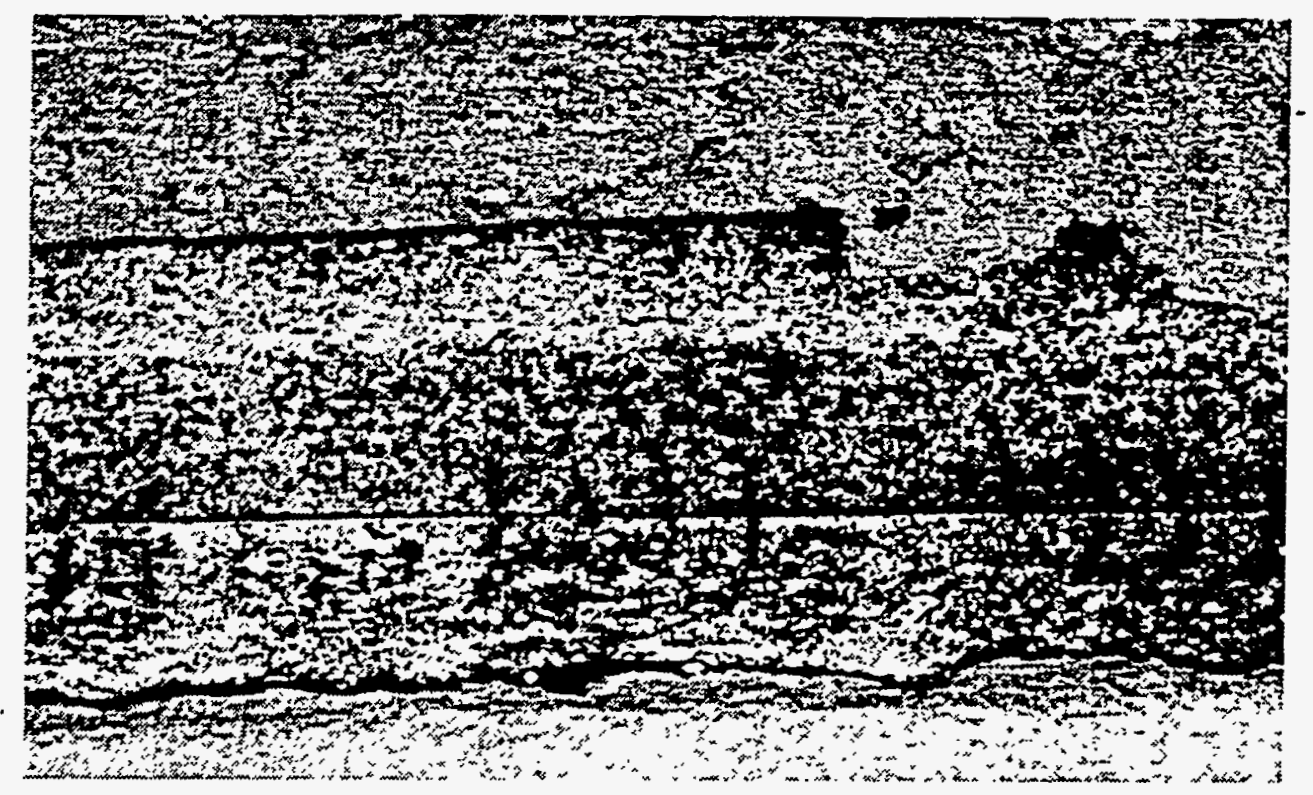

Figure 4.10 Metal cleaned on the edge of an artificial crack.

To study this phenomena a little more closely, a new sample configuration was assembled in which the artificial cracks ran laterally across the sample rather than along its length (Figure 4.11). In this way, the range of the rebounding jet from each metal plate could be restricted. To observe the amount of water coming through the crack, and the time that the flow occurred, an angled mirror was placed beneath the supporting platform (Figure 4.12). A television camera was directed at the mirror so that it viewed the underlying crack surface during each test. Thus, videotapes were taken both of the surface impact of the jet and of the leaking condition beneath the plates.

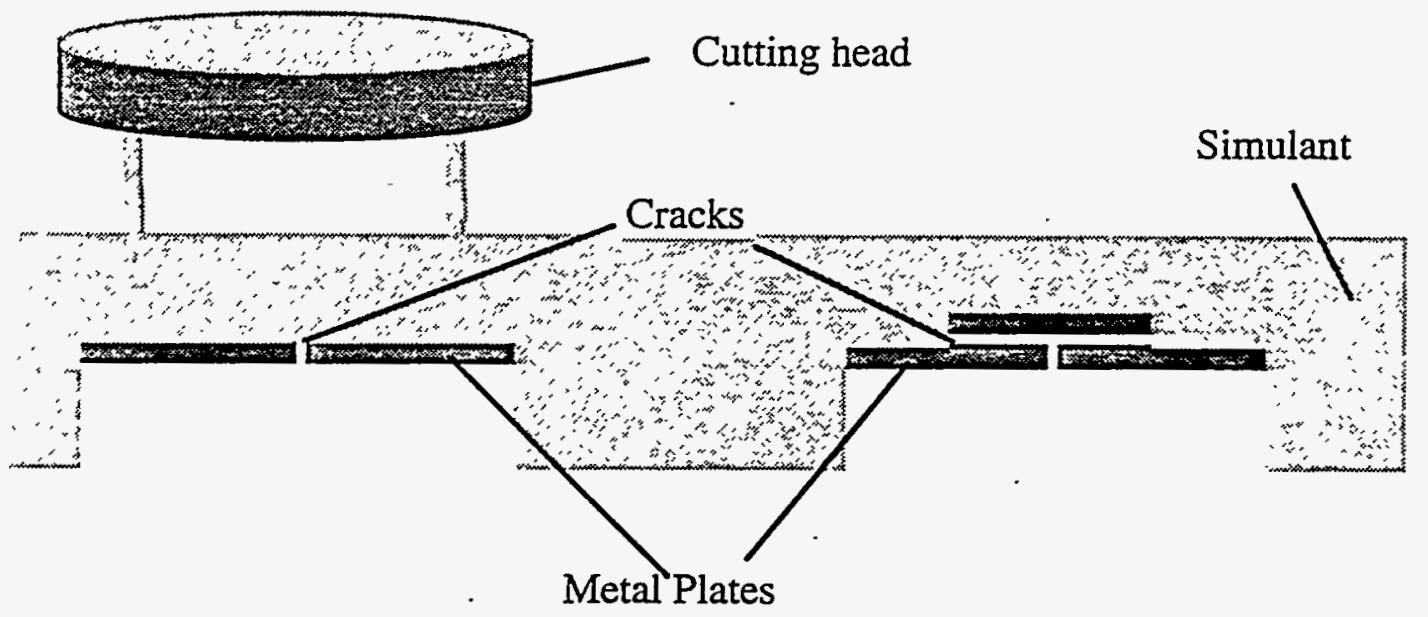

Figure 4.11 Schematic showing the test layout and the artificial cracks. 


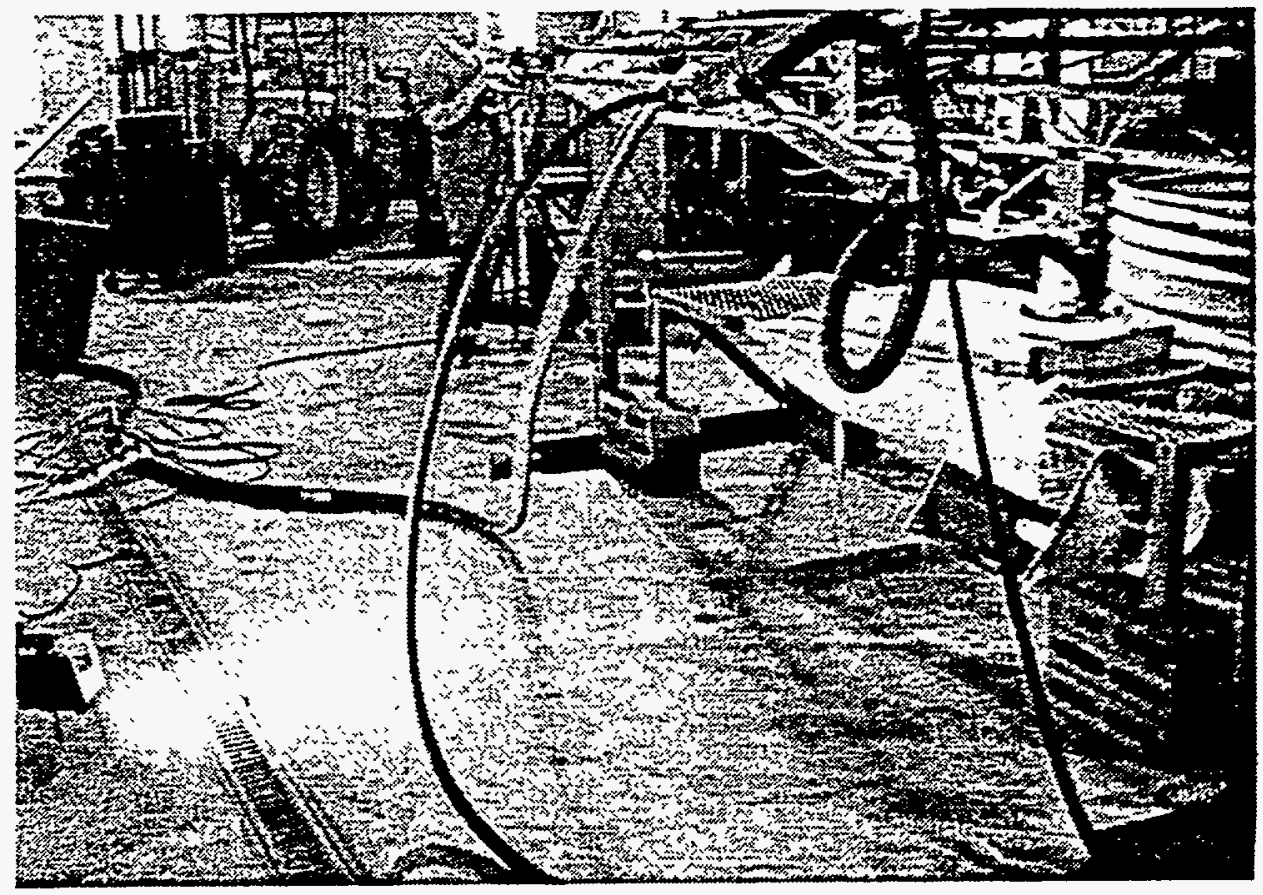

Figure 4.12 Location of the mirror under the test table.

The results from these tests confirmed the conclusions from those carried out earlier. Almost immediately the waterjet penetrated to the metal surface. Lateral fluid flow occurred across the metal with the water being able to escape through any easy path. For example, (Figure 4.13), where an earlier cut path existed the jet would flow over and escape from it. At the same time the water flowed from underneath the sample at a steady rate whenever the jet impacted on the metal surface.

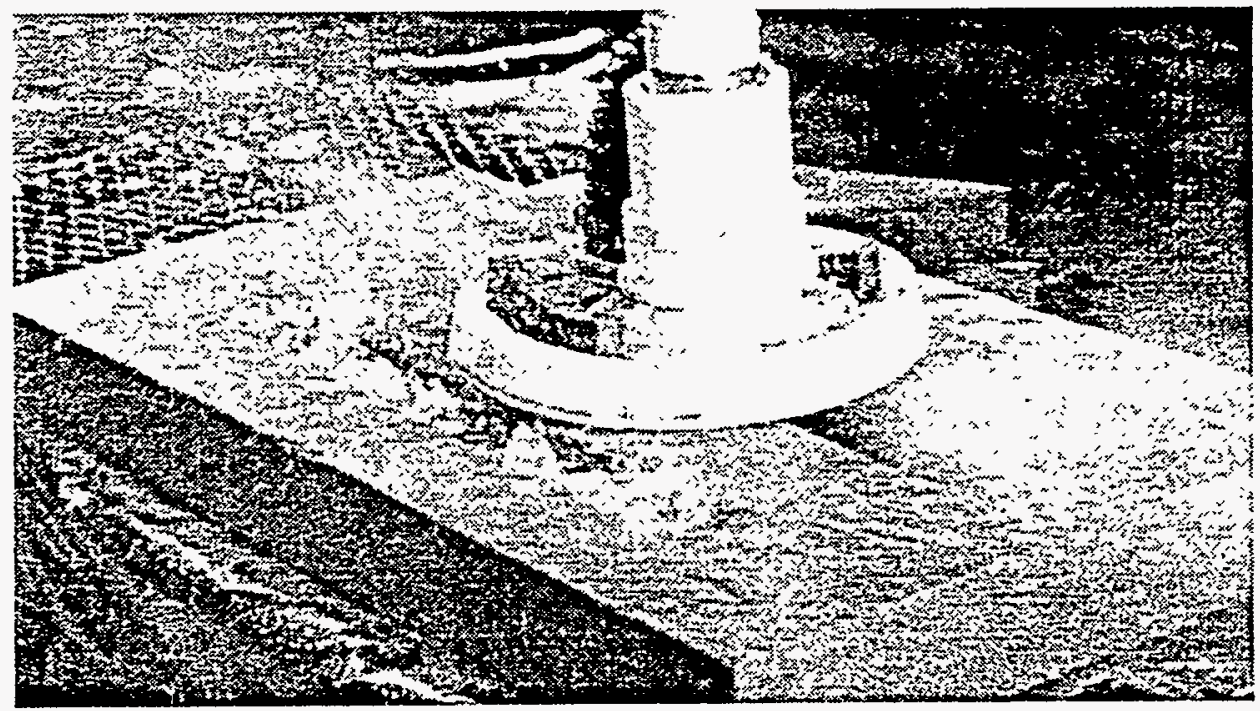

Figure 4.13 Water flow from cuts adjacent to the jet path. 
This finding was consistent over a significant number of tests. It was therefore concluded that the perpendicular impact of a waterjet system on a metal surface, while very effective for cleaning, would also run the risk of allowing significant fluid flow through any adjacent cracks. As in the earlier tests, however, the jets were able to clean the corrosion from the metal. An alternative approach was therefore judged necessary to find a way to clean the metal surface without allowing significant leakage.

\section{Inclined Jet Testing}

A significant part of the problem in perpendicular cutting was the lateral flow of water over the metal surface after impact. It was considered that this could be reduced if the jet were inclined at an angle to the metal surface. Accordingly, a new test series was developed in which the sample was set at an angle on the supporting platform and an angled pair of waterjets traversed across the surface (Figure 4.14).

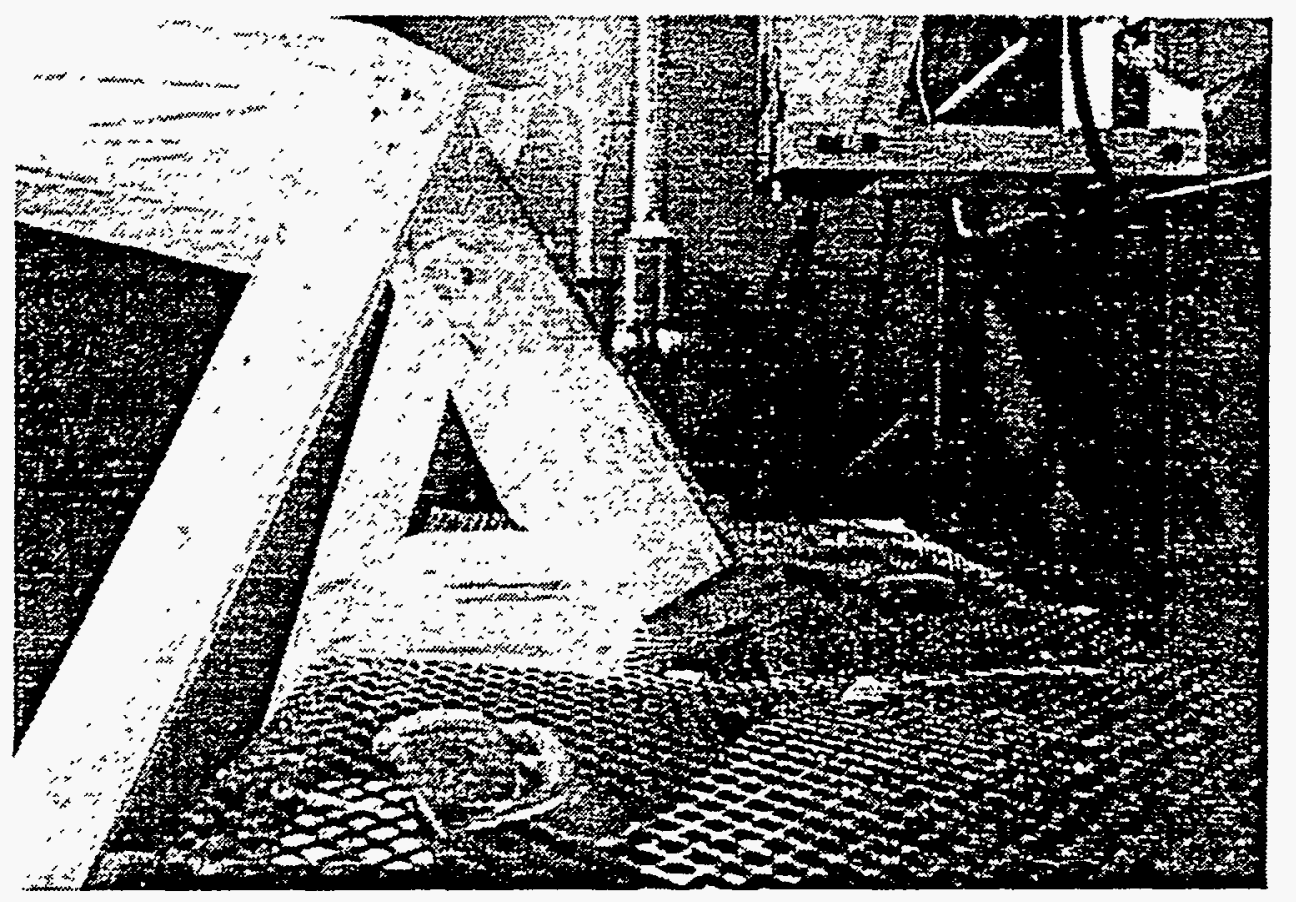

Figure 4.14 Test arrangement for the angled jet setup (jet angle $30^{\circ}$ to surface).

As before, the cracks were assembled to simulate both covered and straight crack penetrations through the metal. However, with the inclined sample it was possible to observe the crack condition without the aid of a mirror throughout the test (Figure 4.15). 


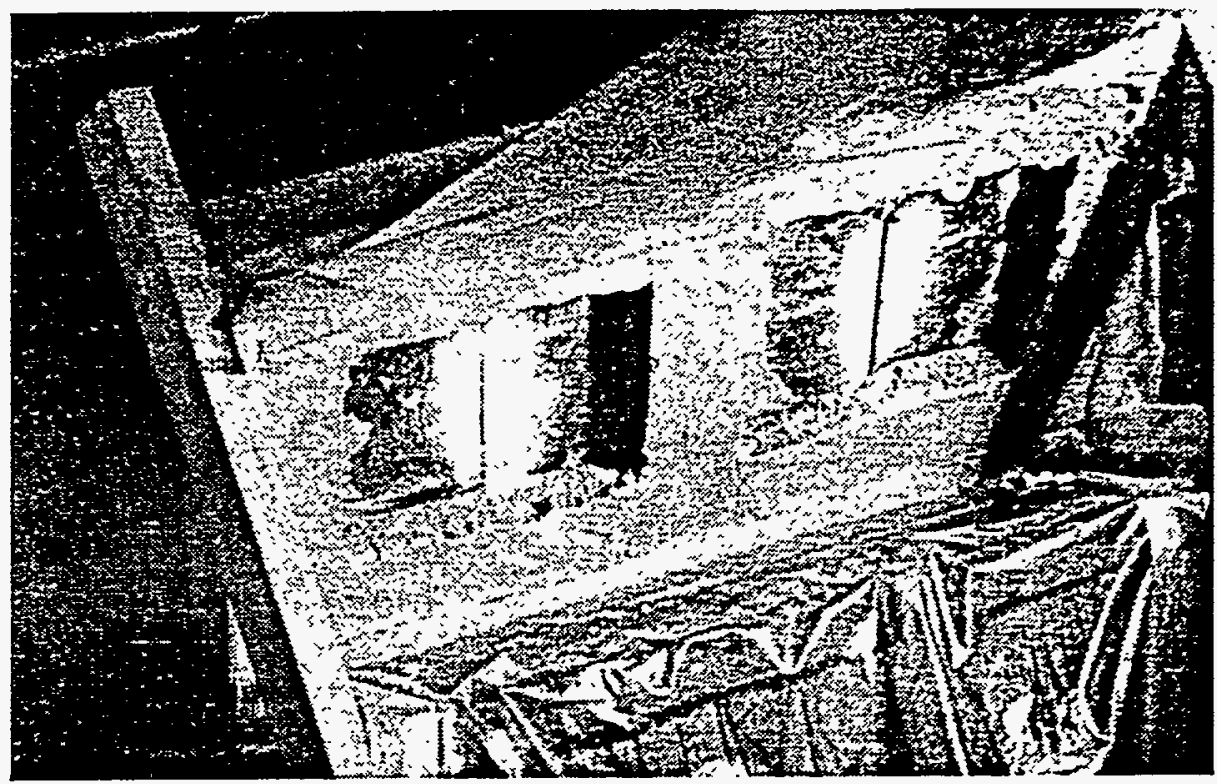

Figure 4.15 View from the rear side of an inclined sample during a test.

Again the sample was monitored through the use of television cameras during the test; however, in contrast to the earlier results, significantly less water came through the cracks and then only where the jet was directly impinging into the crack gap.

In order to determine whether the presence of cracks in the material would have any effect, several samples were prepared in which artificial cracks were driven down through the simulant to the metal surface (Figure 4.16). During the test run this did not seem to significantly influence the result.

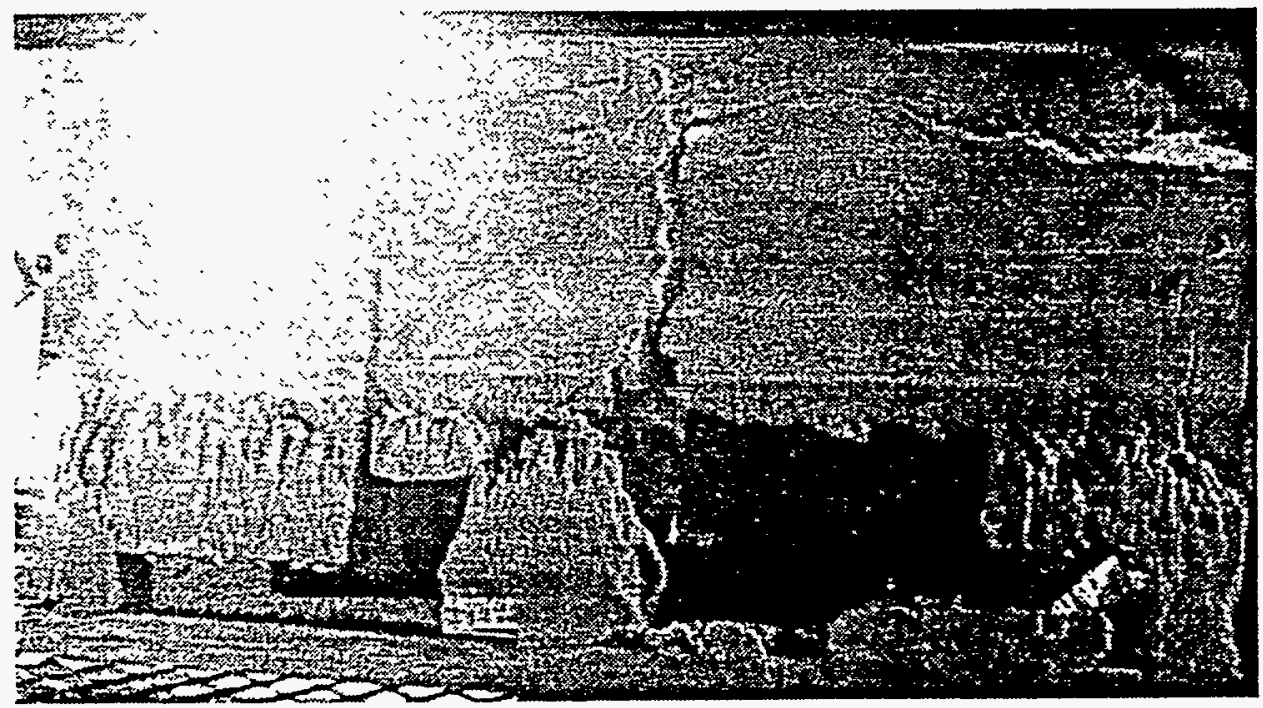

Figure 4.16 Inclined sample after cut showing the location of two "artificial" cracks through the simulant to the metal surface. 


\section{Recommendations and Conclusion}

From these tests it appears that waterjets at a pressure of 10,000 psi are able to clean the metal surfaces of the type likely to be encountered in the underground storage tanks. They will not create new passageways through the metal where those do not previously exist and the jets will be able to clean the surface down to a white metal finish under certain conditions.

The jet cleaning head should, however, be oriented so that the jets do not strike the surface perpendicular to the metal. Such an impact causes a lateral splash along the metal surface which may be deflected into any nearby crack causing leakage. As an alternative approach, where the cleaning jets are directed at an angle to the metal surface, the jets appeared able to penetrate into a crack only when the jet was physically impacting on the crack exposure and not otherwise. 


\section{Chapter 5. DEVELOPMENT OF A FLEXIBLE MOUNT FOR THE CUTTING HEAD}

\section{Introduction}

It was recognized, at the beginning of this effort, that the performance of the cutting head would, to a very great degree, depend on the movement of the controlling robotic arm. Thus, during the time that the program was in effect, a continuing effort was maintained to develop a flexible support for the cutting head, which would allow the levels of maneuverability which would evolve as necessary for the most effective use of the cutting head.

In earlier discussion of the cutting head test results, certain changes in the design requirements were identified. For example, it was originally envisioned that the head would traverse across the surface in a horizontal mode with a set of outward inclined jets cutting the underlying waste free so that it could be aspirated into the conveyance line attached to the module. Such a jet configuration was found to give unreliable levels of waste removal, in part due to the limits on accuracy available with the size of arm required for the task. At the same time it did not allow the most effective capture of the resulting debris, given that much of it could be cast outside the edge of the head.

The design that evolved, therefore, was one in which the jets would be inclined either directly perpendicular to the head motion or, if any inclination were to be used it would be to have the jets inclined slightly inwards so that the debris would be cast into the mouth of the conveyance line.

However, in cleaning around the edges of the tank the access of the jets to the side wall requires that the jets reach out beyond the vertical edge of the sides of the shroud. With jets directed perpendicular to the shroud plane this requires that the shroud itself must be able to tilt back to incline the jets and, in turn, give them access to the material along the walls of the tank and the edges of any "wastebergs" in the material.

These requirements mandated that the holding support mounting for the cutting head should be able to provide directional control for the head in the vertical, horizontal and intermediate planes (Figure 5.1). For the purpose of the design, the underlying cutting head was modeled by the central high-pressure tube feeding water to that head (and hereafter referred to as the "lance"). In the full construction the lance will feed to a central swivel which will allow head rotation and beyond which the flow 
will be divided to the different assemblies within the head. It will then be further subdivided before reaching the cutting nozzles on the ends of the assembled unit.

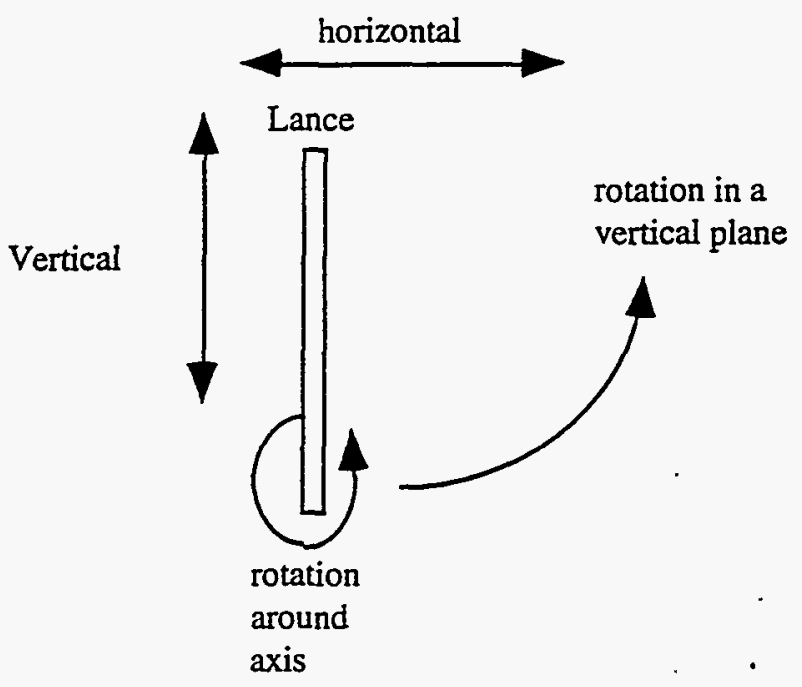

Figure 5.1 Movements Required for the Lance.

\section{Support Design}

Because of the major requirement for accurate positioning in the vertical and horizontal directions, linear bearings were used for the vertical motion component. The environment for the mounting was not benign; early constructions suffered significant corrosion from the chemical and abrasive wear induced from the debris rebounding from the cutting surface. Component parts were therefore chosen to be resistant to this wear.

The vertical drive was assembled so that the mount could move over stainless steel rods with ceramic bearing purchases. In order to protect the sliding surfaces from any debris the mounting blocks were built into protective enclosures (Figure 5.2). In operation the rods would be further protected by collapsible bellow-structured guard tubes. Movement along the rods is driven through a central threaded shaft from an end-mounted motor. 


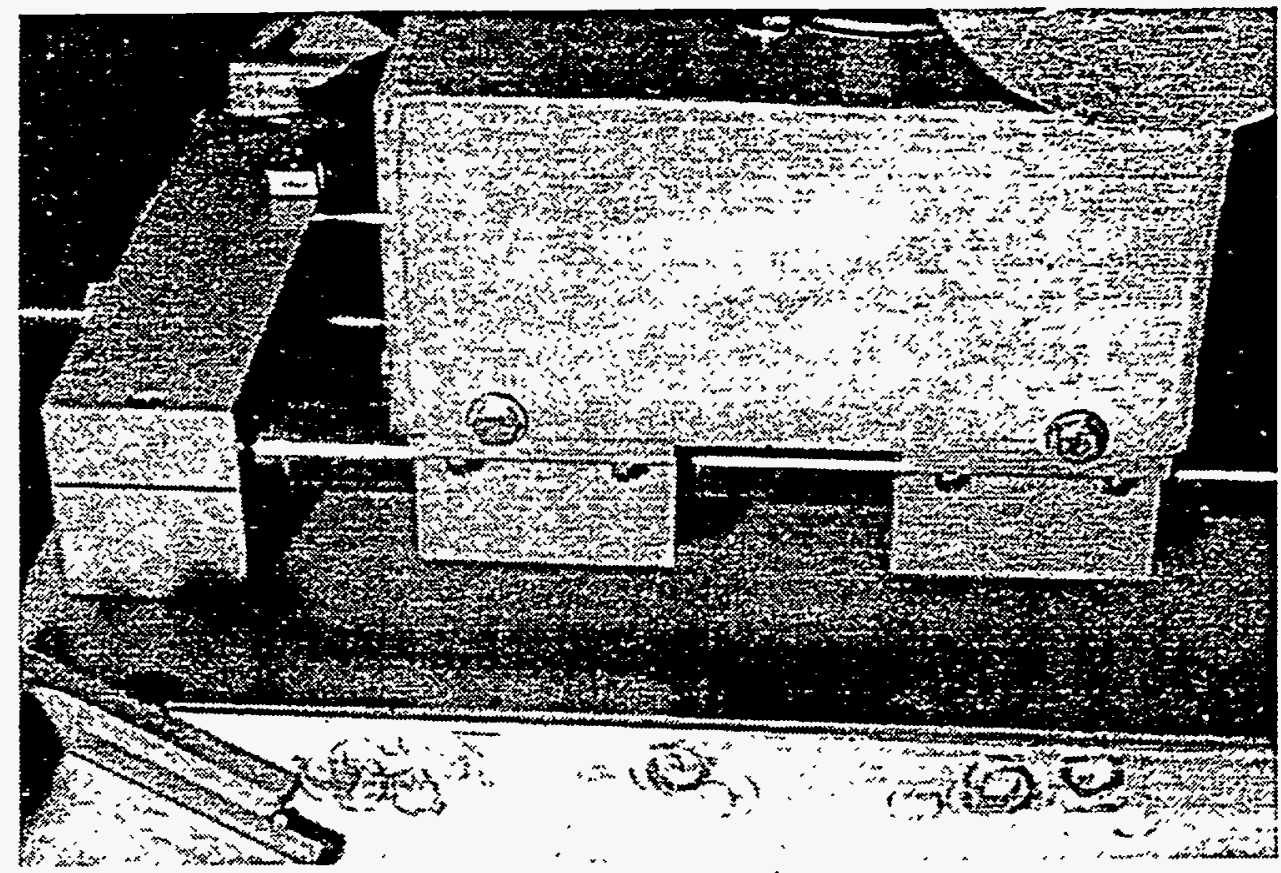

Figure 5.2 Vertical Motion Assembly showing the Guide Rods and Bearing Housing.

In order to reduce the weight of the components, emphasis was placed on smaller and, thus, lighter drive components. At the same time the lance should be positively locked in any inclination to ensure that the angles would be retained during a traverse with the variable loading that this might impose on the supporting assembly. To give this flexibility and concurrent rigidity, a worm gear was used to drive the arc rotation around the bearing pivot. Power to drive the rotation was through a small DC motor with controls (as for the other drives) being provided through the LABVIEW program and with control being maintained from the central workstation.

The final degree of freedom required for the head was for rotation of the lance around its axis. In early models of the assembly, a $1 \mathrm{hp}$ electric motor was used for this drive. This unit was, however, relatively large and weighed over 60 pounds. In other instances hydraulic motors have been used and can be made quite small; however, these require a dual line for the fluid power transmission and the weight for a motor of the required power would be around 25 pounds. By changing to a pneumatic drive, there need be only one feed for the pressurized air and a lighter motor could also be used (Figure 5.3). 


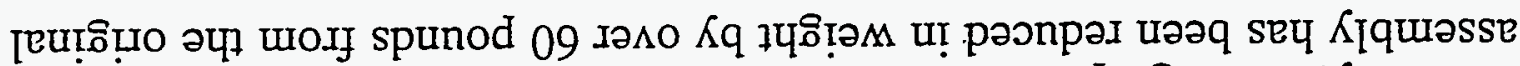

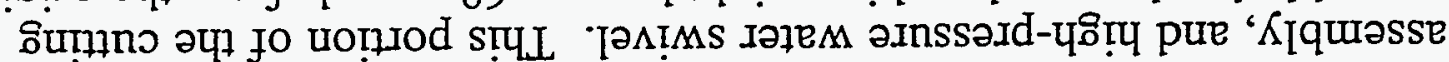

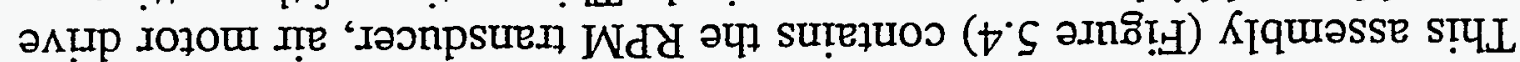

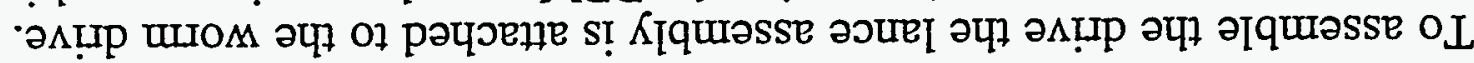

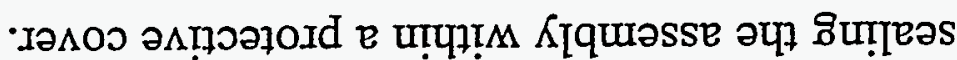

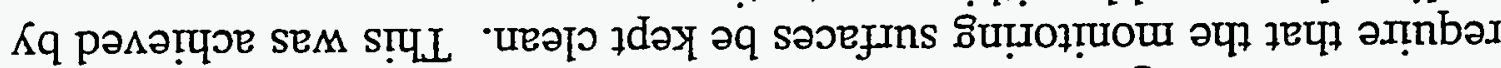

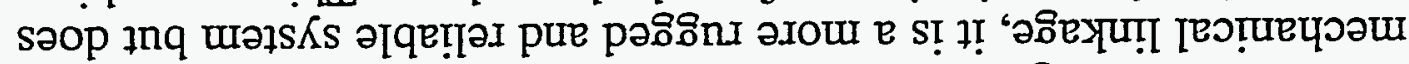

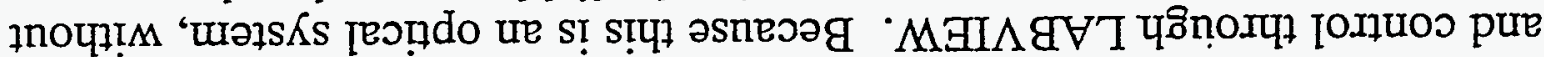

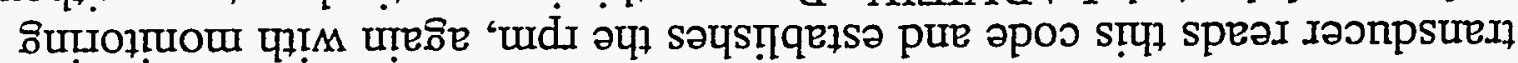

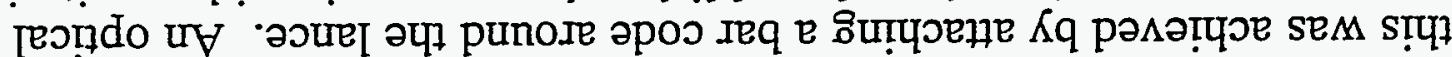

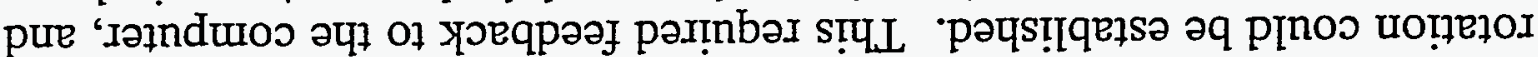

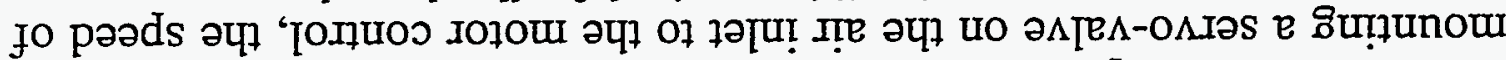

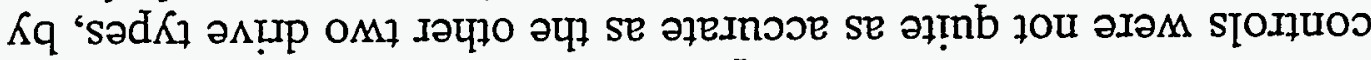

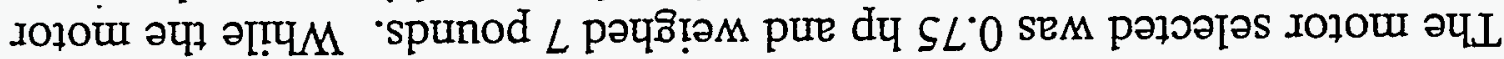

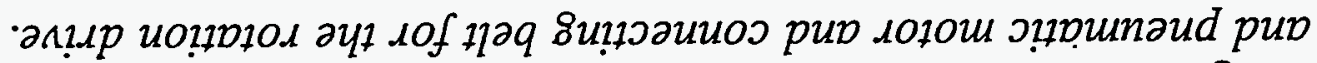

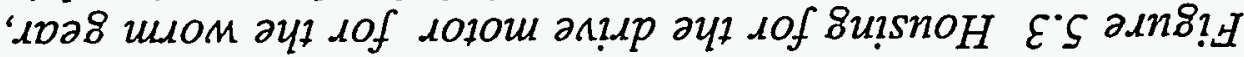

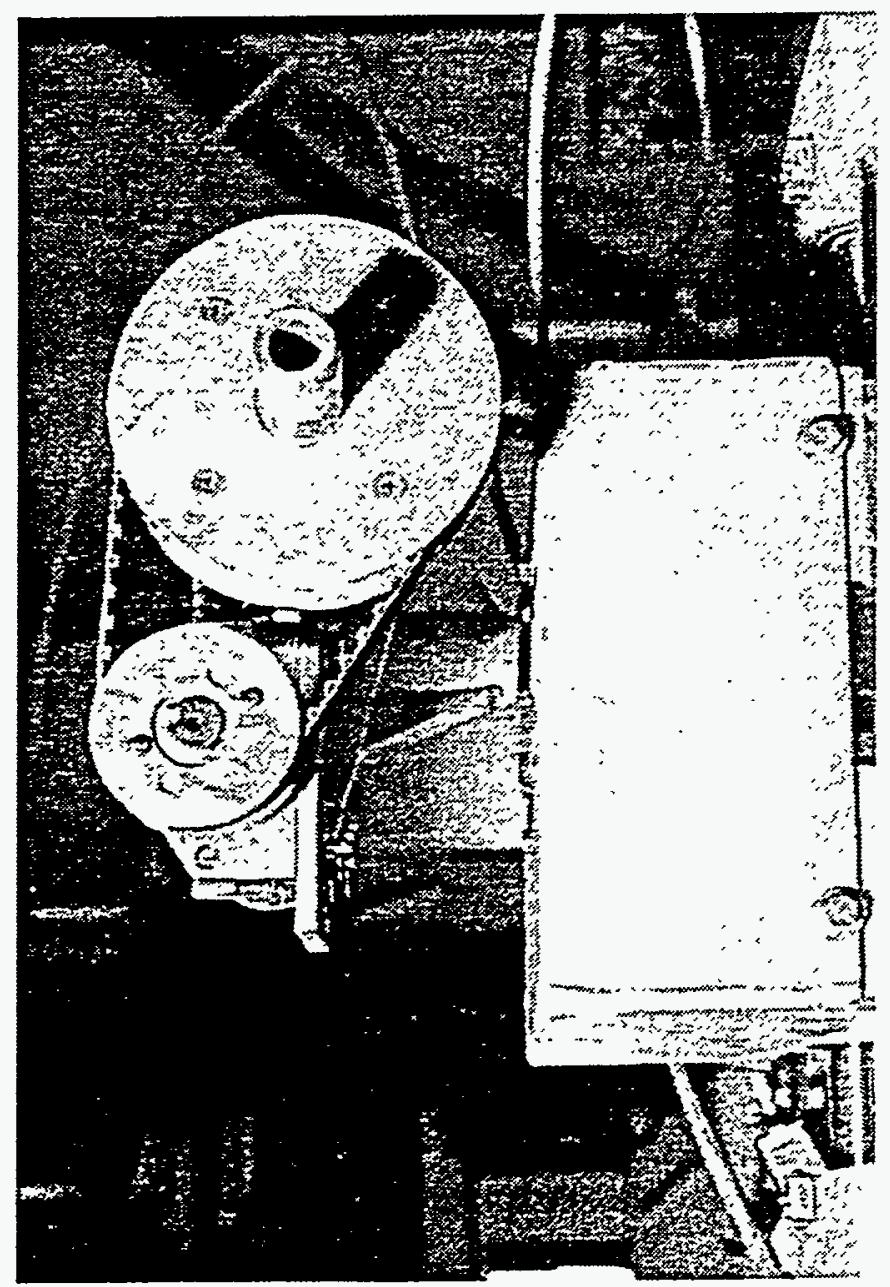


cutting assembly. It is suggested that any instrumentation to monitor bearing loads be located to monitor the forces on the worm drive shaft. This will allow data to be acquired of the forces created by the dislodging tool only and eliminates interaction from the carriage.

The range of motion developed for the cutting head can be illustrated by rotation of the head through a 180 degree arc (Figures 5.4, 5.5, and 5.6) so that the lance is directed either horizontally forward, vertical or horizontally backward.

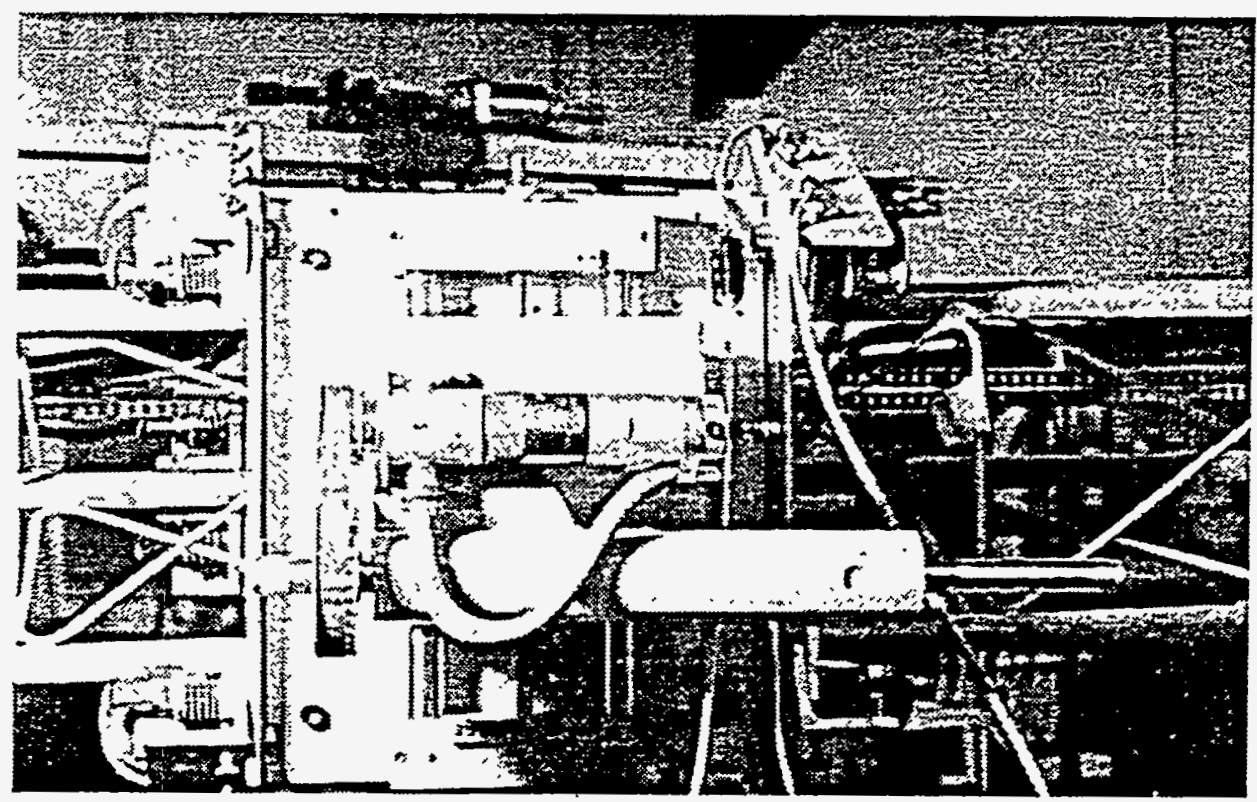

Figure 5.4 Lance attachment to the Worm Gear and Rotation Assembly.

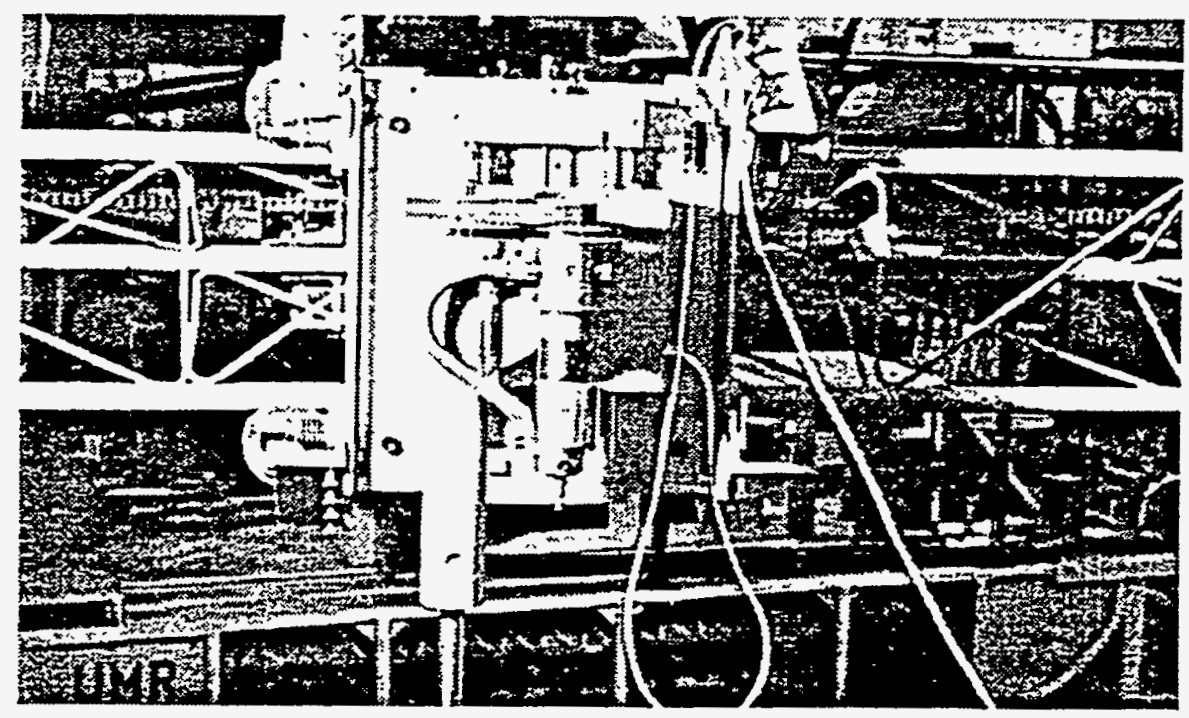

Figure 5.5 Lance Attachment in a Vertical Mode. 


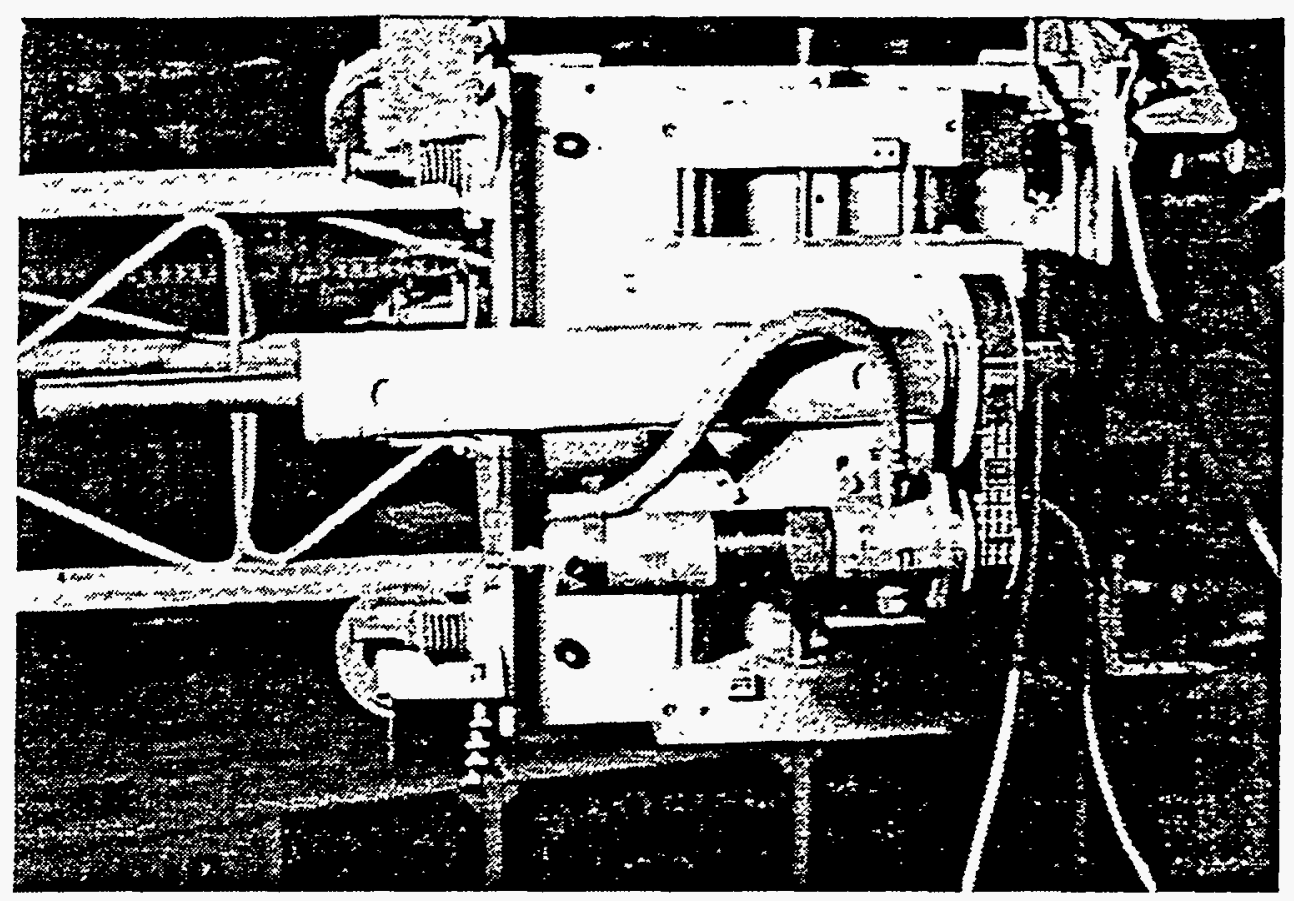

Figure 5.6 Lance Attachment inclined Horizontally Backwards.

\section{Conclusions}

The flexible design developed for mounting the cutting head to the traverse frame (the underlying antenna section shown behind the assembly in Figures 5.3 to 5.6) means that a full range of head motion can be modeled for the cutting head, without the complexity of assembly required for a true robotic arm installation.

This assembly is small, light and capable of operation through a computer controller with minimal operator involvement. The use of non-corrosive materials is required to allow operation of the system within the atmosphere of the working environment. Pneumatic drive for the lance itself is allowed by the higher rotational speeds which the experimentation has determined will be required. In such conditions the air drive should give a smooth rotation to the head and can do so with significantly less weight than other options considered. 


\section{REFERENCES}

1.1 The Labview program is available from National Instruments, (phone number: 800-IEEE-488).

1.2 The MDAS 7000, a Modular Data Acquisition System, was manufactured by Transera, and is now available from Kaye Instruments (phone number: 800-343-4624).

2.1 Mann, M.D., Thompson, S.W., Summers, D.A., "Sandia Jet Pump Test Evaluation for the development of Pumping of Hazardous Materials - Phase 1.1 Report," TTP Number: AL-232003, University of Missouri-Rolla, Rolla, MO 65401, Revised, March 16, 1993.

2.2 See for example Box G.E.P., Hunter, W.G. and Hunter, J.S., Statistics for Experimenters, Wiley InterScience, 1978, pp. 653.

2.3 Computer Associates CA-Cricket Graph III.

2.4 Summers, D.A., "Waterjet Cutting of Rock, Concrete, and Steel Trends for the Future," in Geomechanics '91, ed. Rakowski, Balkema, Rotterdam, 1992, pp. 223 - 231. 


\section{APPENDIX 1}

\section{MSDS MATERIAL ON FERTILIZER}




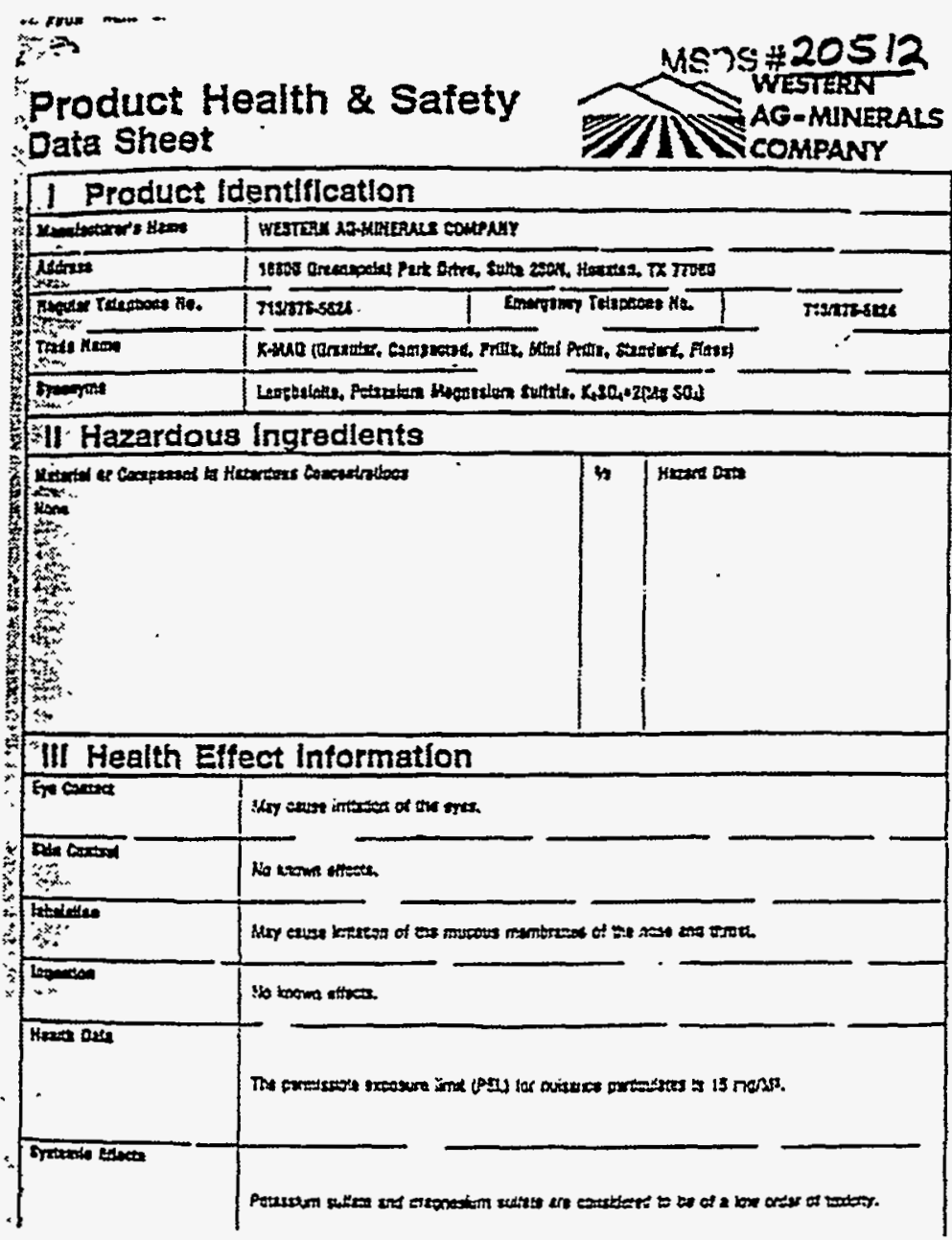




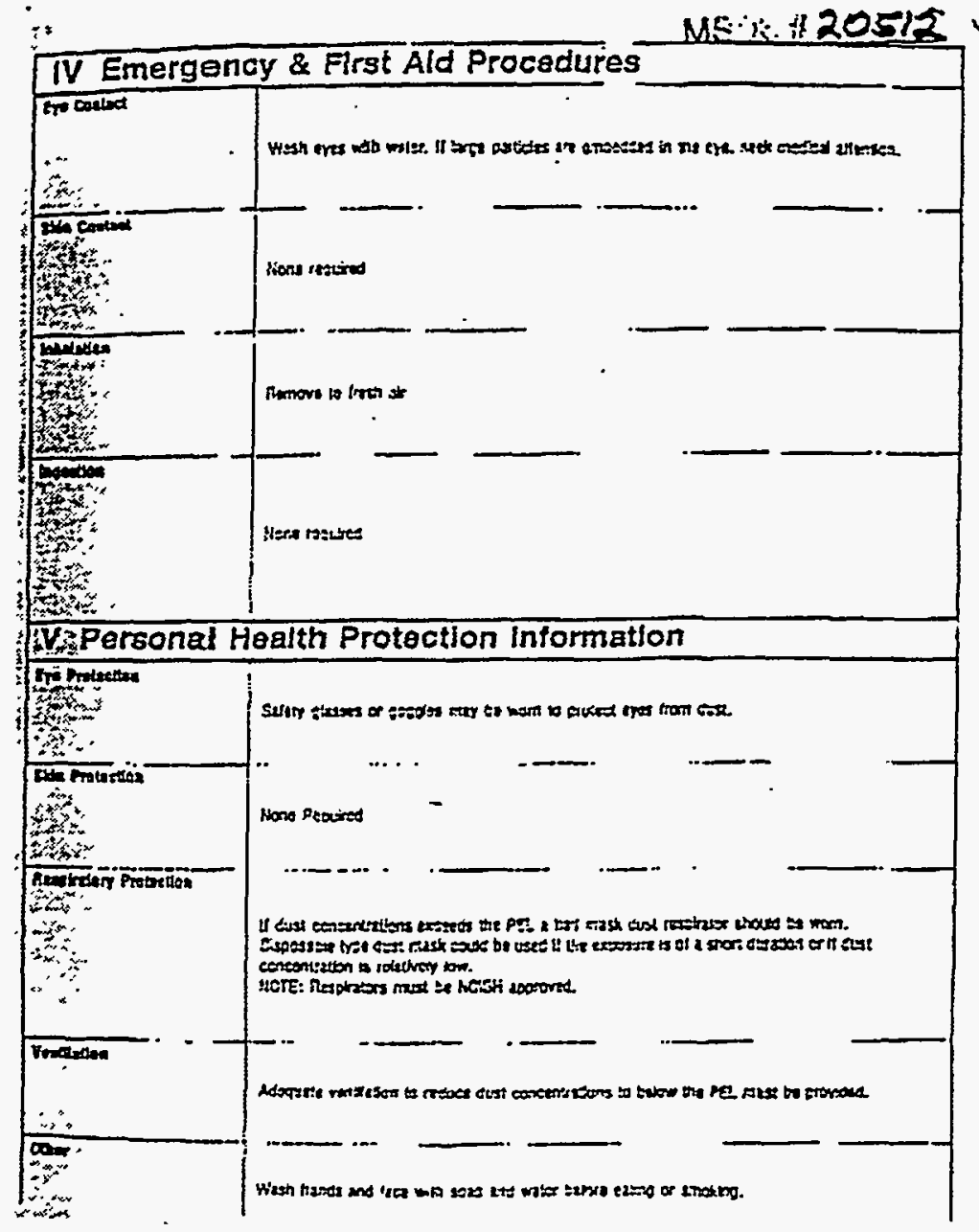




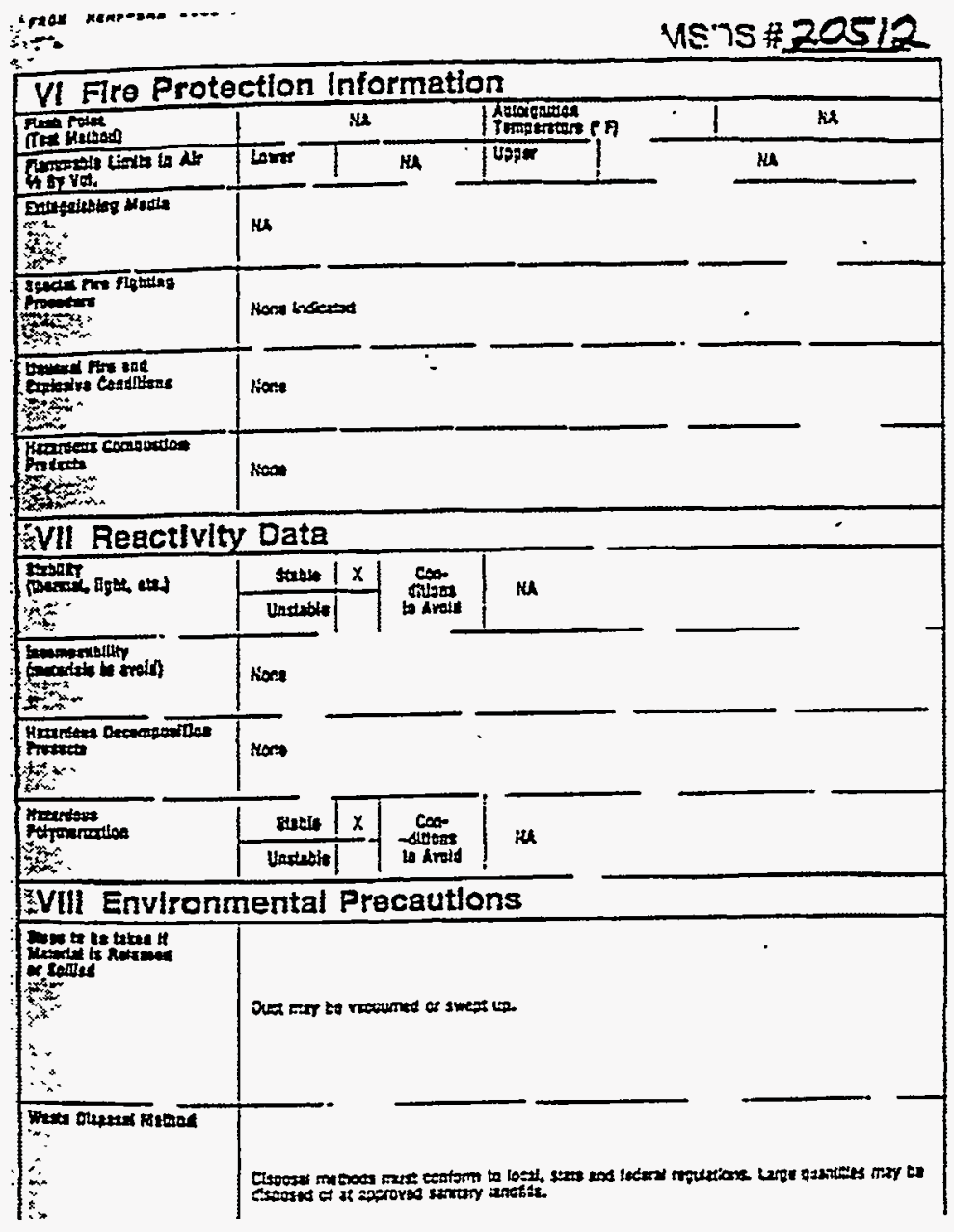




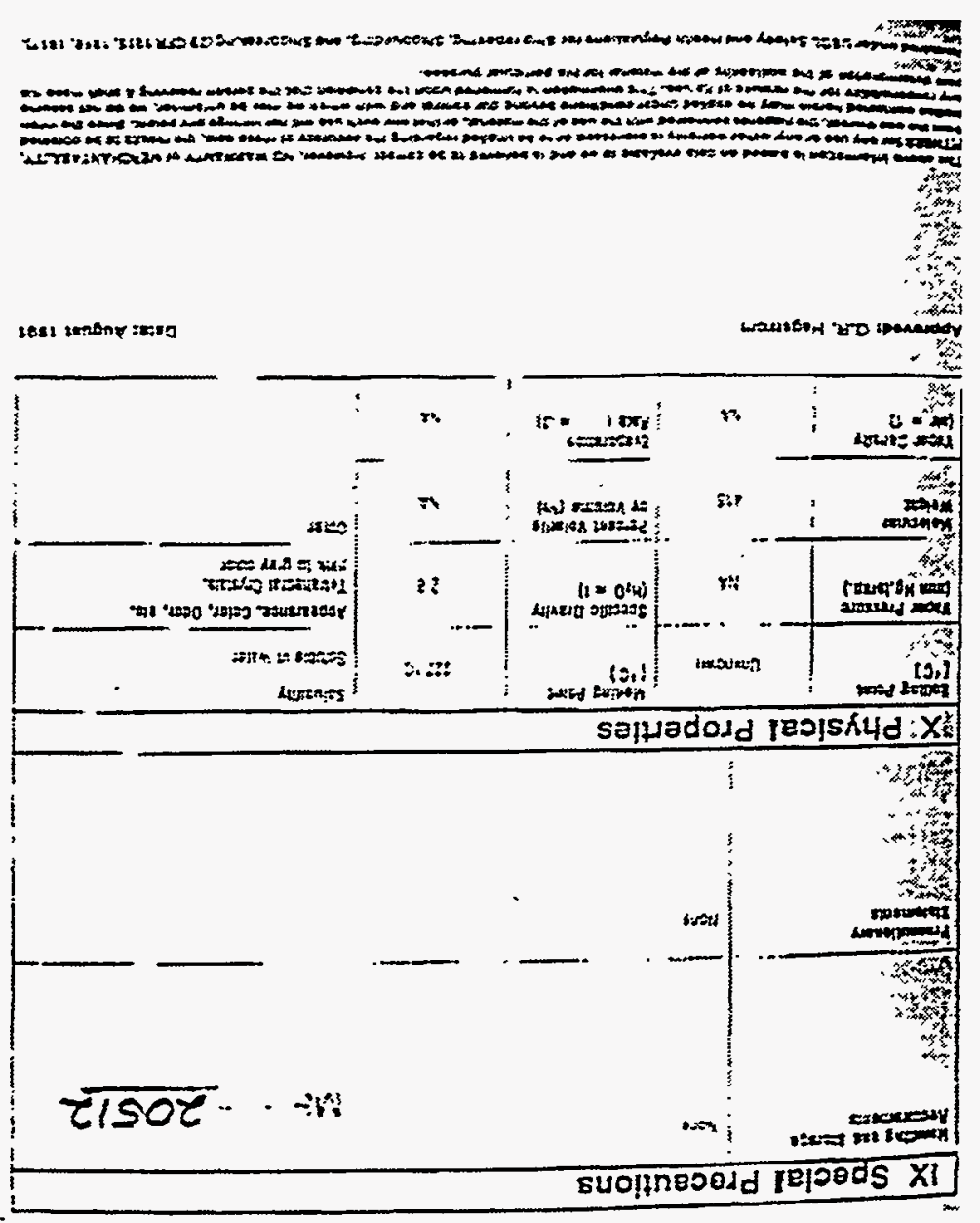




\section{APPENDIX 2}

\section{DATA FROM THE INITIAL TESTS ON}

THE SOFTER FERTILIZER 


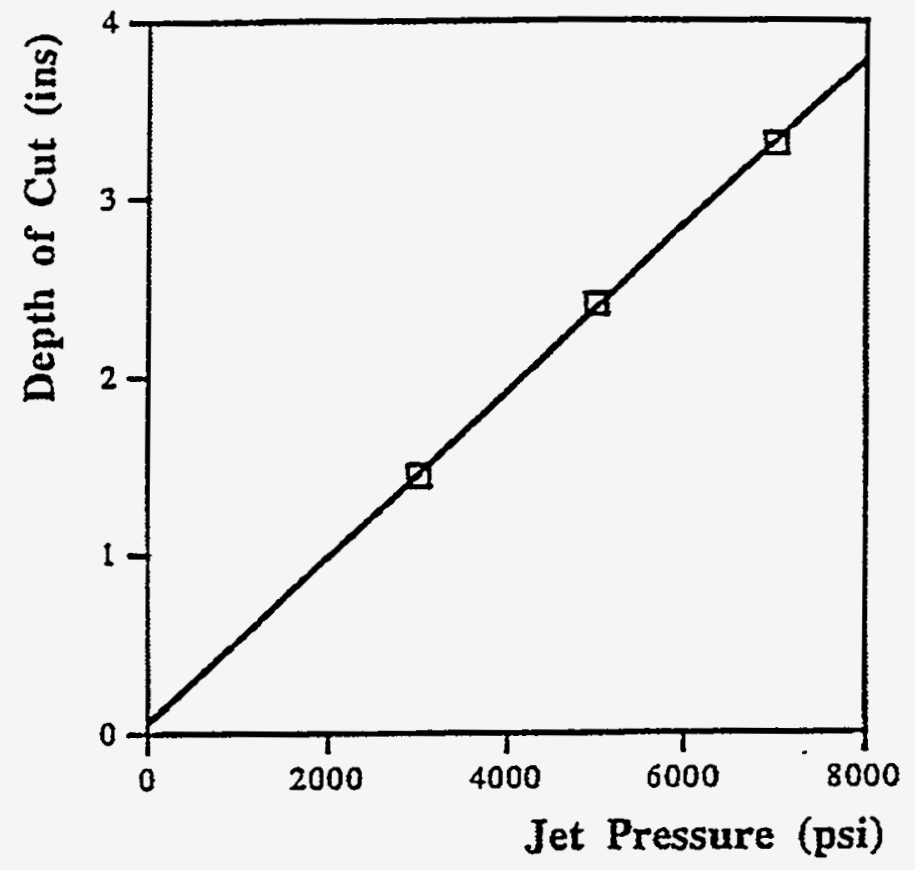

Figure 1 Depth of Cut as a Function of Jet Pressure, 0.062 inch nozzle diameter.

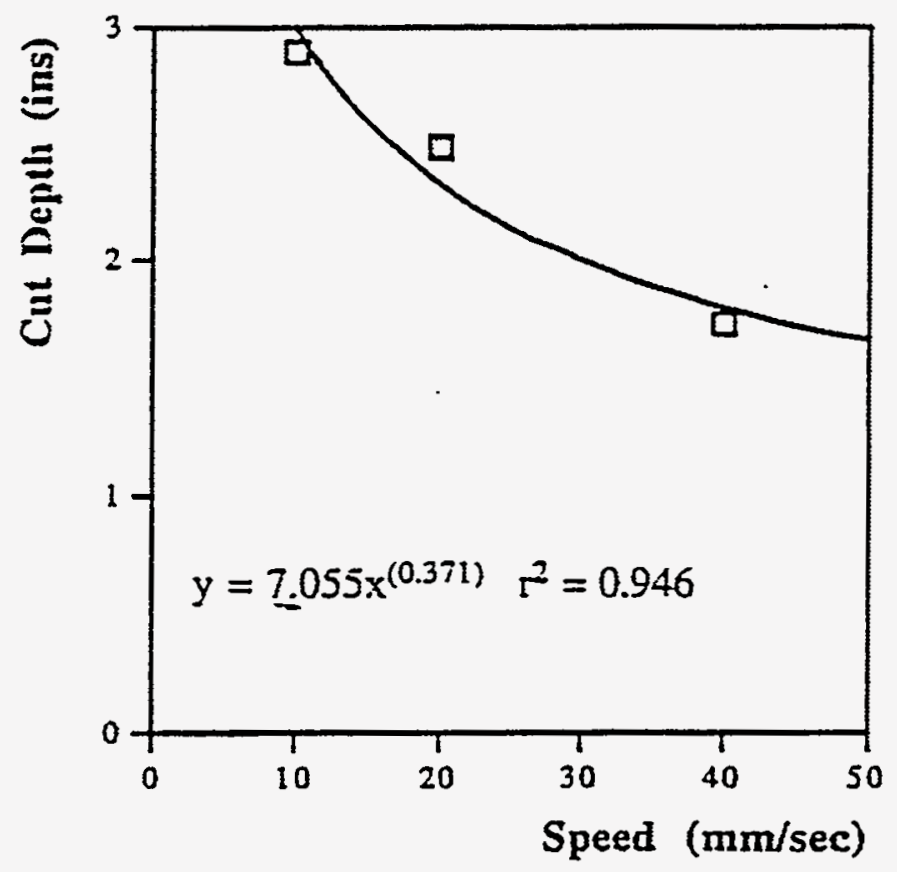

Figure 2 Depth of Cut as a Function of Traverse Speed, 0.062 inch nozzle diameter. 


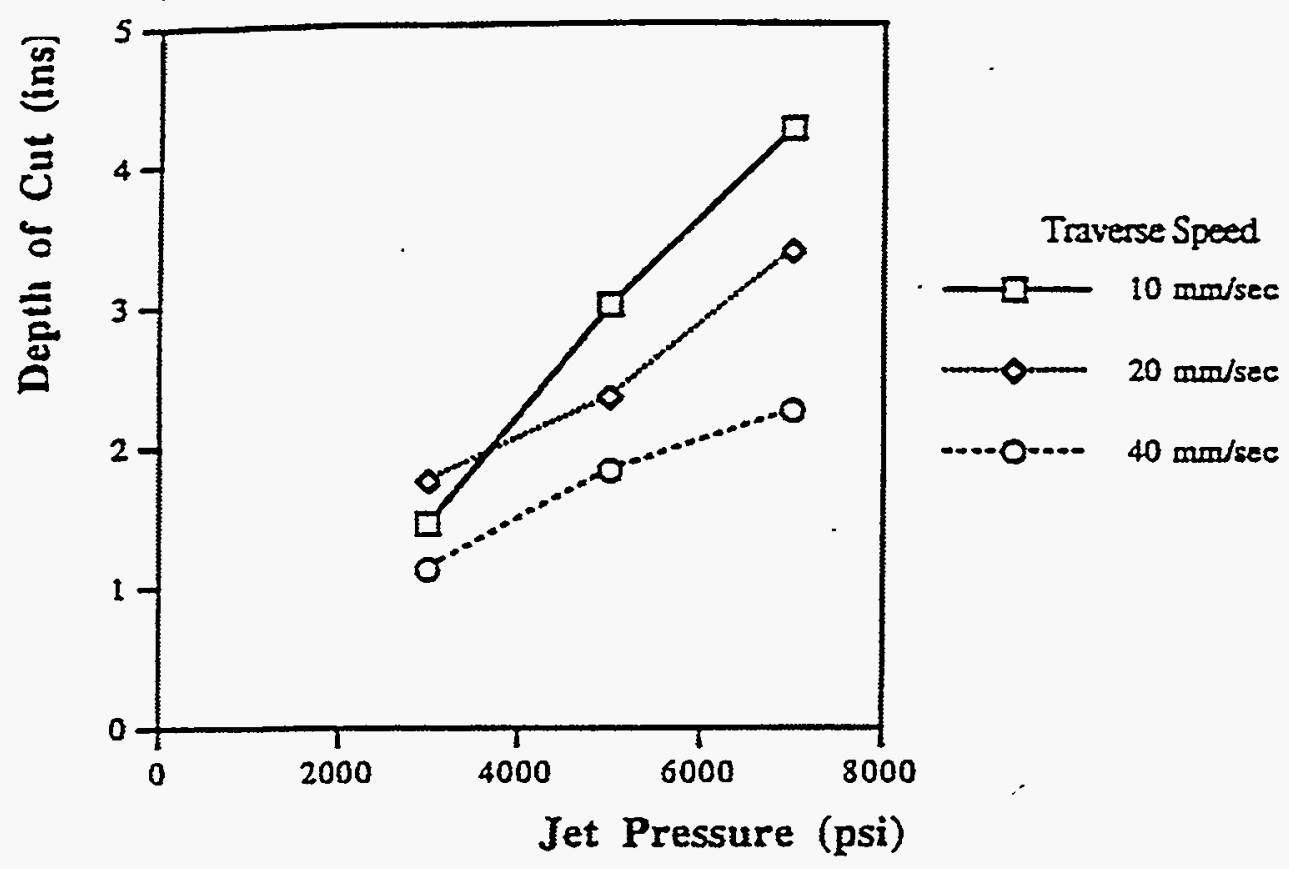

Figure 3 Depth of Cut as a Function of Jet Pressure and Traverse Speed, 0.062 inch nozzle diameter.

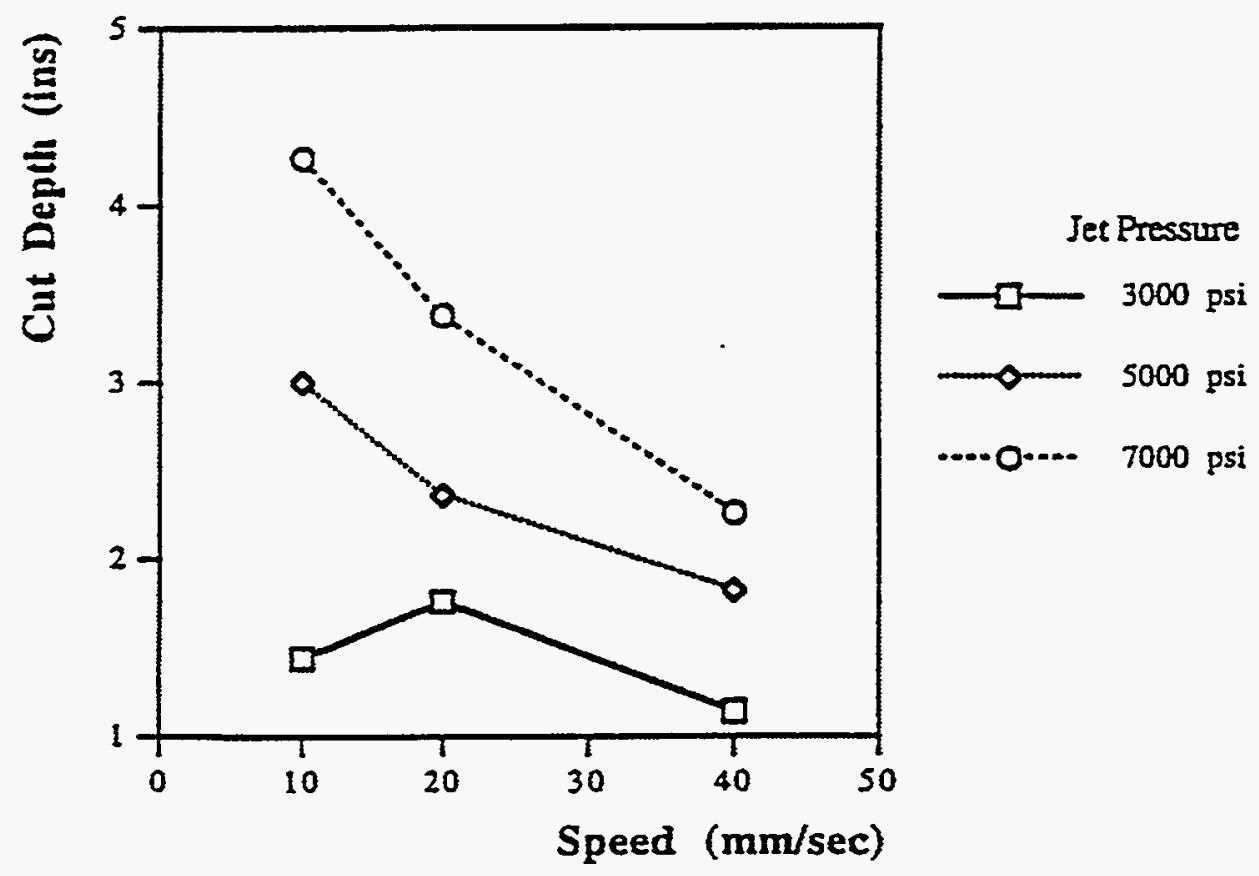

Figure 4 Depth of Cut as a Function of Traverse Speed and Jet Pressure, 0.062 inch nozzle diameter. 
APPENDIX 3

SOP FOR THE TESTING PROGRAM 


\section{Standard Operating Procedure for the Evaluation of Cutting Parameters for the Removal of Simulated Waste.}

\subsection{Objective}

This SOP is written to describe the steps to be taken in carrying out a factorial experiment to determine the relationships between the jet cutting parameters of pressure, jet diameter and traverse speed on the depth of cut in a waste simulant. The experiments will be carried out at the High Pressure Waterjet Laboratory (HPWL) of the Rock Mechanics and Explosives Research Center (RMERC). The tests will be carried out using the equipment manufactured for this purpose, and described below. In addition the test program will use the Hammelmann pump available at the site to provide the high pressure water.

\subsection{Overall Site Description}

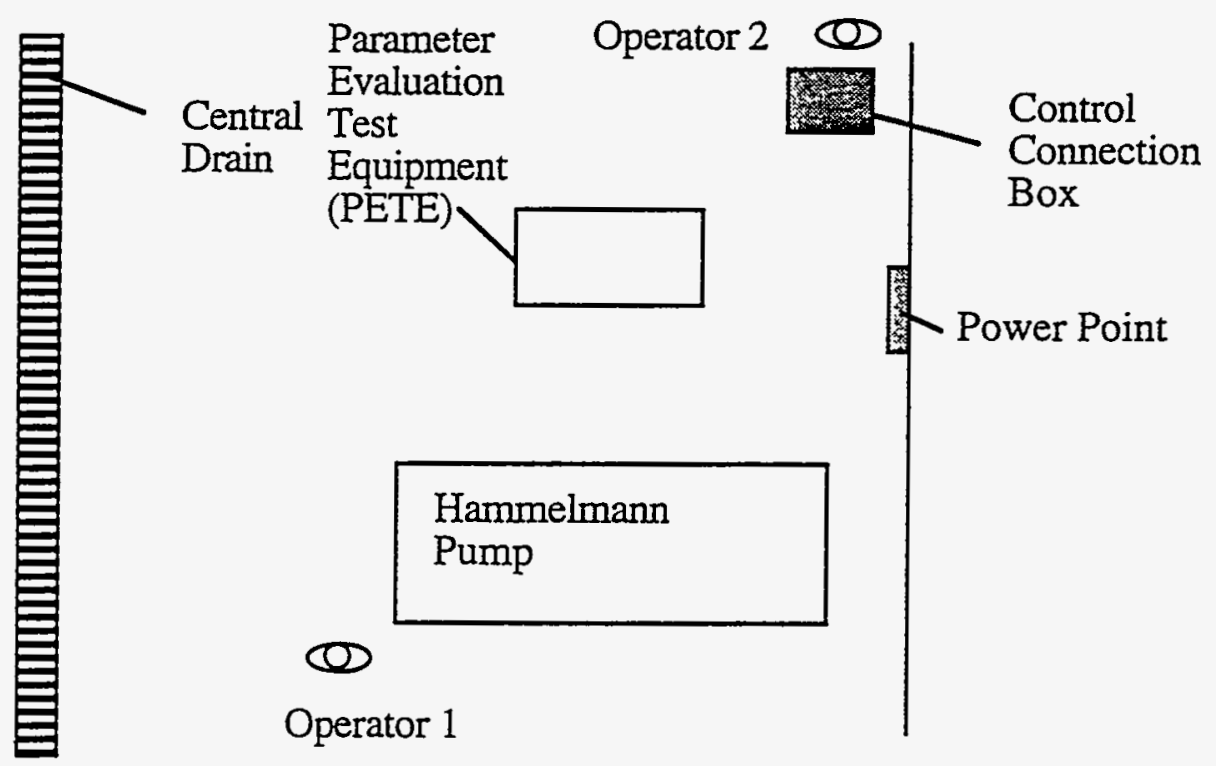

Figure 2.1 Schematic of Test Equipment Layout.

The above schematic representation indicates the relative positions of the test equipment, the adjacent power point, and the control connection box in the Laboratory. It shows the positions of the High Pressure Pump and the Parameter Evaluation Test Equipment (PETE), with the locations at which the two system operators should stand during a test. For the purposes of this SOP the area illustrated above is referred to as the "TEST AREA". 


\subsection{Preliminary Procedures}

At the beginning of each day's operation the following steps must be taken before any test work is undertaken.

3.1 The HPWL Secretary will be informed of the test program to be carried out, and its expected duration.

3.2 There shall be at least two people in any test program team involved at the HPWL. No person shall be a member of the test program team who has not been certified as being trained in the use of the equipment by Dr. Summers.

3.3 Before entering the test area personnel should ensure that they are equipped with, and wearing, a pair of safety glasses, robust clothing and safety toed shoes or boots. Gloves shall be worn when appropriate to provide protection for the work being undertaken. Ear protection will also be worn during the time that the high pressure pump is in use.

3.4 One individual, herein after referred to as the Senior Operator, shall be in designated charge of the day's test program. That person shall be designated by Dr. Summers as having that responsibility. It is the responsibility of the Senior Operator to ensure that all personnel at the test area comply with these procedures.

3.5 All test personnel shall be logged into the daily logbook as well as any visitors. The condition of the equipment shall also be recorded.

3.6 Any visitors to the site shall be appraised as to the operational rules for their presence on site.

3.7 Warning Notices identifying that High Pressure Equipment is in use, and forbidding entry to unauthorized persons shall be erected on the two entrances to the HPWL. 


\subsection{Equipment Preparation}

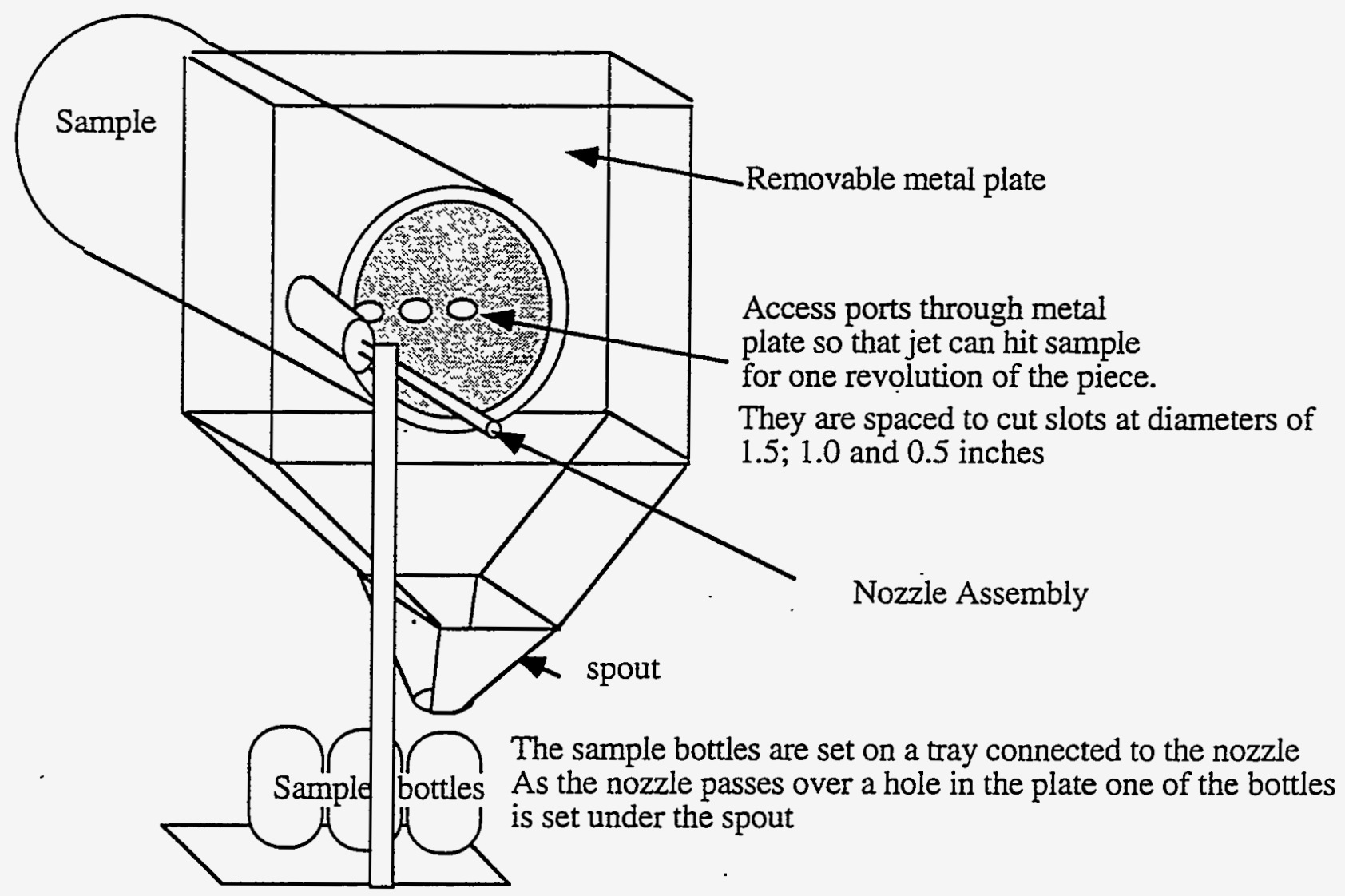

Figure 4.1 Schematic of the Parameter Evaluation Test Equipment (PETE).

The equipment normally used for this program will involve the Parameter Evaluation Test Equipment (PETE), a monitoring television camera, a supplementary flood light, the Hammelmann pump, a television monitor and videotape recorder, and the control box to operate PETE. The following work shall be carried out under the supervision of the Senior Operator.
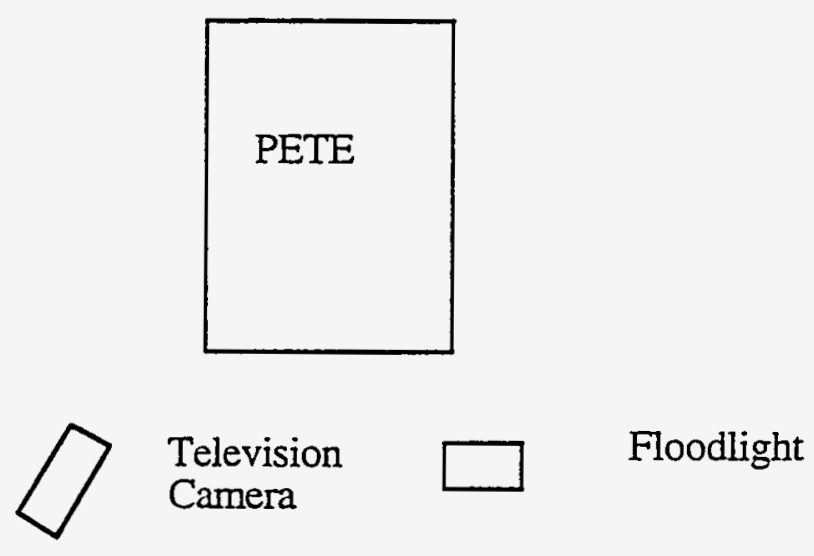

Figure 4.2 Schematic of the Equipment layout. 
4.1 The television camera will be connected to power, and switched on. It will be aligned to view the sample and nozzle assembly within PETE.

4.2 The supplementary flood light will be set up on the opposing side of the nozzle assembly to the television camera. It also will be connected to power.

4.3 The control box switches shall be set in the OFF position.

4.4 The power connections to the nozzle drive motor and to the sample rotation motor shall be connected to power.

4.5 The protective cap shall be removed from the high pressure supply line to the nozzle location. A bucket will be placed under the outlet spout from PETE.

4.6 The low pressure water supply line will be connected to the high pressure pump inlet.

4.7 The low pressure supply pump will be switched $\mathrm{ON}$, and low pressure water delivered to PETE for 20 seconds. This flow will be collected in the bucket. Its purpose is to ensure that the lines are clear and that no foreign matter is present to block the nozzle or impact the specimen.

4.8 The low pressure supply pump will be switched OFF.

4.9 The collected water will be examined visually to ensure it contains no foreign matter of concern. The water will then be returned, from the bucket, to the water reservoir.

4.10 A videotape will be placed in the video recorder and aligned to a fresh start position. The television camera, monitor and floodlight will be switched ON.

\subsection{Validation Test}

At the beginning of each day's operation, the operation of the test equipment PETE and the sample collection equipment will be validated without a sample in the equipment. This is to ensure that there are no malfunctions in the equipment. For this procedure one operator should be 
located by the PETE while the controls are operated, to ensure that they are functioning properly.

5.1 The nozzle lance will be checked to ensure that it is positioned at the left (Home) end of its stroke.

5.2 The motor drive for rotation of the sample will be turned ON.

5.3 The RPM of the sample holder will be checked with a tachometer to ensure that it is rotating at $100 \mathrm{RPM}$.

5.4 The position of the shutter plate will be checked to ensure that the access holes are to the left side of the sample holder centerline.

5.5 The traverse lance motor drive will be switched to $\mathrm{ON}$.

5.6 The time for the lance to traverse between the sample marks on the shutter plate will be timed and recorded.

5.7 The traverse lance motor will be switched to OFF.

5.8 The direction changed to REVERSE.

5.9 The traverse lance motor will be switched to ON. The lance returned to its left home position and the traverse motor switched to OFF.

5.10 The direction of the traverse lance drive will be changed to FORWARD.

5.11 The rotation motor will be switched to OFF.

5.12 The test program matrix will be accessed, and the proper nozzle and orifice for the first test of the day will be firmly tightened on the end of the lance. The retaining pin will be inserted to lock it in place. 


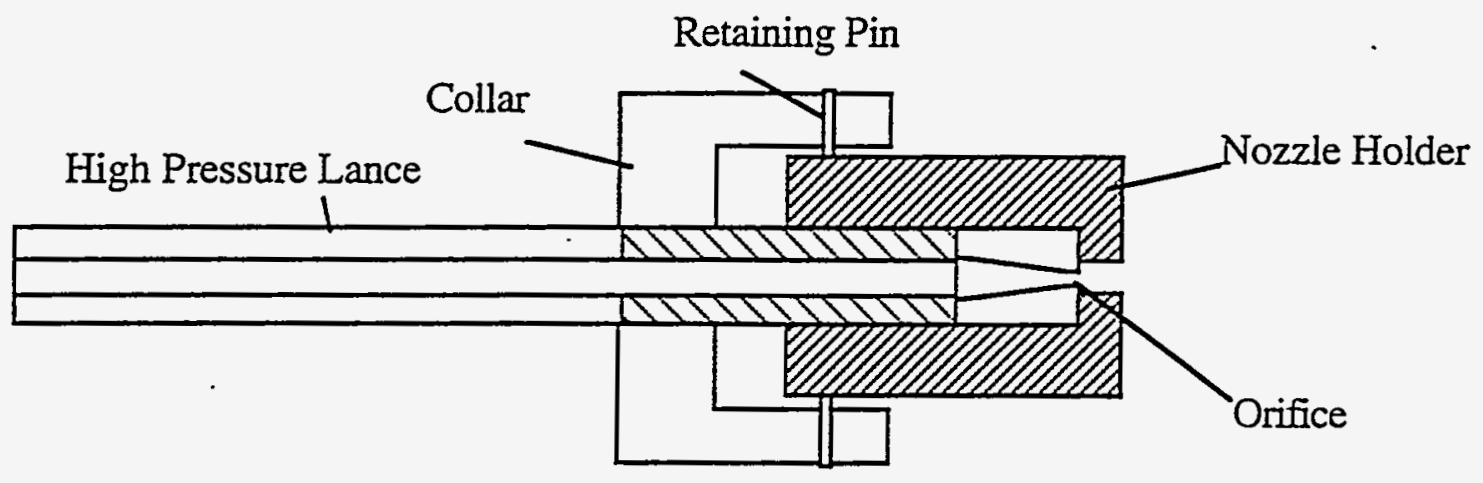

Figure 5.1 Retaining pin fixture on lance.

\subsection{Loading A Simulant Sample}

Simulant samples are prepared as 2-inch diameter cores from prepared blocks of simulant. Each core is mounted in a one-foot section of steel pipe which acts to provide lateral support to the core.

6.1 The sample number and the block from which it was cored shall be noted on the daily record.

6.2 The sample will be inserted into the PETE sample holder and locked in place.

6.8 The sample test program will be reviewed and the shutter plate either removed or left in place, depending on the test to be undertaken.

\subsection{Test Procedure and Records}

The experiments in this program have been randomized in order. This is to minimize the introduction of procedural error into the data collected.

7.1 The Senior Operator will visually inspect the facility to ensure that the equipment is properly connected and that no one is near the test equipment.

7.2 It is the pump operator's task to ensure that no person enters the test area, until after the test is completed and the high-pressure pump has been shut down. 
7.3 Normally the Senior Operator will operate the control box, and the assistant will operate the pump. Although this SOP is written with that arrangement, positions and tasks can be changed, at the Senior Operator's discretion. The Senior Operator will switch the television monitor to ON and will start the video tape recorder.

7.4 The tape record will be identified by a voice input stating the date, the recording person, the sample number and the proposed test conditions.

7.5 The pump operator will give an audible warning to all persons present that the test is about to start.

7.6 All personnel on site shall put on hearing protection.

7.7 The pump operator will check that the relief valve on the highpressure pump is in the OPEN position.

7.8 The pump operator will, upon being informed by the Senior Operator that the controls are ready, press the power button on the pump.

7.9 The Senior Operator will confirm that water is issuing from the nozzle at PETE and will, for the appropriate tests, switch the rotation motor control switch for PETE to ON. The Senior Operator will confirm that the sample is rotating if this is required.

7.10 After the pump has stabilized, the Pump operator will increase the jet pressure, using the pump control valve, to that designated for the test.

7.11 The pump operator will inform the Senior Operator that pressure has been reached.

7.12 The Senior Operator will switch the traverse lance control switch to ON.

7.13 After the 5-second designated test time (giving time for the jet to traverse the sample), the Senior Operator will switch the traverse lance control switch to OFF.

7.14 The Senior Operator will inform the Pump Operator that the test is over.

7.15 The Pump Operator will open the pressure control valve lowering the pump pressure to its low level. 
7.16 The Pump Operator will press the OFF button for the pump.

7.17 The Senior Operator will monitor the condition of PETE and the sample to ensure that no untoward event has occurred.

7.18 The Pump operator will give an ALL CLEAR signal.

7.19 Upon hearing the ALL CLEAR, personnel may remove their hearing protection.

\subsection{Unloading the Sample}

The Senior Operator will first examine the equipment to ensure that it is safe.

8.1 The rotation motor and traverse motor connection cables will be disconnected from power.

8.2 The person(s) to remove the sample will put on disposable gloves.

8.3 The locking mechanism for the sample will be released, and the sample removed from the back of the PETE.

8.4 The sample case will be wiped with a paper towel to remove any residual moisture and material. The towel will be placed in the NORMAL WASTE bin.

8.5 The sample will be removed to a table to measure the slot(s) cut in its surface.

8.6 The video tape recorder will be switched OFF.

8.7 The linear traverse motor cable will be plugged into the power.

8.8 The linear traverse motor direction control will be set to REVERSE. The linear traverse motor control will be set to ON. The lance will be moved back to its left Home position. The linear traverse motor control will be set to OFF.

8.9 The linear traverse motor direction control will be set to FORWARD. 
8.10 The traverse motor connection cable will be disconnected from power.

\subsection{Measurements and Data Collection}

The sample will have been cut with either three sensibly concentric rings or by a single transverse cut across its diameter. The measurement procedure is written for either case, save that the process must be repeated for each cut.

9.1 The length of the cut will be divided evenly into five segments. The location of the dividing line will be lightly marked on the sample with a pencil.

9.2 At each dividing mark the depth of the cut made in the sample will be measured. This is achieved by inserting the measuring instrument wire into the slot to its full penetration, and sliding the clamp down until it engages the sample surface.

9.3 The length of the slot will be measured using a caliper gage to measure the distance from the tip of the instrument wire to the clamp position on the wire.

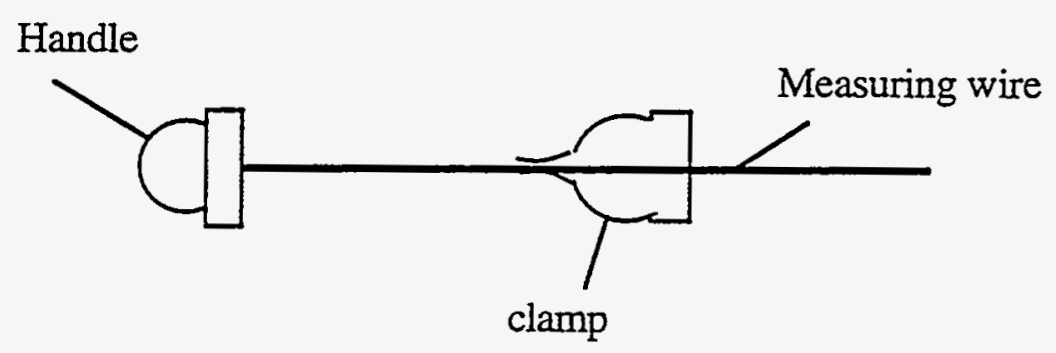

Figure 9.1 Slot Depth Measuring Instrument.

9.4 The five depths of cut measured will be recorded in the daily logbook beneath the line identifying the sample number, the jet test parameters and the person making the measurement.

\subsection{Facility Clean-up}

The continued use of the equipment for different test purposes requires that the test apparatus be thoroughly cleaned after each sample has been tested. 
This procedure must be repeated after each test, therefore, even though the same material may be used in each case.

10.1 The cleaning personnel will wear disposable gloves and arm protection.

10.2 The shutter plate will be removed from the PETE and cleaned using paper towels. It will then be placed on a clean, dry surface.

10.3 The interior surfaces of the PETE, including the lid, will be rubbed down with paper towels to remove surface contamination from the washout test.

10.4 The interior surfaces, including the lid, will be rinsed down with a clean water spray to remove any vestigial surface contamination.

10.5 The towels will be placed in the NORMAL WASTE bin.

10.6 Water draining from the wash down of the PETE, and that surplus to sampling, will have collected in the bucket located under the PETE drain.

This water will be returned to the water reservoir, after being passed through a paper screen filtration. The paper filter will be placed in the NORMAL WASTE bin.

10.7 The retaining pin will be withdrawn and the nozzle holder and orifice will be unthreaded from the lance. The nozzle assembly will be cleaned with a paper towel and then returned to its place in the storage drawer. The towel will be placed in the NORMAL WASTE bin

\subsection{Repeated test procedure}

Where a second, or additional test is planned for the day, then steps from 5.12 to 10.7 will be followed.

\subsection{Equipment Shut Down After Testing}

At the end of testing for the day, it is necessary to secure the facility and leave it in a condition ready for subsequent operation. 
12.1 The Senior Operator will ensure that the cables are disconnected from the rotation motor and the traverse motor on the PETE.

12.2 The television camera will be disconnected and placed in the proper storage cabinet.

12.3 The floodlight will be disconnected and placed in the proper storage cabinet.

12.4 The drainage bucket will be left to drain into the filter over the storage reservoir.

12.5 The protective cap will be placed over the end of the waterjet lance.

12.6 The control box switches be set in the OFF position.

12.7 The water supply line to the pump will be disconnected, and a protective cap placed over both the inlet and the supply hose.

\subsection{Sample Handling and Record Maintenance}

The videotape of the process and all the sample materials and records will be returned to the Rock Mechanics and Explosives Research Center where they will be stored and then delivered for subsequent analysis. The Senior Operator will ensure that the logbook for the day properly identifies the work carried out, and will note the time that individuals left the site.

\subsection{Facility Clean-Up and Shut down}

It is the Senior Operator's responsibility to ensure that the facility, the high-pressure pump and the surrounding area are left in the appropriate condition at the end of the day's work.

14.1 The Warning Notices will be removed and stored in their designated location.

14.2 Prior to leaving the building, the HPWL Secretary, or designated representative, will be informed that the test program for the day has been completed. 


\subsection{Other Operational Practices}

These procedures are not meant to supersede the normal operating procedures for the use of high-pressure waterjet equipment. Those procedures are herein incorporated by this reference and should also be followed.

\subsection{In Case of Accident}

Should there be any untoward occurrence during the course of any test, or while personnel are in the HPWL, the following personnel need to be informed.

16.1 In all cases the Senior Secretary will be informed at the Main Office.

16.2 In all cases Dr. Summers, if not on site, will be informed. His phone numbers are 341-4311 (office) and 3641205 (home).

16.3 In all cases Dr. Miller's office will be informed. His phone numbers are 341-4314 (office) and 3645278 (home).

16.4 Where there is personnel injury then, depending on the severity of the injury:

- a) A medical report of accident will be filled out by the injured party and the Senior Operator.

- b) The Senior Operator will ensure that the injured party is taken to the Hospital Emergency Room (341 3100 or 9911 ) or the Student Medical facility (341 4284) and that they are apprised ahead of time that the injured party is on their way.

- c) An ambulance will be summoned to the site (341 4300 or 9 911).

16.5 In all cases where medical treatment at the hospital is required then the following offices will be informed:

- University Police (341 4300)

- The Dean's Office (341 4753)

16.6 In case of a fire then the Rolla Fire Department $(9-911)$ will be summoned. 
"16.7 Where any incident leads to any possible damage to the operating equipment then the test equipment shall be shut down, and if necessary all power to the building shut off. Where power to the building is shut off it will not be restarted without a faculty member present.

16.8 All incidents shall be fully described in a written report within the daily $\log$. 
PNL-10074

AD-902

Distribution

No. of

Copies

OFFSITE

2 DOE/Office of Scientific and Technical Information

Sherry Gibson

DOE HQ

12800 Middlebrook Rd.

Suite 400

Germantown, MD 20874

JG Blaine

Univ. of Missouri-Rolla

High Pressure Waterjet Lab

Rol7a, MO 65401

B. Burks

Oak Ridge National Laboratory

Oak Ridge, TN 37831-6304

C. Christensen

Idaho National Engrg Laboratory

PO Box 1625

Idaho Falls, ID 83415-3710

M. Christensen

Idaho National Engrg Laboratory

PO Box 1625

Idaho Fal1s, ID 83415-3710

RD Fossey

Univ. of Missouri-Rolla

High Pressure Waterjet Lab

Rol1a, MO 65401

MD Mann

Univ. of Missouri-Rolla

High Pressure Waterjet Lab

Rol1a, MO 65401

DA Summers

Univ. of Missouri-Rolla

High Pressure Waterjet Lab

Ro11a, MO 65401
No. of

Copies

ONSITE

2 DOE Richland Operations Office

DA Brown, K8-50

DE Trader, K8-50

6 Westinghouse Hanford Company

RC Eschenbaum, R3-50

PW Gibbons, S4-58

LB McDaniel, S6-12

OD MulTen, L5-08

EJ Shen, S4-58

JA Yount, L5-08

15 Pacific Northwest Laboratory

JA Bamberger, K $7-15$

WF Bonner, P7-41

DM Boyd, K5-10

GR Golcar, P7-19

BK Hatche17, K5-26

MJ Quadre 11, K1-73

MW Rinker, K5-26 (2)

PA Scott, P7-43

Publishing Coordination

Technical Report Files 